\title{
Assessment of the economic impact of aids at national and multi-national level : development of a scenario-analytic approach to support health-care policy
}

Citation for published version (APA):

Postma, M. J. (1998). Assessment of the economic impact of aids at national and multi-national level : development of a scenario-analytic approach to support health-care policy. [Doctoral Thesis, Maastricht University]. Universiteit Maastricht. https://doi.org/10.26481/dis.19981009mp

Document status and date:

Published: 01/01/1998

DOI:

10.26481/dis.19981009mp

Document Version:

Publisher's PDF, also known as Version of record

Please check the document version of this publication:

- A submitted manuscript is the version of the article upon submission and before peer-review. There can be important differences between the submitted version and the official published version of record. People interested in the research are advised to contact the author for the final version of the publication, or visit the DOI to the publisher's website.

- The final author version and the galley proof are versions of the publication after peer review.

- The final published version features the final layout of the paper including the volume, issue and page numbers.

Link to publication

\footnotetext{
General rights rights.

- You may freely distribute the URL identifying the publication in the public portal. please follow below link for the End User Agreement:

www.umlib.nl/taverne-license

Take down policy

If you believe that this document breaches copyright please contact us at:

repository@maastrichtuniversity.nl

providing details and we will investigate your claim.
}

Copyright and moral rights for the publications made accessible in the public portal are retained by the authors and/or other copyright owners and it is a condition of accessing publications that users recognise and abide by the legal requirements associated with these

- Users may download and print one copy of any publication from the public portal for the purpose of private study or research.

- You may not further distribute the material or use it for any profit-making activity or commercial gain

If the publication is distributed under the terms of Article 25fa of the Dutch Copyright Act, indicated by the "Taverne" license above, 
ASSESSMENT OF THE ECONOMIC IMPACT OF AIDS AT NATIONAL AND MULTI-NATIONAL LEVEL;

development of a scenario-analytic approach to support health-care policy 
ASSESSMENT OF THE ECONOMIC IMPACT OF AIDS

AT NATIONAL AND MULTI-NATIONAL LEVEL

development of a scenario-analytic approach

to support health-care policy

DE ECONOMISCHE CONSEQUENTIES VAN AIDS

OP NATIONAAL EN MULTINATIONAAL NIVEAU

scenario analyse ter ondersteuning van gezondheidszorgbeleid

(met Nederlandstalige samenvatting)

\section{PROEFSCHRIFT}

ter verkrijging van de graad van doctor aan de Universiteic Maastricht,

op gezag van de Rector Magnificus, Prof Dr AC Nieuwenhuijzen Kruseman volgens het beslüt van het College vam Dekanem,

in het openthas te verdedigen

op wrijdag 9 oktober 1998 on 14.00 unr

door

Maarten Jacobus Pastma

geboren op 29 jamuari 1960 , te Gitoningen 


\section{Promotor:}

Prof Dr RM Leidl (Universiteit Ulm Duitsland; voortheen Universiteit Maastricht)

Co-promotor:

Dr JC Jager (Rijksinstiturut voor Volksgezondheid en Milieu RIVM, Bilthoven)

Beoordelingscommissie:

Prof Dr JAM Maarse (voorzitter)

Prof Dr F Antoñanzas (Universitteit la Rioja, Logroño Spanje)

Prof Dr G Kok

Prof Dr EJ Ruitenberg (Universiteit Utrecht)

Prof Dr Ir Drs of Vrieze

The research was financially supported by the Dutch Ministry of Public Health, Welfare and Sports (grants 89-020,90-037 and 90-040) and by the National Institute of Public Health and the Environment (RIVM). A major part of the study was conducted in the framework of the European Union Concerted Action on "Multi-national Scenario Analysis: Concerning the Epidemiological, Social and Economic Impacts of HTV/AIDS on Society" (grant BMH1-CT94-1723).

De uitgave van dit proefschrift is mede mogelijk gemaakt door Stichting Sarphati, Abbott, Stichting AIDS Fonds Amsterdam, NV Interpolis, Pasteur Mérieux MSD, Glaxo Wellcome BV, Universiteit Maastricht en RIVM. 
Aan mijn moeder

Ter nagedachtenis aan mijn vader

Voor Geert 


\section{Curniculum vitae}

Marten Jacobus Postma was born on 290160 in Groningen (the Netherlands). After high-school finals in 1978 (Heymans College Groningen) he entered University. The university career (Groningen University) comprised one year of Historical Sciences and 6 years of Econometrical and Actuarial Sciences. On-the-job training was performed at the Medical Center Leeuwarden, during which period he developed a simulation-model to assess the optimal distribution of hospital capacity over the medical specialisms.

During 1986-1988 he worked as a business econometrician in the marketing department of FBTO insurance company. Responsibilities concerned quantitative analyses of strategic decisions and development of Management Information Systems. His next job was at the National Institute of Public. Health and the Environment (RIVM) as a researcher in health economics.

The basis for this thesis was provided by several research activities at RIVM, such as EU-projects on AIDS economics and a consultancy for the Dutch Association of Life Insurers. One of his current research projects concerns the development of guidelines for cost-effectiveness analysis in infectious diseases through linking epidemiological modelling and costing information (applications for ADS, Influenza, Chlamydia, Hepatitis and Meningitis).

He currently gives courses and leciures in cost-effectiveness analysis in infectious diseases. Furthermore, he works with students (economical, medical and pharmacological) to develop their skills in cost- and cost-effectiveness analysis. 


\section{Contents}

Key Messages

Acknowledgements

Summary

Samenvatting

List of Abbrevlations

1 General Introduction

2 AIDS Impact Scenarios; questions for the years to come (AIDS 1990; 4:1166-7)

A Comparison and Integration of Studies on HIV-related Hospital Resource Utilization and Costs; towards economic scenarios for the Netherlands

(Tijdschrift woor Sociale Gezondheidszorg 1992; 3:189-96)

4 Economic Impact of the AIDS Epidemic in the European Community; towards multi-national scenarios on hospital care and costs (AIDS 1993; 7:541-53)

5 AIDS Scenarios for the Netherlands; the economic impact on hospitals (Health Policy 1995; 31:127-50)

6 A Life-insurance Fund for HIV-infected Persons; financial impact of expected future epidemiology

7 Disease-staging and Cost-standardization for Modelling Healthmcare Impact of HIV/AIDS (Health Policy 1998; 43:45-54)

8 Hospital Care for Persons with AIDS in the European Union (Healh Palicy 1997; 41:157-76)

9 Hospital care for Persons with AIDS in European Union Countries; a cross-country comparison (ADS Cost Analysis and Patient Classification, in press)

10 General Discussion and Main Conclusions

References

Anmex Projecting Utilization of Hospital Inpatient Days in the Netherlands; a time-series analysis

(IMA Joumal of Mathematics Applied in Medicine \& Blology $1995 ; 12: 185-202$ ) 


\section{Key Messages}

Estimates of the resources and costs of hospital care for HIV/AIDS can be used for planning at the national or multi-national level if a standardized approach in epidemiological modelling, economic data-gathering and severity-staging of disease is applied.

Lifetime cosis from the time of HIV-infection onwards are estimated to amount 76000 ECUs in the Netherlands, hospital costs constitute almost $90 \%$ of this figure.

In the Netherlands, approximately one quarter to a half percent of total hospital costs will be required for HIV/AIDS by the end of the century, a sizeable but manageable proportion.

Hospital bed needs for AIDS in the EU by the end of the century will amount $0.5 \%$ to $0.65 \%$ of all hospital beds available in the EU.

Application of the dynamic cost-of-illness approach developed in this thesis is a prerequisite for many economic evaluations in infectious diseases. 


\section{Dankwoord}

Znerst möchte ich mich bei Herm Professor Dr Reiner Leidl bedanken. Ich erinnere moth noch sehr gut an den Tag, an dem wir uns zum ersten Mal auf einer ADDS-Konfienenz in Montreal begegnet sind. Unser beider Interesse galt der Scenarienanalyse von ADS Kosten. Mit Antritt deiner Professorenposition an der Masstricht Universitat ergab sich die konkrete Möglichkeit, unser gemeinsames Interesse in einer Doktorarbeit zu vertiefen. Es freut mich sehr, dass mit Abschluss meimer Doktorarbeit unsere Zusammentubeit nicht endet, sondern in vielversprechende Projekten weiterbesteht. Ich hoffe, dass wir auch in die Zukunft noch viele Themen gemeinsam erfolgreich bearbeiten werden und freue mich schon ganz besonders auf ein Wiedersehen mit Bierbraten und Hefeweizen am wanderschönen Pfuler See.

In het dankwoord wan een proefschrift hoort een "zonder ... was dit werk nooit tot stand gekomen"-zin. Hartelijk dank, Hans. Hans Jager heeft ervoor gezorgd dat er een aantal nationale en internationalle projecten over de AIDS modellering vanuit het RIVM werden gecoördineerd. Deze projecten vormden de infrastructuur voor het onderzoek dat aan dit proefschrift ten grondslag ligt. $\mathrm{K}$ heb grote bewondering voor het geduld, de hwmor en het doorzettingsvermogen waarmee hij onderzoeksprojecten voorbereid, "binnenhaalt", begeleidt en van nazorg voorziet. Ik beschouw het als een groot wootrecht met hem te werken.

I.k dank Dick Reinking en Frans van den Boom voor de samenwerking tijdens de eerste fasen van dit onderzoek. Agradezco a Fernando Antoñanzas el habeme permitido utilizar sus bases de datos para mi trabajo. Many thanks to Eddy Beck for providing me with data from the National Prospective Monitoring Systen and generally stimulating my research very much. Merci beaucoup, Yves-Antoine Flori pour moi fourner la information au DMI2.

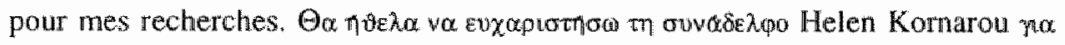
mp noגotum Bonteu ms. Grazie a ill dottone Andrea Tramarin per avermi permessó di utilizzare informazioni raccolte nel suo "database". Ik dank Guus Luijben, René Poos, Hans Houweling en Siem Heisterkamp voor het ter beschikking stellen van gegewens en voor de hulp bij de statistische analyse daarvan. Tevens dank ik Guus em Rene woor hun kameraadschap tijdens het delen van de werkkamers.

Ik dank al mijn mede-auteurs voor hun bijdrage aan dit onderzoek. Met name dank ik Marcel Dijkgraaf voor de co-produktie van hoofdstuk 3, dat tevens als éćn van de latste hoofdstukken in zijn proefschrift functioneert. Het is overigens meer dan alleen 


\section{Acknowledgements}

vanwege kosten effectiviteit dat dit hoofdstuk in twee proefschriften opgenomen is. Het Illustreen tevens de samenhang tussen de twee onderzoeken. Marcel theeft altijd gewezen op het belang zijn onderzok met de mijne te integreren en heeft aldus de totstandkoming vant dit proefschrift sterk gestimuleerd.

Ik dank Marcel en mijn broer Michiel woor hun bereidheid paranimf te zijn. Tevens dank ik Michiel woor zijn bijdrage aan het ontwerp van de omslag. IK vind het erg leuk dal één van onze vele gemeenschappelijke interesses en bezigheden in drie-kleurendruk is vastgelegd. Wk dank Bert woor zijn zorgen over mijn lichamelijke conditie: menig paragraaf in dit proefschrift is geproduceerd tijdens het recupereren wan de immense spierpijnen na weer een hardloop-sessie.

Next to his co-authorship of several Chapters, I thank Keith Tolley from the University of Nottingham for improving style and language. Of course, any mistakes and awkward wordings left are my responsibility. Dear Keith, I hope we will continue comoperating in the years to come. Ich möchte mich bei Hern Robert Welte bedanken weill er in den letzten Wochen dieser Doktorarbeit viel von meiner "daily routine" Arbeit übernommen hat. Auch hat er meine Anwendung der Deutschen Grammatik rücksichtslos korrigierdt (diese zwei Satze ausgenommen). Jan Zweens heeft de schaarse Nederlandstalige zinnen in dit proefschrift geperfectioneerdt (behalve deze).

Ik draag dit proefschrift op aan milin moeder. De steun die ik altijd van haar gekregen heb is nu tevens uitgebreid naar de volgende generatie. Haar grote betrokkenheid bij de opwoeding van haar kleinkinderen is een grote verriking van hun leven en gaf mij waak de gelegenheid woensdagmiddagen en zondagen aan het proefschrift te werken.

Ik dank Ellen, Arjan en Tessa voor meer dan ik hier zwart-op-wit kwijt kan. In de op lagere scholen tegenwoordig zo populaire "wriendenboekjes" kunnen in telegramstijl een aantal favoriete gezinsbezigheden worden opgesomd: vakantie in Griekenland, memory/schaken, woetbal/tennis en Disney video"s geven de energie die nodig is voor het schrijven wan een proefschrift. Dat ik na afronding wan het proefschrift meer tijd voor hun zal hebben is een cliche dat men op deze plats in een proefschrift vaak aantreft. lk wil het niet gebruiken omdat ik de afgelopen jaten niet vreselijk tekort geschoten ben (toch?) en anderzijds verwacht ik ook de komende jaren 's avonds en in hel weekend nog wel wat werk te zullen doen. $\mathrm{Zj}$ het misschien niet aan een tweede proefschrift. 


\section{Summary}

During the second half of the 1980 s interest arose for the economic consequences of the Human Immunideficiency Virus (HIV) that causes AlDS (Acquired Immunodeficiency Syndrome). In European Union (EU) member states, relevant impacts of AlDS on in particular health-care costs and life-insurance losses. This thesis elaborates these issues issues, the first step for which had been taken in the beginning of the 1990s. Some of the methods used in the cost-of-illness approach were adopted. However, this approach had to be extended to include emerging treatment and care patterns of a new disease, for questions of care capacities - especially hospital beds - and the specification with respect to the development over time of a significantly spreading infectious disease, therefore requiring a link with epidemiological modelling. In short, the method used here can be labelled "dynamic cost-of-illness" approach. Methodologically, this can be considered an extension of existing methods of economic evaluation in health care. (Chapters 1-2)

To help publichealth HIV/AIDS planning of health-care facilities in the EU, preliminary economic impact scenarios were developed already in 1993. Using a simulation model, routine AIDS surveillance-data, information on disease progression and hospital-based studies on the health-care utilization were integrated in scenarios at an aggregated EUlevel. Evaluation of published studies on hospital resource utilization and costs for HIV/AIDS patients showed that significant differences exist between countries and studies. These differences are partly related to methodology, illustrating the need for a standardized costing approach. Standardized health-care information in different EUcountries is a prerequisite for construction of multi-national scenarios. (Chapters 3-4)

A specification of the approach to the Netherlands showed that forecasted hospital bed needs for HIV/AIDS by the end of the century is limited compared to projections for coronary heart disease and stroke, but approaches those for lungcancer, pneumonia and diabetes. Hospital costs were estimated to be $85 \%$ of total health-care costs for HIV/AIDS in 1993. Scenarios indicated a decreasing share of outpatient costs, illustrating the growing relative importance of the care-intensive stages of HIV disease. (Chapter 5)

To cope with emerging Dutch questions in Jife insurance a consultancy project was conducted. In particular, losses were feared if groups of persons liwing with HIV and AIDS (PLWHAs) were accepted for insurance, and possibilities to compensate insurers 


\section{Summary}

were discussed. For this purpose, the scemario approach was extended with age-specific analiyses and assumptions on income position and life-insurance needs of PLWHA. Possible demand of PLWHAs was estimated for pension, mortgage and temporary-risk insurance in several scenarios. The size of the Life-insurance Fund, that should provide compensations for insurer's losses, is estimated at 150 to 125 million. (Chapter 6)

Progression of AIDS disease is staged in two substages: the final half year of AIDS preceding death (late stage) and the foregoing period (early/chronic stage). The Dutch hospital costs per person-year in the late stage are almost three times those in the chronic stage. More than half of lifetime hospitalization costs are generated in the late stage. It is illustrated that the choice of an appropriate disease-staging is crucial and averts structural biases in projections of health-care needs. Criteria are formulated for the minimal quality of databases on utilization and costs of health care for PLWHAs. (Chapter 7)

Using the defined quality-criteria, six national studies on the utilization of hospital care for AIDS are selected to provide the data for EU-scenarios. Epidemiological parts of the scenario's are based on standardized modelling for the backcalculation from registered AIDS cases to HIV incidence in the past and the projection of future AIDS incidence, prevalence and mortality. Next, estimated health-care resource needs are linked to epidemiological outcomes. Several scenarios render different possible fiuture health-care resource needs. By the end of the century hospital bed needs of 10 000-12 700 in the EU are indicated, representing $0.5 \%$ to $0.65 \%$ of all hospital beds in the EU. (Chapter 8-9)

Estimates of resources and costs of hospital care for HIV/AIDS can be used for planning at the national or multi-national level if a standardized approach in epidemiological modelling, economic data-gathering and severity-staging of disease is applied. Estimated lifetime costs from the time of HIV-infection onwards are estimated to amount 76000 ECUs in the Netherlands. In the Netherlands, one quarter to a half percent of total hospital costs will be required for HIV/AIDS by the end of the century. Application of the dynamic cost-of-illness approach developed in this thesis is a prerequisite for many (pharmaco-)economic evaluations in infectious diseases. (Chapter 10)

In this thesis a dymamic cost-of-ilness approach is developed for HIV/AIDS. Further research is directed at the development of dynamic costueffectiveness analysis in treatment and prevention of HIV and other infectious diseases. This research is already in progress. 


\section{Samenwatting}

\section{Samenvatting}

Gedurende de tweede helft van de tachtiger jaren onstond er sterke interesse voor de economische "impact" van het Human Immunodeficiency Virus (HIV), dat het Acquired Immunodeficiency Syndrome (AIDS) veroorzaakt. In de Europese Unie (EU) werden aanzienlijke consequenties gevreesd voor met name de gezondheidszorg en de (levens)verzekeringen. Dit proefschrift gaat in op deze kwesties, voortbouwend op onderzoek dat reeds aan het begin van de negentiger jaren starte. De methodiek sluit aan bij de "Cost-of-illness" benadering. Deze benadering is vervolgens aangepast aan de specifieke omstandigheden van de nieuwe ziekte, waarin veel en snel opeenvolgende veranderingen in behandeling en zorg plaatswinden. Daarnaast moest rekening gehouden worden met de dynamiek van de HIV-infectie, hetgeen een directe connectie met de modellering van de verspreiding van infectieziekten vereist. De hier gebruikte methode kan als dynamische Cost-of-illness benadering worden omschreven. Methodologisch gezien is deze benadering een uitbreiding van bestaande methoden wan economische evaluatie in de gezondheidszorg. (Hoofdstukken 1-2)

Om tegemoet te komen aan de informatiebehoefte voor de planning van gezondheidszorgvoorzieningen werden in 1993 voorlopige economische "impact" scenario's voor de EU ontwikkeld. Binnen een simulatiemodel werden gegevens over de incidentie van AIDS, de progressie-van-ziekte en het gebruik van gezondheidszorg geintegreerd tot diverse toekomstscenario's. Evaluatie van de studies over het gebruik van gezondheidszorgvoorzieningen en de daaraan verbonden kosten van HIV/AIDS toonden aan dat er aanzienlijke verschillen zijn tussen studies en landen, ook na correctie voor diverse invloeden. Deze verschillen konden gedeeltelijk worden teruggevoerd op methodologische aspecten, hetgeen de noodzaak voor een gestandaardiseerde aanpak wan studies naar het gebruik en de kosten van gezondheidszorg bij HIV/AIDS illustreert. Gestandaardiseerde informatie over de gezondheidszorg is een noodzakelijke voorwaarde voor multinationale scenario"s betreffende de economische impact van HIV/AIDS. (Hoofdstuk 3-4)

Nadere specilicatie voor Nederland toonde aan dat het voorspelde gebruik van ziekenhuisbedden voor HIV/AIDS aan het einde van de twintigste eeuw aanzienlijk lager is dan soortgelijke extrapolaties voor hart- en vaatziekten, echter in de orde van grootte komt van bedbehoefte voor longkanker, longonsteking en diabetes. De ziekenhuiskosten 


\section{Samenwaning}

werden geschat op $85 \%$ van de totale gezondheidszorgkosien woor HIV/AIDS in 1993 . Verschillende scenario's geven een dalend aandeel van de poliklinische kosten te zien. Dit illustreert het toenemende relatieve belang van de HIV-stadia waarin veel klinische zorg nodig is. (Hoofdstuk 5)

In 1995 speelde in Nederland de vraag of er een speciaal fonds (Garantiefonds) zou moeten komen om bepaalde vormen van levensverzekering ook voor HIV-geïnfecteerden mogelijk te maken. Het Garantiefonds zou aangewend moeten worden om levensverzekeraars te compenseren voor uitkeringen aan HIV-geïnfecteerden. Tijdens een consultancy opdracht is de wraag naar pensioen-, hypotheek- en tijdelijk-risiko verzekeringen geschat voor groepen HIV-geïnfecteerden. Hierwoor werd de scenariomethodologie uitgebreid met een leeftijdsspecifieke aanpak en veronderstellingen over de inkomenspositie en de behoefte aan levensverzekeringen van HIV-geïnfecteerden. De geschatte omvang van het Garantiefonds bedraagt $f 50$ tot 125 miljoen. (Hoofdstuk 6)

Bij de progressie-van-ziekte voor AIDS zijn twee substadia onderscheiden: het laatste half jaar van AIDS, voorafgaand aan overlijden (late stadium) en de daaraan voorafgaande periode (vroege/chronische stadium). In Nederland zijn de zickenhuiskosten per persoonjaar in het late stadium circa drie maal zo hoog als in het chronische stadium. Meer dan de helft van de "lifetime" kosten worden veroorzaakt tijdens het late stadium. Aangetoond wordt dat de keuze voor een adequate indeling van de ziekte in stadia cruciaal is en een structurele overschatting van de gezondheidszorgkosten voor AIDS woorkomt. Tevens worden criteria geformuleerd voor de minimaal vereiste kwaliteit van een observationele studie ower het gebruik en de kosten van gezondheidszorg voor HIV/AIDS patiënten. (Hoofdstuk 7)

Aan de hand van de criteria voor minimale kwaliteit zijn zes nationale Europeese studies over het gebruik en de kosten van gezondheidszorg voor HIV/AIDS patienten geselecteerd. Op basis van deze studies zijn scenario's voor de. EU ontwikkeld. De epidemiologische achtergrond wan de scenario's is gebaseerd op gestandaardiseerde modellering van het "terugrekenen" van gemelde AIDS-gevallen naar de incidentie van HIV in het verleden en het voorspellen van toekomstige AIDS incidentie, prevalentie en mortaliteit. In de volgende stap worden schattingen voor de behoefte van gezondheidszorg gekoppeld met de epidemiologische uitkomsten. Verschillende scenario's tonen diverse mogelijke toekomstige ontwikkelingen voor de epidemiologie en de behoefte aan 


\section{Samenvatting}

gezondheidszorg. De behoefte aan ziekenhuisbedden in de EU wordt voor het einde van de twintigste eeuw geschat op $10000-12700$, heigeen overeen komt met $0.5 \%$ tot $0.65 \%$ van alle ziekenhuisbedden in de EU. (Hoofdstuk 8-9)

Schattingen van de middelen en kosten voor HIV/AIDS ziekenhuiszorg kumnen worden gebruiki voor planning op nationaal en multinationaal niveau indien een gestandaardiseerde aanpak wordt gevolgd woor de epidemiologische modellering, de economische data-vergaring en de indeling van de ernst-stadia van HIV/AIDS. De geschatte "lifetime" kosien vanaf het moment wan HIV-infectie bedragen 76000 ECUs in Nederland. Aan het einde van de twintigste eeuw is een kwart tot een haif procent van alle ziekenhuisbedden in Nederland nodig voor de verpleging van patiënten met HIV/AIDS. Toepassing van de dynamische Cost-of-illness benadering uit dit proefschrift is een noodzakelijke voorwaarde voor de uitvoering van (farmaco-)economische evaluatie bij infectieziekten. (Hoofdsiuk 10)

In dit proefschrift is een dynamische Cost-of-iilness benadering voor HIV/AIDS ontwikkeld. Huidige vervolgwerkzaamheden richten zich op dynamische kosteneffectiviteitsanalyse van preventie en behandeling bij HIV en andere infectieziekten. 
AIDS Acquired Immunodeficiency Syndrome

AZT Azidothymidine

CDC Centers for Disease Control

EC European Communities

EU European Union

GHI Chief Medical Inspector (Geneeskundige Hoofdinspectie)

GP General practitioner

HAART Highly Active Antiretroviral Therapy

HIV Human Immunodeficiency Virus

PCP Pneumocystis carinii Pneumonia

PWA Person with AIDS

PLWHA Person living with HIV/AIDS

PYLL Potential years of life lost

RIVM National Institute of Public Health and the Environment (Rijksinstituut voor Volksgezondheid en Milieu)

STG Steering Committee on Future Health Scenarios (Stuurgroep

Toekomstscenarios Gezondheidszorg)

UK United Kingdom

US United States

WHO World Health Organization 


\section{Chapter 1}

\section{General Introduction}

This chapter is partly based on book contributions:

IC Jager, MH Postma, FMLG wan den Boom et al: Epidemiological Models and Soclo-economic Intormation;

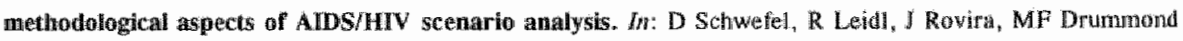
(Eds) Economic Aspects of AIDS and HTW Infection. Derlin: Springerm Verlag 1989, pp 262-81.

MI Postma, GJP van Grienswen: ADS (hoofdstulk 14). In: CW Aakster, G Kuiper "JW Groothoff (EAds)

Medische Sociologie. Groningen: Wolters-Noordhof 1991, pp 129.36.

JC Jager, MJ Postma, K Tolley, J Kenelly: Assessment of the Socio-economic Impact of AIDS; from mational towards multi-national scenarios. In: D Fitzsimons, V Hardy, $\mathrm{K}$ Tolley (Eds) The Economic and Social Impact of AIDS in Europe. London: Cassell 1995, pp 40-53. 



\subsection{Main Initial Questions and Methodological Challenges}

During the second half of the 1980s concern came up about the consequences of the Acquired Immunodeficiency Syndrome (AIDS) for health-care systems in European Union (EU) member states [1]. Furthermore, significant effects of AIDS on the economy were feared, such as productivity losses, life-insurance losses and public-sector compensations [2]. It was felt that health-care cost implications and capacity needs would become main issues concerning the general impact, of the new disease. This thesis elaborates these research issues, the first step for which had been taken in the beginning of the 1990 s. Some of the methods used in the cost-of-illness appraach were adopted [3]. However, this approach had to be extended to include emerging treatment and care patterns of a new disease, for questions of care capacities - especially hospital beds - and the specification with respect to the development over time of a significantly spreading infectious disease, therefore requiring a link with epidemiological modelling. In short, the method used here can be defined as the "dynamic cost-of illness" approach. Methodologically, this can be considered an extension of the existing methods of economic evaluation.

This thesis seeks to provide research contributions to several areas. Firstly, it concentrates on sound methods for measurement of health-care resources and costs and comparisons of results of different studies in this field. Secondly, methods for the assessment and projection of the burden-of-disease and budget impact are developed and comparisons are made with other diseases and among countries. In detail, the role of the case-mix over severity stages of HIV/AIDS is clarified. Thirdly, the special requirements for linking epidemiological models of infectious diseases and health care information are addressed. The information provided in this thesis can contribute to economic evaluation studies, such as cost-benefit and cost-effectiveness analysis. In fact, knowledge about cost measument methods, epidemiological developments, burden-of-disease and budget impact is a precondition for any economic evaluation. In terms of methodology the developments in this thesis include infectious disease modelling, multi-model, multi-parameter and multi-national standardized scenario analysis and the linkage of epidemiological modelling and health-care data.

Ultimately, the type of research presented here aims at underpinning health-care policies. As such, research results should provide a sound basis for estimating and forecasting health-care capacity needs and cost impacts. Outside the health-care sector results could benefit tackling questions arising in prevention, life insurances and marketdevelopments for pharmaceutical industries. 


\section{Chapter I}

\subsection{The Epidemic of HIV/AIDS}

AIDS is an infectious disease caused by the Human Immunodeficiency Virus (HIV), a retrovirus that can be transmitted through sexual contact, blood and blood products and from mother to child [4-6]. According to the AIDS surveillance case-definition, AIDS is a collective noun for a broad range of illnesses that result from a lowered immune system due to the debilitating effect of HIV $[7,8]$. Infection with HIV causes a high susceptibility for several rather uncommon infections, particular cancers and psychiatric disorders such as dementia and depression. AIDS is the last stage of HIV infection and up to now AIDS is perceived to be an incurable disease. There is no vaccine for HIV, nor an effectively curative therapy available. There are however some drugs on the market that slow down the progression from asymptomatic HIV infection to AIDS and that prolong survival in the AIDS stage, such as azidothymidine (AZT)/zidovudine, prophylax is for pneumonia and combination triple therapy [9-11]. Of the recently introduced combination triple therapy the effects on disease progression are promising but as yet uncertain. Prior to the introduction of triple therapy, estimates of the length of the incubation period indicate an average duration of $11-12$ years from the time of infection to the first appearance of AIDS symptoms $[12,13]$. In the incubation period tinree subperiods can be distinguished. Relatively short subperiods of acute infection and symptomatic pre-AIDS surround an intermediate asymptomatic subperiod of 9 -10 years. The average survival time for AIDS patients is estimated at 2-3 years $[14,15]$. Next to the AIDS surveillance case definition a staging system for HIV has been developed by the Centers for Disease Control (Atlanta; $\mathrm{CDC}$ ) that is based on the clinical experience of managing HIV infection in patients (CDC stages) [16,17]. The CDC-stages reflect a hierarchical system from acute infection, through asymptomatic seropositivity to clinical symptoms. The final CDC stage (CDC IV) crudely corresponds with AIDS, though small differences in definitions exist.

In the eighties AIDS surveillance systems have been set up [18]. For example, in the US the CDC took up this task. The long incubation period of HIV/AIDS means that AIDS surveillance can only reflect "the top of the iceberg". AIDS cases reported to the surveillance systems provide a minimum estimate of total HIV seroprevalence. National surveillance systems for HIV have proven not to be feasible (see for example [19] for the Netherlands). "Therefore, several methods have been applied for estimating HIV seroprevalence [20]. In the US, AIDS was first reported at the beginning of the eighties in the cities of Los Angeles, New York and San Francisco [21,22]. HIV was probably first present in the Netherlands in the late-seventies or early-eighties, as the first AIDS 


\section{General Introduction}

pattent was diagnosed in April 1982 [23]. The surveillance of AIDS in the Netherlands is undertaken by the Chief Medical Officer of the State Supervision of Public Halth (Geneeskundige Hoofdinspectie; GHI) in Rijswijk [24]. Up to December 1996 all least 4288 cases of AIDS had been diagnosed [25]. The estimated number of AIDS diagnoses woldwide amounted to 7.7 million by mid-1996, with the majority (77\%) of these cases in African countries [26]. UNAIDS estinated by mid-1996 the worldwide number of persons living with HIV/AIDS at 22 million - with $64 \%$ in Africa [2]] - which was slightly higher than the corresponding estimate in ADS in the World [281. In mid-1996, in the US over half a million of AIDS cases had been reported to the CDC, and an estimated 200000 European AIDS cases had been diagnosed [26]. In western Europe 640000 persons were estimated to be living with HIV/AIDS by mid-1996. For the European region the Centre for the Epidemiological Monitoring of AIDS (Paris) prowides standardized information on AIDS surveitlance and estimations of HIV infections [29]. Recent estimations for the EU, Austria and Swizerland show that during the period 1990 1994 almost 90000 AIDS cases have been diagnosed, half of which are intravenous drugusers (homosexual men account for $40 \%$ ) [30].

\subsection{Costing and HIV/AIDS; a global view}

HIV/AIDS has had and will have a considerable impact on the health-care systems of many countries. As mentioned, the perspective adopted in this thesis is a dyramic cost-ofillness assessment, conducted at the population level. Adjacent areas in health-economics science involve cost-of-illness analysis at the patient level and economic evaluation [31]. Among others, this thesis builds on work described in another thesis on the patient-based registration of HIV/AIDS that has been used in some Dutch hospitals [32]. As an appropriate costing of disease provides a basis for economic evaluation studies, this thesis can contribute to the set-up of such studies in the field of HIV/AIDS and infections diseases in general.

In a cost-of illness analysis, several classifications are used for exprassing the consequences of disease on resource utilization and costs" direct versus indirect costs, patient-related vs. general program costs and health care vs. non-health care costs [3335]. These classifications have also been used to express the financial/economic consequences of AIDS [2,36-39]. Direct costs arise from the treatment and care of patients in different health-care settings and from research, public information, prevention 


\section{Chapter I}

and media campaigns. These costs can be linked directly to a specific disease. Indirect costs relate to production losses as a result of premature death (potential years of life lost; PYLL) or illness (sickness absence). Patient-related costs are those incurred by each individual in a certain disease stage [40]. These costs comprise the direct costs of treatment and care and indirect costs. General program costs cover the costs of research, prevention, public information and the maintenance of services for the benefit of the entire population. In this thesis the main focus is the assessment of the patient-related direct costs of HIV/AIDS in the hospital sector. By illustration, some attention thas been given to indirect costs based on PYLL, and out-of-hospital costs, such as medication and district nursing costs.

In 1986 the first papers on the health-care costs of persons with AIDS (PWAs) in the US appeared in the literature, most of them focussing on hospital care [41-45]. The first paper in this set [41] is now generally considered to have overestimated lifetime cosis per PWA at US\$147 000. The other US-studies gave lower estimates. Expressed per person per year the early US-studies reported cost figures of up to US\$75 000 [44] and 100000 [41]. Using the data of [42] and predictions of future ALDS incidence produced in 1986, it was estimated that towards the end of the 1980s hospital bed needs for AIDS would approach $1 \%$ of all hospital beds available in the US [46]. This type of projection. reflected with pessimistic epidemiological forecasts, an immense economic impact of HIV/AIDS by the end of the eighties, involving major health-care management problems. Also outside the health-care secior major problems related to the management of HIV/AIDS were envisaged. For example, HIV/AIDS was thought to be a serious threat to the private life-insurance system. In response, specific conditions for HIV-tests of lifeinsurance applicants were defined [47].

Hay et al. [48] were one of the first to provide a detailed estimate of the AIDScosts distribution over the several health-care sectors. After inpatient hospital care, outpatient hospital resource utilization represented the second largest cost sector with $35 \%$ of total health-care costs. Medication - in particular, AZT/zidovudine - is estimated to represent $14 \%$ of health-care costs with $10 \%$ of costs covered by nursing-home care and the home-care setting, such as district nurse and general practitioner (GP).

Hay et al. and other later publications quoted considerably lower cost estimates for the US than the early studies did, ranging from US $\$ 25000$ to 40000 per person-year [48-50]. In [50] estimated lifetime costs in 1988 amount to US\$57 000. Since then, the same author has produced similar estimates for 1991, 1992 and 1993 [51-53]. Each new estimate surpassed the previous one by approximately US\$20 000. The final 1993- 


\section{General Introduction}

estimate was US\$119000, an increase of over $100 \%$ in a five-year period and again approaching the cost estmates of the early studies. Scitovsky\&Rice [54] compared the costs of treatment and care of AIDS with those of other diseases and causes of death and grimly projected that in 1991 only the total direct costs of car accidents would surpass those of AIDS.

As in the US, the early studies in Europe focused on the hospital costs [55-62]. estimated per person-year hospital costs ranged from US\$22 100 to 46800 [39]. It was suggested that the treatment of AIDS patients involved somewhat lower costs in Europe than in the US. Information on out-of-hospital care is currently still scarse in the $\mathrm{EU}$. with only tentative estimates of quantitative figures for the Netherlands, Italy and the UK [63-66]. Wiggers\&Bergsma $[63,64]$ estimated that in 1988 Dutch direct costs of HIV/AIDS amounted to US\$40 million, with $70 \%$ of these costs from pravention, testing and scientific research. At that time hospital costs were estimated at US\$6,7 million of only US\$9,3 million for the total costs of treatment, care and counselling (nursing home,

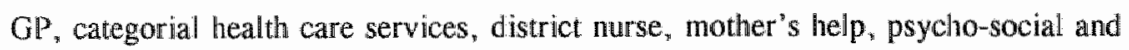
psychlatric care). As the epidemic has progressed the patient-related direct casts have obviously increased since then.

In contrast, in Africa and other developing countries the direct costs per case of AIDS are much lower, reflecting the lower gross national product and budgets for health expenditure. However, AIDS is straining an already overburdened health-care system to an extent which is not yet fully clear. Available estimates for African developing countries indicate that annual gross national product per capita (for example, US\$150-300 for Zaire, Tanzania and Rwanda) is a reasonablle proxy for the direct medical costs per patient with ALDS $[67,68$. In African countries the number of people progressing to endstage HIV disease is escalating rapidly. Hospital services are increasingly burdened due to growing case-loads and budget restrictions. In response to hospital bed shortages, additional costs are being incurred in Africa through the development of AIDS home-care programmes throughout different countries. In countries such as Zambia and Zimbabwe several home care programmes have been established in the beginning of the 1990s 169. 711. Furthermore, projections for Asia show for example that in the year 2000 up to 12 per cent of total hospital bed needs may be for AIDS $[$ 72]. As the AIDS epidemics seem to have affected the economically and socially active upper and middle classes disproportionally, the indirect costs are even more relevant than the direct costs and their monetary valuation could exceed the direct costs several times. This has also been illustrated for the developed world $[73\}$. 


\section{Chapter I}

\subsection{Scenario Analysis;" linking epideniological models and cost studies}

As future epidemiological prospects are at the basis of any economic projection, full economic impact assessments are necessarily preceded by epidemiological modelling. A wide range of models is used for HIV/AIDS [74]. Epidemiological models for quantitatively expressing the HIVIAIDS epidemic can broadly be divided into empirical and population-dynamical models. The former uses surveillance data on ADDS incidence, often in combination with some assumption on progression-of-disease, such as the incubation period. So, empirical modelling is basically the application of statistical methods to AIDS incidence. Empirical models can be further divided into models that project the future AIDS incidence by performing trend extrapolation of AIDS cases and models that estimate the likely HIV epidemic associated with the AIDS figures. The former were used in the early days of AIDS modelling [75-79]. Later the incorporation of information on the natural history of HIV enabled the application of the latter type of empirical models, which are usually referred to as backcalculation models [80-83]. Also, recent estimates of HIV incidence and prevalence and future AIDS incidence by the Paris Centre on the Epidemiological Monitoring of AIDS [84] used the backcalculation approach.

Population-dynamical models explicitly take into account the specific characteristics of the mechanisms that dictate the course of the epidemic [85]. Particular characteristics that population-dynamical modellers are interested in comprise the size of high-and low-risk groups, number of sexual or needle-sharing partners and the infectivity of HIV [86-90]. Some mixed empirical/population-dynamical models have also been used. These mixed models apply the backcalculation procedure within the framework of a population-dynamical model, which implies that succesive HIV incidences are not independent but adhere to a postulated functional form [91,92].

An epidemiological projection, by providing estimates of the future pattern of HIV/AIDS incidence, prevalence and mortality, provides the basis for producing socioccononic scenarios. The two main methods for linking epidemiological information with socio-economic data are the incidence-based and the prevalence-based ones [40]. Incidence-based modelling accounts all future consequences to the year of first occurrence; for example, the lifetime costs for treating and caring for HIV/AIDS are designated to the year of HIV infection. Prevalence-based modelling designates the consequences to the year in which they occur; for example, hospital costs are accounted 
to the relevant budget year. In essence, a modelling framework should be designed such that consequences can be expressed according to both approaches or combinations of both [93]. Therefore, the output of the epidemiological models should exceed the basic information on incidence of HIV and AIDS, and be extended to comprise survival, mortality and prevalence. During the spread of HIV/AIDS disease the prevalent case mix has a significant influence on needs for health-care resources. Information on case mix reflects differences in important medical elements (such as diagnosis, prophylactic and late-stage care), treatment patterns, resources (such as inpatient and outpatient care needs) and monetary costs. Furthermore, the case mix should bear a close relationship with severity-of-disease in a patient population. Obviously, different stages of severity require different health-care inputs. In consequence, the investigation of the economic impact of HIV/AIDS involves consideration of multi-dimensional dynamics and uncertainty in basic parameters. The epidemic evolved in societies with changing population distributions (for example, over risk and age groups), rapid developments in medical technology and reforms in the financing and delivery of health care. Furthermore, in a European perspective we are dealing with differences in health-care systems, in the organisation of AIDS care and related differences in resource needs between countries.

The early studies on the economics of AIDS have demonstrated wide variation in costing methods. In order to derive valid cost data at the European level standardization in the methodology of AIDS economic impact studies is needed [94]. The explicit use of a standardized framework for estimation of hospital resources and costs would help improve the quality of methods in resource utilization and cost studies and enhance the comparability of estimates produced, and therefore maximuse their usefulness for a range of research and policy purposes at the local, national and multi-national (ie EU) levels $[95,96]$. Finally, there is a high degree of uncertainty surrounding the economic impact of HIV/AIDS. There is uncertainty about epidemiological developments, impact of prevention, changes in the progression-of-disease due to new therapies and prophylactics and about resource needs in different disease stages. The scenario methodology is chosen as the tool to present the future economic impacts of HIV/AIDS. The technique is designed to deall with multi-disciplinary (biomedical, epidemiological and economic) and multi-national inputs [97]. In addition, it can cope with a high degree of uncertainty by projecting different futures by "if-then" reasoning together with comprehensive sensitivity analysis and analyses of interventions, such as drug therapies.

Scenario analysis emerged during the early 1950 s as a technique applied by the Rand Corporation in Santa Monica to military problems. Since then scenario analysis has 


\section{Chapter 1}

become popular in other fields as well $[98,99]$. Initiated by the Steering Committee of Future Health Scenarios (Stuurgroep Toekomstscenario"s Gezondheidszorg; STG) in the 1980 s, public health in the Netherlands also became a field for applications of the technique [100]. In 1992 STG published the report on AIDS scenarios in the Netherlands [101-103], which has provided the starting point of this thesis. Previously, scenario analysis was used to investigate the consequences of AlDS in Germany [104]. A scenario is a description of a possible path, governed by a series of developments, leading from the prevailing state of a part of society to a future state, with the goal to gain insight into the mechanisms that determine the path, the future state and the possibilities of influencing these mechanisms [105]. Kahn\&Wiener [106] define a scenario as a hypothetical sequence constructed for the purpose of focussing attention on causal processes and decision points. The so-called reference scenario is an exploration of the future in which all developments continue their current course. It is an exploration of trends that already exist in society. It might be conceived as a prediction, given unaltered policy. With respect to AIDS we might imagine the reference scenario as a description of the path of the epidemic and the resource-needs implications in an environment in which no new developments (therapeutics, vaccine) or prevention activities occur. Next to the reference, alternative scenarios explore a future in which ceriain, clearly defined, new developments occur (for example, new AIDS therapies).

\subsection{Context}

At the initiative of the World Health Organization (WHO), STG commissioned the Netherlands Institute of Mental Health (NcGv) and the National Institute of Public Health and the Environment (RIVM) to conduct a pilot study into the feasibility of a scenario approach to the socio-cultural and economic impact of AIDS on society. This study started in November 1988. Based on the results it was decided to set up a full-scale project, and a scenario committee was appointed. The afore-mentioned NcGV/RIVM research team was responsible for project implementation. The team comprised six persons. Furthermore, two persons of the STG were involved. In developing the Dutch AIDS Scenario project the Program Coordinating Committee on AIDS Research also played a pivotal role. Furthermore, the Chief Medical Officer (GHI) was involved in the project through various consultations of the anonymous register of PWAs in the Netherlands. The final report on the Dutch AIDS scenario project was presented at a 


\section{General Introduction}

symposium in the Hague in 1992.

At delwery of the Dutch ADS scenario study, most impact scenarios had been confined to regional and mational projections with little use for multimational projections [107]. In the late-eighties, workshops had been organised by the EU [108, 109] and WHO [110] to explore possibilities for the construction of multi-national economic impact scenarios, and a Concerted Action of the EU on this topic started a few years later [1111]. The set-up of this multi-national project reflects the involvement of different disciplines in scenario analytic research. Over 50 participants from 30 European universities (European Research Team on AIDS Scenarios) and institutes were assigned to four working groups on epidemiology, modelling aspects, economics and social aspects. A co-ordinating team ensured that the work of an individual working group was tuned to developments in other working groups. The working groups convened half-yearly. Furthermore, all participants met at yearly plenary meetings. The European Research Team on AIDS Scenarios has drawn attention to HW/AIDS impacts on society through reports and scientific publications [112-114]. In addition, the economic impact of HIV/AIDS at the EU-level was investigated in the related EU-project "Managing the Costs of HIV Infection" (project number SOC $9420018005 \mathrm{FO} 1$ ) $[66,95,96]$. This project assessed the feasibility of developing a standardized costing framework for HIV/AIDS hospital treatment and care, by investigating the possibilities of applying standardized methods for the collection, processing and presentation of information on resource utilization and costs. Comparable economic information for the different EU-countries is a prerequisite for the construction of multi-national scenario assessments.

Also in the row of International Conferences on AIDS the attention for the economic impact has grown. Where in Paris (1986) only eight abstracts [115-122] were directed at the economic impact, at the Vancouver Conference (1996) 24 abstracts were classified as referring to the economic impact and over 50 abstracts were classified as addressing health care costs/direct costs/hospital costs. Finally eleven abstracts involved the projection of costs. Furthermore, a substantial number of abstracts addressed the costeffectiveness of various interventions, treatments and medication ffor example HIVscreening of pregnant women, intensive case management and conbination tripletherapy). At the Oslo conference (1988) for the first time three absiracts were explicitly directed at cost projections $\llbracket 123-125 \rrbracket$. In Montreal (1989) the scenario-analytic approach was specifically introduced [126], 24 abstracts were classified as economic impact and 2 involved cost projections $[127,128]$. In San Francisco (1990) the Dutch application of the scenario-analytic approach to the economic impact of AIDS was presented for the first 


\section{Chapter I}

lime [129]. In the next years in Florence (1991) and Amsterdam (1992) the Dutch research team presented several abstracts on scenario analysis for AIDS impact in the Netherlands [130-135]. In Amsterdam (1992) the number of abstracts on direct/health care/hospital costs, economic impact, cost projection and scenario analysis reached its current maximum with almost 100 abstracts. In Vancouver (1996) the multinational reference scenario on the economic impact was presented in a set of four abstracts [136$139]$.

The types of investigations pursued in this thesis should come up with information that is relevant for health-care policy making. Obviously, costing aspects are a concern of health-care policy and information about the costs of a new and spreading disease such as HIV/AIDS informs decision makers about the size of the problem. Current estimations of this size and future projections thereoff give a basis for allocating budgets, capacities and funds. Also beyond the health-care sector such estimations and projections are of relewance, for example in marketing pharmaceuticals and impacts on life-insurance markets. Furthermore, sound costing analysis is basic to any cost-effectiveness approach in the field of HIV/AIDS. Important emerging questions on whether or not to screen subpopulations for HIV, to apply very costly triple therapies to different exposure groups or to set-up/intensify prevention programmes can only be adequately addressed from an economic point of view if good cost estimates for the present and future are available.

\subsection{The Objectives of the Thesis}

This thesis highlights the important issues that emerge in attempts to move on from the use of scenario analysis at the national level to the multi-national (EU-)level. In particular, the thesis focuses on the projection of hospital resource needs and corresponding costs of HIV-infected persons in the Netherlands and the EU by the end of the century. The specific objectives are:

1 To develop a standardized methodology for the estimation of HIV/AIDS-related personal health-care costs, to allow valid comparisons between economic impact studies performed at different times, in different research settings and in different countries;

2 To develop methodological quality criteria and applying these criteria to identify economic impact studies in various European countries, that provide high-quality basic data for multi-national scenarios; 
3 To develop a disease-staging model that reflects relevant differences in resource needs and costs;

4 To develop a general framework for linking epidemiological modelling and economic impact in a scenario-analytic approach that encompasses further methods to deal with uncertainty (confidence intervals and sensitivity analysis);

5 To estimate the economic parameter values in mixed epidemiological/economic models for impact assessment and scenario analysis relating to future needs for hospital resource utilization and corresponding costs;

6 To project the consequences for health-care resources and costs of potential future trends in the epidemic in sets of future scenarios and to relate these projections to national estimates of health-care resources utilization and costs;

7 To construct a generic/standardized approach to allow comparison of future projections of HIV/AIDS health-care impacts between countries and with other diseases;

8 To identify differences in AIDS care between EU-countries and to relate these differences to variations in characteristics of health-care systems;

9 To support the development of health-care policy in the field of HIV/AIDS at the national and multi-national EU-level, ie to inform policy makers on costing aspects;

10 To contribute to health-economics science in developing a dynamic cost-of-illness approach, viz an approach for estimating cost-of-illness of infectious diseases; and

11 To provide the basis for cost-effectiveness analysis in the field of HIV/AIDS and infectious diseases in general.

\subsection{Outline of the Thesis}

As a first illustration and as a basis for the more recent work, chapter 2 presents PYLL per 1000 population in three EU-countries. Trends for AIDS incidence are projected using an "early-type" empirical modell, assuming a constant future growth rate. Therefore, chapter 2 serves as a motivation for scenario analysis enabling more than just projecting current and recent courses by incorporating knowledge from different research fields. In chapters 3 and 4 data gathering and data evaluation for scenario analysis at the Dutch and EU-level are presented. In addition, chapter 4 shows the development and application of a population-dynamical model to the epidemic in the EU as a whole. Some preliminary 


\section{Chapter 1}

scenarios on hospital bed needs and costs for 1995 are presented. Chapter 5 provides the results on scenario construction for the Netherlands, in particular for tesources and cosis in the hospital sector. The annex to this thesis prowides the background for chapter 5 its comparison of HIV/AIDS hospital bed needs projections with those for other diseases. Based on a specific research request from the State Secretary of Health, chapter 6 extends chapter 5 its results to non-health-care sectors, in particular to the Jife-insurance sector. The discussion of national scenario analysis in chapter 7 illustrates the importance of an appropriate staging of HIV/AIDS for health-care resource needs. Furthermore, this chapter discusses the importance of a standardized approach to estimating HIV/AIDS costs in the different EU-countries. In chapters 8 and 9 , the scenario-analytic approach is extended to the EU-level. In particular , chapter 8 provides the reference scenario at the global EU-level by connecting information from databases on AIDS hospital resource utilization in six EU-countries to recent empirical projections of future AIDS incidence produced by the European Centre for the Epidemiological Monitoring of AIDS in Paris. From this, future scenarios on hospital care for the EU as a whole have been produced. Chapter 9 presents the details on AIDS hospital care for several EU-countries. Also, this chapter tries to relate differences in AIDS hospital care in two selected countries to the respective characteristics of the health-care systems. Finally, chapter 10 concludes the thesis with discussions and the main conclusions. 


\section{Chapter 2}

\section{AIDS Impact Scenarios; questions for the years to come}

This chapter was published as a letter to the editor with the same titte by $\mathrm{JC}_{\mathrm{C}} \mathrm{Jager}$, MJ Postma, R Leid, B Majnoni d"lntignamo, AE Baert in ADS (1990, 11:1166-7); reprinied with permission 


\section{Chapter 2}

If is generally agreed that research to support the fight against AIDS requires an international and inter-disciplinary approach to the broad rarige of problems emerging from the three successive epidemics: (1) infection with HIV (2) the occurrence of AIDS and other HIV-related conditions and (3) the epidemic of socio-economic consequences of HIV infection and AIDS [140]. Since it has become clear that AIDS will be more than a short-term challenge to biomedical scientists, coping with social "psycho-social and economic impacts may be considered an important health-policy issue. Recently, the Council of the European Communities (EC) and the Ministers of Health of the Member States stressed the importance of, research into and evaluation of socio-economic impact [1].

Analyses of the third epidemic are demanded, including impact forecasts and scenarios. Two EC-activities prepared the ground for co-ordinated research in this field: the Concerted Action on the Statistical Analysis and Mathematical Modelling of AIDS (Bilthowen workshops 1986 [141,142]. and the Study on Economic Aspects of AIDS and HIV Infection (Munich workshop, 1989 [109]). Both 1989 workshops began to explore impact scenarios and the perspective for linking models for HIV transmission with socioeconomic information. Here some preliminary results are presented of a collaborative (Netherlands, FRG, France) study on short-term forecasts concerning the impact of AIDS compared with a number of other death causes liable for prevention. As one indicator for the social burden of diseases, potential years of life lost (PYLL) are used. PYLL are defined as the remaining life expectancy at time of death; here, 1985 data were used (sources: Centraal Bureau voor de Statistiek, Statistisches Bundesamt, Institut National de la Santé et de la Recherche Médicale). PYLL are reported per 1000 population.

Figure 2.1 shows observed and projected trends of PYLL due to AIDS and due to infectious diseases other than AIDS (ICD 001-139), lung cancer (ICD 162), road traffic accidents (ICD E810-819) and suicide (ICD E950-959). PYLL due to AIDS are based on the surveillance of AIDS cases by date of diagnosis (WHO Collaborating Centre on AIDS, Paris), adjusted for reporting delay [143] up to June 30st 1989, the observed age distribution of AIDS cases, and an assumed survival time of 1.5 years after diagnosis. Trends for AIDS cases are projected assuming a constant growth rate equal to the observed rate during the last 3 years, for the respective countries. The present procedure is held to give reliable forecasts only for the short-term (2-3 years). Trends for other death causes are based on mortality data registered over the period 1980-1987 and are 
projected by linear extrapolation of the observed data.

The three countries show rather similar patterns: stable or slowly changing PYLL due to infectious diseases, lung cancer and suicide, decreasing trends for road accidents, and an increase for AIDS. In a few years, PYLL due to AIDS tend to exceed those due to other infectious diseases. They come close to other death causes before 1995. As a first hypothesis on future trends, extrapolations were also projected beyond what statistically would be considered reasonable in terms of confidence limits (grey areas). A detailed discussion of methods and results is presented elsewhere [144]. The techniques are already useful in ranking risks and in communications between researchers and policy makers. In wiew of the uncertainties and gaps that were met when trying to produce reliable impact forecasts and scenarios of possible futures, only research priorities are focussed on. One is confronted with two kinds of gaps - gaps with respect to data and gaps with respect to methodls.

Fig 2.1

Observed and projected (grey arear: long-term projections beyond confidence limirs) porential years of life lost (PYLL) per 1000 population for AIDS (line), infectious diseases (short dashes), lung cancer (tong dashes), suicide (alternating dashes), road accidents (dots)

The Netherlands

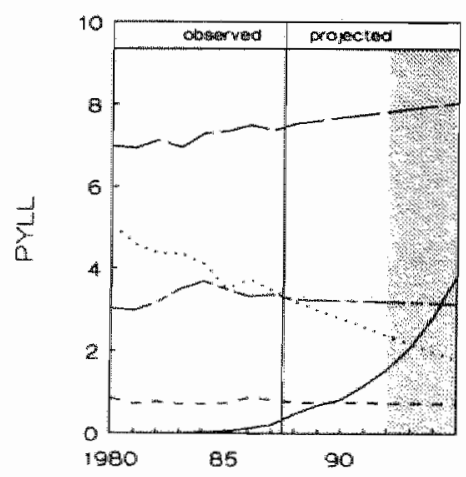

F. A. Germany

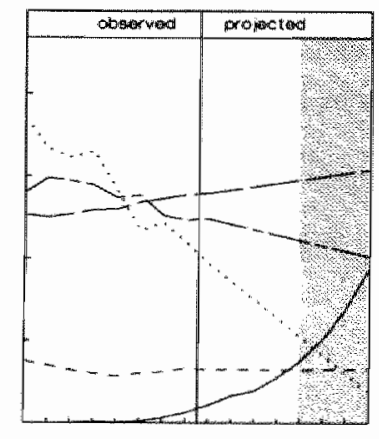

so
85

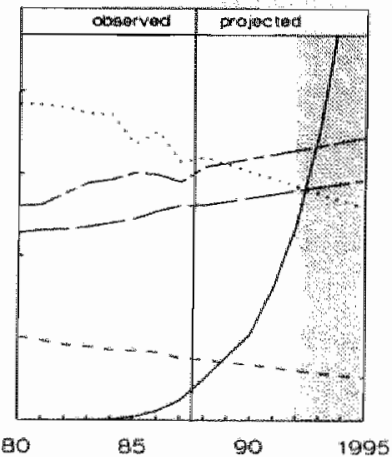


Gaps in data concern epidemiological and behavioural aspects of the transmission and prevalence of HIV infections. These have been specified by model-builders and are wellknown in the literature [145]. The main information source of the epidemic is still the surveillance of AIDS cases; but should AIDS incidence be the focus in the context of improving medical care [126]? Early interventions could infuence the progress of the disease in individuals and affect the number of people to be cared for in the different stages of the disease. Consequently, for impact assessment, the prevalences in the different stages of the disease are needed as an epidemiologic basis; yet, they are not awailable. Even for the achual number of infected in developed countries, only vague estimates are available. For seemingly simple indicators such as the survival time of AIDS, another important impact determinant, accurate data are currently lacking. The same is true for the pre-AIDS stages. Economic impact data is also too scarse to describe the situation comprehensively. Studies [109] tend to be in incomplete terms of sectors of care covered, time span included, and disease stages dealt with. Often, studies only refer to hospital costs for full-blown AIDS at one point in time. Also one has very little empirical knowledge about the extent of actual utilization of our health-care systems. For the quantitative study of impacts, we are just beginning to learn how much we do not know, referring to all three epidemics - HIV, AIDS and socio-economic impactconferences clarified essential gaps in methodology.

International and inter-disciplinary work - between disease modellers, epidemiologists and economists are a necessary condition for work on scenario construction. Comparable data collection in epidemiological and impact studies is one of these communication issues. Methodologically, tools for complex reasoning are required to link epidemiology and economics.

In the light of these problems, the prelimininary nature of this attempt to measure the future shott-term impact of ADDS is stressed. Systematization of procedures for data gathering, and development of methods to build scenarios referring to the three epidemics simultaneously, are urgently needed for the development of health policy. 
Chapter 3

\section{A Comparison and Integration of Studies on HIV-related Hospital Resource Utilization and Costs; towards economic scenarios for the Netherlands}

The Dutch version of this chapter was published by MJ Pogtrna, MOW Dijkgrate, ICC Borleffs, DP Reinking, FMLG wan den Boom, JC Jager in Tijdschrift woor Sociale Gezondhetdszorg (1992, 70:189-96); reprinted with permission 


\section{Summary}

The results of three Dutch studies on the economic impact of HIV infections and AIDS for the hospital are compared. All three studies involve a co-operation between a hospital and a research centre. Even after data have been converted to similar dimensions results differ. This can be atributed to several factors, related to for example the operationalization of the term "costs" and characteristics of the patient population. Discussing these factors the possible significance of the results, especially with regard to use in prediction and scenario analysis, is treated. The comparison renders information which can be linked to epidemiological modelling for impact assessment. The studies indicate that in the CDC-IV stage hospital inpatient days per person-year range from 51.1 to 58.4. Hospital costs per person-year of CDC IV are $f 36300$ (SZ/KPMG) and $f 46800$ (AZU/RIVM). Resulis suggest that homosexual men generate higher costs and bed needs per person-year of CDC IV than intravenots drugusers. For building future scenarios the point of departure in 1990 has been established: (1) the need of hospital beds for CDC IV halfway 1990 is $\$ 46$ beds based on data from AZU/RIVM and 150 beds based on SZ/KPMG; (2) hospital costs for CDC IV amount to 37 million (AZU/RIVM) and $f 28$ million (SZ/KPMG); (3) hospital costs for all stages are estimated $f 44$ million based on data of AZU/RIVM. For scenario analyses an integration of methods from the studies discussed in this paper would form the optimal source of information at the monent: longitudinal research into the amount and type of care linked to estimates of the cost prices of the several activities.

\section{List of Abbreviations to Chapter 3}

AZU Academisch Ziekenhuis Utrecht/University Hospital Utrecht

AZUA Academisch Ziekenhuis van de Universiteit van Amsterdam / Teaching Hospital of the University of Amsterdam

KPMG KPMG Klynveld Management Consultants

NIPG Nederlands Instituut voor Praeventieve Gezondheidszorg / Netherlands Institute for Preventive Health Care NIPG-TNO

$S Z$ Slotervaart Ziekenhuis / Slotervaart Hospital

CoTG Central Board for Health-care Tariffs / Centraal Orgaan Tarieven Gezondheidszorg 


\subsection{Introduction}

The Dutch AIDS scenario analysis started in the summer 1990 on the initiative of WHO and STG. The project "Scenario analysis of the socio-cultural and economic consequences of AIDS for the Netherlands" was carried out by the Netherlands Centre for Mental Health (NcGv: Nederlands centrum Geestlijke volksgezondheid) and RIVM. This paper on the impact of the AIDS epidemic on hospital resource utilization is based on the research within the framework of the project into the economic consequences.

At a macro level, the costs of hospital care are yet but a small percentage of the total direct and indirect costs of the HIV and AIDS epidemic $[63,64]$. The importance of insight into the resource utilization and corresponding monetary costs of inpatient care for HIV-infected people is particularly relevant at a meso level and for future years. The more the epidemic spreads, the more important the regional and national planning of hospital resources and the detection of financial bottlenecks will become [146].

To date there have been three Dutch studies investigating the impact of the HIV/AIDS epidemic on thospital resource utilization and corresponding monetary costs. The studies carried out by the Netherlands Institute for Preventive Health Care (NIPG) in collaboration with the Teaching Hospital of the University of Amsterdam (AZUA) $[60,61,147]$, and that carried out by KPMG Klynveld Management Consultants (KPMG) in collaboration with the Slotervaart Hospital (SZ) in Amsterdam [148-150] have been finalized. The study by the University Hospital of Utrecht (AZU) in collaboration with the RIVM in Bilthoven [58,151-153] is a long-running project and is still in progress.

The studies differ in their design and emphasis. Also they are not solely restricted to hospital resource utilization and corresponding costs:

- the AZUA/NIPG-study examines, in addition to hospital costs, those of outpatient care, research, prevention and the indirect costs (absenteeism, years of life lost); the AZU/RIVM-study also focuses on the assessment of the effectiveness of care and trends in resource utilization and costs in time; and the SZ/KPMG-study examines the extra costs of hospital care - defined as the difference between the incurred costs and the budgeted costs of care and treatment - for the purpose of assessing the need for extra financing facilities for AIDS hospitalisations.

The aim of this study is to determine reference values for parameters by comparing and integrating the results of the different studies. These values are needed to make short-term forecasts and scenario analyses of resource utilization (future bed needs) 


\section{Chapter 3}

and total hospital costs. The following sections describe the characteristics of the studies, as well as results considered relevant to scenario analysis. To facilitate comparison of the studies, some of the data are re-calculated in that they can be presented in the same dimensions. The results of the different studies are discussed with regard to aspects of the methodology and design of the individual studies, such as the composition of the study population, the use of cost prices instead of charges, etcetera. It will be made clear that the parameter estimates should be used with care for both current estimations and scenario analyses. The last section gives an overview of the recommendations for the design of future research. This study should provide a step towards the aims of WHO and the EU that internationally comparable methods should be used for the calculation of the economic consequences of the HIV/ALDS epidemic $[66,154]$.

Table 3.1 Registration period, study approach, design, setting and site of three Dutch studies into the impact of $A D D$ s on hospitals

\begin{tabular}{lll}
\hline AZUA/NIPG & AZU/RIVM & SZ/KPMG \\
& & \\
1982-88 & 1987 -present & 1989 \\
Retrospective & Prospective & Prospective \\
Longitudinal & Longitudinal & Cross-sectional \\
University hospital & University hospital & General hospital \\
Amsterdan & Unecht & Amsterdam \\
\hline
\end{tabular}

\subsection{Study Characteristics and Basic Data}

Study characteristics that are relevant to hospital resource utilization and monetary costs are given in Table 3.1. The AZUA/NIPG-study is retrospective, with longitudinal collection of data over the period January 1982 through to spring 1988 (6.5 years). Data were collected in a teaching hospital in Amsterdam. The AZU/RIM-study started in 1987 and is prospective (directed data collection during the period of conducting the study). The study design is longitudinal, and data are collected at the University Hospital Utrecht. The SZ/KPMG-study is prospective with a cross-sectional design and was carried out in a general hospital in Amsterdam. Data were collected in the spring of 1989 (5.5 months).

Table 3.2 provides information about the length of the registration period, the composition of the patient populations according to the classification of HIV infection by the CDC $[16,17]$, the total number of observation-days, and the total costs generated (inpatient and outpatient care and treatment). The definition of the term cost used in the 
different studies will be discussed later.

Table 3.2 Length of registration period (in years), number of patients, number of observation days and rotal hospital costs (in guilders)

$\begin{array}{cccc} & \text { AZUA/NIPG } & \text { AZU/RIVM } & \text { SZ/KPMG } \\ \text { Registration period } & 6.5 & 2 & 0.45 \\ \text { Patients } & & & \\ \text { CDC II } & - & 21(-4)^{*} & 16(-1) \\ \text { CDC III } & 195(-195) & 15(-1) & 1 \\ \text { CDC IV } & 230 & 21 & 63 \\ \text { All stages } & 230 & 52 & 79 \\ \text { Observation days } & & & \\ \text { CDC II } & - & 4753 & 1710 \\ \text { CDC III } & 57340 & 6034 & 7023 \\ \text { CDC IV } & 77240 & 5125 & 8889 \\ \text { All stages } & 134580 & 15912 & \\ & & & 43000 \\ \text { Total costs (D) } & - & 65000 & 800 \\ \text { CDC II } & - & 70000 & 699000 \\ \text { CDC III } & - & 657000 & 743000 \\ \text { CDC IV } & 15640000 & 792000 & \\ \text { All stages } & & \end{array}$

"For this study the table reflects the data for patients with AIDS (CDC IV) and for those in the pre-AIDS stages (CDC II); The numbers in parentheses represent patients diagnosed as CDC IV (or AIDS) during the registration period.

In the AZUA/NIPG-study data refer to 230 patients, all of whom diagnosed as having AIDS according to the surveillance case-definition $[7,8]$. Data on resource utilization and costs generated by 195 patients $(85 \%)$ in the pre-AIDS stage are included in the total. The registration period is 6.5 years, and during this time 134580 observation-days are counted. The number of observation-days of a patient is the time between the first contact with the hospital (for HIV-related purposes) and the moment when the hospital loses contact with the patient, due to change of hospital or death. The total costs calculated during the regisiration period amount to f 15640000 .

Up to the end of 1988 , the patient population of the AzU/RIVM-study consisted of 2I patients with asymptomatic HIV infection (CDC II), 15 patients in CDC stage III, and 21 patients in CDC stage IV. Four of the CDC-II patients and one of the CDC-III patients 


\section{Chapter 3}

developed stage IV symptoms during the study period, covering 1987-1988. So, the total number of patients during the study period is $52^{1}$. During this 2-year period neariy 16 000 observation-days are counted - 4753 for CDC-Il patients, 6034 for CDC-III patients, and 5125 for CDC-IV patients. The total costs are $f 792000$, of which $f 657000$ is for CDC-IV patients, $f 70000$ for CDC-III patients, and $f 65000$ for CDC-II patients.

The \$2/KPMG-study involves 79 patients. At entry, 15 Patients are classified in CDC stage II. 1 patient in CDC stage III, and 63 patients in CDC stage IV. One CDC-II patient developed symptoms consistent with CDC IV. The registration period is 0.45 year (165 days), and the total costs are 7743000 for 8889 observation-days. The distribution of costs over the various CDC stages is $f 43000$ for 1710 observation-days of CDC-II patients, $f 800$ for 156 observation-days of the CDC-III patient, and $f 699000$ for 7023 observation-days of CDC-IV patients.

\subsection{Comparison of Study Results}

Table 3.3 gives an overview of the hospital costs for patients with HIV infection by CDC stage. The average costs are expressed per observation-year and indicate the costs that an average patient would generate in a full year of observation. Expressing costs in terms of observation-years is preferred because the length of the observation-period can be eliminated as an explanation for any differences observed. This choice of representation is consistent with that used internationally [156].

The AZUA/NIPG-study includes only those patients who finally developed AIDS, whereas $60 \%$ of the patients in the AzU/RrvM-study and $20 \%$ of the patients in the SZ/KPMG-study are not classified as CDC IV. It is not possible to calculate costs per CDC stage on the basis of the data in the AZUA/NIPG-study. The costs per observation-year for AIDS patients will be higher than the $f 42500$ mentioned in the AZUA/NIPG-study, given that AIDS patients cost more per observation-year than pre-AIDS patients.

Remarkably, both the AZU/RIVM and the $\$ Z / K P M G$ studies show hospital costs to be lower for CDC-III patients than for asymptomatic CDC-II patients. This might be explained by the costs of the one-off diagnostic examinations to determine the medical history of the patient.

Only the AZUA/NIPG-study provides data about the lifetime costs of AIDS. A group

"At the end of June 1990 there were 126 patients in the study. Data gathered up to June 1990 were presented at the International AIDS Conference in Florence [155]. 
of 127 patients could be formed for whom the entire course of the illness, from first contact with the hospital for symptoms of HIV infection to death, falls within the registration period. The costs are $f 87000$ per patient.

Table 3.3

Hospital costs per person-year in guilders $(0)$

AZUA/NIPG AZU/RIVM SZ/KPMG

$\begin{array}{lcrr}\text { CDC II } & - & 5000 & 9200 \\ \text { CDC III } & - & 4200 & 1900^{\circ} \\ \text { CDC IV } & - & 46800 & 36300 \\ \text { All stages } & 42500 & 18200 & 30500\end{array}$

* Data from one patient only.

Table 3.4 gives an overview of the average resource utilization per observationyear in terms of the number of admissions and the number of inpatient days. The resource-utilization data for HIV-infected patients during the period in which they were classified as CDC IV are given in parentheses. These data can be used to project future bed needs.

Table 3.4 Amount of care for HW-infected persons (CDC-IV patients in particular) in terms of number of admissions per person-year, inpatient doys per persion-year and length of stay (impatient days per admission)

AZUA/NIPG AZU/RIVM SZIKPMG

\begin{tabular}{llll} 
Adrnissions & 1.9 & 0.8 & 2.6 \\
lapatient days & $37.4(58.4)$ & $17.2(51.11)$ & $44.4(52.5)$ \\
Length of stay & 19.4 & $20.7(23.1)$ & 17.4 \\
\hline
\end{tabular}

AIDS.

Analysis of the data for the above-mentioned 127 patients in the AZUA/NIPG-studly show that, during the full course of the illness, HIV-infected patients are admitted more than three times on average, with a totall of 77 inpatient days. The average length of stay is 23.3 days. So, the patients who died were thospitalized longer than the patients who were alive at the end of 1988.

Comparison of the studies, ignoring the CDC classification of the patient population, shows that the average costs per observation-year vary between the studies, from $f 18200$ (AZU/RIVM) to $f 42500$ (AZUA/NIPG). Even when calculated per CDC stage, 


\section{Chapter 3}

still a substantial variation in costs between studies remains.

Although the awerage length of stay shows only a small variation $(17.4$ days to 20.7 days), the average number of admissions per observation-year varies between 0.8 en 2.6, and the average number of inpatient days per observation-year varies between 17.2 days and 44.4 days. "The variation in the number of inpatient days per observation-year of CDC-IV/ADS is much smaller: 51.1 to 58.4.

\subsection{Integration of Study Results.}

There are several factors that can explain the differences between the study resuls. A factor that is typically related to the methodology used is the operationalization of costs and different types of costs. The operationalizations of the costs used in the studies are given in Table 3.5, and discussed below for the costs of care during an inpatient day.

Table 3.5 Operationalization of costs per hospital activity: charges based on national health tariffis, estimated cost prices and prices paid by the hospital to third parties

Actiwity
Artificial ventiation
Blood transfusion
Consultation
Diagnostics
Medication
Inpatient day

AZUA/NIPG

Charges

Charges

Charges

Charges \& prices

Prices

Charges
A2U/RIVM

Charges

Charges

Charges

Charges \& prices

Prices

Cost prices
SZ/KPMG

Cost prices

Cost prices

Cost prices

Cost prices

Prices"

Cost prices

* Retail price plus overhead for the pharmacy.

The AZUA/NIPG-study uses mainly charges from the National Health Tariffs Authority (COTG: Centraal Orgaan Tarieven Gezondheidszorg; all-in charges, so that most common specialist treatments are included), with the exception of diagnostic examinations and drugs prescribed by thind parties but charged to the AZUA. The charge per inpatient day varies between $f 692$ and $f 780$ (average: $f 740$ ), depending on the utilization of intensive care.

The AzU/RIVM-study uses both COTG charges and prices (both cost prices and prices paid by the hospital). The estimated cost price per inpatient day varies between $f 261$ and $f 848$, depending on the daily intensity of care (low, medium, high, intensive care). This cost price includes the necessary care provided by nurses, internists, and their 
assistents. For the period 1/1/87 to $31 / 12 / 88$ the average cost of care per inpatient day was $f 483$.

The sZ/KPMG-study makes as much use as possible of pre-calculated cost prices. The cost price of care during an impatient day is on average $f 289$, depending on the intensity of care (the operationalization of this term is different from that of the AZU/RrVM-study). This cost price included the daily use of medical means, nursing, and appropriate overhead costs.

The use of charges rather than pre-calculated cost prices leads to overestimation of the costs of an inpatient day and to underestimation of the costs of diagnostic examinations and other interventions. In practice, the COTG charges for inpatient care are used to adjust hospital finances once the external budget has been determined. There is no ono-on-one relationship to the real costs of an inpatient day and, as a result, the relative influence of different types of costs on the overall cost of an inpatient day is unclear.

Besides this distinction between charges and (cost) prices, the selection of the types of costs included determine what is understood by "hospital cosits". All of these studies omit certain types of costs. For example, none of the studies explicitly takes the costs of interest and depreciation into consideration. Both the SZ/KPMG and AZU/RIVM studies take most of the material costs into consideration. The sz/KPMG-study explicitly includes personnel overheads and the costs of training. If the AZU/RIvM-study were to take these cosis into account, then the figures given in Tables 3.2 and 3.3 would have to be adjusted upwards. At the moment it is not possible to determine the extent of this adjustment. In the AZUA/NIPG-study, these types of costs, as well as interest and depreciation, are implicitly included in the charge per inpatient day.

The studies also differ with respect to the reference year on which all costs are based. The AZUA/NIPG-study uses 1988 prices, the AZU/RIVM 1987/1988 prices, and the Sz/KPMG-study 1989 prices. However, these price differences will have little impact on the data.

The time and site in which the research is carried out are factors that could also contribute to the differences in the costs and resource-utilization data. The time periods when the studies were carried out are not completely the same. In contrast to the AZU/RIVM and SZ/KPMG studies, the AZUA/NIPG-study includes data from the early phase of the epidemic in The Netherlands. Only the last 1.5 years of the registration period are the same as in the AZU/RIVM-study. The AZU/RIMM and SZ/KPMG studies are more similar with regard to the study period. Thus the study period (especially with regard to changes 


\section{Chapter 3}

in treatment strategies) will hawe had similar effects on the results of the two most recent studites.

The conduction of two of the studies (AZUA/MIPG and SZ/KPMG) took place in Amsterdarn, the third (AZU/RVM) in the Utrecht-region. Because the first cases of HIV and ADS occurred in Amsterdam, Amsterdam functioned as a national AIDS centre, certainly in the beginning of the epidemic. Up to 1987 patients throughout the Netherlands were referred to Amsterdam. Expertise in unpatient and outpatient care probably developed faster in Amsterdam than elsewhere, whith consequences for resource utilization. For example, better developed outpatient services reduces demand for inpatient services, which could have lowered the resource utilization and costs of both Ansterdam studies relative to those of the AZU/RIVM-study.

In addition, time and site refer directly to differences between hospitals in the protocolling of care and treatment. Experience, new insights, and the availability of outpatient services leads to differences in the protocols, which in turn are related to the amount and costs of care. The results of these studies bear a strong relation to the way in which care and treatment were provided by the hospitals involved.

The sz/KPMG-study has explicitly described the protocols for treatment and care to be used in the hospital [150], under the concept of "good practice". However, this "good practice" can deviate from the care and treatment generating the cost and resourceutillzation data reported.

Other influencing factors of importance are the size - which is also partly dependent on the duration of follow-up - and the composition of the patient population. The size of the patient population and the duration of the follow-up period indicate to what extent study results are representative. There was quite a large difference among the three patient populations with respect to size ( 52 to 230 patients) and to the total number of days the patients were monitored (8 889 to 134580 observation-days, Table 3.2). The AZUA/NIPG-study had 4.5 more patients and 9 times the number of observation-days than the AzU/RIVM-study, and 3 times more patients and 15 times more observation-days than the $\$ Z / K P M G-s t u d y$. The sZ/KPMG-study had few observation-days for the pre-CDC-IV stages. Clearly, the results of the AZUA/NIPG-study are most likely to be representative ones.

The composition of the population with regard to the various risk groups can also affect the results. Table 3.6 shows results of the SZ/KPMG-study for homosexual men and intravenous drug users. Per observation-year, intravenous drug users are more expensive and require more impatient days than homosexualbisexual men in the CDC-II stage. This 
relationship is reversed in CDC-IV patients, although it should be borne in mind that eight CDC-IV homosexual men died during the study, and that the relatively high costs of providing care for these patients in the terminal stages are included in the data. In the SZ/KPMG-study, the costs of care per patient are nearly three times higher for the patients. who died than for the patients who stayed alive (ail CDC stages). No intravenous drug users died during the study period. The data shown in Table 3.6 seem to contrast data from the US that intravenous drug users generate higher costs than homosexual men, because the latter have a better developed social support network [157]. In general, at the moment one does not know to what extent the socio-economical background of a risk group influences costs and resource utilization.

Table 3.6 Number of observation days, inparient days and costs (in guilders) per person-year for homosexual men and intravenous (iv) drug users (including homosexual intravenous drug users) per $C D C$ stage

\begin{tabular}{llccc}
\hline CDC-stage & Risk group & Observation days & Inpatient days & Costs $(f)$ \\
II & homosexual men & 689 & 4.2 & 5700 \\
& iv drug users & 468 & 33.5 & 14100 \\
III & homesexual men" & 156 & 0 & 1900 \\
\multirow{2}{*}{ IV } & iv drug users & 0 & - & - \\
& homosexual men & 5992 & 47.9 & 34800 \\
All stages & iv drug users & 633 & 16.1 & 15.300 \\
& homosexual men & 6837 & 42.4 & 31100 \\
& iv drug users & 1101 & 23.5 & 14800 \\
\hline
\end{tabular}

\footnotetext{
"Data from one patient only.
}

Source: SZ/KPMG.

There are relativelly fewer intravenous drug users in the A.ZU/RIVM-study population (accounting for $5.3 \%$ of the total number of observation ways) than in the SZ/KPMG-study (accounting for $12 \%$ of the total number of observation-days). The number of intravenous drug users in the AZUA/NIPG-study population is not known.

The patient populations of the three studies can also be distinguished in terms of the proportion of patients who died. In the AZUA/NIPG-study, $65 \%$ of the patients died during the registration period, as compared to $17 \%$ in the AZU/RrvM-study, and $11 \%$ in the Sz/KPMG-study. Given that the patients who died generated, on average, higher costs than the patients who stayed alive during the study period - because of the high costs of terminal care - it is expected that the per observation-year costs of AIDS in the AZUA/NIPG-study is higher than those of the two other studies. 


\section{Chapter 3}

\subsection{Concluding Remarks}

With regard to the specific field of hospital care, three Dutch studies which pay attention to the amount and costs of care and treatment were analyzed. The studies report different data on resource utilization and costs, which can be explained by various aspects of the methodology and design of the individual studies. These explanations should be borne in mind when determining parameter estimates for impact assessment and scenario analyses.

The three studies each have advantages and disadvantages with regard to application in scenario analysis. The AZUA/NYPG-study has the advantage of a large population (large number of observation-days), but the disadvantages that it might be outdated (protocols and clinical practice have changed) and that it uses all-in charges throughout. The \$Z/KPMG-study has the advantage that cost prices were consistently used to determine costs, but the disadvantage of a relatively short observation-period (few observation-days for pre-CDC-IV stages). The AZU/RrvM-sudy has the advantage of a Jongitudinal design (increasing number of observation $\sim$ days, making it possible to determine trends) but, as yet, only makes partly use of cost prices.

The results of these studies can be used within the framework of the scenario project to determine the number of beds needed and the total costs of hospital treatment and care for HIV-infected people on a national basis, in the present and in the future. By linking estimates of the number of inpatient days per observation year of AIDS and per observation-year estimates of hospital costs to output for 1990 of available epidemiological models $[23,144]$, illustrations of these calculations are gained:

on average, 146 beds were needed for CDC-IV patients on any day in 1990 on the basis of the AZU/RIVM data, and 150 beds on the basis of the SZ/KPMG data, applying a bed occupancy of $75 \%$ [158];

- hospital cosis of CDC-IV patients were $f 37000000$ in 1990 on the basis of the AZU/RIVM data, and $f 28000000$ on the basis of the Sz/KPMG data; and hospital costs of patients in all stages were $f 44100000$ in 1990 on the basis of the AZU/RIVM data [131].

The AZUA/NIPG data do not allow us to differentiate costs per CDC stage, refer to a previous phase of the epidemic and are therefore less suitable for these type of calculations.

The difference between the costs of care for CDC-IV patients in the three studies is noteworthy. Besides the other factors mentioned, the use of cost prices (SZ/K.MMG-study) versus a combination of cost prices and charges (AzU/RIVM) is responsible for this 


\section{Three Dutch Sudies}

difference. From a methodological point of view, estimates based on cost prices are to be preferted (s2/KPMG-study). However, because of the limited number of observation-days for pre-CDC-IV stages in the SZ/KPMG-study, calculations of the costs of all stages were based on the data from the AzU/RIVM-study alone.

The SZ/KPMG and AZU/RIVM-studies gave very similar estimates of the bed needs for CDC-IV patients. Both studies reported a similar number of observation-days for CDC-IV patients, and the definitions of the term inpatient day were unequivocal. Hence. the bed requirements can be determined with some degree of certainty.

For future years much can change in the hospital care and treatment of HIVinfected persons. For this reason it is important to monitor and analyse the costs, and amount and type of treatment and care against a background of certain distinct developments [130]:

the changing composition of the patient population:

increasing use of early intervention;

other developments in medical technology and the associated increasing survival; and

the shift in the relationship between in-patient and out-patient care.

This makes it possible to adjust the parameters used for calculations in future scenarios. "The most recent data avallable from the AZU/RWM-study show drastic reduction in the number of inpatient days per obserwation-year [159], which will have direct consequences for future bed requirements.

Bearing this in mind, an integration of the methodologies used in the above studies would seem to provide an optimal source of data for scenario analyses, namely, longitudinal research into resource utilization combined with cost-price estimates of the various components of care and treatment.

\section{Acknowledgements}

The study presented in this chapter was carried out within the framework of the research projects "Scenario analysis of the socio-cultural and economic consequences of AIDS for The Netherlands" (conducted on the initiative of the STG, as a collaboration between NcGv and RIVM) and "Quantitative estimation of hospital costs and measurement of effectiveness of health care for patients with HIV infections" (AZU/RIVM). The authors are indebted to the scenario committee of the STG project and thank Prof Dr EI Ruitenberg (chairman), Dr R Naaborg, Dr ACP Verster, and HM Weigel, internist for 


\section{Chapter 3}

their involvement in this paper. The authors also thank Drs PM Ansems and Drs AB Hemkes for supplying available and generating additional information from the SZ/KPMGstudy, and Drs CCMC Wiggers for information about the AZUA/NIPG-publications.

The research was funded partly by the Ministry of Welfare, Public Health, and Cultural Affairs and partly through an existing collaboration between the AIDS Centre of Middle Netherlands (ACMN) and the Working group Technology Assessment Utrecht (WTAU). 


\section{Chapter 4}

Economic Impact of the AIDS Epidemic in the European Community; towards multi-national scenarios on hospital care and costs

This chapter was published whith the same ditle by MJ Postma, R Leid, AM Downs, Rovira, K Tolley, M Gyldmark, MC Jager in $A$ DOS $(1993,7.541-53)$, reprinted with permisston 


\section{Summary}

Objective To underpin multi-national public-health HIV/AIDS planning in the European Community (EC) by integrating national studies on HIV/AIDS in scenario analysis. Data \& Methods Three types of data are used: routine surveillance-data, information on disease progression and observational studies on the economic impact. The HIV/AIDS epidemic is simulated using two models (MIDAS and PC-based AIDS Scenarios).

Selected simulations, consistent with surveillance data, are connected to economic impact (hospital bed needs and annual hospital costs for AIDS patients). Parameter values expressing per person-year economic impacts are derived from a structured review of publications on economic aspects of HIV/AIDS.

Results Evaluation of published studies on hospital resource utilization and costs in ECcountries shows that there are significant differences between both countries and studies, even after conversion to simillar measures (for example, using purchasing power parities). These differences are partly due to factors such as the composition of the patient population and differences in methodology. Economic impact is analysed for combinations of three factors: survival time after AIDS diagnosis, hospital inpatient-days needed per person-year and corresponding per person-year hospital costs. All scenarios indicate 1995 hospital bed needs above the 1990 level of 5400 beds. Hospital cost projections for 1995 vary (up to US\$1050 million).

Conclusions (1) For economic impact assessment, there are important data gaps in epidemiological and economic areas, and in the methods for linking these. (2) Standardization of studies on resource utilization and costs of HIV/AIDS is necessary to provide a sound basis for multi-national scenarios. (3) Preliminary multi-national scenarios show that by 1995 hospital bed needs for AIDS might reach $0.45 \%$ of all hospital beds available in the EC, and that hospital cost projections for AIDS in that year will range from $0.15 \%$ to $0.30 \%$ of $\mathrm{EC}$ health-care expenditure.

\section{Sponsorship}

This research resulted from two activities co-ordinated and sponsored by the EC (the Concerted Action on Statistical Analysis and Mathematical Modelling of AIDS and the European Study on Economic Aspects of AIDS and HIV Infection). The STG and WHO also contributed to the international co-operation on AIDS scenarios. 


\subsection{Introduction}

Research to support the fight against AIDS has become inter-disciplinary. Coping with the broad range of socio-economic impacts is considered a significant health-care policy issue, since it has become clear that AIDS is more than a short-term challenge for the basic sciences. The importance of studying socio-economic impacts has recently been emphasized within the EC [1]. This study develops and applies methods to construct scenarios on the economic impact of AIDS, through the integration of mathematical models and three types of information: (1) routine surveillance-data on AIDS incidence;

(2) data on disease progression; and (3) information from observational studies on economic impacts.

Co-ordinated research linking epidemiological models and socio-economic information ( $\mathfrak{i}_{\text {.e. }}$, exploring impact scenarios) results from two EC-activities: the Concerted Action on the Statistical Analysis and Mathematical Modelling of AIDS (Bilthoven workshops 1986 [141,142], 1988, 1989 [108] and 1992) and the Study on Economic Aspects of AIDS and HIV Infection (Munich workshop, 1989 [109]). The needs and constraints of developing an integrative approach have been discussed elsewhere $[152,160]$. Earlier work [144] considered the use of both a statistical and a simulation technique to model the past, present and future impacts of the HIV/AIDS epidemic. Impact assessment was illustrated by extrapolation of potential years of life lost in three countries of the $\mathrm{EC}$.

This study focuses on: (1) a description of the epidemiological data and models to be used; (2) a review of available EC-studies on hospital bed utlization and correponding costs, together with an assessment of the problems involved; (3) preliminary scenario results, with projections of hospital costs and number of hospital beds needed for fullblown AIDS patients in the EC; and (4) an outline of future requirements concerning collection and comparison of impact data with regard to scenario analysis, resulting in guidelines for the standardization of collection.

The approach advocated and applied here contributes to the integration of national studies and will be useful for public-health strategy development at a multi-national level. This study should contribute to the EC objective adopted by all member states to continue the fight against AIDS and, as a possible future objective, contribute to a public-health strategy [1]. 


\subsection{Data and Methods}

\subsubsection{Survelllance and Progressiton-of-disease}

\section{Surveillance data}

The surveillance of AIDS in Europe is co-ordinated by the European Centre for the Epidemiological Monitoring of AIDS, a WHO-EC Collaborating Centre established for this purpose in 1984. Working in close collaboration with nationall institutions, standardized data are collected from all countries of the European region of WHO. All 12 EC-countries were reporting by December 1985 . Halfway-1991 a total of 50673 AIDS cases had been reported in the EC (Belgium: $1.8 \%$; Denmark: $1.6 \%$; France: $30.7 \%$; Germany: $13.0 \%$; Greece: $1.0 \%$; Ireland: $0.4 \%$; Italy: $19.3 \%$; Luxemburg: $0.1 \%$; Netherlands: $3.4 \%$; Portugal: $1.3 \%$; Spain: $18.0 \%$; UK: $9.4 \%$ ) [161].

The data reported to the Centre relate to AIDS cases fulfilling the original or revised surveillance case-definitions of the $\mathrm{CDC}[7,8]$. The 1987 revision was adopted for European surveillance purposes on January 1st 1988. Aggregate data are presented in regular Quarterly Reports and may also be consulted electronically through EURAIDS (an on-line service). The public version of the European Non-Aggregate AIDS Data Set contains individual data on more than $95 \%$ of the reported cases. This study uses reported AIDS incidence up to June 30st 1991. Uncidence is adjusted for estimated reporting delays [143] but not for under-reporting. The size of under-reporting is highly uncertain and national estimates vary between $0 \%$ and $20 \%$ [162].

\section{Data on disease progression}

Data on disease progression - the incubation period from infection (or seroconversion) to AIDS and the length of survival after AIDS diagnosis - are required to model the epidemic.

Recent evidence on the progression to AIDS in infected homosexual men indicates a median incubation period of 10-11 years and progression of approximately $25 \%$ after 7 years [163-165]. Similar findings have been reported for other risk groups [166-174]. However, there appear to be significant variations in disease progression according to age and treatment regimen. The older the individual at infection, the shorter the incubation period may be $[170-173,175-177]$. Changing treatment patterns, such as the use of AZT/zidovudine before AIDS development (for example, by those with CD4-cell counts below $200^{*}\left(0^{6} / 1\right)$, appear to be related to an increase in the incubation period $[171,178,179]$. 
Survival rates following the diagnosis of AIDS have been shown to depend on disease manifestation at diagnosis, age and year of diagnosis. In particular, several studies have shown significant improvements in survival among cases diagnosed in 1987 compared with those diagnosed earlier, presumably largely as a result of therapeutic intervention. Some of these studies also showed (less marked) increases since 1987. Overall median survival times among adults (including all disease manifestations and all ages) are estimated to have increased from approximately 12 months for patients diagnosed before 1987 to $18-20$ months for diagnoses in 1987. [14,165,180-183]

The analysis presented below uses data on disease progression from the San Francisco City Clinic Cohort of homosexual men [165]. The observed cumulative progression rates after infection in this cohort were 51 and $54 \%$ after 10 and 11 years, respectively. Because no empirical data are available beyond 11 years, the following progression rates have been assumed: 57,63 and $69 \%$ after 12,14 and 16 years, respectively. Age and treatment effects are not taken into account in the present analysis. For survival time, exponential distributions are postulated. The mean survival of patients diagnosed after 1986 is assumed to be 2 years (the corresponding median being just below 18-20 months), whereas AIDS patients diagnosed earlier are assumed to have a mean survival of 1 year. However, since the observed lengthening of survival time might continue, also calculations have been included based on an increased survival time (with a mean of 3 years) for AIDS cases diagnosed in or after 1992.

\subsubsection{Epidemiological Models}

\section{Statistical model for reporting delay adjustment}

Several statistical estimation procedures have been developed to cope with the problem of delays in reporting AIDS cases. Here, the method by Heisterkamp et al is used [75, 143]. Estimates of the parameters representing reporting delay are based on the AIDS surveillance data reported in successive 6-month periods and ordered according to the half-year of diagnosis. It is assumed that diagnoses arise from a Poisson process, all distributions being independent. Parameter estimation is based on maximum likelihood with goodness - of -fit measured by the deviance [184]. A software package (MIDAS) is available [185]. Because reporting patterns can change over time [186], estimates are based on more recent reports only; reports from June 1989 onwards are used. Because reporting delays show considerable between-country variation, country-specific data are adjusted before pooling to obtain adjusted AIDS incidence at the EC-level. AIDS inciden- 


\section{Chapter 4}

ce, adjusted for reporting delays, serves as input for the population-dynamic model.

\section{Population-dynamic model}

The population-dynamic model describes the spread of HIV and AIDS in a two-group population. It links a model of the spread of HIV infection with disease progression. The cumulative incidence of HIV infection in each group is assumed to follow a logistic curve. The underlying model structure and its equations have been explained in detail elsewhere $[91$ 187]. The two groups are: (1) those with high-risk behaviour (HR; including homosexual men, intravenous drug users and heterosexuals); and (2) those with low-risk behaviour (LR; including heteroxuals, but also, for example, homosexual men with low-risk behaviour). The model is available as a software package (PC-based AIDS Scenarios).

Both groups can include individuals who are relatively less susceptible to HIV infection. A considerable proportion of the low-risk group will be such individuals. The high-rik group will include individuals whose number of partners and lack of preventive measures (high-risk activities) are offset by their specific partner networks, resulting in relatively low risk of infection. Thus, there is a maximum level for the cumulative proportion infected (saturation level) in both groups. The number of individuals who are not susceptible is the total population size minus the appropriate proportions of both risk groups (controlled for the saturation levels in the groups). A renewal rate, potentially an important parameter [188], is incorporated only for the high-risk group (details are described elsewhere [187]). Assuming a non-zero renewal rate implies the replacement of the logistic curve by a different function.

The two-group model is a first step towards modelling sub-epidemics defined by risk-related behaviour, rather than by membership of a "risk group" (a risk group may include individuals who face different levels of risk). This represents a novel approach compared with multi-group models that define risk by membership of established risk groups. An obvious advantage of the approach is that the level of risk of the resulting groups is more homogeneous. Risk depends on transmission probability, number of partners and preventive measures taken. Since it is not possible to establish the size of each group empirically, plausible combinations are obtained as a result of the search process described below. Thus the approach does not necessitate deriving the relevant information (group sizes, risk behaviour) for each of the risk groups in each EC-country. Reliable instruments and data are limited in the EC - for example, with respect to estimations of this information for the Netherlands problems to validate these estimates 
occur [88].

Values for the following nine parameters have to be specified for each simulation: size of the high-risk group (sHR); saturation level in HR; renewal rate into HR (rHR); size of low-risk group (sLR); saturation level in LR; cumulative number of high-risk individuals initially infected by 1980 ( $\mathrm{HRI}$ ); cumulative number of low-risk individuals initially infected by 1980 (LRi); initial growth rate of the HIV epidemic in HR (HRw); and initial growth rate of the HIV epidemic in LR (LRw). The high-and low-risk groups together define the total population (340 million in the EC). Thus, within the model structure, only one of the two risk group sizes can be varied independently. For the specification of the number of susceptibles, sHR and its saturation level directly depend on each other. Thus there are seven independent variables.

All simulations begin in 1980. A multi-stage, systematic (but subjectively guided) heuristic approach is used to search for parameter values. In contrast to optimizing algorithms, it does not render a "best" solution, but provides severall well-fitting, possible courses for the epidemic, corresponding to specific combinations of the parameter values. In the first stage, the parameter space, defined by extreme figures for all parameters that are to be varied, is systematically investigated to identify areas of possible relevance (with a good fit). Goodness-of-fit is assessed by the sum of absolute residuais expressed as a percentage of cumulative AIDS incidence. The step size by which the parameter space is uraversed depends on the goodness-of-fit: it is reduced in areas where the fit seems good.

The saturation llevels do not vary in this application. The saturation level in the high-risk group, which in the fitting process is directly linked to the size of the high-risk: group. was assumed to be $90 \%$; that of the low-risk group, which does not restrict the growth rate of HIV infection within our time-frame, was assumed to be $20 \%$. Extreme figures and step sizes were thus specified for six parameters, resulting in millions of simulations.

In the second stage, possible courses for the epidemic are selected on the basis of goodness-of fit. They are required to exhibit a sum of absolute residuals below $4 \%$ of cumulative AIDS incidence up to January Ist 1991. Within this set, simulations are compared on the basis of redundancy and heterogeneity, perhaps resulting in a description: of only a few structurally different types that can "explain." the AIDS epidemic. They correspond to alternative hypotheses concerning the past course of the HIV epidemic, and so determine a set of alternative future courses of the epidemic within the model framework, resulting in alternative impact scenarios. 


\section{Chopter 4}

\subsubsection{Concepts for Linkage with selected economic impact studies}

\section{Linkage with economic impact indicators}

In assevesing the economic impact of $A{ }^{2}$ DS, case-related and general programme costs must be distinguished. Case-related costs refer fo resource utilization attributed directly to the patient at a particular stage of HIV infection (for example, hospital, nursing home, district mursing care, physician consultation, family help). General programme costs refer to the provision of general services, such as publichealth education, research, $\mathrm{HIV}$ testing and service use by the "worried-well".

Case-rellated costs of per person-year estimates of resource utilization and corresponding monetary amounts can be linked to the output of epidemiologic models in terms of (period-) prevalences (number of person-years during the year) [5!, 144, 156]. Projected prevalence at the end of each year is used to derive the annual number of person-years. The accuracy of this approximation depends on the difference between the number of months lived by those who died in a given year and the number of months lived in that year by cases newly diagnosed with AIDS during that year. These could differ as a result of either increasing or decreasing incidence. (The former would result in an over-and the latter in an underestimate of the number of person-years, all other things remaining equal.) Technically, based on last year's prevalence, the highly aggregate and discrete model excludes cases who died during the year and attributes all other cases to the new AIDS prevalence. The prevalence-based approach used to project annual estimates of resource needs and costs combines (ranges for) parameter values expressing the economic impact with the projected prevalences into scenarios on economic impact (see $[101,102]$ for an application to various health-care sectors in the Netherlands).

This paper focuses on hospital resource utilization for full-blown AIDS, since this constitutes the main part of the direct costs of the epidemic in Europe [189]. To determine capacity needs, prevalence-based projections of hospital inpatient days are expressed as the daily mean number of beds needed during the respective year. This approvich uses a modification of the formula defining the occupancy rate of hospital beds [144]. Further illustrations of the method are shown using projected annual hospital costs.

\section{Study setection}

The per person-year parameter values expressing the hospital inpatient days needed and hospital costs are determined by a structured methodologic review of publications on economic impact. Several reviews summarizung and comparing the results of studies on 
the resource utilization and costs of HIV/AIDS have been published [39,93, 153]. Because of steadily changing treatment techmologies for HIV/AIDS, it is important that cost estimates are continually updated; the update provided here is restricted to hospital resource utilization and costs in the EC-countries. Further criteria for the inclusion of studies are: (1) a clear explanation of the methodology used, allowing identification of cost components, method of data collection, and of cost estimation procedure; (2) per person-year averages given or derivable directly from the data provided; and (3) inpatient days utilization and/or costs attributable to the different stages of HIV infection $[7,8,16,17]$.

\subsection{Results}

\subsubsection{Existing Evidence on hospitall resource utilization and costs}

Application of the criteria for the selection of economic impact studies identified nine suitable studies in seven EC-countries (Table 4.1) $[56,59,61,153,190$-1944].

The estimates in Table 4.1 are shown as costs per person-year in 1990 US dollars. Costs from the study-year's price level were converted to 1990 prices using national health-care-specific price indices. Purchasing power parities (PPP) for gross national product were used to adjust for differences in the relative unit costs of health-care services across countries $[195,196]$. Although these two techniques account for timerelated changes in prices between studies and differences in purchasing power between countries, they do not standardize changing treatment technologies over time. This could be integrated by co-ordinated multi-centre international studies, or partial sensitivity analyses; however, neither option is pursued here.

As shown in Table 4.1, all but one [61] of the studies are small (they were based on study populations of 7.0-15.6 person-years). Only one study is relatively recent $[194]$; the others cover various periods between 1982 and 1988 . Their size and date indicate that the basis for economic impact projections is limited - projections can only be preliminary. Furthermore, Table 4.1 shows that per person-year hospital costs for AIDS (one study gives CDC stage IV figures) vary widely. Interestingly, the studies in EC-countries with relatively low per capita gross domestic product (GDP) reported higher costs per personyear (Greece, Spain). This is in contrast to investigations based on cross-sectional data in several countries showing health-care expenditure increasing proportionally more than per 


\section{Chapter 4}

Capita GDP; wealthier countries tend to spend considerably more on health care [197].

Table 4.1 Rewiew of studies an ADDS-related hospital costs in EC-countries: country. reference, study-period, stucty-size, average per person-year (ppy) inpatient days and costs

\begin{tabular}{llcccc}
\hline Couniry & Ref & Period & size & Ppy days & Ppy costs \\
& & & & & \\
Belgium & {$[190]^{2}$} & $1987-88$ & 15.6 & 106 & 21900 \\
Gernnany & {$[191]$} & $1985-86$ & 10.0 & 66 & 13000 \\
& {$[59]$} & $1985-87$ & $13.0^{3}$ & 130 & 26400 \\
France & {$[56]$} & 1986 & 4 & 5 & $22.300^{\circ}$ \\
Greece & {$[192]$} & 1988 & $<7.0$ & 110 & 70400 \\
Netherlands & {$[153]^{7}$} & $1987-88$ & 14.0 & 51 & 19000 \\
& {$[161]$} & 1982.88 & 211.6 & 58 & 27800 \\
Spain & {$[193]$} & $1987^{\circ}$ & 6.3 & 130 & 25400 \\
& {$[193]$} & $1987^{\circ}$ & 8.5 & 105 & 28200 \\
\hline
\end{tabular}

${ }^{1}$ Costs were converted into 1990 US dollars using purchasing power parities and appropriate inflation rates (see text): ${ }^{2}$ Including approximately one person-year ADS-related complex and corresponding costs; ${ }^{3}$ Hospital inpatient and outpatient costs are based on different patient populations; "Cannot be deriwed, because a sarnple of 100 hospitalizations was examined; 3 Inpatient days are not reported; ${ }^{\circ}$ Based on an assumed survival of 1.5 years after AIDS diagnosis; "Results are for CDC stage IV; " Reported figures do not allow separation of costs in AIDS and pre-AIDS stages; "Basurto region; 10 Aranzazu region.

With the exception of two outliers (US\$13 000 and 70400 ), the costs are between US\$19000 and 29000 . Estimates of the underlying utilization of inpatient days are lowest in the two Dutch studies and one of the German studies. All other studies reported over 100 days of hospital care per person-year. Several factors account for variation in amount of health-care utilization (and thus corresponding costs) between sites and countries. These include availability of services, organisation of local and national healthand social-care systems, and type and structure of treatment and care provided. The latter refers to the changing patterns of care and treatment with time: a shift from intensive care to AIDS wards, and from hospital to ambulatory care, and the changing pattern of AZT use. Follow-up of the study by Borleffs et al. [153] demonstrates a significantly decreasing trend in inpatient days per person-year $[155,159]$.

Service utilization is also influenced by the patient population. The utilization rates of specific patient groups (grouped according to risk group, deceased versus alive, manifestation of AlDS) are significantly above average. The Dutch study by Borleffs et 
al. [153] found that the costs of CDC-IV patients in the 3 months before death might be as high as US $\$ 44500$ per person-year, because of a higher level of inpatient stays. Another Dutch study found that intravenous drug users used only 9 hospital inpatient days per person-year CDC IV, compared with 48 days by homosexual men $[62,148]$. Rees [194] found marginally lower costs for haemophiliac AIDS patients, and Lambert\&Carrin [190] found patients with Kaposi's sarcoma to be twice as costly as Pnewimocystis carinit pneumonia patients. However, not all sudies allow an identification of the distribution of costs across these important patient classifications.

Differences in methodology of monetary cost measurement have also influenced the results in Table 4.1. To allow comparisons, the results should be presented so that the costs of care in a given country can be identified as either a higher utilization of real resources or a higher unit cost of the resources. For cost estimation and cost comparison, accurate information is required on the number of inpatient days, input in hours of medical, nursing and ancillary personnel, numbers and type of diagnostic tests, amounts of medication and unit casts of such items. The availability of such information varies for the studies included in Table 4.1.

Lambert\&Carrin [190] used hospital bills, including those for outpatient hospital services, to estimate costs. Their study included personal expenditures and the costs borne by the Belgian Health Insurance Scheme; the former appeared to be up to $13 \%$ of patient's income. However, their presentation does not include a breakdown of the resource utilization, or unit costs.

Hanpft et al. [191] derived cost prices for physician consultations, hotel function (for example, food, linen, cleaning) and nursing from the hospital cost-accounting centre. Nursing time per AIDS patient was assumed to be 1.6 times the hospital average. Other medical services were valued by means of charges. Costs of drugs were based on purchase prices. Only resulting total costs per inpatient day were reported (US\$197 for AIDS patients). Koock-Walewski [59] used total mean costs per impatient day of US\$173 and considered outpatient hospital costs (15\% of total costs).

Hatzakis and Trichopoulos [192] used medical charges in a small retrospective scudy of seven patients. The costs per person-year were US\$16900 for AZT/zidovudine and US\$53 500 for inpatient treatment and care. The Greek and Spanish studies included only AZT-treatment and inpatient costs.

Borleffs et al. [153] used estimated average cost-prices for an inpatient day of US\$249. This was assumed to include the salaries of an AIDS internist and a consultant nurse. Diagnostic tests, consultations (except by AIDS internists), blood-transfusions and 


\section{Chapter 4}

artificial ventilation were monetarily valued using charges, as provided by health insurance funds. Market prices were used for the costs of medication and drugs. The study included outpatient hospital costs and psychiatric hospital care.

Ginestal Comez 11931 used approximate average expenditure per bed (US\$182 in Basurto and US\$2 12 in Aranzazu). Estimated costs of AZT-utilization were approximately US\$3000-4000 per person-year. The studies from the UK [194] and France [56] did not consider any kind of breakdown of the costs.

Treatment patterns have been (and are) changing: the period of treatment has become significantly longer, and new (more costly) medication has been introduced (such as aerosolized pentamidine). In view of this, and the observed interstudy differences, hospital impact scenarios should be constructed for several values of the relevant economic impact parameters. Therefore, ranges have been developed for hospital costs per person-year as well as for impatient days per person-year.

Ranges for economic parameters to investigate the impact on hospitals (bed needs, annual costs) were created by weighting the averages shown in Table 4.1. The weights used were the study size in person-years and the cumulative number of AIDS cases up to June 30st 1991 in the respective country (see Table 4.1 ). The first takes into account that a result based on a large study is more valuable (more representative of the country concerned) than a result from a small study (the sizes of the sudies from Greece and the UK are asstimed to be 3.5 and 6 person-years, respectively). The second accounts for the relative importance of the AIDS epidemic in a country, compared with the $\mathrm{EC}$ as a whole. This relative importance is assumed to be constant (future changes in the distribution of AIDS cases between EC-countries are not considered). The upper and lower bounds of the range are defined by expanding the symmetric interval around the weighted average to the point where all reported study results, except some extreme values (130 inpatient days; costs of US\$13 000 and US\$70 400), are included.

Projections of hospital bed needs are based on the weighted average of 80 inpatient days per person-year, with lower and upper range values of 50 and 110 days, respectively. The weigluted average of US\$23 300 per personyear is used for projections of annual hospital costs. The range around the average is US\$18 $400-28200$. 


\subsubsection{EC-scenarios}

The methods described, together with the available information on hospital costs for fullblown AIDS patients, were used to design scenarios for the EC. The paranteters of the simulation model were tuned to the anmual AlDS-incidence between 1981 and 1990 as reported by June 30st 1991 [198] and adjusted for reporting delays (Fig 4.1).

Fing 4.1

Aros incidence in the European Communiry by 6-month period (1. Jamuary-June; H: July-December), as reported up to June 30 st 1991 and as expected after adjusment for reporting delays (white: reported; black: expected)

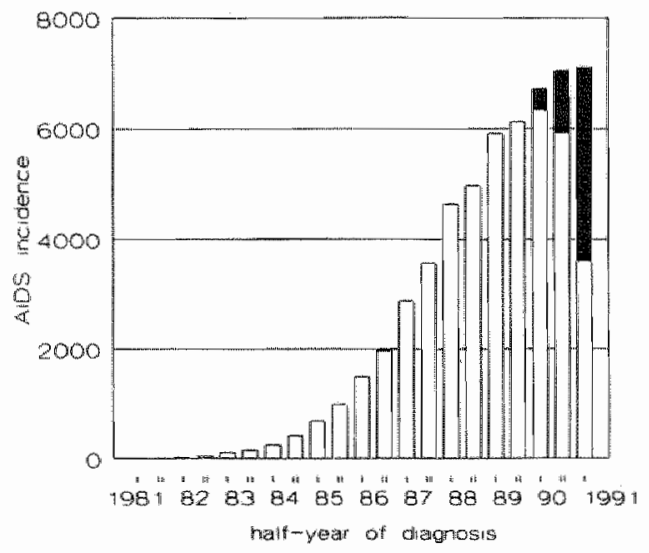

Several hundreds simulations showed a goodness-of-fit below $4 \%$. All involved a similar basic type of subepidemic: an extremely fast infection in a small high-risk group, in which the major proportion of susceptibles had been infected for at least 2 years. They appeared to fall into four groups, differing in two important and sensitive coefficients: (1) the initial growth rate of the HIV epidemic in the low-risk population (LRw); and (2) the renewal rate of the high-risk group (rHR). Four typical and well-fitting simulations (one from each group) were selected for further analysis (Table 4.2). To optimally reflect the effects of the essential differences, the parameters HRi, HRw and LRi were set to the same values in each of the four simulations, although small changes would (slightly) improve the goodness-of-fit. Typically, a non-zero rHR has to be accompanied by a slightly smaller sHR to attain the desired level of goodness-of-fit. 


\begin{tabular}{lllllllll} 
& SHR & HRi & MRW & rHR & SLR & LRi & LRw & Goodness of fit \\
A & 230 & 4.1 & 240 & 0 & 340 & 100 & 10 & 2.5 \\
B & 215 & 4.1 & 240 & 5 & 340 & 100 & 10 & 3.5 \\
C & 230 & 4.1 & 240 & 0 & 340 & 100 & 60 & 2.6 \\
D & 215 & 4.1 & 240 & 5 & 340 & 100 & 60 & 3.7 \\
\hline
\end{tabular}

sHR: size of high-risk group in thousands (saturation lewel: $90 \%$ ); HRi: number (thousands) with high-risk behawiour infected by 1980; HRw: initial growth rate of the HIV epidemic in HR in per annum; rHR: maximum animal renewal rate in HR in of per annum; sLR: size of low-risk group in millions (saturation level: 20\%); LRi: number with low-risk belhaviour infected by 1980; LRw: initial growth rate of the HIV epidemic in LR in $\%$ per annum; Goodness-of-fit: sum of absolute residuals expressed as pencentage of cumulative AIDS incidence (up to January Ist 1991).

The types of epidemic described all feature a very high initial annual growth rate in the cumulative number of HIV infections, which later declines rapidly to a minimum (scenarios $\mathrm{A}$ and $\mathrm{C}$ ) or to a long-term steady-state growth (for models with renewal of the high-risk group - scenarios B and D). (Fig 4.2)

Given the development of AIDS incidence in the EC, and the two-group approach, it wass not possible to identify any narrow ranges for the initial growth rate of HIV infections in the low-risk population. Accordingly, two alternatives are presented: an "optimistic" simulation with a relatively low growth rate (which could be even smaller), and a "pessimistic" simulation with a relatively high growth rate (which could be even higher). Thus the type of epidemic hypothesized is that of a "flash" of infection in a small group of individuals with high-risk behaviour, together with a quite different (and so far unknown) secondary epidemic in the low-risk group.

The best-fitting models had no renewal rate for the high-risk group, and so support the "flash" hypothes is, although the assumption of stability of membership of the highw risk group for over 10 years appears somewhat implausible. Hence, two less well-fitting simulations with small renewall rates have also been included. 
Fig 4.2 Growth rate of cumulative incidence of HIV infections (Rogarithuntic scale) in four scenarios - scemario A (triangles top-up): Low rate of infection in low-risk group $(L R]$, no renewal in high-risk group (HR); scenario $B$ (circles). Low rate of infection in $L R$, with renewal in $H R$; scenario $C$ (boxes): high rate of infection in $L R$, no renewal in $H R$; scenario $D$ (triangles top-down): high rate of infection in $L R$, with renewal in HR (see Table 4.2 for specification of scenarios)

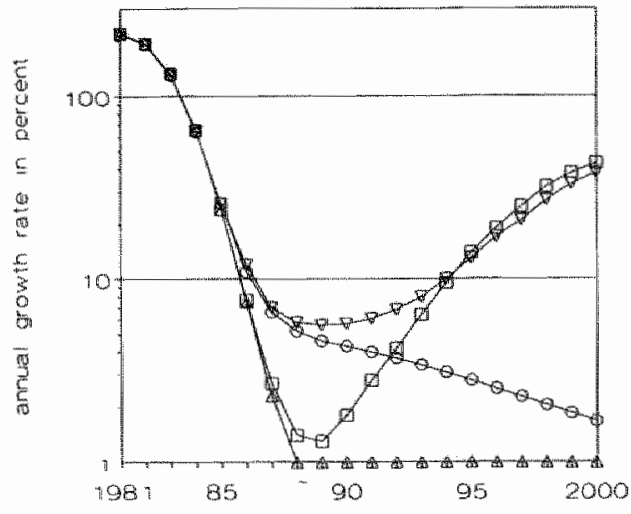

Fig 4.3 Estimated annual incidence of HIV infections: reconstruction (1980-1990) and projection (1991-2000) according to four scenarios - scenario A (triangles top-up): low rate of infection in low-risk group (LR), no renewal in high-risk group (KR); scenario $B$ (circles): Low rate of infection in $L R$, with renewal in $H R$; scenario $C$ (boxes): high rate of infection in $L R_{\text {, }}$ no renemial in $H R_{;}$scenario $D$ (triangles topdown): high rate of infection in $L R$, with renewal in $H R$ (see Table 4.2 for specification of scenarios)

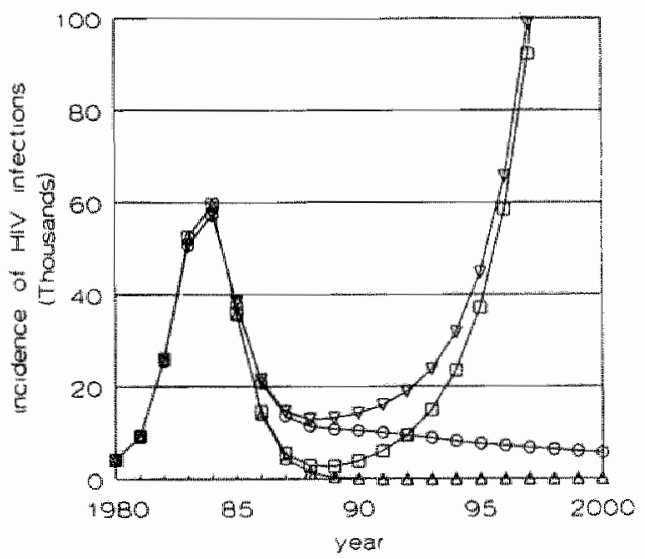




\section{Chapter 4}

Two types of future spread can be clearly differentiated by the rate of infections in the low-risk group, rather than by the renewal rate in the high-risk group (Fig 4.3). All four scenarios show a peak in HIV incidence around 1984 (range for annual number of cases: 57 300-59 600). The modelled cumulative HIV incidence on December 31st 1988 was 207 000-234 000, which is rather low compared with a recent report of approximately 400000 (using backcalculation) [199】. However, the latter estimates were for AIDS incidences that had been inflated for undler-reporting (10\%) and adapted for revisions in the AIDS case-definition. An important implication of the "flash" hypothesis developed within the present model is that the main groups currently at risk, and thus the potential targets of preventive action, may not be well identified, while the "old" and recognized dangers could now have a relatively less important role. Compared with HIV infection, the corresponding ADS incidence curves display a smaller but still significant variance between the hypotheses (Fig 4.4). A peak in AIDS incidence following that in HIV incidence is projected around 1992 (range for anmual number of cases:

$15500-17300)$.

Fig 4.4 Annual ADS incidence: fitted values (1980-1990) and projecrions (1991-2000) according to four scenarios - scenario A (rriangles top-up): Low rate of infection in low-risk group (LR), no renewal in high-risk group (HR); scenario B (circles). Low rate of infection in $L R$, with renewal in $H R$; scenario $C$ (boxes): high rate of infection in $L R$, no renewal in HR; scenario $D$ (triangles top-down): high rate of infection in $L R$, with renewal in HR (see Table 4.2 for specification of scenarios)

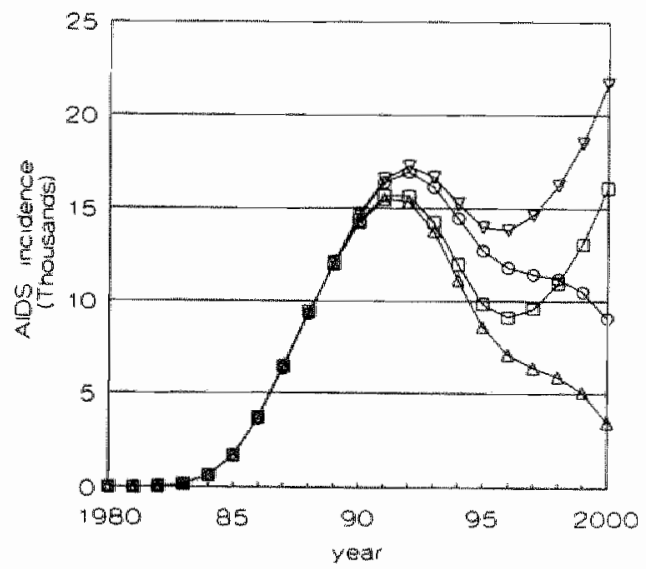


Impact assessment is based on prevalence figures. Simulations with the lowest and the highest future AIDS prevalence (scenarios A and D) hawe been used for the presentation of the future impact of full-blown AIDS. Because of the high uncertainty about future AIDS incidence and prevalence (future modelling of which may have to account for significant effects of changes in medical technology and inclusion of new population groups), impact scenarios are restricted to the medium term only (1995).

For comparative purposes, the impact assessment also includes the year 1990 as baseline (scenarios A through D have approximatelly the same prevalence at the end of 1990 of 20800 AIDS cases). Survival times of persons with full-blown AIDS will also affect the future need for hospital care and corresponding costs. A current mean of 2 years is assumed and unchanged in scenarios $A$ and $D$; however, given current and future improvements in AIDS treatment, an increase to 3 years for AIDS cases diagnosed from 1992 onwards is also considered ( $A^{*}$ and $D^{*}$ ). Resource utilization (and costs, see below) per person-year are assumed to be the same for both survival distributions. Therefore, a lengthening of survival is accompanied by a proportional increase in resource utilization and costs during the whole AIDS stage. 1995 AIDS prevalence figures in A, A*, D and $D^{*}$ are $21800,28200,29300$ and 37300 cases, respectively.

An $85 \%$ occupancy rate has been assumed for hospital beds (see [200] for a similar analysis for Germany). Assuming 80 hospital inpatient days per person-year, scemario D* indicates a need for 9600 hospital beds in 1995 (Fig 4.5). All scenarios are above the 1990 level of 5400 beds. The use of the broad range of inpatient days per person-year accounts for most of the variation in the 1995 projections. Lengthening survival increases bed needs by approximately $28 \%$ (in both scenarios A and D), whereas differences in the epidemiological course of HIV infection produce a variation of approximately $33 \%$ (both between $A$ and $D$ and between $A^{*}$ and $D^{*}$ ).

Analogous hospital cost projections for care and treatment of full-blown AIDS patients are shown (Fig 4.6). Projected costs are based on constant (1990) prices and constant PPP. Assuming an average cost of US\$23 330 per person-year the high annual cost projection of scenario $D^{*}$ is US $\$ 870$ million in 1995 (compared with the 1990 baseline estimate of US\$ 485 million), whereas the lowest projection for 1.995 in scenario $A$ is US $\$ 510$ million. The use of the range around the average for the hospital costs per person-year (US\$ $18400-28200$ ) extends the range for annual hospital costs in the EC to US\$ 400-1050 million. 


\section{Chapter 4}

Prig 4.5 Prevalence-based estimates of hospital bed meeds in 1995 in two wariants of scentrios $A$ and $D(A, D$. mean survival of 2 years; $A * D *$ mean survival of 3 years) for a range of inpatient days per person-year ALDS, compared to 1990 as baseline - scenarios $A$. $A$ : Low rate of infection in lowrisk group (LR), no renewal in high-risk group (HR); scenarion $D, D^{*}$ : high rate of infection in LR.

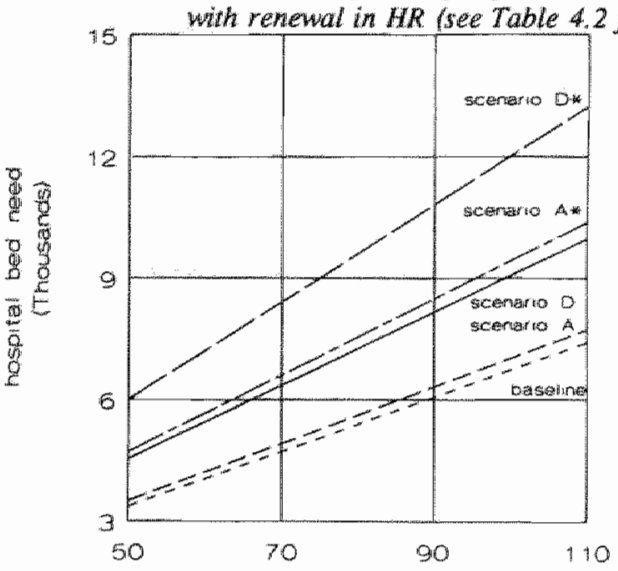

mpatert days per person-year

Fing 4.6 Prevalence-based estimates of annual hospital costs in 1995 in two variants of scenarios $A$ and $D\left(A, D\right.$ : mean survival of 2 years;" $A^{*}, D^{*}$ : mean survival of 3 years) for a range of hospital costs per person-year AIDS, compared to 1990 as baseline - scenarios $A$. A* low rate of infection in low-risk group (LR), no renewal in high-risk group (HR); scenarios $D$, $D *$ : high rate of infection in $L R$, with renewal in HR (see Table 4.2 for specification of scenarios)

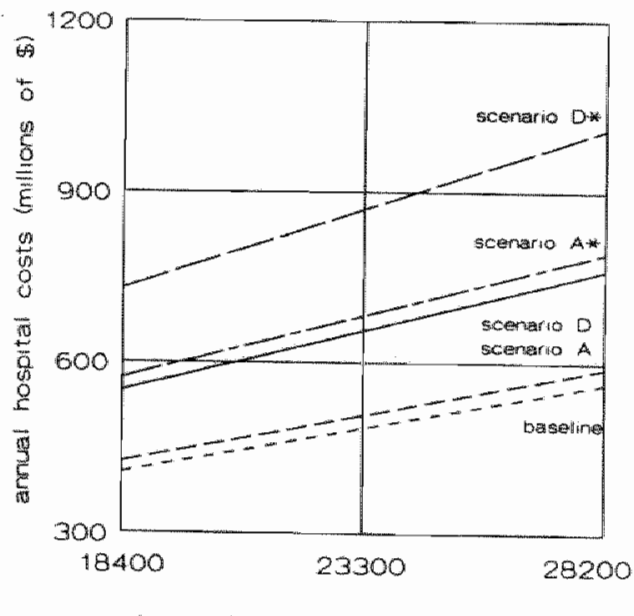

hospital costs per person-year (s) 


\subsection{Discussion}

\subsubsection{Scenario Results}

In this paper methods have been developed to assess the economic impact of HIV infection and its related diseases. A population-dynamic simulation model of the epidemic has been used to obtain projections for two important impact indicators - hospital bed needs and costs - for the EC-countries. Because information on the rate of infection, disease development and needs and costs of care and treatment remains incomplete, the resulting projections are preliminary. However, this is inherent to addressing the impact of a rapidly evolving health problem, in contrast to many economic impact studies in the health-care field directed at more-or-less steady-state situations.

The application of a statistical procedure has allowed to make appropriate corrections to reported AIDS incidence to account for delays in reporting AIDS cases. A population-dynamic simulation model has been used to attribute the resulting (adjusted) AIDS incidence to alternative types of underlying HIV epidemic. One such epidemic in the high-risk group appears to be consistent with the data: an extremely rapid infection of a small high-risk group, with the majority of susceptible individuals having been infected for more than two years (the "flash" of infection hypothesis). Two extremes of the possible types of spread, consistent with the data, are presented for the low-risk population. One is based on an "optimistic" simulation of the epidemic with a relatively low infection rate; the other on a "pessimistic" simulation with a relatively high infection rate. An important implication of the "flash" hypothesis is that the main groups currently at risk, and thus the potential targets of preventive action, are not well identified, while the known dangers may now be playing a relatively less important role (although probably continuing to exist). For both types " one simulation with and one without renewal in the high-risk group were selected for impact assessment. Compared to another recent estimate of 400000 [199], the four resulting scenarios indicate a rather low cumulative HIV incidence in EC-countries (of $207000-234000$ as of December 31st 1988) and all project. a peak in AIDS incidence around 1992 of $15500-17300$ cases per year. Of course, these ranges depend strongly on the assumption of the "flash" of infection and on uncertainty about the follow-up epidemic.

It has been shown that, without a change in the needs of inpatient days per personyear, even in the most optimistic epidemiological simulation, hospital bed needs for fullblown AIDS in the EC in 1995 will be above the estimated level for 1990 . If 80 inpatient 


\section{Chapter 4}

days per person-year are assumed for 1995, the most pessimistic epidemiological simulation projects a maximum of 9600 beds needed for that year, which on the basis of current esimates could represent $0.45 \%$ of the total number of hospital beds available in the $\mathrm{EC}[196]$.

The hospital cost projections for full-blown AIDS in 1995 range from US $\$ 400$ million to 1050 million. Cost of hospital treatment and care for AIDS patients by 1995 may at best be similar to that today (approximately $0.15 \%$ of health-care expenditure of all EC-countries). This percentage could be as high as $0.30 \%$ if the upper bound of the range applies. It should be noted that the awailability of health-care-specific PPP expressed in ECUs would improve this type of EC-directed studies [196,201,202].

Hospital costs for HIV/AIDS constitute an estimated $86 \%$ of the direct patientrelated costs in the Netherlands [101]. Furthermore, the estimates of hospital resource utilization and corresponding costs presented here are all minimum estimates, in that hospital bed needs and costs of patients in pre-AlDS stages are not included. Leidl et al. [144] discuss the impact of their inclusion.

It is important to note that the assumptions of a constant incubation period distribution and a constant or even increasing survival time could be inaccurate. Although early treatment with $A Z T / z i d o v u d i n e$ will lengthen progression to AIDS, it may shorten survival time after developing AIDS [203]. The use of antiretroviral drugs in combination with prophylaxis (for example, for Pneumocystis carinii pneumonia) appears to be an important intervention in the AIDS-free stage, also prolonging the incubation period. This may increase costs in the AIDS-free period, and perhaps decrease the per person-year parameter values for inpatient days and costs in the AIDS stage. It is not yet possible to predict the effect of these influences on impact scenarios. Investigations of these developments have either indicated cost savings [126,204], or changing patterns of spread of HIV, possibly increasing the AIDS-related death rate $[92,205]$.

HIV/AIDS-modelling is still developing. Future work might include mathematical modelling using differential equations and/or an extension of the two-group structure to more than two groups. Possible links between the groups should also be studied [88]. Several model types, requiring different types of information, have been developed for HIV/AIDS [141, 142,206]. These data needs, which have been specified by modellers and are well-known in the literature, include estimates of infectiousness and transmission probabilities, incubation time distribution, trends in HIV incidence/prevalence (within risk groups and regions), occurrence of risk behaviour (sexual, drug use) and effectiveness of prevention and treatment [207]. 


\subsubsection{Data Requirements for Scenario Analysis}

Cost data from existing studies can be used to produce preliminary and illustrative projections of AIDS impact on hospitals. However, standardization of these estimates must be improved if they are to be more valuable for the specification of impact parameters in scenario analysis. The main objective of standardization is to separate the influence of methodological factors (for example, concepts and procedures) causing variations in cost estimates, and to devise a protocol to standardize methodology " such that actual variation in resource utilization and costs can be more clearly identified. Retrospective adjustment of results is likely to be difficult and time-consuming, and may allow only small improvements in comparability.

The methodological aspects of standardization of cost studies discussed here are restricted to patient-related costs of HIV/AIDS. Prevention (for example, screening of blood donations), AIDS education and information and research are excluded; as are indirect costs (such as loss of productive capacity) associated with life-years lost and absence from work; and reduction in quality-of-life. Preliminary work on a standardized cost framework has involved the identification of sets of guidelines in several areas for which standards can most profitably be applied [66]:

(1) a standardized approach to health-care utilization data collection;

(2) standard principles for estimating the unit costs of service use; and

(3) use of a standard format for the presentation of results.

For (1), the basic methodological requirement is that information on service use must be recorded or available on an individual (patient) basis. Prospective data collection is generally preferred to retrospective collection, mainly because the latter soon tends to produce inaccurate reflection of the present resource utilization an costs (due to rapidly altering treatment patterns). Prospective data collection also allows inclusion of all relevant parameters, giving rise to fewer data interpretation difficulties and errors. However, it is relatively time-consuming and expensive.

For (2), cost estimates involve multiplying the physical quantities of resources used to provide HIV/AIDS-related treatment and care (for example, staff hours, inpatient days, medication) by a price for each unit of resource input. Prices should reflect the true opportunity cost (the value of the best alternative use of the resources, assessment of which will depend on local circumstances) as closely as possible. If possible " current market prices of different resource inputs should be used (for example, hospital-staff time spent on treatment and care should be valued using hourly payment rates, and dailly 


\section{Chapter 4}

medication administered should be valued at the current commercial prices). Hospital charges are likely to be highly unrepresentative of opportunity costs and should not generally be used. The method used for apportioning overhead, administration, training and hotel costs should be made explicit. If costs are not based on direct accounting, a precise description of the ad hoc procedure of estimation should be provided. Information availability and accounting procedures are likely to be heterogeneous among countries and even among institutions in a country. Priciples in this area should therefore represent generic recommendations rather than strict operational procedures or criteria for computing costs.

Several dimensions should be considered for (3). Per person-year estimates should be available for annual budget planning, and lifetime cost estimates are required for mapping trends in average costs over the course of HIV infection and AIDS. It is important that definitions and classifications of disease stages, risk groups and other variables relevant for categorizing individuals are agreed upon. Presentation should explicitly include the period of data collection, the number of person-years of observation and the number of individuals surveyed.

One concludes that uncertainty about available evidence on resource utilization and costs in Europe (due to differences in data collection and cost-estimation methods) is an important source of variation when deriwing parameters of economic impact functions. Although a considerable number of cost studies have been conducted, they have produced few data of use in developing impact functions over time. More (prospective) longitudinal empirical work is required. Furthermore, these studies did not use a standard approach, hindering their comparison and integration. This problem has also been recognised in economic investigations of treatment and care for other diseases [208]. It is therefore proposed that guidelines be provided for estimation of HIV/AIDS-related personal healthcare costs, allowing valid comparisons between studies performed at different times and settings and by different researchers.

Thic torsussion in this paper represents a starting point for systematic inter and intranational estimation and comparison of HIV/AIDS resource utilization and costs. The principles of cosit standardization should be developed and extended. On a practical level, difficulties in data collection and limited research resources mean that, for studies to be comparable, the initial application of a standardized cost framework is likely to be restricted to hospital treatment and care for people with symptoms of HIV infection. The further away one moves from strict hospital costs, the more uncertain and unreliable data become $[134,209]$. Inclusion of data on resource utilization and costs in pre-AIDS stages 
allows analyses on the impacts of treatment interventions on a large scale, particularly in the early stages of the disease. A longer-term objective would be to extend the standardized framework to measurement of resource utilization and costs outside the hospital (i.e., community and social care) and to other major diseases. The combination of estimates produced within a standardized cost framework and epidemiological data would produce higher quality scenarios on current and future aggregate resource utilization and costs in the health-and/or social-care sectors of individual European countries or regions such as the EC. This would allow more valid multi-national comparisons of the total cost of AIDS in a country (in absolute terms) and as a proportion of health-care budgets.

\section{Acknowledgements}

The authors wish to thank the following organizations for supplying data: Conseil Supérieur de pour la Co-ordination de la Lutte Contre le SIDA, Institut d'Hygiène et d'Epidémiologie, Brussels, Belgium; Statens Serum Institute, Copenhagen, Denmark; Direction Générale de la Santé, Paris, France; AIDS Zentrum im Bundesgesundheitsamt, Berlin, Germany; Ministry of Health, Athens, Greece; Department of Health, Dublim, Ireland; Ministry of Health, Rome, Italy; Ministère de la Santế, Luxemburg; Staatstoezicht op de Volksgezondheid, Rijswijk. The Netherlands; Instituto Nacional de Saude, Lisbon, Portugal; Instituto de Salud "Carlos III", Madrid, Spain; Communicable Disease Surveillance Centre, London, United Kingdom. Furthermore, SH Heisterkamp and MJJC Poos are thanked for their contribution to estimating the reporting delays and to $\mathrm{MC}$ Delmas and $H$ Houweling for their advice on epidemiological aspects. Finally, two anonymous referees are thanked. Their comments and proposals have undoubtedly improved the quality of this study. 


\section{Chapter 5}

\section{AIDS Scenarios for the Netherlands; the economic impact on hospitals}

This chapter was published writh the same title by MJ Postona, JC Jager, MGW Dijkgrat, JCC Borleffi, , K Tolley, RM Ledd in Fealth Polticy $(1995,31: 127,50)$; reprinted with permission 


\section{Chapter 5}

\section{Abstract}

Objective To assess the financial-economic impact of HIW/AIDS on the health-care system in the Netherlands.

Data \& Methods Two types of data are used: (1) routine surveillance-data on AIDS incidence; and (2) information on inpatient and outpatient hospital resource utilization and corresponding monetary costs. Progression-of-disease is modelled using a multi-stage model, with stages corresponding to clinical classifications and different phases of healthcare need. Economic impact is analyzed for all stages in three scenarios: a reference and two allernative scenarios.

Results By the end of the century hospital annual bed needs would reach 220 beds if yearly new HW infections in the 1990 s remain at the level estimated for the end of the 1980s, and if the intensity of hospital care remains constant. Minimum needs of 125 is projected if no new HIV infections occur in the 1990 s. Hospital costs in 1993 are estimated to amount 33.8 million ECUs. Scenarios indicate a range of 26.7-50.7 million ECUs for annual hospital costs by the end of the century (price level: 1993). The proportion of the costs for hospital inpatient care and cure in total hospital costs increases.

Conclusions Projected hospital bed needs of 125-220 for HIV/AIDS by the end of the century is limited compared to the projections for coronary heart disease and stroke, but approaches that for lungcancer, pneumonia and diabetes. Hospital costs are estimated to have been $85 \%$ of total health-care costs for HIV/AIDS in 1993. In 1993, the estimated proportions in hospital costs are $41 \%$ for inpatient care, $20 \%$ for inpatient cure and $39 \%$ for outpatient facilities. Scenarios indicate a decreasing share of outpatient costs - possubly down to $30 \%$ of total hospital costs for HIV/AIDS by the end of the century - illustrating the growing relative importance of the inpatient-care-intensive full-blown AIDS stage for the hospital costs. Annual hospital costs for HIV/AIDS by the end of the century are projected to reach up to $0.53 \%$ of extrapolated hospital costs for all diseases. A present walue of 38 million ECUs $(23 \%)$ of hospital costs projected in the reference scenario might be avoidable, during the period 1994-2000. However, with unchanged treatment patterns a present value of 127 million ECUs for hospital costs during the same period is projected to represent unavoidable costs (discount rate: $5 \%$ ). In the Netherlands, data needs in the field of economic impact assessment of HIV/AIDS especially refer to registrations of non-hospitral outpatient resource utilization and costs. 


\subsection{Intraduction}

In 1992 the Duich AIDS Scenario Study, conducted within the framework of a WHOinitiative, was concluded $[100,101]$. The study describes the epidemiological, socio-cultural and economic impact of AIDS in the Netherlands during the first decade of the epidemic (1980-1990). Scenario analysis is used to project the impact of AIDS up to the year 2000. This paper presents an update of this analysis focusing on financial-economic aspects. Projections by means of similar methods have been published in the literature for the US [48,52,210], the UK [211], Catalonia [212], Spain [213], Portugal [214] and Germany [200].

The importance of studying the economic impact of disease has been emphasized by the EC [1]. In the case of AIDS the importance is strengthend since the epidemic is ongoing and effective control measures have been [215] and are still scarse. Results on impact assessment are valuable for planning disease-specific services and allocating resources over health-care sectors and diseases. One way of analyzing economic impact is by scenario analysis linking patient-based information on resource utilization and monetary costs with epidemiological modelling. These aspects have been discussed previously [216]. Other work has examined the needs and limitations of scenario analysis for linking a range of impact indicators with epidemiological modelling [160]. This research builds on results from two activities of the $\mathbb{E C}$ : the Concerted Action on Statistical Analysis and Mathematical Modeling of AIDS $[108,141,217]$ and the Study on Economic Aspects of AIDS and HIV Infection [109]. Also some WHO activities have addressed the same problems $[39,154]$. In the Biomedical and Health Research Programme (1990 1994; BIOMED D) of the EC the field of research will be developed further in the Concerted Action on Multi-national AIDS Scenario Analysis [107]. Recently, preliminary scenarios on hospital bed needs and costs for EC-countries thave been published $[144,218]$.

This paper focuses on: (1) an updated application of epidemiological modelling using recent surveillance data; (2) an extension of the epidemiologic model to better distinguish disease stages according to different health-care needs; (3) the linking of epidemiological developments with recent data on hospital inpatient-days utilization and corresponding costs; and (4) scenario results on hospital resource utilization and monetary costs up to the year 2000 . 


\section{Chapter 5}

\subsection{Data}

\subsubsection{Epidemiologic Data}

\section{Surveillance}

The surveillance of ADS in The Netherlands is undertaken by the GHI in Rijswijk. The surveillance case definition of 1987 is applied [7,8]. Reporting of AIDS diagnoses is on a voluntary basis, and usually takes place within several months post-diagnosis, but in exceptional cases can be over two years. The annual number of diagnoses are adjusted for this reporting delay [143], using the GHII report as of June 30st 1993 [219]. This analysis is done separately for the main patient groups of homosexual men, intravenous drug users, heterosexuals and others. The former three groups make up $95 \%$ of the cumulative reported diagnoses. The majority of the rest of reporked diagnoses are recipients of blood and blood products.

\section{Progression-of-disease}

Data on disease progression - the incubation period and survival after AllDS diagnosis are required to model the epidemic. Based on an analysis from the European Centre for the Epiderniological Monitoring of AIDS (Paris), an overview of both aspects has recently been presented [218]. The analysis presented below uses an incubation period closely resembling that observed in the San Francisco City Clinic Cohort of homosexual men [12]. Variability in incubation period due to age and patient group are not taken into accoumt in the present analysis. For AIDS-stage survival Dutch data are used: median survival was found to have risen from 12 months for patients diagnosed before 1987 to 20 months for patients diagnosed in 1987 [14]. Since it is unknown whether survival will remain constant or keeps increasing both possiblities are incorporated into the scenarios.

\subsubsection{Economic Data}

Information on hospital resource utilization and corresponding monetary costs is derived from a database at the University Hospital Utrecht (Academisch Ziekenhuis Utrecht; $\mathrm{AZU}$ ). This registration system has been developed by AZU in co-operation with RIVM. The design of this system has been described previously [151] and analyses of the data for the period January 1987-June 1990 have been published [220].

Resource utilization is influenced by patient-population characteristics such as 


\section{Dutch AIDS Scenarios}

disease stage and patient group [62]. Table 5.1 shows, for different disease stages and pathent groups, the number of hospital impatient-days per observation-year (poy) during January 1988-December 1991*. Patient data for 1987 are not considered, since they are assumed not to reflect the current inpatient-day utilization. In the early period of HIV/AIDS treatment, poy hospital inpatient days were significantly higher than later in later years $[220]$. It is likely that specialists experience of treating the first wave of HW/AIDS patients led to an improved management of care for later patients [221].

Table 5.1 Inparient days per observation-year and number of abserwation-years: (between parentheses) by CDC stage and patient group

Homosexual men Drug users Heterosexuals Total

\begin{tabular}{llccc} 
CDC IIIII & $1.7(136.3)$ & $0.2(17.4)$ & $1.1(26.5)$ & $1.5(180.2)$ \\
CDC IV & $28.7(108.2)$ & $29.3(3.2)$ & $31.3(5.0)$ & $28.9(116.4)$ \\
Early-CDC-IV & $24.7(48.5)$ & $-* *$ & $-*$ & $24.8(50.6)$ \\
Late-CDC-IV & $101.2(14.3)$ & $-*$ & $-*$ & $93.8(17.1)$ \\
\hline
\end{tabular}

CDC stages II and III are combined (CDC M/III). For CDC IV separate figures for the final half year before death (late-CDC-IV) and the remaining part of the stage (carly-CDC-IV) are presented (see text)

"Including homosexual intravenous drug users; Number of observation-years insufficient for reliable estimation.

Source: AZU/RIVM-registration system.

In Table 5.1 disease stages are classified according to the $\mathrm{CDC}$ definition $[16,17]$, with CDC stages II and III combined (CDC II/III). In the CDC-IV stage, higher poy utilization rates are reported for patients who have died compared to those alive, due to a higher inpatient-stay frequency [153]. Therefore, CDC-IV stage is divided into two phases:

1 the final half year in CDC IV preceding death ${ }^{3}$ (late-CDC-IV); and

2 the whole CDC-IV stage excluding that final half year for deceased patients and excluding the second half year of 1991 for patients alive by the end of 1991

${ }^{2}$ The observation-year concept is used to take into account that some patients enter the registration system during a year, whereas others leave during a year. One observation-year corresponds to one patient being in contact with the hospital for a whole year, or with two patients both in contact with the hospital for a half year, etcetera. Dividing the total number of registered inpatient days by the number of observation-years results in poy inpatient days.

${ }^{3}$ In case the period between CDC-IV diagnosis and death lasted less than a half year the whole CDC-IV stage is used. 


\section{Chapter 5}

(early-CDC-IV).

Finally, inpatient-day utilization differences according to the three main patient groups are examined in the Table.

As yet, insufficient observation-years are available to be able to identify statistically significant differences between patient groups in early-CDC-IV and late-CDCIV. One striking finding is the low impatient-day utillization of intravenous drug users in the CDC-II/III stage. This finding contrasts with results assessed in an Amsterdam hospital, where intravenous drug users were found to have a higher inpatient-day utilization than homosexual men in the CDC-ll stage [62]. For the scenarios patientgroup-specific figures are not yet used, untill more reliable data are available.

Monetary cost estimates used in the scenarios are direct medical costs. The cost per inpatient day for the period January 1988-December 1991 is estimated at 310 ECUs for CDC-IV-stage patients and 210 ECUs for CDC-11/111-stage patients. The higher costs for the former reflect the greater intensity of care they receive. Based on estimated cost prices and pharmacist prices [58], these hospital inpatient-care costs include "hote] costs" " costs of nursing, use of disposibles and general drugs. However, they exclude treatment (for example, artificial ventilation, blood transfusion), consultations (for example, internist, AIDS nurse), diagnostic procedures (for example, blood-cell counts) and AIDSspecific drugs (for example, AZT/zidovudine, acyclovir and ddi). These costs are defined as the costs of hospital inpatient cure. A third set of costs are those of hospital outpatient facillities.

Since no recent figures for the costs of inpatient cure and outpatient facilities are yet available the ratio of poy estimates for inpatient-cure costs, outpatient costs and inpatient-care costs as reported earlier for 1987-1988 is applied [153] $]^{5}$. For the whole CDC-IV stage, poy inpatient-care costs, inpatient cure costs and outpatient costs constitute, respectively 53,26 and $21 \%$ of total hospital costs. For the CDC-II/III stage the respective percentages are 9,7 and $84 \%$. As poy hospital inpatient-care costs for CDC-IV have decreased by almost $25 \%$, a similar decrease is assumed for both inpatientcure and outpatient hospital costs. Further, for the costs of cure in both the early-CDC-IV and the late $-\mathrm{CDC}$-IV phases a proportional relationship with respect to inpatient days is

Amounts are expressed in 1993 prices. To transform the original cost figures - expressed in 1988 Dutch guilders $(f)$ - the nominal growth (factor: 1.21) of Dutch bealth care costs during 1988-1993 is used [222]. For the exchange of $f$ into ECUs the exchange rate of September 7 th 1993 is used (1 ECU equals 2.12 ).

s In the discussion section sensitivity analysis is performed with respect to this assumption. 


\section{Durch AJDS Scenarios}

assumed. For outpatient costs an inversely proportional reiationstip in these two phases is assumed, demonstrating that outpatient costs will be relatively low during periods with high inpatient-dlay utilization. Both assumptions are in line with previous findings ${ }^{6}$. Inpatient-cure and outpatient costs are based on tariffs and pharmacist prices. The poy cost estimates are presented in Table 5.2. Assumptions on hospital costs (in 1993 ECUs) per observarion-year by CDC-siage

$\begin{array}{lll}\text { Hospital inpatient care } & \text { CDC-IV } & 8940(7734,29079) \\ & \text { CDC-IUIII } & 312 \\ \text { Hospital impatient cure } & \text { CDC-IV } & 4381(3776,14199) \\ & \text { CDC-IIIII } & 214 \\ \text { Hospital outpatient } & \text { CDC-IV } & 3487(4045,1076) \\ & \text { CDC-IIIII } & 2778\end{array}$

CDC stages II and III are combined (CDC II/III). The figures for CDC IV corresponding to earlyCDC-IV and late-CDC-IV, respectively (see text) are presented in parentheses. Source: AZU/RIVM-registration system.

\subsection{Methods}

\subsubsection{Introduction}

The AIDS-impact model links an epidemiological progression-of-disease submodel with a submodel for hospital inpatient-day needs and costs. The model has been used in the Durch AIDS Scenario Study conducted by RIVM and the Netherlands Institute for Mental Health, commissioned by the STG. The present model represents an extension of this work enabling us to take the effects of early treatment into account. In recent years treatment with antiretroviral drugs (AZT/zidovudine) in combination with prophylaxes (for example, for Pneumocystis carinii pneumonia) has become widely used in the asymptomatic pre-AIDS stage, affecting the epidemiology of AIDS as well as health-care resource utilization. Adherence to early treatment is assumed to cause an extension of the

- Borleffs et al. [153] assessed that for patients in the last three months of CDC-IV betore death poy hospital inpatient-care costs , hospital inpatient-cure costs and hospital outpatient costs were, respectively US\$23 800, US\$10 500 and US\$1800. Excluding these final three months of deceased patients the amounts were, respectively US\$8800, US\$4400 and US\$4400. The more than halving of inpatient-care and inpatient-cure costs is accompanied by more than a doubling of outpatient costs. 


\section{Chapler 5}

incubation period of, on average, one year" .

\section{Fig 5.1}

Diagram reflecting the model for progression of disease:

five stages facute infection, unknown asymptomatic infection, known asymptomatic infection. symptomatic pre AIDS disease and AIDS),

the froction of HV-infected persons adhering to early treatment 0 and mean durations of stay (within the boxes)

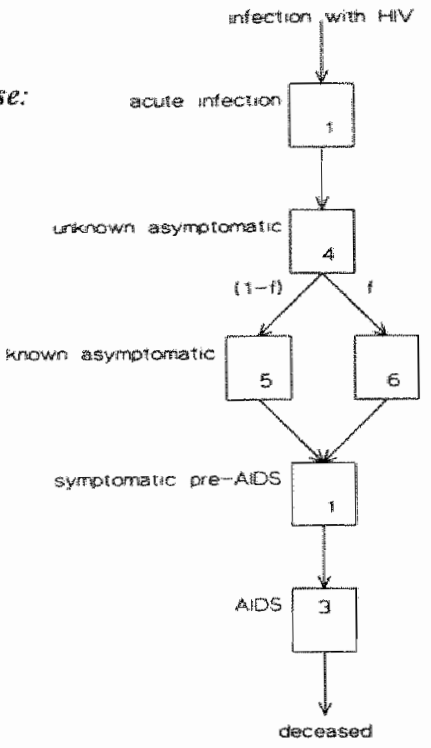

\subsubsection{Epidemiologic Modelling}

\section{Progression - of-disease submodel}

The progression-of-disease submodel has two characteristics:.. a compartmental structure with the duration-of-stay in each compartment exponentially distributed (Fig 5.1). The compartmental structure differentiates between the five relevant stages for health-care need, also corresponding to clinical classifications. The first stage represents acute infection. The asymptomatic phase of HIV infection is represented by two stages (unknown and known asymptomatic). The former comprises persons unaware that they are seropositive. Known asymptomatic is the stage when the infected persons have learned about their serostatus. In this stage a person becomes eligible for early treatment and is assumed to be under observation in a hospital. Adherence to early treatment prolongs the duration of stay in this stage by one year on average. Therefore the stage of known asymptomatic is illustrated by two equivalent boxes (fraction $f$ adheres to early treatment,

"This assumption could be challenged, though. Some recent studies indicate that the effect of AZT/zidovudine is rather limited or even absent at all $[223,224]$. 


\section{Dutch AIDS Scenarios}

fraction $(1-f)$ does not) $)^{8}$. Finally, the symptomatic pre-AIDS stage, and the final stage of AIDS are included. Persons in these two stages are assumed to be aware of their seropositiveness. The combined stages of known asymptomatic and symptomatic preAIDS are referred to as the phase of known seropositive.

Reasonable values for the mean durations of stay in the five stages are, respectively $1,4,5$ (6 in case of early treatment), 1 and 3 years (also reflected in Fig 5.1). The resulting incubation period excluding early treatment (see Fig $5.1 ; f=0$ ) has a median of 9.6 years and mean of 11 years. This median survival time in the AIDS stage is slightly above results for 1987 of the Dutch AIDS survival study, mentioned above. Also, the lengths of the acute infection, asymptomatic and symptomatic pre-AIDS stages are conform to the notions that one has about them. Pragmatically "it is assumed that on average an HIV-infected person becomes aware of seropositivity, halfway through the asymptomatic pre-AlDS stage (including acute infection and excluding early treatment).

\section{Backcalculating and projecting incidence and prevalence}

The progression-of-disease submodel comes into the modeling process twice: it is central in the backcalculation procedure for estimating past HIV incidence and is necessary to make projections (1993-2000) of the future epidemic (and connected hospital inpatient-day needls and costs). The estimated past HIV incidence (infection curve) is assessed backcalculating on the basis of the AIDS incidence $[20,80,83,225]$. Since the attack rate of AIDS is low in the first years after infection the AIDS incidence provides little reliable information to estimate HIV incidence in the most recent years. Therefore estimates of the infection curve are confined to the period up to 1990 only. In addition, a more stable infection curve is achieved by aggregating the attack rates in the first three and a half

In this paper for simplicity assume $f=1$ is assumed, from 1990 onwards, and $f=0$ in previous years. This corresponds to a full coverage of the infected population since 1990 (which certainly in an overestimate).

The backcalculation procedure is as follows:

$A(t)=\sum_{s=0}^{i} P(s) * l(t-s)$

where $A(v)$ is the AIDS incidence in year $t ; P(s)$ equals the probability of developing AIDS in the sth year after the year in which infection took place; $I(l)$ equals the HIV incidence in year $t$. For A(b) the ADS incidence 1982-1992 as registered by June 30st 1993 and adjusted for reporting delays is used, $I(t)$ is established by iterative calculus. In our model $A(t)$ occurs over the duration of the year, whereas $I(t)$ is assumed occuring at the mid-point of the year. These assumptions enable to accurately calculate the relevant quantiles of the incubation period distribution. 


\section{Chapter 5}

years and relating this total to the period between two and a half years and three and a half years. Thus, implicitly the start of the epidemic of HIV infections is assumed three years before the start of the AIDS epidemic (1979 and 1982, respectively). Further, it is assumed that $90 \%$ of the HIV-infected persons will have developed AIDS after 20 years; in the long run, theoretically, this even approaches $100 \%$. Possible mortality in pre-AIDS stages and persons who will never develop AIDS (possibly due to immunological or virological reasons) are not included. Apart from a British study which suggests a possible relevant effect there is no empirical evidence to assess the extent of pre-AIDS mortality [226]. Even if it occured, evidence of HIV-infected persons not going to develop AIDS would not be available until the late 1990s at the earliest.

In the next step the progression-of-disease submodel is used together with the infection-curve for projecting the HIV/AIDS epidemic for 1993-2000 within three variants. In the first wo variants - R(eference) and T(herapy) - the infection curve for 1990-2000 is projected to equal the average level of the estimated three most recent HIV incidences (1987-1989) 10 . Variant $R$ serves as the point of reference, assuming a constant distribution of survival in the AIDS stage. In variant $T$, new AIDS therapy causes a lengthening of survival in the AIDS stage from 3 years on average to 4 years (starting in 1992). The third variant $S$ assumes no new infections in 1990-2000. This variant basically constitutes a subvariant of the other two representing the "unavoidable part of the epidemic". In variant $S$ no lengthening of survival is assumed. In-migration of estimated and assumed HIV incidence, progression-of-disease and out-migration due to AlDS deaths determine the prevalences in each stage.

\subsubsection{AlOS-impact Model}

The final component of the AIDS-impact model links the output of the epidemiological submodel with a framework defining hospital inpatient-day needs and costs per personyear (ppy), for each disease stage ${ }^{1 !}$.

Observed hospital inpatient-day utilization per observation-year (poy) and estimated poy monetary costs of inpatient care, inpatient cure and outpatient facilities are

10 An anallogous assumption is used by Brookmeyer and Liao [210] to assess future health care costs due to HIV/AIDS in the US.

"One person-year in a particular disease stage cortesponds to one person being in the stage for a whole year, or to two persons both in the stage during a half year, etcetera. 
used as proxies for ppy hospital inpatient-day needs and ppy monetary costs of hospital inpatient-care, inpatient-cure and outpatient resource needs (Tables 5.1 and 5.2). Utilization figures of CDC-IV and CDC-II/III disease stages are assumed for needs of AIDS and known seropositive patients, respectively ${ }^{12.13}$. Ppy needs and costs are assumed constant during the seropositive stages, whilst separate estimates for poy earlyCDC-IV and poy late-CDC-IV utilization and corresponding costs are used to reflect ppy resource needs and costs in the AIDS stage ${ }^{14}$.

Scenarios of hospital resource needs and corresponding costs are produced by multiplying the annual numbers of person-years of known seropositive and AIDS patients by ppy inpatient-day needs and cost estimates ${ }^{15}$. The assumption is made that stagespecific ppy needs and costs are stable over time, ensuring that any differences between 1993 and 2000 are due to changes in epidemiology.

Using the AIDS-impact model three scenarios are derived. The three epidemiological variants $R, T$ and $S$ result in, respectively, the reference scenario $R$, the therapy scenario $T$ and subscenario $S$. As mentioned above, scenario $S$ - the one referring to the smallest epidemic - describes the part of scenarios $\mathrm{R}$ and $\mathrm{T}$ estimating the potential impact on the hospitals based on only the HIV epidemic estimated for 1980-1990, also assuming no lengthening of AIDS survival.

Hospital inpatient-day needs are transformed into hospital bed needs using an occupancy rate of $90 \%$ [222]. Whenever appropriate, a discount rate of $5 \%$ for future monetary costs is used; this discount rate has been recommended for public sector

1.2 The definitions classifying patients as CDC IV or AIDS are not completely identical. In presence of laboratory evidence of HIV infection, CDC IV encloses all types of AIDS (AIDS dementia, HIV wasting syndrome, specitic cancers, and secondary infectious diseases of the AIDS surveillance definition) in CDC IVa, IVb, IVc-1 and IVd. Further the CDC-IV definition inclucles some secondary infectious diseases not resulting in the AIDS diagnosis (CDC IVC-2) and a restgroup (CDC IVe).

13 For one person it is assumed that person-years and observation-years coincide in the submodel stages of AIDS and known seropositive (known asymptomatic and symptomatic preAIDS).

sh The model assumes that every patient is at least a half year in the CDC-IV stage.

15 Following the literature on epidemiological modelling one may say that noeds and costs in the last half year of the ADS stage are modelled incidence-based; the incidence of death results in accouming costs to the preceding half year. Whereas, other costs are modelled prevalence-bised; the presence of a patient at a particular point in time results in accounting costs. For prevalencebased modelling calculated prevalence halfway each year is used to give annual numbers of person-years for each particular stage. 


\section{Chapuer 5}

analyses in the Dutch context [34,227].

Application of the AIDS-impact model is limited to the three main patient groups of homosexual men, intrawenous drug users and heterosexuals. HIV infections due to mother-child transmission are excluded since both the incubation period and healthwcare resource witization differ substantially for babys $[228,229]$. Up to June 30 st 1993,13 AlDS cases due to mother-child infections have been reported. Recipients of blood and blood products are excluded since their contribution to the future epidemic will be negligible due to the safeguarding of blood supplies. Finally 43 AIDS cases of unknown group adherence are not considered.

\subsection{Resullts}

\subsubsection{Epidemiologic Results}

Backealculation of the infection curve shows a peak in the incidence of HIV infections in 1984 and 85 (Fig 5.2, presenting the infection curve as a three-yearly moving average). The epidemic among homosexual men dictates the overall pattern. The steep decrease since the mideighties is in line with the decline in incidence in an Amsterdam cohort of homosexual men 22301. However, recent studies by the Municipal Medical and Health Department of Amsterdam report possible resurgence in the infection curve for this group $[231,232]$. Since 1984 the estimated infection curves for intravenous drug users and heterosexuals both fluctuate around a level of 100 infections per year. The levels of HIV incidence in the period $1990-2000$, as indicated by the assumption for $\mathrm{R}$ and $\mathrm{T}$ are 361 (homosexual men), 97 (intravenous drug users), 119 (heterosexuals) and 577 for the three groups together. By definition, scenario S does not incur new HIV infections in the 1900 s.

For scenario $R$, moderate increase is estimated in the prevalence in both AIDS and pre-AIDS stages (Fig 5.3 and 5.4). For 1993 , 1995 and 2000 June-30st levels are, respectively 1130,1340 and 1620 for AIDS and 6480,6610 and 6720 for pre-AIDS. In $199554 \%$ and in $200057 \%$ of pre-ADS prevalence is known seropositive and is assumed to need hospital services. For 1993 the model estimates $51 \%$ to be aware of the positive serostatus, which is in line with HVV-tesing results among homosexuals [233]. The proportion of homosexuals in pre-AIDS prevalence decreases from over $70 \%$ in 1993 $1065 \%$ in 2000 . 


\section{Dutch AIDS Scenarios}

Fig 5.2 Smoothed estimated annual incidence of HV infections for the three main risk groups and their total (three-yearly moving averages): homosexual men (dots). intravenous drug users (boxes), heterosexwals (diamondis) and total (crosses)

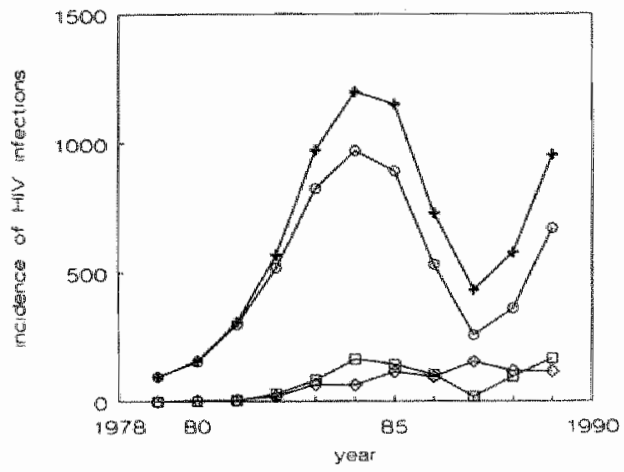

Fig 5.3 Projected AIDS prevalence as of June 30st in scenarios $R$ (dots). $T$ (crosses) and $S$ (triangles)

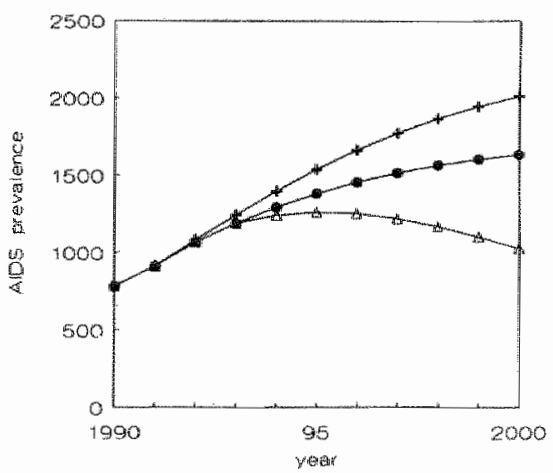


Chapter 5

Fig 5.4

Projected pre-AWDs prevalence as of dune 30 st in scenarios $R$ (dots), $T$ (dors) and $S$ (triangles)

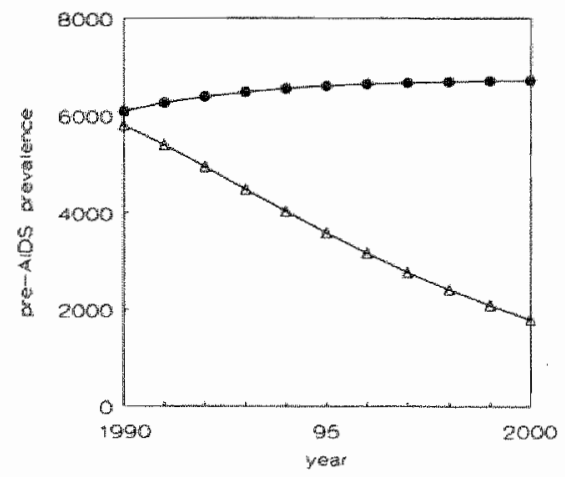

In scenario $\mathrm{S}$ prevalences decrease. This is especially the case in the pre-AIDS stage (1993: 4480 with 65\% known seropositive; 1995: 3580 with $73 \%$ known seropositive; 2000: 1800 with $87 \%$ known seropositive). AIDS prevalence exhibits only a moderate decrease: 1110 halfway 1993,1230 halfway 1995 and 1060 halfway 2000 . In $\mathrm{T}$ pre-AIDS prevalence is of course analogous to that in R. In this scenario, AIDS prevalence, however reaches almost 2000 cases by the end of the century. 


\section{Durch AIDS Sicurios}

\subsubsection{Economic Results}

The 1995 projections of hospital bed needs amount to at least 150 bedis in scenario $\mathrm{S}$ (Fig 5.5). Scenario $T$ produces the highest estimate of bed needs at 170 beds in 1995 . Despite a significant higher AIDS prevalence projection in scenario $T$ relative to scenario $R$ in 1995, bed needs for the two scenarios only deviate slightly. This is due to the assumption on the lengthening of survival so that only the early-CDC-IV phase, with relatively low impatient-days needs, is prolonged. Bed needs projections for 2000 are 125 in scenario $\mathrm{S}$ and allmosi double this amount in scenario $\mathrm{T}$ ( 220 beds). Scenario $\mathrm{R}$ indicates a level of 195 beds.

Fig $5.5 \quad$ Projected hospiral bed needs in 1995 and 2000 in scenarias $R$ (black), $T$ (thghtgrey) and $S$ (dark-grey)

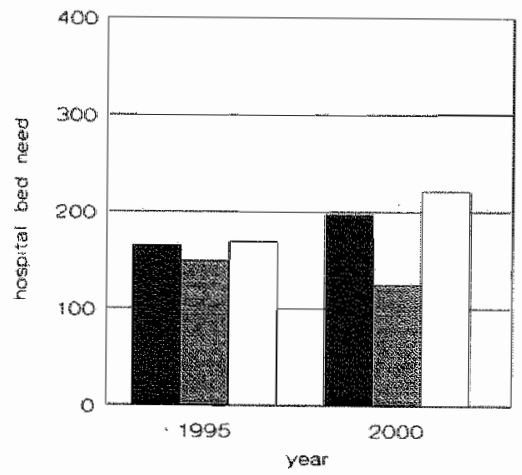

Inclusion of monetary cost estimates for inpatient-care and impatient-cure needs and need for outpatient facillities produces an overall hospital cost estimate of 33800 thousand ECUs in 1993 (Fig 5.6). For 1995 projected hospital costs are of at least the same level as in 1993. The cost projections for scenarios $\mathrm{R}$, T and $\mathrm{S}$ in 2000 are, respectively 45600,50700 and 26700 thousand ECUs. 
Fig 5.6 Projected hospital costs in 1993 ECUs (inpatient care: grey. impatient cure: boxer: outpatien facilities: black in 1995 and 2000 in scenarios $R$ (reference scenario), $S$ (subscenario) and T (therapy scenario)

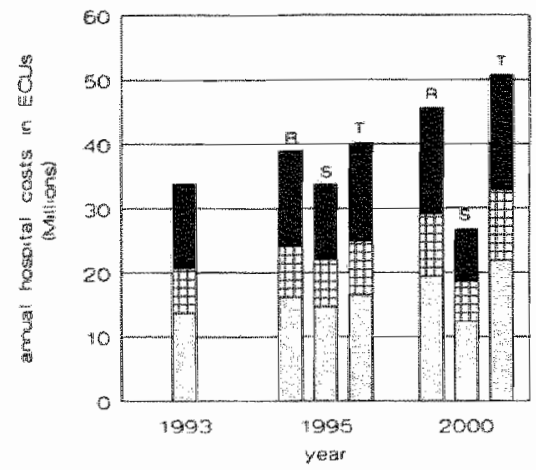

It is estimated that in 1993 inpatient care constituted $41 \%$ of total hospital costs, inpatient cure was $20 \%$ and outpatient facilities were $39 \%$. Up to 2000 , inpatient-care and -cure proportions are projected to increase in all scenarios (to $47 \%$ and $23 \%$, respectively in scenario S), whilst a corresponding decline is projected for outpatient-facilities needs (to only $30 \%$ in scenario 5 ). As most impatient care and cure is required in the final phase of AIDS, where needs for outpatient facilities are low, this trend demonstrates the increasing importance of this stage in hospital cost projections.

\subsection{Discussion and Conclusions}

\subsubsection{Epidemiologic assumptions}

"The epidentological development underlying two of three scenarios is based on the assumption that no fundamental changes take place with respect to the recent levell of HIV incidence. The average of the estimated incidences of 1987,1988 and 1989 is applied to all future years up to 2000 (577 new infections per year). This epidemiological course indicates lower projections in the medium-term than the short-term projections presented earlier for The Neherlands. In 1987. Houweling et al. [234] estimated a prevalence of HIV-infected persons of 20000 . In 1990, Jager et al. [23] indicated a range for the prevalence of HIV-infected persons of 90001013000 . The estimate of the prevalence of 


\section{Dutch AIDS Scenarios}

HIV-infected persons as of January 1st 1990 amounts to 6630 (of which 630 are AIDS patienis), which is in line with those reported by van de Water et al. [235]. Based on AIDS data as of December 1990 , they estimated a prevalence of HIV-infected persons of approximately 7000 as of December 1988 .

Underlying the ADS-impact model is a backcalculation procedure. Recently backcalculation procedures have had to be adapted to take the effect of early treatment into account $[92,210,236]$. Prior to this adaption, backcalculating negative incidences of HIV infections have been attributed to the effect of early treatment $[237,238]$. Here, the effect of early treatment has been incorporated into the backcalculation procedure. However, as procedure is deterministic in nature negatives are not ruled out, although at the moment one does not encounter them. Further work will be directed to assessing the impact on health care, including a probabilistic mechanism for backcalculation (see for example, [239]).

The impact of AIDS is still very uncertain - this uncertainty is reflected in the construction of the scenarios. There remains a need to improve the reliability of data concerning the prevalence of persons with HIV infections, progression to AIDS and trends in HIV incidence. For example, clearly the scenarios are very sensitive to the incubation period distribution, since backcalculation and epidemiological projection are based on it ${ }^{1 / 6}$. The most recent insights from the literature are used and experts have been consulted in an attempt to overcome this lack of empirical data.

In contrast to the subscenario assumption, there will probably be a future spread of HIV infections. The impact of AIDS will therefore be more widespread than is the case in the subscenario. The HIV/AIDS incidence and prevalence in the reference scenario is greater than that produced by the subscenario and this difference increases over time, whilst the therapy scenario projects an even higher AIDS prevalence. The difference with the subscenario shows that continued efforts in the area of public education could prevent thousands of HIV infections and lower hospital resource utilization and corresponding costs significantly.

\subsubsection{Economic Assumptions}

The model projections are based on stable hospital inpatient-day needs per person-year (ppy) and stable ppy monetary costs of inpatient care and cure and outpatient facilities; in

"This sensitivity is shown by Bloom ${ }^{4}$ Glied $[240]$ in an application to US-data. 


\section{Chapter 5}

other words stable treatment teclinology, intensity of care and prices are used. Further work could be directed to introducing trend developments into these parameters. A downward trend in ppy hospital inpatient-day utilization is reported [220]. Also, since a pollicy of substituting outpatient for inpatient care is favoured by the Dutch government [241], one might expect trends in hospital (and correspondingly non-hospital) resource utilization for HIV/AIDS. This development is present in the US [242,243]. For the Netherlands the development of a monitoring system for outpatient resource utilization and costs for HIV/AIDS has just started.

The model uses a single estimate of the costs per hospital inpatient day for earlyCDC-IV and late-CDC-IV. In reality, it might be assumed that costs in the late-CDC-IV stage will be considerably higher due to more intensive care. In addition, the assumption is made that per observation-year (poy) hospital inpatient-cure and hospital oupatient costs have decreased in proportion to the decrease reported for poy hospital inpatient-care costs. As only partial information is available (information on trends in resource utilization but no information on costs [220]) to verify this assumption, it could be challenged, in particular for outpatient costs. Possibly, substitution of outpatient for inparient activities has raised the importance of outpatient costs, relative to inpatient care costs.

Indeed, the reported decrease of poy hospital costs of care could be connected with increasing poy utilization of hospital outpatient facilities and corresponding costs. Assuming the poy decrease in inpatient-care costs for CDC-IV shifted completely to outpatient hospital services, this would raise hospital costs by less than $10 \%$ during the period 1991-2000 in each scenario. Obviously, this is a maximum estimate of the effect of substitution. Since one of the reasons for substituting outpatient for inpatient care is cost reduction, one expects lower rises in hospital outpatient costs. For CDC-II/III any significant effect seems to be absent altogether. So, the sensitivity of scenario results, concerning the assumption of proportional decrease of hospital outpatient costs, is only limited.

Finally, one should notice that the model projections are, at the moment, based on information on hospital resource utilization and corresponding costs of patients in the Uniwersity Hospital Utrecht. At the moment it is unclear if this hospital is representative of HIV/AIDS hospital costs. Two other patient-based Dutch studies on HIV/AIDS hospital costs in Amsterdam are available: the Teaching Hospital of the University of Amsterdam [61] and Slotervaart Hospital [148]. Comparison of the Utrecht data with those of both Amsterdam studies is limited, due to differences in period of registration, 


\section{Dutch ADS Scenarios:}

pattient population, scudy design and measurement of monetary costs [62]. Onty the Utrecht registration in Utrecht contains recent information on hospital resource utilization and costs. Since 1991 the registration has been extended to include further hospitals in Amsterdam, the Hague and Arnhem $[2441$. Comparative results of this multi-hospital study will be published shortly.

\subsubsection{Comparative Analysis}

It is estimated that hospital bed needs for HIV/AIDS are at maximum 220 and at minimum 125 in 2000. A recent study by RIVM produced some projections for hospital inpatient-nday needs for selected diseases with a current major impact on hospitall resource utilization $[245,246]$. As quanitative epidemiological data are often lacking, hospital inpatient-day needs projections for 2000 of lung cancer (ICD 162), diabetes (ICD 250), cononary heart disease (ICD 410-414), stroke (ICD 430-438) and pneumonia (ICD 480486) are based on time series analysis of utilization data for 1980-1990 [247,248] (see Annex of this thesis]. Time series analysis is performed on age- and sex-group-specific series of monthly standardized per capita hospital inpatient-day utilization (standard population is the average population in 1990). Including a factor for a sizable growth due to the aging of the population - as opposed to HIV/AIDS - for all five diseases, hospital bed needs projected for lung cancer, diabetes and pneumonia are approximately three- to fourfold that for HIVIAIDS, whereas those for coronary heart disease and stroke are over 10 times those for HIV/AIDS (Table 5.3).

Table $5.3 \quad$ Utilization of hospital beds in 1990 and projected bed needs in 2000 for lung cancer, diabetes, coronary heart disease, stroke and pnewmonia

\begin{tabular}{lcc} 
& 1990 & 2000 \\
& 634 & 610 \\
Lung cancer & 840 & 660 \\
Diabetes & 2400 & 2640 \\
Coronary heart disease & 1950 & 2210 \\
Stroke & 560 & 600 \\
\hline
\end{tabular}

Source: SIG Health Care Information, Utrecht, the Netherlands; data processed by RIVM.

As demonstrated in the Annex of this thesis, projected decreases in the number of beds in 2000 for lung cancer and diabetes result from a sharp fall in the standardized 


\section{Chapter 5}

mean duration of stay in 1980-1990, whereas the standardized number of inpatient stays is fairly stable (lungcancer) or even decreasing (diabetes) in that same period. For diabetes the probable explanation is a substitution of outpatient care for hospital inpatient care. For pneumonia in 1980-1990 a sharp fall in the standardized mean duration of stay has been offset by an increasing standardized number of stays. A varied pattern for the different age and sex groups is found here: for elderly women and young boys the time series on bed utilization has a stable mean, for young girls the mean shows a significant decrease and for elderly men there is a significant increase in the mean. Finally, both diseases of the circulatory system show projected increases in the number of beds slightly below that which might be expected on the basis of demography alone. This pattern occurs as during 1980 1990 a fairly stable standardized mean duration of stay and number of stays (for stroke) and a decreasing standardized mean duration of stay combined with an increasing standardized number of stays (for coronary heart disease) results in a slight downward trend in standardized bed utilization.

Patient-related costs are the costs that can be attributed directly the treatment and care of patients with HIV and AIDS. Previously, the largest proportion of these costs was assessed to be associated with the hospitals [134]. For an updated comparison with other patient-related costs separate ppy monetary costs estimates for nursing home, district nursing, home help, general practitioner and intensive home care derived from an earlier report [101] and updated to 1.993 prices, is used. As the Netherlands does not yet have an adequate system for registering outpatient and community care resource utilization, any cost estimate has to be based on fragmented research evidence.

The cost of AZT/zidovudine has typically represented a sizabie proportion of the total costs in the AIDS stage [249], but now also represents a cost component in the preADSS stages for early treatment. Unit costs are based on tariffs (nursing home, general practitioner and intensive home care), estimates of hourly cost prices (district nursing and home help) and market prices (AZT). Hospital costs are estimated to represent $85 \%$ of total patient-related costs in 1993 (Fig 5.7). The general practitioner and home care (district nurse, mother"s help and intensive home care) comprise a small share of total costs. Of non-hospital costs the use of AZT in early treatment represents the largest share. 


\section{Dutch AIDS Scenarios}

Fig 5.7 Estimated distribution of patient-related costs (estimated 39800 thousand 1993 ECUs) over various sectars in 1993: hospital; genteral practitioner (GP); nursing home; home care (mother's help, district murse, intensive home care); and early rreatment (with AZT)

Source: STG IIOIJ.

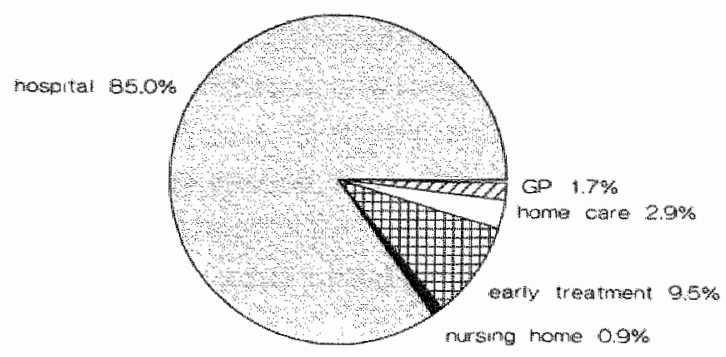

In addition to patient-related costs, there exists a range of general program costs. This costs division has proven to be useful in analyzing HIV/AIDS costs $[2,156,250,251]$. The general program costs due to HIV/AIDS can be estimated up to 26 million ECUs in the Netherlands in 1993. This amount is allocated between prevention (13 million ECUs, excluding AIDS prevention among dentists), research (5 million ECUs), HIV testing (5 million ECUs, with $80 \%$ for safeguarding the blood supply) and 3 million ECUs on planning and organisation $\lceil 63,147,222,252\}$.

An increase in hospital costs of HIV/AIDS is projected from 33.8 million ECUs in 1993 up to 50.7 million ECUs in the therapy scenario T for 2000 (price year: 1993). Using the average growth rates for the costs of Dutch hospitals in 1988-1993 (4.9\%) hospital costs for all diseases in 2000 are projected to amount to 22939 million ECUs 12221. In comparison, the costs in scenario $T$ in 2000 of 66.3 million ECUs (price year: 2000; including an assumed yearly nominal growith rate of $3.9 \%$ in future years [222]). constitute $0.53 \%$ of the all diseases figure. The reference scenario $R$ and subscenario $S$ indicate lower shares $(0.47 \%$ and $0.28 \%$, respectivelly). Therefore, the scenarios demonstrate that approximately one quarter or a half percent of total hospital costs will be required for HIV/AIDS in the year 2000 , a sizeable but probably manageable proportion.

Comparison of scenario $\mathrm{R}$ and scenario $\mathrm{S}$ provides insight into the potential gains from preventive efforts. Starting from the assumption that costs indicated by scenario $S$ 


\section{Chapter 5}

are unavoidable, given unchanged treatment patterns, the excess costs of scenario $R$ over scenario $S$ increase from 6.0 million ECUs in 1995 to 22.1 million ECUs in 2000 . Continuation or even an expansion of preventive efforts could counter this rise. If the most effeciive prevention programme resulted in an epidemiological outcome consistent with scenario $S$, the model implies, for the hospitals a potential preventive benefit of present valued 38 million ECUs for the years 1994-2000, relative to the reference scenario $^{17}$. This represents $23 \%$ of the present valued total costs of the latter. A considerable financial gain is possible through effective prevention, in addition to the human gains of reduced death and suffering. However, there remains unavoidable present valued costs 127 million ECUs for scenario $S$ for the same period.

\subsubsection{Summary of Results}

Projected hospital bed needs in the year 2000 of 125-220 for HIV/AIDS are limited compared to projections for coronary heart disease and stroke, but approach that for lung cancer, pneumonia and diabetes.

Hospital costs are estimated to have caused $85 \%$ of total health-care costs for HIV/AIDS in 1993. In 1993, the estimated proportions of hospital costs are $41 \%$ for inpatient care, $20 \%$ for inpatient cure and $39 \%$ for outpatient facilities. The scenarios indicate a decreasing share of outpatient costs - possibly to $30 \%$ of total hospital costs for HIV/AIDS in 2000 - illustrating the growing relative importance of the AIDS stage for the hospital cosits. Hospital costs for HIV/AIDS in 2000 are projected to reach up to $0.52 \%$ of projected hospital costs for all diseases.

A present value of 38 million ECUs (23\%) of the hospital costs projected in the reference scenario might be avoidable, during the period 1994-2000. However, with unchanged treatment patterns a present value of 127 million ECUs of hospital costs during the same period is projected to represent unavoidable costs (discount rate: $5 \%$ ).

In the Netherlands, data needs in the field of economic impact assessment of HIV/AIDS especially refer to registrations of non-hospital outpatient resource utillization and costs.

Following standard text books, when assuming benefits of preventive efforts, a discount rate to future monetary figures is applied [34]. So, in this paragraph cost figures are present values at $5 \%$ discount rate. 
At first sight, impact analysis by multiplying prevalence (or incidence) and hospital cost estimates seems to be a quite straightforward procedure. Due to differences by patient group affected, type of hospital care rendered, and stage of disease dealt with, however, as well as due to the spread of HIV infection, the quantification of current and future impact of HIV/AIDS on Dutch hospitals is quite a complex task. By integrating most recent and detailed data with respect to the above categories, this paper has achieved an important step in improving the current state of information. Nonetheless, uncertainty still remains, leaving issues such as national representativity, impact on other health-care sectors, and more accurate or even dynamic integration of treatment technology for future work. For the time being, an indication of the order of magnitude of AIDS impact on Dutch hospitals has been develped, and it is clear that HIV/AIDS will be on the agende of hospitall issues in the coming years.

\section{Acknowledgements}

The authors would like to thank:

- The collegues in conducting the Dutch AIDS Scenario Study: FMLG van den Boom, DP Reinking, and CES Albers, the members of the supervising Scenario Committee (Chairman: EJ Ruitenberg of the Central Laboratory of the Netherlands Red Cross Blood Transfusion Service) and the Steering Committee on Future Health Scenarios (RF Schreuder and EM de Bruijn);

AM Downs and MC Dellmas from the Paris centre for the Epidemiological Monitoring of AIDS in Europe for their analysis of progression-of-disease studies; and

- The members of the scientific committee (Chairman: J Rovira of The University of Barcelona) of the Econometrics of AIDS conference in December 1993 for giving the opportunity of presenting a previous version of this work. The conference presentations and discussions contributed enormously to the construction of this paper.

The update of the epidemiological projections was done within the framework of a study on the quantitative impact of the AIDS epidemic on life insurance, on behalf of the National Commission for AIDS Control (grant by the Ministry of Welfare, Public Health and Cultural Affairs of the Netherlands). 



\section{Chapter 6}

\section{A Life-insurance Fund for HIV-infected Persons; financial impact of expected future epidemiology}

As extended version of this chater was published as an RTVMineport (No 432501001 1994, Mogelijke Uibrending van lyet Garantiefonds voor HIV-geinfecterde Personen; financièle consequenties van verwachte epiaemiologische ontwikkeingen) by MJ Postma, H Houweling, SH Heisterkamp and JC Jager 


\section{Chapter 6}

\section{Management Summary}

Objective: To assess the financial consequences of extending the Life-insurance Fund for HIV-infected hacmophilia-patients to comprise all HIV-infected persons.

Data \& Methods: Three types of data are used: (1) routine surveillance data on AIDS incidence by year of diagnosis, year of reporting, age and risk group; (2) interview data on income position of homosexual men from a study among readers of a national magazine; and (3) information on the need of several types of life insurance. Progressionof-disease (HIV infection, asymptomatic and symptomatic pre-AIDS disease, AIDS) is modelled by a multi-stage model. (Sub)stages of the model correspond to clinical classifications of HIV/AIDS and to the relevant stages for life-insurance need. A tentative anallysis has been carried out by means of two scenarios on the financial consequences of the possible extension of the Life-insurance Fund.

Results: Extending the Life-insurance Fund, scenarios indicate an average extra yearly demand for life insurance, varying from $f 20.5$ to 31.5 million. Demand is expressed in terms of insured amounts for three types of life insurance (pension, mortgage and temporary risk). Mortgage insurance is responsible for allmost $80 \%$ of the amounts. A minimum demand of approximately $f 45$ million is estimated for the homosexual risk group alone for the period 1995-1997.

Conclusion: Including future years up to 2005 , premium-payments and discounting, the estimated size of the Extended Life-insurance Fund varies from $f 50$ to 125 million.

\section{Acknowledgements}

The University of Utrecht (ThGM Santfort) is acknowledged for supplying interview-data that were processed in this research. L Markenstein and J Legemate of the National Committee on AIDS Control (NCAB) are thanked for commenting on draft-texts. 


\subsection{Introduction}

The background of this study is the impact of HV/AIDS on the life insurance-industry. In general , life insurers conceive persons with HIV/AIDS to be non-insurable with respect to insurances payable at death. For people with AIDS, insurers refer to the burning-house principle: insurance is impossible if the to be insured risk has already taken place. In general, persons with an increased risk of death are offered life insurance with increased premiums. For HIV, insurers have up to now indicated that the risk camnot yet be adequately estimated and accounted for in life-insurance calculations.

The non-insurability of persons with HIV has given rise to many discussions. Dutch insurers have urged for HIV-tests for insurance applicants. In addition, a code of behaviour has been defined that should lead to a restrictive testing policy of insurers. In short, the code specifies that an applicant for a life insurance below 1200000 (payable at death) can be demanded to be tested under certain curcumstances ${ }^{18}$. Applicants for life insurance above 200000 are always requested to have an HIV-test. Furthermore, insurers have the right to ask applicants whether they have AIDS or are HIV seropositive and to deny insurance for HIV-infected persons [253]. In the period March 1991-March 1992 mineteen persons applying for an insurance below $f 200000$ were tested, including one positive test $[254]$.

The National Commitsee on AIDS Control (Nationale Commissie ALDS Bestrijding; $\mathrm{NCAB}$ ) has urged that a provision should be developed to enable certain kinds of insurance for people who are aware of their HIV infection. This is to avoud the impossibility of full-participation in society for people who have several years of disability-free life still ahead. In particular, it is argued that life insurance is a "social good", as opposed to normal market commodities [255]. Social goods are thought to serve a social function and are instruments to secure a certain economic standard of living. In securing a decent standard of living for the dependants in the event of death, life insurance is essential. Then again, insurers claim that a less stringent code for HIVinfected persons is not in line with the probabilistic principles of insurance and point to the risilk of self-selection, wiz persons with a higher risk of death are tempted to apply for higher amounts of insurance $[256,257]$.

For haemophila-patients a provision has been designed by the Dutch Society of

in The code specifies that the insurance company is allowed to ask some particular questions, such as "did you have a blood transfusion abroad?" and "do you use drugs intravenously?". Based on the answers the insurer can ask for an HIV-test. 


\section{Chapter 6}

Life Insurers (Nedterlandse Vereniging van Levensverzekeraars; NVL) and the Dutch Red Cross, enabling the small-scale buying of life insurance. A lot of Dutch haemophiliapatients have been infected with HIV in the early days of the epidemic. The Ministry of Welfare, Public Health and Culture accounted for the financial part of the arrangement. In short, the provision enables heamophilia-patients to buy life insurance up to 7200000 without any restriction. If the insured person dies as a result of HIV/AlDS the insurance company involved is compensated out of the Life-insurance Fund (Garantiefonds). This provision has existed since January 1 st 1993.

On June 1 st 1993 the Secretary of State for Public Health, announced a study on the feasibility of extending the Life-insurance fund to encompass more persons at risk of HIV/AIDS. A study by NVL recommended a provision providing a benefit for relatives, but this has never been implemented [258]. Finally, NCAB has been asked to organize a feasibility study, covering important aspects such as epidemiological expectations and indications of possible sizes of the Extended Life-insurance Fund. Based on the experiences in the Dutch AIDS Scenario Study [101] on quantitative epidemiological aspects, modelling and financial-economic impact assessments RIVM was requested to perform this study " with $\mathrm{NCAB}$ merely acting as supervisor.

The need for life insurance depends on several personal aspects, such as age, income, housing, partnership and parenthood. Furthermore, the type of insurance is of importance, such as pension, mortgage, temporary risk and work-disability insurance. In general, life insurance serves two purposes. Life insurance can be of importance to secure financial independence for relatives (for example, to garantee the financial means for housing in mortgage insurance). Furthermore, life insurance can be of importance for the insured person's participation in business if it is associated to a loan or credit. For example, having one's own business can be dependent on the possibility of obtaining a life-insured credit.

The nature of the Extended Life-insurance Fund restricts the scope of this chapter to those insurance types that are payable at death by the insurer. These types of insurance are payable if the insured person dies before the expiry-date, viz at premature death of the insured person. This study focuses on savings-mortgage, temporary risk and pension insurance. For the latter, in particular the widow and partner-components are important. Outside the scope of this study are life insurances that are payable at life at a specified end-date, such as a life-annuity, and work-disability insurance. In view of the complex discussions surrounding the general organisation of the latter type of insurance a separate study is recommended. 


\section{Life-insurance Impact}

This study examines expected epidemiological developments in the short-term. In particular, the consequences in the first three years after an assumed extension of the Life-insurance Fund as of January Ist 1995 are estimated. For the years beyond 1997 a crude indication is provided.

\subsection{Data and Assumptions}

\section{Epidemiology}

The epidemiological data have been described in Chapter 5 of this thesis. Very brief, AIDS-registration as of June 30 th $1993^{19}$ [219], and an average survival in the AIDSstage of two years are used [14].

\section{Income and housing}

A specific study of the readers of a newspaper, directed at homosexual men $(\mathrm{N}=1199)$ provides insight into the income and housing circumstances of this AIDS risk group [259]. Table 6.1 summarizes some of the findings. Important findings were that $83.7 \%$ of those 25 years and younger have an income below $f 2000$. Furthermore, of these $19.4 \%$ live with a steady partner. Steady partmerships occur in $20 \%$ of men aged 25 years and younger, $30 \%$ in men aged 26-35 and for $40 \%$ of men older than 35 years. As can be expected, the income distribution exhibits a "shift to the right" as age progresses. Almost $50 \%$ of men older than 40 years are in the upper incone classes ( $\geq f 3000$ ), and of these $45 \%$ thas a steady partnership. In particular for the largest income class $(2000-3000)$ the percentage having a stable partnership remains similar as age progresses. In consequence, the general picture of an increase in steady partnerships seems to be related to the changing income distribution.

Of course, the representativeness of these data for all Dutch homosexual men can be questioned. Furthermore, due to lack of other sources, these data are also assumed for other AIDS risk groups, viz intravenous drug users and heterosexuals. Even more, representativeness of the data for these patient groups presents a problem. Below, all financial results are presented seperately for homosexual men and for all risk groups together.

"Haemphilia AIDS-patients and paediatric AIDS-cases due to vertical transmission are exchuded as these groups are not intended to be reached by the Extended Life-insurance Fund. 
Table 6.1 Percentage distribution over net monthly incomes (in f) and per age-cotegory (berween brackets the percentage is shown of persons living with a steady parmer)

Income $\quad \leq 2000 \quad 2000-3000 \quad 3000-4000 \quad \geq 4000 \quad$ total

Age

\begin{tabular}{llllll}
$\leq 25$ & $83.7(19.4)$ & $14.0(25.0)$ & $1.2(0.0)$ & $1.2(0.0)$ & $100(19.8)$ \\
$26-30$ & $44.6(34.0)$ & $44.2(33.3)$ & $9.4(28.6)$ & $1.8(75.0)$ & $100(33.9)$ \\
$31-35$ & $26.2(24.1)$ & $49.0(31.7)$ & $18.0(27.0)$ & $6.8(42.9)$ & $100(29.6)$ \\
$36-40$ & $23.0(38.3)$ & $45.1(33.7)$ & $21.1(41.5)$ & $11.8(62.5)$ & $100(39.7)$ \\
$\geq 40$ & $17.5(28.6)$ & $32.8(33.1)$ & $29.9(45.5)$ & $19.8(46.3)$ & $100(38.6)$ \\
\hline
\end{tabular}

Source: [259]; data processed by RIVM.

\section{Life insurance ${ }^{20}$}

This section specifies the assumptions used to assess the relationship between personal circumstances and the desired level of each selected type of life insurance.

Of persons without a steady partnership $20 \%$ are assumed to buy their own house, and a connected savings-mortgage insurance. For those living together with a steady partner this percentage is assumed $40 \%$. These supposedly conservative estimates are thought to reflect the scarcity of own homes in Amsterdam, where the majority of HIV seropositives live. The "rule-of-thumb":" in determining life insurance is that the insured amount equalls two and a half times gross income in paid employment, and twice gross income in self-employment.

For persons who are aware of their HIV seropositivity, $10 \%$ are known to be selfemployed [260]. It is assumed that $50 \%$ of self-employed HIV-seropositive persons are in need of a temporary risk insurance connected to business credit. Furthermore, it is assumed that those living with a steady partner, wish to buy this type of life insurance for their partner (the "classical type" of life insurance in the Hollywood-movies). It is assumed that $80 \%$ of the self-employed and $30 \%$ of the paid-employees buy temporary risk insurance for their partners. Obviously, paid-emplyees without a steady partner are in no need for this type of insurance. The general rule in life insurance equals a temporary

20 This section is designed in cooperation with W de Boer MSc, who is a member of the AIDS-research committee of the Dutch Society of Insurers (Nederlands Verbond van Verzekerals:

at Of course in practice, one might deviate from the "rule-of-thumb" calculus, when for example a smaller amount is sufficient. 


\section{Life-insurance Impact}

risk insured amount to gross inconne (in paid employment) or half of gross income (in self-employment).

Partner-pension insurance is considered indispensable for self-employed persons in a steady partnership. The formula for the insured amount operates on the amount of gross income above 25000 . The amount is halved to arrive at the usual level of the pension and multiplied by a factor 20 to approximate an indexed unit of partner pension; viz insured amount equals: (gross income $-25,000$ ) $* 0,5 * 20$.

Finally, tyhe point of departure has to be assessed for estimating actual demands for life insurance. In particular, a part of life insurance needs might have already been covered in the past. For example, a person might have purchased his own house prior to seropositivity. As no adequate information is available, crude assumptions are applied. Obviously, the older the person is, the greater the proportion of total needs already covered will be. It is assumed that those aged $40+$ already have $75 \%$ covered, those aged 35-39 already have $50 \%$ covered, those aged $30-34$ already have $25 \%$ covered and the rest has no coverage yet. Obviously, for the last group demand equals need.

\subsection{Method}

\section{Epidemiology}

The progression-of-disease model has been described in detail in Chapter 5 (Fig 5.1). Here, it is recalled that five stages are distinguished: acute infection, asymptomatic HVV infection, symptomatic pre-AIDS disease and AIDS. Furthermore, asymptomatics are separated into two groups, depending on whether HIV-infection status is known or unknown. The combined stages of known asymptomatic and symptomatic pre-AlDS will be referred to as the stage of known seropositive. The combined stages of acute infection and unknown asymptomatic will be referred to as the unknown seropositive stage. This difference in unknown and known is crucial for insurance purposes: knowledge of one's seropositivity should be specified on the life-insurance application form, resulting in denial of access to insurances that are payable at death. This means that known seropositives are likely to have major problems in buying life insurance. As explained in Chapter 5, the progression-of-disease model is combined with a backcalculation procedure on AIDS surveillance data to estimate past incidence of HIV infections.

For the future, assumptions are specified for HIV infections, resulting in the reference and the subscenario. The influx of estimated past and assumed future incidence 


\section{Chopter 6}

of HIV infections, the flow through the different disease stages and AIDS-related deaths determine the incidence and prevalence of known seropositives (compare Figs 5.2 and 5.4). Known seropositives can be assumed to have been denied life insurance in the past or have refrained from attempts to buy insurance, knowing that denial is likely. On the other hand "unknown seropositives can be assumed to often have been able to buy insurance through regular channels. Therefore, only the needs and demands for life insurance of known seropositives are specified.

The subscenario reflects a part of the reference by calculating only the consequences of incidence of HIV infections before 1990 ("unavoidable epidemic"). In particular, persons infected before 1990 can have experienced problems in their access to the life-insurance market. Recently infected persons have only experienced this blockade for a relatively few years and might already have covered a lot of insurance needs before infection. Summarizing, the demand for life insurance can be conceived as a function of age-related income increases (higher age/income induces higher demand), age-related proportion of need already covered (higher proportion covered lowers demand) and duration of seropositivity (longer durations are related to higher demands). As such, the method integrates these different relationships by using age-dependent needs and agedependent proportions of cowered needs in combination with different scenarios. Obviously, age should be the variable to relate epidemiology to life-insurance needs/demand.

\section{Linking epidemiology and life insurance}

The epidemiological projections can be readily extended with an estimate of the age distribution of incidence and prevalence in the various stages. As a basis the age distribution of cumulative AIDS incidence at June 30st 1993 is taken. This distribution is assumed to be stable over the years. Age-specific prevalence of known seropositives is directly transferable into a distribution of known seropositives according to income and housing circumstances, using Table 6.1. As mentioned, income and housing are assumed to determine the need for life insurance ${ }^{22}$. used:

22. To transform net monthly income from Table 6. 1. to gross annual income the next table is

Table Gross anmual income per net monthly income (in $1990 \mathrm{f}$ ) and housing sinuation (grosg annual income is based on the midpoints of the net income intervals)

Net monthly incone $<=2000$
Without partier

35000
With partner

30 opo 


\section{Life-insurance Impact}

To determine the need for life insurance the prevalences as of the beginnnings of 1995,1996 and 1997 are used. To translate needs into actual demand it is taken into account that life insurances can be obtained up to 1200000 per person (aggregated over the three forms of insurance considered). This is conform the design of the Life-insurance Fund for haemophilia-patients. The model therefore cuts off individual demands at a maximum of 200000 . Extension of the Life-insurance Fund as of January 1 st 1995 would mean that life insurance needs of the present known seropositives become actual. This results in a demand for life insurance. It is assumed that in the first year (1995) one third of uncovered needs is actually demanded. In 1996 and 1997 again one third is demanded. This even spread of demand over three succesive years is rather arbitrarily. Progression to AIDS might prevent demand, as the Extended Life-insurance Fund does not apply to AIDS patients. Their needs remain uninsurable. For the new known seropositives of January 1 st 1996 and 1997 the same rule of "even spread" applies. Thus, the additional needs due to incidence of known seropositives in 1995 and 1996 are taken into account, viz unknown seropositives as of 01011995 who become aware of their serostatus in 1995 and 1996.

Table 6.2 Projected prevalence as of January 1st in Reference and Subscenario (the latter berween brackets): Total (all patient groups") and Homosexual men only"; all (known and unknown seropositives) and known seropositives only

\begin{tabular}{llllll} 
& & 1994 & 1995 & 1996 & 1997 \\
Total & all & $6620(3872)$ & $6673(3429)$ & $6712(3014)$ & $6739(2631)$ \\
& known & $3445(2780)$ & $3567(2579)$ & $3653(2364)$ & $3727(2149)$ \\
\multirow{2}{*}{ Homosexual } & all & $4606(2843)$ & $4579(2512)$ & $4547(2204)$ & $4512(1920)$ \\
& known & $2503(2063)$ & $2551(1905)$ & $2571(1742)$ & $2587(1579)$ \\
\hline
\end{tabular}

"Excluding haemophilia-patients and vertical transmission; "* Including intravenous drug using homosexual men.

$2000-3000$

$3000-4000$

$>=4000$ 


\section{Chapter 6}

Table 6.3 Age distribution of ADS (as of June 30st 1993) and HIV incidence (estimated: assumed stable during time) for all patient groups" (between brackets: homosexual men onty")

\begin{tabular}{lll}
\hline & AIDS & HIV \\
$<=19$ & $0.3(0.0)$ & $10.7(9.6)$ \\
$20-24$ & $2.7(2.1)$ & $18.1(17.1)$ \\
$25-29$ & $14.0(13.4)$ & $21.3(21.1)$ \\
$30-34$ & $22.0(20.4)$ & $19.0(20.5)$ \\
$35-39$ & $20.8(21.9)$ & $14.0(15.4)$ \\
$40-44$ & $17.4(19.6)$ & $8.0(8.5)$ \\
$45-49$ & $11.0(12.0)$ & $4.4(4.2)$ \\
$50-54$ & $5.3(5.5)$ & $3.1(2.5)$ \\
$55-59$ & $3.6(3.1)$ & $1.4(1.0)$ \\
$>=60$ & $2.8(2.1)$ & $0.0(0.0)^{* * *}$ \\
\hline
\end{tabular}

- Excluding haemophilia-patients and vertical transmission; " Including intravenous drug using homosexual men:

Source: GHI [219]; data processed by RIVM.

Table 6.4 Estimated age distribution as of January 1 st 1994 in the Reference scenario of total pre-ADDS prevalence and known seropositives only, for all patient groups" (between brackets: homosexual men only*)

\begin{tabular}{llc} 
& Total & Known \\
$<=19$ & $4.3(3.2)$ & \\
$20-24$ & $8.7(7.6)$ & $2.7(1.8)$ \\
$25-29$ & $15.7(14.4)$ & $5.9(5.0)$ \\
$30-34$ & $19.5(19.3)$ & $13.5(12.3)$ \\
$35-39$ & $18.4(19.5)$ & $19.3(18.6)$ \\
$40-44$ & $14.2(15.8)$ & $19.7(20.4)$ \\
$45-49$ & $9.2(10.3)$ & $16.0(17.7)$ \\
$50-54$ & $5.4(5.6)$ & $10.8(12.1)$ \\
$55-59$ & $3.1(2.9)$ & $6.2(6.6)$ \\
$>=60$ & $1.6(1.4)$ & $3.7(3.5)$ \\
\hline
\end{tabular}

"Excluding haemophilia-patients and vertical transmission; " Including intravenous drug using homosexual men. 


\section{Life-insurance Impact}

Table 6.5 Estimated age distribution as of January 1 st 1994 in the Subscenario of total preAIDS prevalence and known seropositives only, for all parient groups" (between brackets: homosexual men only")

\begin{tabular}{lll} 
& Total & Known \\
$<=19$ & $2.0(1.2)$ & $2.0(1.2)$ \\
$20-24$ & $5.0(4.3)$ & $4.5(3.8)$ \\
$25-29$ & $13.1(11.9)$ & $12.4(11.3)$ \\
$30-34$ & $19.5(18.7)$ & $19.2(18.3)$ \\
$35-39$ & $20.1(20.8)$ & $20.3(20.8)$ \\
$40-44$ & $16.6(18.3)$ & $17.0(18.7)$ \\
$45-49$ & $11.2(12.5)$ & $11.7(13.0)$ \\
$50-54$ & $6.4(6.8)$ & $6.7(7.1)$ \\
$55-59$ & $3.8(3.6)$ & $3.9(3.7)$ \\
$>=60$ & $2.3(1.9)$ & $2.4(2.0)$ \\
\hline
\end{tabular}

"Excluding haemophilia-patients and vertical transmission; "Including intravenous drug using homosexual men.

\subsection{Results and Discussion}

\section{Epidemiology}

Table 6.2 shows projected prevalences in the pre-AIDS stages. In the Reference scenario, the percentage of known seropositives in all seropositives ranges from $52 \%$ in 1994 (all risk groups) to $57 \%$ in 1997 (homosexual men only). In the Subscenario, the percentage of known seropositives increases from $68 \%$ in 1994 to $82 \%$ in 1997. Tables 6.3 through 6.5 show the age distributions of incidence and pre-AIDS prevalences in both scenarios. Table 6.3 illustrates the difference in the age distributions of HIV and AIDS, that currently amounts to more than 8 years in average. In the long-term and under specific conditions this difference will approach the average incubation period of 12 years. Almost $80 \%$ of HIV incidence is in persons below 40 years and almost $60 \%$ is for persons between 20 and 35 years of age.

Tables 6.4 and 6.5 indicate that the group of known seropositives has an average age that is of course higher than that of the average seropositive, viz known seropositives are up to 3.2 years (homosexual men in the Reference scenario) older than unknown seropositives. Obviously, this difference is in line with the durations of both stages of unknown and known seropositive, and will in the long-term and under specific conditions approach 6 years. Estimated age distributions for January Ist in later years are rather 


\section{Chapter 6}

similar in the Reference scanario. In the Subscenario, the average age roughly increases by one year per year passing.

Recently, the number of HIV-infected homosexual men during the early nineties has been estimated at 6500 to 15000 by Wiessing et al. [233]. The estimates (Table 6.2) are obviously below the lower bound of this estimate. Other than the backcalculation approach for estimating HIV prevalence, in [233] seroprevalence is estimated through a direct method, based on the data from [259]. In line with the analysis, the proportion of known seropositives in [233] is estimated at $50 \%$.

As explained in Chapter 5 , the backcalculation approach used is a deterministic one. This implies that, for example, negative estimates of HIV incidence are not excluded at forehand, although at the moment they are not encountered. But in general, the model doesn't separate incidental fluctuations from structural developments. To confront this general flaw in the model a new method has recently been developed $[239]^{23}$.

Application of the model to the Dutch situation implies cumulative HIV incidence of 6510 per as of January 1st 1990 among the three major risk groups: homosexual men, intravenous drug users and heterosexuals. For comparison, in the above analysis the corresponding figure is 7140. Also the most recent estimated level of new HIV infections is lower in Heisterkamp et al. [262]. The current estimate and input for the Reference scenario amounts to 579 new HIV infections per year. In [262] only 180 new infections annually are estimated. Although large confidence intervals are indicated, the possibility should be considered of significantly lower levels of HIV incidence than currently underlying the Reference scenario. Finally, the estimate for January 1st 1994 of pre-AIDS prevalence amounts to 4260 in [262], which is between the Reference and Subscenario estimates. An analogous partition of the incubation period produces an estimate of $68 \%$ known seropositive, corresponding with the Subscenaric.

\section{Scenarias for life insurance demand}

Life insurance demands of known seropositives in the years 1995, 1996 and 1997 are respectively $330.4,31.6$ and 32.7 million in the Reference scemario and $f 23.2,20.4$ and 17.7 million in the Subscenario. Comparison of both scenarios indicates that more than three quarters of demand come from persons infected with HIV before 1990. As mentioned, to this part of demand a higher likelihood is assigned than to the rest. of

23 No specifically defined functional relationship for incidence of HIV infections is assumed. As un [261] a stylized pattern for HIV incidence is applied: incidence in one year is not allowed to substantially deviate from those in surrounding years. 


\section{Life-insurance Impact}

course, in 1997 the share of the Subscenario in the Reference scenario is smaller (just ower $50 \%$ ) than in both pervious years. Homosexual men account for $67-74 \%$ of demand. Furthermore, the shares of savings-mortgage, businesss temporary-risk, partner temporary-risk and pension insurance are quite stable at respectively $80 \%, 3 \%, 10 \%$ and $7 \%$.

Life insurance demands in the Subscenario reflect those of known seropositives who might possibly have been blocked for several years in their access to the lifeinsurance market. They have been seropositive for at least five years and might be "waiting" for an Extended Life-insurance Fund. The probability of the realisation of this part of demand is therefore high. This part is $50-75 \%$ of the Reference scenario. Furthermore, reasoning that intravenous drug users might buy less life insurance even under the new Exiended Fund, an expected minimum demand of approximately $f 45$ million is estimated for homosexual men in the Subscenario during 1995-97.

For the years after 1997 a significantly lower demand is estimated, as the "catchup" demand of the large group of known seropositives prevalent as of January 1st 1995 is assumed to take place during 1995, 96 and 97 . For the years after 1997 only the needs of the new incident known seropositives and the changes in needs due to progression in age and in disease are of relevance. The Reference scenario assumes 579 new HIV infections annually, corresponding to an annual demand for life insurance of approximately $f 15$ million. In the Subscenario demand decreases from $f 2$ million to a negligible amount in 2005.

\subsection{Conclusion and International Comparison}

For an integrative estimate for the total size of the Extended Life-insurance Fund one has to cover two further aspects: premium-payments and discounting. The former aspect would at a maximum allow a lowering of the Extended Fund by $10 \%$, as the vast majority of the HIV-infected persons are aged between 25 and 45 years, and premiums are relatively low for this age group. Furthermore, premiums will only be paid for a period in the order of magnitude of the incubation period. A discount rate has to be used to recalculate all monetary amounts into their present value. As in the previous Chapter a $5 \%$ rate is used. Including a $10 \%$-lowering due to premium-payments and discounting the Reference scenario and Subscenario indicate funds of respectively $f 125$ and $f 50$ mill ion to cover demands in the period 1995-2005. For comparison, the current (non-extended) Life- 


\section{Chapter 6}

insurance Fund is $f 5$ million.

It may be that demand is lower than that considered here. For example, severall HIV-infected persons might have attracted funds through other channels, such as personal loans. Furthermore, the general calculus rules in life insurance might very well indicate amounts above those that are necessary. As mentioned, intravenous drug users might have significantlly lower needs and demands than the income and housing data for homosexual men indicate. On the other hand the construction of the Extended Life-insurance Fund could stimulate the willingness to be HIV-tested, increasing the number of known seropositives in the short-term. However, perhaps the most serious caveat for the new fund is the Dutch membership of the European Single Market. Non-Dutch HIVseropositive European citizens could start buying life insurance in the Netherlands. HIV prevalence rates in several other EU-countries such as Spain, France and Italy are several times that in the Netherlands. Exclusion from the Extended Life-insurance Fund of nonDutch applicants has been argued to be difficult [263]. These legal aspects are not further ellaborated here.

Of course, the same discussions exist in other European countries and elsewhere life insurances are denied to HIV-infected applicants, HIV-tests are required and specific questions are asked. For example, in the UK a lot of concern has been generated by a policy of denying life insurance to anyone ever having had an HIV-test or even for just belonging to a high-risk group. Furthermore, large companies generally require a test for all amounts over $\mathfrak{f 4 0} 000$ for single males, compared to much higher limits for others [264]. In Belgium, France and Italy applicants for amounts over respectively BF5 million, FF1 million and ITL300 million are required to have an HIV-test. In Germany applicants for amounts over DM250 000 are medically examined, this may include an HIV-test. In France, the code of conduct in life insurance prohibits questions into the applicant's private life, whereas in Sweden the entire private life should be discussed with a playsician $[265,266]$. Obviously, because of some strict regulations elsewhere, HIV seropositives from abroad might try to seek insurance through an extended Dutch Lifeinsurance Fund. In consequence, from this international perspective, we should note that the potential number of HIV seropositives who might come to the Netherlands is substantial and could further burden the Extended Fund. 


\section{Chapter 7}

\section{Disease-staging and Cost-standardization for Modelling Health-care Impact of HIV/AIDS}

The first part of this chapter was putished by MI Postma, JC Jager, D Ruwaard, NCM wan Loy, RM Leidl ans a part of Disease-staging fort Modlleling Current and Future Health-care Impact of Disease; ilfustrations for Diabetes mellitus and AIDS (Heatin Policy 1998, 43:45-54); reprinted with permission The second part of this chapter is basedi on A Standardized Costing Framework for HrV/ADDS Hospital Care th the European Union by K Tolley, M Postma, JC Jager, M Good in: J Kyriopoulos el al. (Edis) AIDS Cost Analysis and Patient Classification (in press) 


\section{Chapter 7}

\section{Abstract}

This paper addresses the economic relevance of appropriately staging progression-ofdisease for cost assessment and future projection. An illustration is drawn from a Dutch cost-of-illness study for AIDS. The disease staging specifies a separate late stage to capture terminal high-intensity care for end-stage complications. Data are used from a detailed database on AIDS hospital care and costs. Neglecting the separation of a specific late stage is estimated to overestimate hospital bed needs for AIDS in the Netherlands by almost $15 \%$. In particular, confidence intervals of future projections for AIDS hospital beds - using respectively staged and non-staged models - do not overlap. AIDS hospital costs are overprojected by almost $11 \%$ in the non-staged model. In conclusion, an appropriate disease-staging averts structural biases in estimations of bed needs and costs, and therefore benefits the planning of hospital care facilities.

Obviously, specific disease-staging requires reliable and detailed data on hospital care and costs, preferably drawn from databases. A standardized approach in gathering this information would allow the extension of the Dutch methodology to other countries. For the purpose of extending the method to the $\mathbb{E U}$ as a whole, criteria and recommendations are specified in the Standardized Hospital Costing Framework.

\section{Acknowledgements}

This paper benefitted from the European Union Concerted Action on Multi-national AIDS Scenarios (project leader: Johannes C Jager; BIOMED contract number PL941723). The authors thank J Rovira, $\mathrm{K}$ de Wildt (University of Barcelona) and $\mathrm{F}$ Antoñanzas (University of la Rioja) for their involvement in our presentation of this paper"s previous version at the $6^{\text {th }}$ International Conference on System Science in Health Care (Barcelona, September 1996). 


\section{Disease-staging and Cost-standardization}

\subsection{Introduction}

Cost-of-illness studies form one of the starting points of health economics thinking. These type of studies typically address the costs on society of particular diseases that are of specific interest. Generally, two motivations for performing such studies emerge $[3,267]$ : (1) tho assess the current health-care burden of disease on society (some Dutch examples are $[246,2681) ;(2)$ to define parameter values for projecting future health-care burden of disease (two Dutch examples are $[62,269])$. Estimates of current and future burden of disease attribute to health-policy making, in particular to the planning of care services. This chapter addresses the economic relewance of appropriately staging progression of disease and the need for standardizing the methodology for cost-of-illness studies. In particular, this chapter focuses on cost-of-illness studies of HIV/AIDS in the European Union and derives some specific results for one Dutch cost-of-illness study. This chapter builds on previous publications on this topic $[66,101]$.

This chapter extends work conducted in the framework of the Dutch Steering Committee on Future Health Scenarios, which has guided many research projects in the fields of health and health care [146]. Examples on AIDS will be used to illustrate the importance of appropriately staging progression-of-disease for averting biases in projections of future health-care needs and costs. Stages of disease should be chosen such that individual stages reflect important differences in the intensity of resource utilization, needs and corresponding costs. Furthermore, this chapter elaborates on the EU-project "Managing the Costs of HIV Infection" (EU-project SOC 94 20018005FO1) [95,96]. "This project developed the so-called "Standardised Hospital Costing Framework for HIV/AIDS treatment and care" (SHCF). The explicit use of standards in this field helps improve the quality of methods in resource utilization measurement and cost studies and enhances the comparability of estimates produced. Thus, usefulness of the estimates is maximized for a range of research and policy purposes at the local, national and multi-national (European Union) levels. 


\subsection{Disease-staging of HIV/AMS}

In the previous chapters estimates of the current impact of HIV/AIDS on hospital bed needs and hospital costs and future scenarios thereoff were presented. Hospital costs included those of inpatient care and cure and utilization of outpatient facilities. In addition to the Dutch results presented in chapter 5 , the contributions to hospital bed needs and hospital costs of pre-AIDS and AIDS stages in the Reference scenario can be examined in more detail (Fig 7.1). A clear overall decreasing pattern is exhibited in the percentage of pre-AIDS in total bed needs and costs. In particular in the beginning of the epidemic, the number of persons in the pre-AIDS stage is relatively high as compared to the number of persons with AIDS (PWAs). Both indicators decrease from 100\% in 1980, through 34\% (beds) and $70 \%$ (costs) in 1985 to $9 \%$ (beds) and $28 \%$ (costs) in 2000. In the Subscenario and the Therapy scenario the decrease of the share of pre-AIDS in the total is even steeper.

Fig 7.1 Percentage of hospital beds (solid line) and hospital costs (internupted line) for pre-ADDS of respective totals for HIVIAIDS

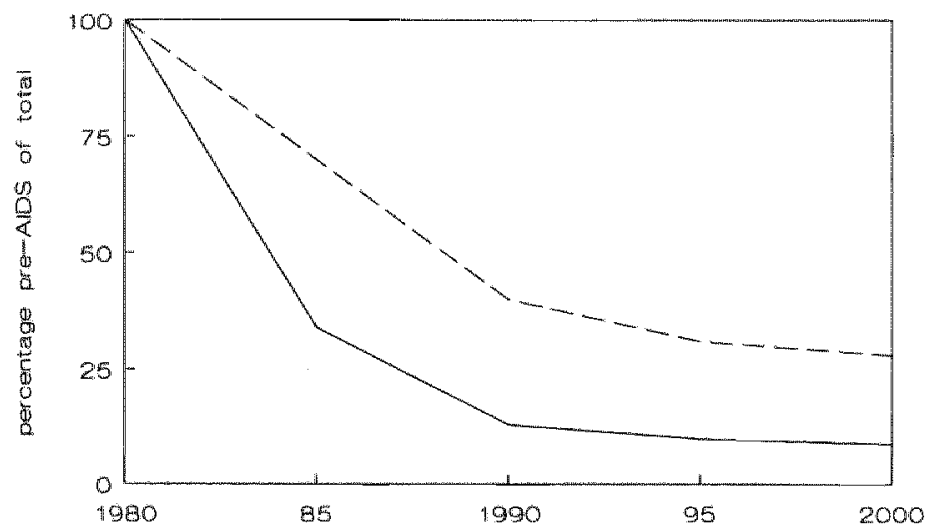

In chapter 5 progression of AIDS disease was staged into two subcategories: the final half year of AIDS preceding death (late stage) and the foregoing period (early/chronic stage) [270]. Summarizing chapter 5 its findings, the costs per person-year (ppy) in the late stage are almost three times those in the chronic stage (Fig 7.2).

Furthermore, more than half of lifetime hospitalization costs are generated in the late stage. Also, the intensity of hospital impatient days utilization in the late stage appeared to 
be almost four times that in the chronic stage (94 versus 25 days). Similar findings are reported in the American literature [271-273]. For example, one study shows that hospitalization costs in 1990 91 for PWAs rise sharply in the final half year prior to death up to US\$23 000, compared to below US $\$ 7000$ in other sixmonthly periods [273].

Fig 7.2 Hospital inpatient-day urilization (grey; left axis) and hospinal costs (black; right axis) per person-year (ppy) in the chronic and late srage of ADDS (see tex for

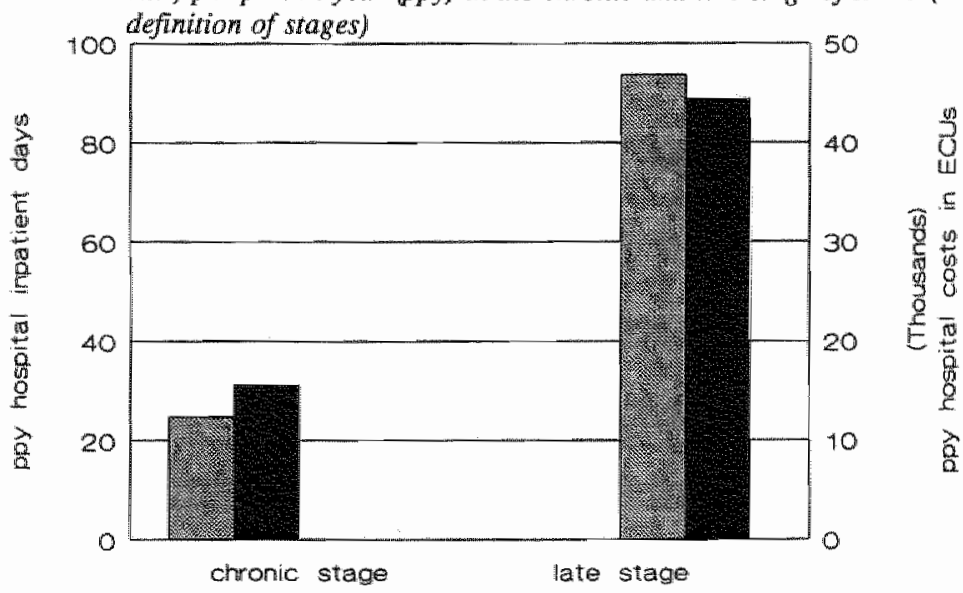

Using the data from Fig 7.2 and an AIDS-survival of 3 years in average, lifetime hospital bed needs and hospital costs can be derived for a hypothetical cohort of 1000 incident PWAs in the Netherlands (Fig 7.3, light bars; for the derivation of confidence limits, see chapter 9) ${ }^{24}$. Average AIDS survival has increased from one year in the beginning of the epidemic to two years currently and might be assumed to further increase to three. Improvements in survival prolong the chronic stage, thus raising the relative importance of resource needs and costs in this less-resource-intensive and relatively cheap stage, compared to the late stage. A non-staged AIDS-disease model would not be able to grasp this changing relative importance of both stages (Fig 7.3, dark barsi. The non-staged model overprojects future hospital bed needs; the $95 \%$-confidence intervals of both models do not overlap. A similar result was found for hospital costs, with the 60.4 million ECUs according to the staged model not included in the $95 \%$ confidence interval of the non-sitaged model"s projection. In consequence, it has been

24 The incidence-based approach is used for linking epidemiology and health care [274] and an occupancy rate of $85 \%$ is applied for transforming hospital inpatient days to hospital beds [275]. 
shown that the choice of an appropriate disease-staging averts structural biases in projections of AIDS health-care inpacts.

Fig 7.3 Lifetime hospital bed needs and costs (survival in AIDS stage of 3 years) according to a staged model (fight) and a non-staged model (dark), including $95 \%$ confidence intervals
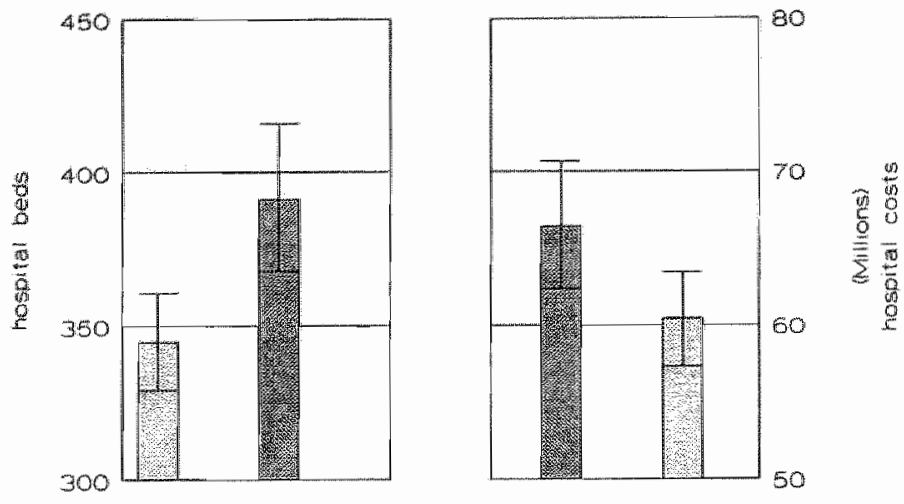

\subsection{Standardised Hospital Costing Framework (SHCF)}

Extending the Dutch scenarios of the previous section to other countries and the multinational EU-level involves an investigation for suitable and comparable information sources on HIV/AIDS hospital resource utilization and costs. To enhance comparability the SHCF has been developed [276]. As a part of the SHCF five specific fields for standardization of such studies are identified. (1) Information should be detectable from a sufficiently large patient sample size in the relevant disease-stages and sufficient patient follow-up for recording resource utilization and costs should be ensured. (2) To produce representative estimates for national and regional planning purposes a sufficient number of the main treatment sites covering the country/region should be included. (3) The possibility to break down aggregates so as to identify the contribution of different components of care in the care and cost totals should be supplied. (4) The possibility should be build-in to produce homogeneous cost groups, for example using several classifications such as CDC-stages [16,17], Turner-stages [277,278] or specific diseasestaging definitions as late versus early/chronic AIDS. (5) Finally, a standardised methodology in approach and presentation should be followed to enable the effect of "true factors" to be identified (differences in epidemics, health-care structure and practice, 


\section{Disease-staging and Cosi-standardization}

pricing structures and local health-care labour markets). The SHCF is intended to provide recommendations in these five fields of standardization and could possibly serve as a clearing howse for designing studies in HIV/AIDS resource utilization and cosis.

The SHCF is in essence a hierarchy of technical "accounting" steps associated with estimation of mean resource utilization and costs per person-year for pre-AIDS stages, AIDS-stage, specific episodes and of the lifetime resources and costs. The accounting framework is grounded on a number of elements of standard economic costing practice. Five main standards were used to develop the SHCF. (1) As a starting point, clarification of the perspective of the evaluation should be provided, viz the hospital or the health services planner at the national or multinational (EU) level. (2) Next, cost components and resource utilization units should be identified according to the perspective adopted. The framework covers four standard cost components, viz impatient, outpatient, day care (inpatient for several days with no overnight stay) and day case (admitted and discharged in one day). For specific purposes the last two or three components are taken together as respectively day care and outpatient care. (3) For measurement of physical resource utilization rigorous methods of study design and data collection are essential, viz predominantly patient-based (bottom-up) assessment of resources should be pursued. (4) Valuation of resources should be done using appropriate methods of unit cost (or price) estimation that closest reflects opportunity cost, viz caution must be exercised in using health-service charges or tariffs. (5) Production and presentation of mean resource and cost estimates should be according to the decision-making context for which they are to be applied (total, AIDS-stage, pre-AIDS stages, clinical condition or transmission group). Together, the accounting framework and the standard priciples that it is based on - if adopted in new cost studies - should produce cost estimates that compared to previous studies more meet the normative criteria of good quality and comparability.

The SHCF has both retrospective and prospective applications. Retrospectively, it can be used to enable assessments of the quality and comparability of estimates from previous studies. Through this application it illustrates the level of detail for which meaningful comparisons from existing studies are possible. An example, from a review of EU cost studies published between 1985-95 is presented in Table 7.1. In general, it is possible to make comparisons of hospital inpatient care for AIDS, and to a very limited extent for outpatient care and pre-AIDS care. Prospectively, the SHCF provides standards from which recommendations for new HIV/AIDS costing studies can be developed. 
Chapter 7

Table 7.1 Overview of studies on hospital resource utilization and costs: country, reference. study size in patients and inpatient days per person-year (ppy)

\begin{tabular}{lllcc}
\hline Country & Reference & Study period & Size & Inpatient days ppy \\
& & & & \\
Belgium & {$[190]$} & $1987-88$ & 24 & 106 \\
Denmark & {$[279]$} & $1980-86$ & 33 & - \\
France & {$[56]$} & 1986 & $100^{\circ}$ & - \\
& {$[280]$} & 1986 & 35 & - \\
& {$[281]$} & $1988-93$ & 2800 & 41 \\
Germany & {$[191]$} & $1985-86$ & \pm 29 & 66 \\
& {$[59]$} & $1985-87$ & 10 & 130 \\
Greece & {$[192]$} & 1988 & 7 & 110 \\
& {$[282]$} & $1988-91$ & 60 & 27 \\
& {$[283]$} & $1990-91$ & 105 & 13 \\
Italy & {$[284]$} & $1984-88$ & 51 & 185 \\
& {$[285]$} & $1985-88$ & 77 & 99 \\
Netherlands & {$[65]$} & $1990-91$ & 68 & 47 \\
& {$[62]$} & $1982-88$ & 230 & 58 \\
& {$[62]$} & 1989 & 79 & $513^{*}$ \\
& {$[220]$} & $1987-90$ & 126 & $28-90^{\circ}$ \\
Portugal & {$[270]$} & $1988-92$ & $296.6^{\circ}$ & 29 \\
Spain & {$[214]$} & 1991 & 96 & 22 \\
& {$[193]$} & 1987 & 6.36 & 130 \\
& {$[193]$} & 1987 & 8.5 & 105 \\
UK & {$[212]$} & 1990 & 156 & 26 \\
& {$[55]$} & $1985-86$ & 16 & 90 \\
& {$[194]$} & 1989 & 12 & - \\
& {$[286]$} & $1982-90$ & 459 & 33 \\
& {$[287]$} & $1984-92$ & 187 & -24 \\
& {$[288]$} & $1991-93$ & 60 & 24 \\
& {$[289]$} & $1983-90$ & $354.8^{\circ}$ & $31-92$ \\
\hline
\end{tabular}

"Not reported; + Admissions; " Figure refers to CDC IV; ${ }^{\infty}$ In person-years. 


\subsection{Discussion and Conclusions}

This paper has illustrated that the choice of an appropriate disease-staging averts structural biases in projections. Obviously, a first staging of HIV-disease in an AIDS and a pre-AIDS stage is essential. The dynamics of the HIV/AIDS epidemic causes the distribution of HIV-infected persons over these two stages to change continuously. In combination with major differences in resource needs and associated costs between these stages, these dynamics have major implications for aggregate resource needs and costs. The illustration has shown that the miscalculation in projecting future health care impact of AIDS neglecting pre-AIDS stages is less serious for the hospital resource needs than for the hospital costs. This is an important finding, in view of the lack of accurate data on the health care utilization in these pre-AIDS stages in most countries [95]. Furthermore, it has been illustrated that a further substaging within the AIDS-stage in a chronic and a late stage is crucial for averting structural biases in future projections. In consequence, any extension of the scenario methodology to other countries and regions, such as the European Union, should control for disease-staging.

As studies on Medicare-patients in the USA show, the concept of a relatively expensive late stage for AIDS can be extrapolated to other diseases. Overall, ppy health-care costs in the last whole year of life are 6.8 times those in other stages of disease $[290,291]$. Sector and death-cause specific results show that the difference is particularly high for hospital costs of cancer (12.2) and respiratory diseases (11.2). Furthermore, a similar pattern is reported for ppy hospital discharges. Some further details of this study enable us to calculate the overall costs in last half year of life, that appears to cause $80 \%$ of the costs in the last whole year (Fig 7.4). For comparative purposes the AIDS-staging is included, showing that the difference must be much more pronounced for several other diseases. Consequently, neglection of a resource-intensive and costly late stage in modelling other diseases - such as respiratory diseases and cancer - might introduce serious biases there as well. 
Fig 7.4 Hospital costs for ADDS in ECUs (grey, left axis) compared to Medicare costs in USS (black" night axis) per person-year (ppy) in the late stage (last hatf year of life) and its complementary chronic stage (sources (270) joy AIDS: 291 f for

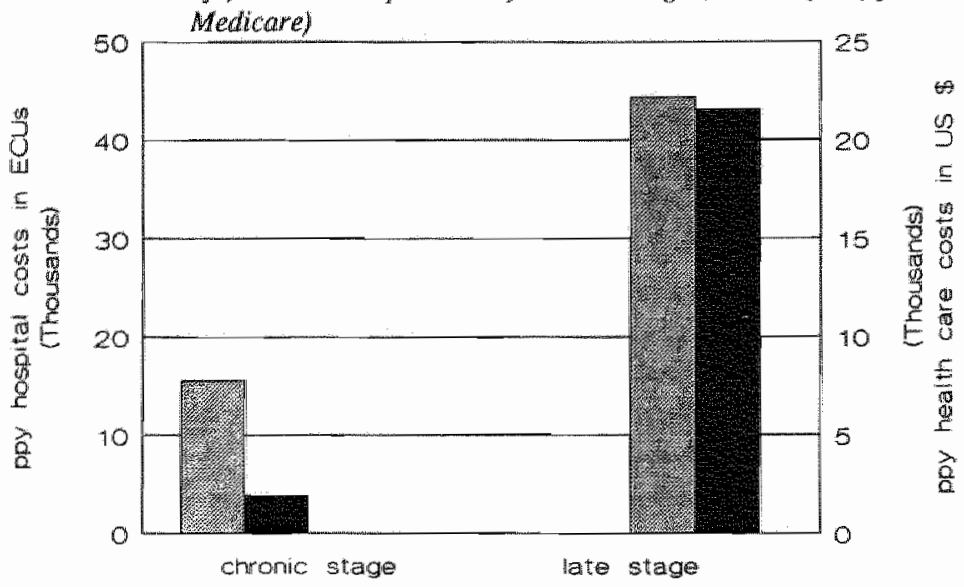

Methodologically, further refinement of the staging-mechanism can be pursued.

Currently, the most important refinement would concern the explicit modelling of healthcare needs for "short-survivors". On a per person-year basis in the late stage, persons with AIDS surviving less than a half year have been shown to be admitted to hospital four times as often than persons with AIDS surviving longer than a half year (Fig 7.5 ; [292,293]). Furthermore, the staging concept can be extended to other diseases. For example, in modelling the costs of diabetes mellitus one could consider the separation of an expensive late stage, reflecting resource needs and costs of complications that may occur many years after the onset of the diabetes [294]. Also, gathering comparable information and developing similar methodology on diseases, such as respiratory disease, cardiovascular disease and cancer, is needed and could benefit policy decisions in these fields. This staging of disease for economic reasions can follow different strategies, depending on study purpose, disease characteristic and data availability; they typucally have to be developed, motivated and tested just as any other analytical concept in economic evaluation. 


\section{Disease-staging and Cost-standardization}

Fig 7.5 Hospital impatient stays during the whole stage (light left axis) and pey person year (dark; right axis): $C S$ - chrontic stage; LSI - late stage with a duration of stay of 0.5 year; $L 52$ - Lare stage with a duration of sray below 0.5 year (see tew)

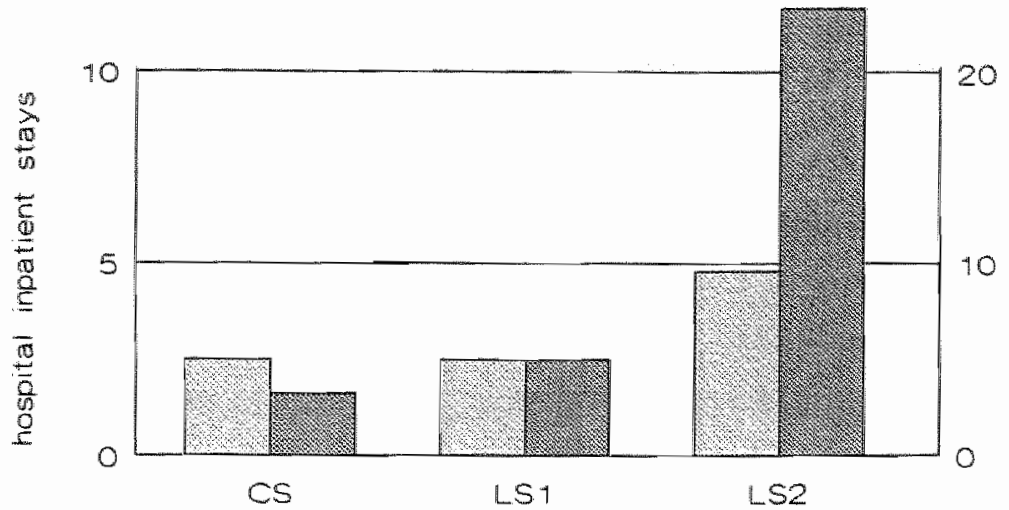

Obviously, the type of analysis requires a rather detailed patient-based registration, that is ideally set-up with the purpose of providing information for cost-of-illness and future projections. Furthermore, the type of information required can only be retrieved from bottum-up patient-based data on health-care resource utilization and costs, in case of timerelated staging of disease with a documentation over the full life span of a specific patient. This detailed information enables us to provide cost-of-illness assessments in the present and in future projections supporting health-policy decisions. They provide a quantitative order of magnitude for health-care resources. They specify the patient-mix for example in terms of chronic and late, which is an important indicator for planning hospital staff and capacity.

The SHCF can help in designing bottum-up patient-based costing studies that render the appropriate information. If SHCF-standards are followed the information that is meccessary for cost assessment and projection is identifiable. Further application of the SHCF could involve the examination of local, national and multi-national variations in hospital resource utilization. If bias due to methodological differences is minimised, cost variations due to differences in clinical practice, health-care structure and organisation and epidemiology can be more readily identified. In addition, the SHCF-standards should improve investigation of resource-utilization variations over time in one or more sites. Furthermore, detailed analysis could be done in specific areas of treatment and care, and could facilitate investigation of the cost-effectiveness of alternative policy and care options 


\section{Chapter 7}

in these areas (for example, HIV screening and combination triple therapy). Finally, the SHCF could provide a starting point for further development of the approach to cover non-hospital care and social care. It could prove a useful basis for investigating the feasibility of applying general principles to other diseases, such as diabetes, cancer, lung and heart disease. This would enable valid comparisons of the intra-national and multinational cost impact of different diseases. However, ultimately the viability and usefulness of a standardised costing framework for HIV/AIDS care can only be fully tested through its application, in particular in the development of multi-national scenarios. 


\section{Chapter 8}

\section{Hospital Care for Persons with AIDS in the European Union}

This chapter was published with the sane title by MI Postma, K Tolley, RM Leid, AM Downs, EJ Beck, AM Tramarin, YA Flori, M Santin, F Anlonanzas, H Kornarou, V Paparizos, MGW Dijkgrataf, JCC Borloffs, AHP Luijhen, JC Jager for the European Research Team on AIDS Scenarios in Health Pollcy (1997, 41:157-76); reprinted with permission 


\section{Chapter 8}

\section{Abstract}

This study estimates the current and future hospital resources for AIDS patients in the European Union (EU), using multi-national scenario analysis (EU Concerted Action BMHI-CT-941723). In collaboration with another EU-project ("Managing the Costs of HIV Infection"), six national European studies on the utilization of hospital care for AIDS have been selected to prowide the data for our analysis. The selection criteria inwolve recentness, quality, comparability, accessibility and representativeness. Baseline hospital resource utilization is estimated for hospital inpatient days and outpatient contacts, using a standardized approach controlling for two severity stages of AIDS (chronic stage and late stage). The epidemiological part of the study is based on standard models for backcalculating HIV incidence and projecting AIDS incidence, prevalence and mortality. In the next step, baseline resource utilization is linked to epidemiological information in a mixed prevalence- and mortality-based approach. Several scenarios render different future epidemiologicall developments and hospital resource needs. For the year 1999 hospital bed needs of 10 000-12 700 in the EU are indicated, representing an increase of 20-60\% compared to the estimated current (1995) level. The projected range for 1999 corresponds to a maximum of $0.65 \%$ of all hospital beds available in the EU. The growth in the number of outpatient hospital contacts is projected to possibly exceed that of inpatient days up to 1.82 million by the end of the century. Our methodologgy illustrates that estimation of current and future hospital care for ADDS has to be controlled for severity stages, to prevent biases. Further application of the multi-national approach is demonstrated through a what-if analysis of the potential impact of combination tripletherapy for HIV/AIDS. Estimation of the economic impact of other diseases could as well benefit from the severity-stages approach.

\section{Context}

This study has been performed for the European Reaserch Team on AIDS Scenarios, that exists within the framework of the European Union Concerted Action on Multinational AIDS Scenarios (project-leader: Johannes $\mathrm{C}$ Jager $\mathrm{PhD}$; co-ordinator economic aspects: Maarten J Postma MSc; BIOMED contract no PL941723). The co-operation with the other members of the co-ordinating team of the Concerted Action is kindly acknowledged: H Houweling MD (epidemiological aspects), SH Heisterkamp (modelling aspects) and DP Reinking MSc (social aspects). 


\subsection{Introduction}

Several studies in the European Union (EU) have produced projections of the future costs of HIVIAIDS $[213,270,295-298]$. To date, such economic impact estimation has been limited to the level of an individual region or country. Only one study has attempted to go beyond the national level by developing several scenarios of the future bed needs and hospital costs for the EU as a whole [218]. Recently, an EU Concerted Action was initiated for the development of multi-national scenarios to estimate the epidemiological and socio-economic impacts of AIDS [107,111]. In this paper the impacts of AIDS on the hospital care systems are reported. Estimation of this impact at the multi-national level must be based on a standardized approach towards analyzing available national information on health-care resource utilization and costs, as has been developed in a parallel EU-project $[66,95,96]$. In addition, standardized surveillance and modelling of the national HIV/AIDS epidemics is needed, since the expected number of AIDS cases is the starting point of any estimation of the national burden on health-care resources $[20,210]$.

Scenario analysis provides techniques for estimating disease impact under uncertain future conditions in terms of epidemiology, prevention, medical treatment and health-care technology. It involves the definition of a generic set of future projections, representing different "what-if" scenarios which are compared to a specifically defined baseline including the reference scenario [97]. Our previous analysis [218] suggested that hospital bed needs of persons with AIDS (PWAs) in 1995 would range from 5000 to 10000 for the EU as a whole, based on reported average intensities of care in the few European studies on hospital resource utilization that were available at that time. It was impossible to specify the care intensities according to patient characteristics, such as severity level of AIDS. Since this time, more data have become available and further progress has been made in the methodology of multinational scenarios through the EU Concerted Action. In the present paper, methodological improvements in the scenarios on hospital care and updated muliimational scenario results are presented. In particular, an approach is applied that allows the specification of relevant stages of disease severity. The choice for an actual severity staging is related to differences in health-care utilization within the AIDS stage, between the AIDS stage and pre-AIDS stages and to effects of recently introduced new therapies to HIV/AIDS (for example, combination tripletherapy).

The next paragraph focusses on a standardized approach for comparing data from international databases on hospital resource utilization of PWAs; accounting for stages of 


\section{Chapter 8}

disease severity. Furthermote, the incorporation of severity stages in the projection/scenario methodology is described. As primary result a baseline set of scenarios is presented for hospital bed needs and outpatient hospital facilities by the end of the century for the EU, using a standardized model for the past, current and future development of national HIV/AIDS epidemics. Finally, a "what-if" analysis of the potential impact of combination rriple therapy is presented and an application of our approach to other diseases is discussed. In general, this study can benefit the planning of hospital care facilities for PWAs in the next years at the EU-level.

\subsection{Data and Methods}

\subsubsection{Backcalculation and Epidemiological Information}

In the framework of a previous $[108,141]$ and the current EU-Concerted Action an empirical backcalculation methodology has been developed and applied as a standard approach for epidemiological estimations in all European countries [299]. Our latest application [84] was based on AIDS surveillance data as of March 31st 1994 according to the 1987 AlDS surveillance case definition [7,8]. A staged model is used for disease progression [300] that takes into account under-reporting, delays in reporting [143] and possible effects of pre-AIDS treatments [301]. Work to improve and update the epidemiological model is still ongoing in the Concerted Action. Therefore the estimates used in this paper should be considered as preliminary.

For each individual EU member-state, the output of the epidemiological nodel comprises estimated (1978-1993) and projected (1994-1999) annual adult transmissiongroup-specific incidence of HIV and AIDS ${ }^{25}$. In these calculations, two assumptions for the post-1993 HIV incidence were used to predict post-1993 AIDS incidence. In one, annual HIV incidence is constant from 1994 onwards at the estimated average 1990-1993 level. In the second no new infections occur after 1993, and thus provides an estimation of the unawoidable future AIDS epidemic given the prevailing treatment standards. Linking both assumptions with hospital care gives rise to respectively the Reference

25ecause of small numbers the method was not applied to Luxembourg. In the present analysis we do not consider Luxembourg since the contribution to EU-totals on incidence, prewalence and health care-needs can be neglected. The three countries who joined the EU in 1995 (Austria, Fintand and Sweden) are not yet included. 
scenario $(R)$ and the Unavoidable scenario $(U)$. In the present amalysis, prevalence and mortality of PWAS have been estimated from an assumed exponential survival distribution in the AIDS-stage with a mean of two years for PWAs diagnosed in 1987 or later, and one year for those diagnosed earlier [218]. In view of ongoing developments in AIDS therapies and related survival improvements [15,302], a third scenario is investigated labelled Therapy scenario (T). This scenario indicates the impact on prevalence and hospital care of prolonging survival to at mean of 3 years.

\subsubsection{Information on Hospital Care in the EU: study sellection}

Several reviews summarize studies on the impact of AIDS on European health-care systems $[109,110,303,304]$. In addition, several new studies in this field have reported results in the last three years. In total 22 studies have reported results for hospital care utilization: one for Belgium [190], France [281] and Portugal [214], two for Germany $[59,191]$ and Spain $[193,295]$, three for Greece $[192,282,283]$, Italy $[65,284,285]$ and four for the Netherlands $[62,220,270]$ and the UK $[55,286,288,289]$. Of the studies $50 \%$ refer to the $1980 \mathrm{~s}$, the rest include 1990 or later years. In general, sizes and distributions of the patient populations in these studies do not yet allow the assessment of differences between transmission groups. Inclusion of studies in this list is based on minimum technical standards on quality and comparability, related to the sample size, registration period and reporting (for example, of disease stage) [95].

For the present purpose of linking epidemiology and health care in future scenarios a further selection of studies was necessary. Three criteria were adopted. Firstly, information should be recent ( 1990 or later) reflecting current efficiency of practices in hospital care. During the 1980 s and into the 1990 s, efficiency has changed due to increasing experience with managing PWAs [221,305]. Furthermore, resource utilization has been controlled by more effective use; for example the substitution of less expensive outpatient care for hospital inpatient care [306]. Secondly, selected studies should include data that can be assumed to be representative of the national situations. Representativeness of study estimates is considered to be safeguarded in multi-center studies. Thirdly, the resource utilization data of selected studies should be patient-based, enabling resource utilization to be linked to individual patients, patient groups and disease stages, such as HIV infection and specific opportunistic illnesses. The studies satisfying most of these criteria are summarized in Table 8.1 [32,292,307-313]. 


\begin{tabular}{llcrrr} 
Country and reference & Period & Hospitals & PWAs PYCs & PYL $^{\text {PS }}$ \\
France $[281,292,293,307]$ & $1992-93$ & 9 & 1384 & 922 & 237 \\
Greece $[282,283,308-310]$ & $1990-91^{*}$ & 2 & 101 & 86 & 36 \\
Italy $[65,311]$ & 1994 & 10 & 264 & 104 & 40 \\
Netherlands $[32,270]$ & $1991-92$ & 4 & 182 & 145 & 39 \\
Spain $[312]$ & $1990-93$ & 1 & 97 & 30 & 21 \\
UK $[286,313]$ & $1990-91$ & 1 & 122 & 67 & 25 \\
\hline
\end{tabular}

\begin{tabular}{llcrrr} 
Country and reference & Period & Hospitals & PWAs PYCs & PYL $^{\text {PS }}$ \\
France $[281,292,293,307]$ & $1992-93$ & 9 & 1384 & 922 & 237 \\
Greece $[282,283,308-310]$ & $1990-91^{*}$ & 2 & 101 & 86 & 36 \\
Italy $[65,311]$ & 1994 & 10 & 264 & 104 & 40 \\
Netherlands $[32,270]$ & $1991-92$ & 4 & 182 & 145 & 39 \\
Spain $[312]$ & $1990-93$ & 1 & 97 & 30 & 21 \\
UK $[286,313]$ & $1990-91$ & 1 & 122 & 67 & 25 \\
\hline
\end{tabular}

Hospitals

PWAS PYCS PYLS

The table includes the estimation period, number of hospitals involved, number of persons with AIDS (PWAS), number of persom-years in the chronic stage (PYCs) and the number of personyears in the late stage (PYis).

"In the Greek study some pre-1990 registration could not be excluded.

\subsubsection{The Severity-Staging Concept}

Several studies have indicated the importance of severity-af-illness for resource utilization of PWAs [277,278,314-317]. In some studies a U-shaped relationship between AIDSrelated resource utilization and disease progression has been hypothesized [318-320]: high resource utilization immediately following the AIDS diagnosis and during the late terminal stage and low resource urilization during the intermediate period. This pattern describes the development of economically defined severity levels. Fig 8.1 presents information for hospital inpatient days using data from one Dutch study [320]. Clearly, the rise in resource-utilization intensity is more pronounced for the late phase and extends over several subperiods, whereas the rise in intensity after AIDS diagnosis seems to exist only in the first subperiod. Further analysis excluding PWAs with Pneumocystis carinit pneumonia (PCP) as AIDS-defining diagnosis, demonstrated intensities of hospital inpatient-days utilization below the average level in both the period following the onset of the disease and the intermediate phase (Fig 8.1). The availability of PCP prophylaxis in recent years supposedly contributed to "a shift in inpatient days utilization from the time neall date of diagnosis toward the time of death" [321]. Compared to other periods, almost fourfold hospital inpatient resource-utilization or costs during the last half year of life is reported for the Netherlands and the USA in the early 1990s [270-273]. 


\section{European AIDS Scenarios}

Fig 8.1. Mean number of impatient doys per person-year in the Academic Hosputal Utrech (Netherlands; (320) for 111 consecutiwe subperiods during the ADS stage for all parients who died in $1990-92$ (black bars; $=54$; 43.28 persan-days per subperiod) and excluding those with Pneumocystis carinii pnewnonis (PCP) as ADS-defining diagnosis (grey bars; $n=32 ; 36.82$ person-days per subperiod); lines indicate average levels for all parients (solid) and for non-PCP patients (diotied)

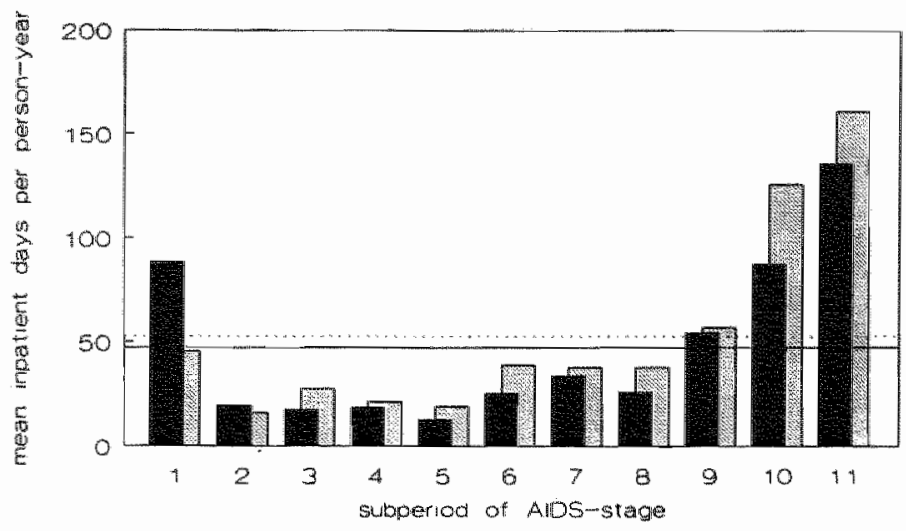

In consequence of the above, a study with a relatively large share of late-stage PWAs is likely to report a completely different pattern of hospital inparient resource utilization than one with predominantly non-late stage (chronic) PWAs. Neglecting this phenomenon could lead to serious errors in estimating hospital resource-utilization parameters per person-year (ppy) [156,322]. Two stages for PWAs are therefore differentiated: a final stage of maximally 6 months before death (late stoge; LS) and a stage for the foregoing period (chronic stage; CS). Thils staging concept has previously been applied to the Netherlands [270].

\subsubsection{The Severity-Mix Modelling Approach}

Standardized data on person-years, impatient days and outpatient contacts (outpatient visits or day-care treatments) were collected from the selected studies, in order to estimate fesource utillization ppy in CS and LS. Person-years and resounce utilization were attributed to LS if they occurred during the final half year of AlDS preceding death ${ }^{26}$

26 If the period between AIDS diagnosis - or the start of the registration - and death was less than half a year, the whole period was attributed to $\mathrm{LS}$. 


\section{Chapter 8}

and were attributed to CS if they occurred before the final 6 months preceding death (for deceased patients) or before the last 6 months of their registration (for patients alive by the end of the registration or follow-up period). The last column in Table 8.1 shows person-years in CS and LS in the selected studies.

In the next step epidemiological information was linked with ppy hospital resource needs of PWAs. Estimated ppy hospital resource utilization was used as a proxy for resource needs, implicitly assuming that recorded resource utilization reflects actual care needs. The approach adopted for linking was a mixed prevalence- and mortality-based approach. Annual resource needs for CS were estimated by multiplying the annual periodprevalence in CS by the appropriate ppy resource-need parameters for $\mathrm{CS}^{27}$. Annual resource needs for LS were estimated by multiplying annual mortality by the duration of stay in LS (6 months or less) and the appropriate ppy resource-need parameters ${ }^{28}$. It was assumed that ppy resource need remains stable over calendar time in each stage so that the effect of changes in epidemiology can be isolated. Estimates are presented for the years 1990, 1995 and 1999, using computer simulation and a spreadsheet. The year 1990 was chosen as the baseline year since epidemiological estimates are reliable and the economic data used are centered around 1990 in the original studies. The year 1995 was included to enable comparison with our previous estimates.

${ }^{n}$ Period-prevalence of PWAs was measured in terms of person-years. For simpliciry, we modelled the AIDS incidence to cecur halfway the year. The formula for the number of personyears in CS in year $t . \mathrm{PY}^{\mathrm{Cs}}(\mathrm{t})$, is

$$
(\mathrm{P}(\mathrm{t})-\mathrm{I}(\mathrm{t}) * \mathrm{P}[\mathrm{S}>0.5])^{* 1.0}+\mathrm{I}(\mathrm{t}) * \mathrm{P}[\mathrm{S}>1.0]^{*} 0.5+\mathrm{I}(\mathrm{t})^{*} \mathrm{P}[0.5<\mathrm{S}<1.0]^{*} \mathrm{E}[\mathrm{S}-0.5 \mid 0.5<\mathrm{S}<1.0]
$$

With $\mathrm{P}(\mathrm{t})$ the end-of-the-year prevalence, $\mathbb{I}(\mathrm{t})$ the incidence in year $t, \mathrm{P}[\mathrm{S}>0.5]$ is the probability of a PWA surviving longer than a half year after AIDS diagnosis, P[S $>1.0]$ is the probability of a PWA surviving longer than one year after AIDS diagnosis, $\mathrm{P}[0.5<\mathrm{S}<\mathbb{1}$.0] is the probability of a PWA surviving between a half and one year and $E[S-0.5 \mid 0.5<S<1.0]$ the expected survival in CS of PWAs surviving between a half and one year (slightly less than 0.25 years due to the cliaracteristics of the exponential distribution). The factors 1.0 and 0.5 represent the durations of stay in CS of respectively the non-incident and the incident parts of end-of-the-year prewalence.

xk The formula for the person-years in the late stage in year $t, P^{L S}(t)$, is

$$
(\mathrm{M}(\mathrm{t})-\mathrm{P}[\mathrm{S}<0.5] * \mathrm{I}(\mathrm{t})) * 0.5+\mathrm{P}[\mathrm{S}<0.5]^{*} \mathrm{I}(\mathrm{t}) * \mathrm{E}[\mathrm{S} \mid \mathrm{S}<0.5]
$$

With $\mathrm{M}(\mathrm{t})$ mortality in year $t, \mathrm{P}[S<0.5]$ reflects the probability of a PWA surviving less than a balf year after AIDS diagnosis and $E[S \mid S<0.5]$ the expected survival of PWAs dying within a half year after AIDS diagnosis. The latter duration is smaller than 0.25 years due to the characteristics of the exponential distribution used. The factor 0.5 in the first part of the formula reflects the duration of stay in LS of PWAs surviving half a year or longer. 


\subsubsection{Ceneralization to the Whole EU}

Table 8.1 provides a partial picture of AIDS hospital resource utilization patterns in the EU. No adequate hospital resource-utilization information could be selected for Ireland (no studies available), Belgium (most recent available study was from 1988), Denmark (most recent available study was from 1986) and Germany (most recent available study was from 1987) and Portugal (no patient-based information and no information on ambulatory hospital services available). To generalize our results to the whole EU, average ppy resource needs in CS and $\mathbb{L S}$ for each year in the countries of Table 8.1 were calculated, and applied to the countries with missing information. To indicate some of the sensitivity of the results with regard to this assumption, as an alternative data of neighboring countries were applied to the missing countries (Dutch data for Germany and Denmark; French data for Belgium; Spanish data for Portugal; UK-data for Ireland).

\subsection{Results}

Table 8.2 presents estimated hospital resource utilization per person-year for the two severity stages of PWAs. Inpatient days ppy vary between 4 (Greece; CS) and 160 (Spain; LS). Inpatient days ppy in the late stage are several times those in the chronic stage. In Greece relatively frequent use is made of outpatient services for CS patients (one of the two Greek hospitals specializes in dermatology, involving a high intensity of outpatient-care management). In both Italy and Greece total hospital contacts ppy are rather similar for CS and LS ${ }^{29}$. France and Spain exhibit the opposite pattern of a high proportion of inpatient resource utilization (up to $93 \%$ for LS patients in France). Furthermore, in these two countries and the Netherlands and the UK total hospital contacts ppy exhibit greater care intensities for LS than for CS. Total hospital contacts ppy in CS are around 70-80 for France, Greece and Italy and around 35-45 for the Netherlands, Spain and UK. Estimated ppy outpatient contacts don "t provide an obvious pattern: lower for CS than LS in Spain and the UK, similar in France and the Netherlands and higher for CS than LS in Greece and Italy.

The epidemiological results for the EU are used as a basis for estimating total current hospital resources for PWAs and producing future resource-needs scenarios. End-

\footnotetext{
29 Total hospital contacts are the sum of inpatient days and outpatient contacts and represent the intemsity of hospital-patient interaction.
} 
of-the-year prevalence is estimated to have grown from 25000 PWAs in 1990 to 49000 in 1995 (Fig 8.2). Projections corresponding to the three scenarios all demonstrate a higher prevalence in the year 1999 (up to 86000 PWAs for the therapy scenario T). The projection for the unavoidable scenario $U$ - without new HIV infections since 1993 shows an increase of $18 \%$ between 1995 and 1999 . The reference scenario $\mathrm{R}$ - including new HIV infections from 1994 onwards - indicates an increase of $27 \%$ over the same period. Due to the fact that AIDS incidence is higher than AIDS mortality, the estimates of person-years (Fig 8.2) are below estimated prevalences (end-of-the year prevalence includes incident cases and neglects mortality). The severity mix is such that $22 \%$ of the person-years refers to LS, except in scenario T where only $15 \%$ refers to LS. The NorthSouth shift in the AlDS epidemic causes the proportion of person-years in Spain and Italy in the EU-total to increase from $42 \%$ in 1990 to $56 \%$ in 1999 .

Table 8.2 Hospital resource utilization per person-year of AIDS by country and patient group (chronic versus late; see text)

\begin{tabular}{llccc}
\hline Country & AlDS stage & Inpatient days & Outpatient contacts & Total contacts \\
& & & & \\
France & Chronic & 57.2 & 12.7 & 69.9 \\
& Late & 143.4 & 11.0 & 154.4 \\
Greece & Chronic & 4.3 & 75.6 & 79.9 \\
& Late & 44.1 & 33.8 & 77.9 \\
Itally* & Chronic & 32.6 & 44.1 & 76.7 \\
\multirow{2}{*}{ Netherlands } & Late & 59.8 & 28.5 & 88.3 \\
\multirow{2}{*}{ Spain ${ }^{\oplus}$} & Chronic & 23.5 & 21.0 & 44.5 \\
& Late & 79.7 & 22.9 & 102.6 \\
& Chronic & 22.6 & 13.6 & 36.2 \\
& Late & 159.8 & 22.9 & 182.7 \\
& Chronic & 26.8 & 14.9 & 41.7 \\
& Late & 65.1 & 22.8 & 87.9 \\
\hline
\end{tabular}

- Due to the relatively short registration period of 7 months, the last 6 months before registration closure of surviving patients were not discarded, which would have left only one month per surviving patient; instead, all person-years and resource utilization of patients with a relatively short life expectancy were attributed to LS, in particular of those diagnosed in the most severe Turner-stage with an estimated median survival of 7 months $[277,278]$; the Italian database is the only selected database that includes information on the Turner-stages; Since the registration is based on episodes of disease, the last half year had to be approximated by taking the last or last few episodes.

Sources: as in Table 8.1. 
Fig 8.2 AIDS prevalence (black bars) and person-years in 1990, 1995 and three scenarios for $1999(R, U$ and $T$ : see text); person-years are differentiated between chronic stage (CS; grey bars) and late stage $(L S ;$ white stacked bars)

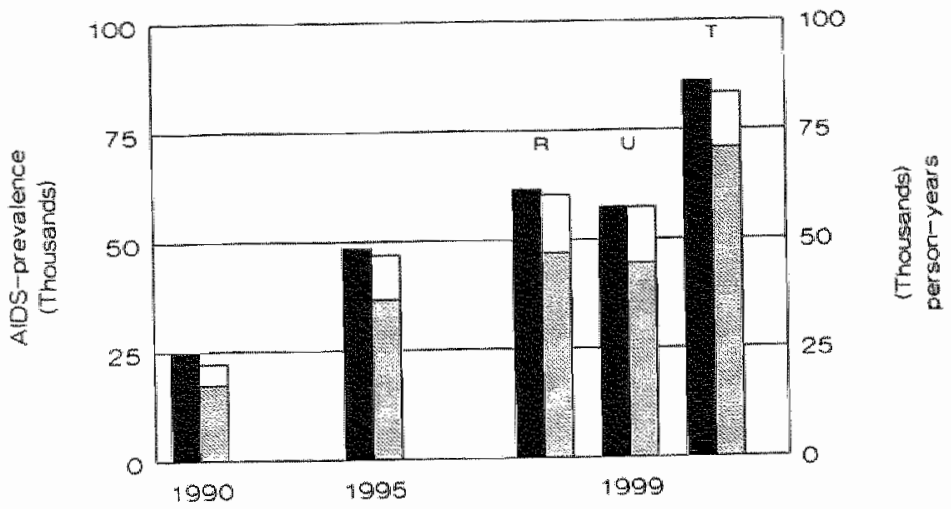

Fig 8.3 Hospital bed needs (left bars; left axis) and outpatient contacts (right bars; right axis) for AIDS in 1990, 1995 and three scenarios for $1999(R, U$ and $T$ : see text); contributions to resource needs are differentiated between chronic stage (CS; black bars: beds; dark grey: outpatient contacts) and late stage (LS; light grey stacked bars." beds" white: outpatient contacts)

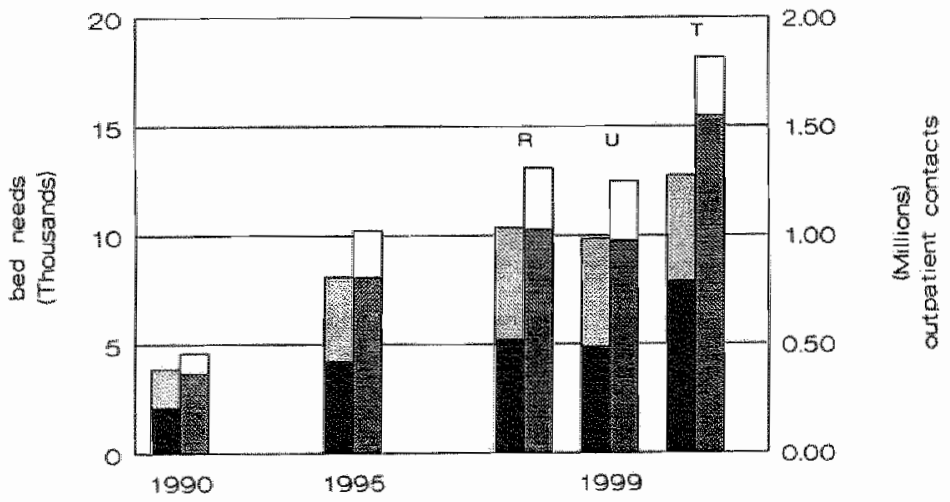




\section{Chapter 8}

In the reference scenario, hospital bed need is projected to increase by $28 \%$ from 8100 in 1995 to 10400 in 1999 (Figure 8.3) ) $^{30}$. Respective growth rates for scenarios U and $\mathrm{T}$ are $22 \%$ and $57 \%$. The latter growth rate for scenario $\mathrm{T}$ indicates that person-years outgrow hospital beds by $13 \%$. The corresponding projected trend in ppy inpatient days is therefore downward in scenario $T$, as opposed to the stabilization projected in scenarios $R$ and $U(1990: 54.5 ; 1995 ; 53.7 ; 1999 \mathrm{R}: 53.3 ; 1999 \mathrm{U} ; 53.4 ; 1999 \mathrm{~T}: 47.4)$. The trend in this "average EU ppy inpatient-days figure" is affected by two driving forces: the distributions of person-years (1) over countries (geographical development) and (2) over CS and LS (severity-mix development). The increasing relative importance of the Spanish and Italian epidemics in the EU causes a downward pressure on total EU ppy inpatient days due to the relatively low ppy impatient days for CS in Spain and LS in Italy. Reductions in overall ppy inpatient days for scenarios $\mathrm{R}$ and $\mathrm{U}$ can be explained by the dominance of the geographical development. The severity-mix development dominates scenario $T$, where the explicit assumption of increasing survival inflates the relative importance of CS with relatively low ppy inpatient days. Ppy inpatient days for CS and for LS are respectively 34-37 and 118-119. Except for scenario T, there exists a tendency of a growing contribution of LS to EU bed needs, towards $50 \%$ in 1999. Because the intensity-of-care in terms of nursing, specialist consultations and drugs is probably higher for PWAs in LS, the average inpatient day in 1999 carries a higher burden-of-care. As an important consequence, in two of the scenarios a higher average burden-of-care per inpatient day adds to the projected growth in the number of inpatient days.

In the reference scenario, hospital outpatient contacts are projected to increase from 1.0 million in 1995 to 1.3 million in 1999 (Fig 8.3). Respective growth rates for scenarios $\mathrm{U}$ and $\mathrm{T}$ are $22 \%$ and $78 \%$. For all scenarios, growth rates are identical to those for totall person-years. Therefore, corresponding projected ppy outpatient contacts. are stable over time and between scenarios with a range from 20.9 in 1990 to 21.8 in later years. The increase from 1990 onwards can be explained by the increasing importance of the Italian epidemic in the total EU-epidemic, with relatively high ppy outpatient contacts in Italy. Ppy outpatient needs differ little between CS and LS (respectively 22 versus 21 ). As for person-years, approximately $80 \%$ ( $85 \%$ in scenario T) of outpatient contacts are associated with CS. In general, the share of outpatient contacts in total hospital contacts is projected to increase slightly from $29 \%$ of 3.5 million contacts

30enarios on bed needs are derived from the inpatient days estimates, assuming a bedoccupancy rate of $85 \%$ 
in 1995 to up to $31 \%$ of 5.8 million contacts in scenario $\mathrm{T}$ in 1999.

\subsection{Discussion and Conclusions}

\subsubsection{The Severity-mix Approach}

To make relewant comparisons and projections, resource utilization studies have to be standardized with respect to the severity mix of the patient population. Neglecting the severity mix would overestimate resource utilization of the "average PWA in a study with a relative high proportion of severe patients. As mentioned above, our severityweighted EU-awerage in 1990 for ppy inpatient days amounts to 54.5 . Its unweighted counterpart would be 62.6 ppy inpatient days in that same year, illusitrating the importance to account for severity mix. Out operationalization of the severity concept in chronic and late stages (CS and LS) has been chosen in accordance with major European resource-utilization studies and with the outcomes of epidemiological modelling. The estimates demonstrate a significantly higher ppy inpatient-day utilization in LS than in CS. Our findings on the relatively high resource utilization in the late stage of AIDS resemble results of US-studies on health-care resource utilization in the late stage of any disease [323-326]. In 1961 it was assessed that hospitalization costs of adults who died in that year were 3 times those of survivors [327]. Lubitz and Prihoda [328] found that 5.9\% of: Medicare insured (primarily elderly) patients who died in 1978 accounted for $27.8 \%$ of total Medicare expenditures. In general, ppy costs in the final year of life are 6.8 times those for patients who were alive at the end of the year, ranging from 5.2 to 10.3 times depending on the underlying cause of death [290,291,329]. Hospital inpatient days ppy exhibit a similar factor of 6.8 on average. Up to $80 \%$ of costs in the final year of life appear in the final 6 months of life (for example, in 1988 ppy Medicare expenditures in the last half year of life were 11.1 times ppy expenditures excluding the last 6 months). Therefore, severity staging as applied to AIDS is probably relevant to other diseases as well. Furthermore, our severity-staging can easily be extended to other diseases since it is relatively straightforward, based on time distance to the point of death.

Several studies have registered decreasing trends in ppy hospital inpatient days $[220,286,289]$. It has been shown that an important factor for explaining these trends is a shift in the severity mix in favor of CS if survival increases. Extending our model backwards gives ppy impatient days for the pre-1990 period, as an example the year 1986 


\section{Chapter 8}

is elaborated here (Fig 8.4). In 1986 the patient group with one year average survival dominated and ppy inpatient days is estimated at 67 for the EU as a whole. Fig 8.4 reflects modelled response of ppy inpatient days to an ongoing increase in survival from 1 year in 1986, 2 years in 1995 to three years in 1999 in scenario $T$. The country-specific resulis of our severity-staging model are in line with the reported trends in the Netherlands and the UK $[220,286,289]$. Similar mechanisms can be assumed for other countries als well (Spanish results are shown in Fig 8.4 as well).

Fig 8.4 Model-based trends in hospital inpatient days per person-year: back-projected (1986), estimated (1995) and projected (1999) in scenario $T$ (see text) for three countries and the EU as a whole

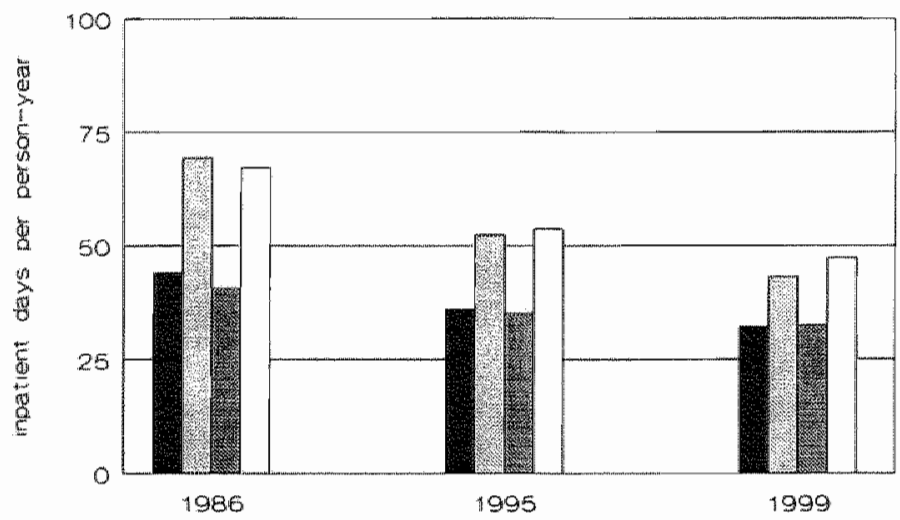

\subsubsection{Comparative Analysis}

To compare the scenarios in this paper with our previously published projections [218], our current estimate of 54.5 ppy inpatient days in the EU in 1990 is substituted into the previous methodology. This would have produced a bed need of 3700 in 1990 and projections for 1995 ranging from 3800 to 5000 . Our current estimates for those years are sightly higher for 1990 (3900) and significantly higher for 1995 (8200). Our previous approach to estimating person-years was based on the assumption that each AIDS case prevalent at the end of the year accounts for the whole of the respective year. Our current approach involves specific estimates of person-years for incident patients, patients who were prevalent during the whole year and for mortality. In addition, the correction for under-reporting of AIDS cases was undertaken for the current scenarios only, increasing the estimated prevalence by $18.5 \%$ for the whole EU in 1990 and 1995 . These two 
factors together can explain the slight increase for 1990 . The major explanation for the significant difference in 1995 is a drastic change in epidemiological projection, previously showing a decrease in AIDS incidence to a low level in 1994 and 1995. Based on more recent AlDS incidence data [84], our current estimate shows an increasing or levelling AIDS incidence in the period 1990-1995, corresponding to a current AIDS prevalence estimate for 1995 of 48500 . This is $66 \%$ higher than the maximum estimate (29 300) in [218]. Obviously, there are still several factors causing under-estimation of the future health-care impact. The recent (1993) extension of the AIDS case definition to include pulmonary tuberculosis will increase the number of new AIDS cases. Furthermore, resource needs for pre-AIDS stages were not included, which might become more important if prophylactic treatment preventing the onset of AIDS becomes increasingly effective. Though the AIDS stage is certainly the most resource-demanding stage, further work should include multi-national research into resource needs of pre-AIDS stages.

In three scenarios hospital bed needs in 1999 are projected to increase by up to $57 \%$ compared to 1995 . This corresponds to $0.40 \%$ in 1995 and up to $0.65 \%$ in 1999 of all EU-beds currently available [330]. Even in scenario U, reflecting the unavoidable future burden of AIDS on hospital care in 1999, a growth in hospital care needs of over $20 \%$ is indicated compared to 1995 . Associated to survival improvements, the share of outpatient contacis in total hospitall contacts is projected to rise from $28 \%$ to $31 \%$ in scenario $T$. The validity of such results is significantly extended by the severity staging used in this paper. Employment of this concept enables dynamic modelling of important model parameters, such as ppy inpatient days. Time-distance to the point of death has been used as the severity indicator. The relevance of this indicator for health care utilization and costs has long been recognized in the analysis of patient-based data across all diseases [290,291,323-329]. It has been used here to analyze the impacts of one specific disease on the health care systems. The indicator can obviously only be measured ex-post, and cannot be used to stage individual, living patients. In the scenario analysis presented, the ex-post measurement proved to be useful and feasible, because historical data on resource utilization developments preceding death were available for individual patients, and because future AIDS prevalences and mortalities could be described by an epidemiological model. 


\subsubsection{Further Application of the Multi-national ADS-model}

Our method involves the extrapolation of average results for France, Greece, Italy, Netherlands, Spain and the UK to Belgium, Denmark, Germany, Ireland and Portugal. One could question the representativeness of our selected countries for the rest of the EU. The share in total person-years of the six EU-countries included in the scenario analysis is $84 \%$ of the whole EU in 1990 , with an expected increase to $89 \%$ in 1999 . The potential imipact on the whole EU of the countries without resource utilization information is therefore only limited. For the "unknown" part of the EU, Germany constitutes $50.75 \%$ of the person-years of AIDS. As an alternative the situation where ppy hospital resourceneed parameters in LS and CS applied to neighboring countries is considered. Generally, this lowers the resource needs by approximately $10 \%$ in $1990,6 \%$ in 1995 and $4 \%$ in 1999 for both hospital beds and outpatient contacts. The decrease of this percentage in time supports the robustness of our EU scenarios based on data from six countries. In two of these six countries data were available from one hospital only to describe the national situation. As has been shown for France [292] great differences between hospitals exist, implying that our estimates for Spain and the UK might not be representative. Further research involving more hospitals, is needed in these countries. Therefore, one should conceive the absolute level of our scenario results with great caution.

Our baseline set of three scenarios projects the future course of hospital care needs based on the most recent analyses of survival patterns and standardized multinational information on resource utilization. Recently, preliminary evaluations of new antiretroviral combination triple-therapy have given rise to speculations on drastic improvements of survival and corresponding prolongation of the chronic stages of HIV/AIDS [11]. The actual effect on survival is as yet highly uncertain and the effectiveness will depend on other factors, such as the acceptance, availability, patient and doctor compliance and costs of the new therapy. In particular, the costs are considered to be relatively high - approximately 15000 ECUs per year of combination triple-therapy. However, significant cuts in HIV/AIDS hospitalizations in consequence of the new therapy have been suggested [331] and might impact on hospital resource needs for HIV/AIDS in the EU. This impact will involve structural effects due to increases in HIV/AIDS prevalence and transient effects due to the sudden introduction of the new therapy. In particular, a transient drop in hospital resource needs might currently take place because of the delay in progression to the resource-intensive late stage of AIDS. A similar phenomenon was previously observed when pre-AIDS AZT/zidovudine treatment 


\section{Eurapean ALDS Scenarios}

was introduced in the early 1990s [92]. At the moment the standardized information to estumate the full impact on resource utilization patterns and costs is lacking, in particular at the multinational EU-Jevel. As our scenario analytic design specifies the relevant purameters involved in the impact of the new therapy, it does provide the setuing for a what-if investigating into this impact on the short-term. Table 8.3 shows a range for the change in hospital bed needs in 1999. assuming extensions of HIV/AIDS survival due to combination triple-therapy of 3 and 5 years. As a first variant, ppy impatient days estimates for the chronic AIDS stage (CS) are used for the years gained by the new therapy. As chronic-ALDS-stage's figures might not be representative lower levels of ppy impatient days are included, in line with reported levels for pre-AIDS stages [95]. Tabulated calculations singgest that a larger number of patients will be alive and in treatment than the reference scenario indicates, bed needs vary between levels of plus $15 \%$ and minus $35 \%$ of the reference scenario. Momentarily, these indicative results are investigated in depth by using the French and UK databases $[286,2921$. As assessments of the cost-effectiveness of new therapies is becoming more and more the vogue [31], our reference scenario is crucial in providing the point of cleparture to measure the impact of the new combination triple-therapy.

Table 8.3 Potential cansequences of combination triple therapy in 1999: percentage changes in HIVIALS prevalence and bed needs compared to the reference scenario

\begin{tabular}{lllllll} 
Survival increase & \multicolumn{3}{c}{3 years } & \multicolumn{3}{c}{5 years } \\
Irpatient-day needs & $100 \%$ & $50 \%$ & $25 \%$ & $100 \%$ & $50 \%$ & $25 \%$ \\
& & & & & & \\
Prevalence & $+50 \%$ & id & id & $+69 \%$ & id & id \\
Bed needs & $+14 \%$ & $-15 \%$ & $-30 \%$ & $+18 \%$ & $-19 \%$ & $-37 \%$
\end{tabular}

Different assumptions refer to therapy-related increases in HIV/AIDS survival of 3 and 5 years with inpatient-day needs similar (100\%) to those in the chronic AIDS stage or lower (50 and $25 \%$

The scenarios on the health-care impact of AIDS presented provide information that can be used to support health-policy decisions in the field of AIDS. First, scenario results give an order of magnitude of future health-care needs in terms of total hospital beds, outpatient contacts and the patient-mix to be cared for. In addition to hospital capacity planning, the nulti-national EU-scenarios also provide background information for the further planning of EU AIDS research and prevention programs. At the national level and even at lower levels, the scenarios provide an indication of the change in 


\section{Chapter 8}

severity-mix that can be expected within total hospital need for AIDS patients, which under certain circumstances has been shown to vary significantly and which can pose new management tasks. International comparison has further made clear that future analyses, either at the national or at lower levels, must account for severity-mix in order to avoid bias in any projections. Future research work could further refine the staging-mechanism in case of AIDS, and would certainly require to continue, extend and validate the national databases used. This paper has presented scenario information for health policy making at the EU-level and at the national levels on the case of AIDS. It is also obvious that comparable information on other diseases which are in the special focus of EU policy, such as cardiovascular diseases and cancer, is lagging behind as compared to the information now available for AIDS. 


\section{Chapter 9}

\section{Hospital Care for Persons with AIDS in European Union Countries; a cross-country comparison}

This chapter is based on Hospital Care for Persons with AIDS in Greece and the Netherlands; fasessment of curmient and future impact by MJ Poscma, H Kormarou, V Paparizos, R Leid, K Tolley, J Kyriopualow, JC

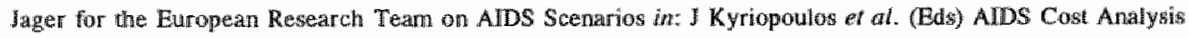
and Patient Classufication (in press) 


\section{Chapter 9}

\section{Abstract}

This paper investigates AIDS hospital care in selected European Union (EU) countries. In particular, hospital resource utilization in multi-hospital registrations in France, Greece, Italy, the Netherlands, Spain and France is analyzed. Baseline hospital resource wtilization is estimated for hospital inpatient days and outpatient contacts, using a standardized approach controlling for severity stages of AIDS. These estimations are linked to standard models for epidemiological estimation and projection, in an incidence-based approach. Respective estimations are compared between countries and related to characteristics of the national HIV/AIDS epidemics and health care systems. These country-specific results are underlying a set of projections for the EU as a whole (published elsewhere previously).

A person with AIDS (PWA) has some kind of contact - inpatient day or outpatient visit - with the hospital in 14\% (UK) to $24 \%$ (France) spend in the AIDS stage. Estimated hospital bed needs for AIDS in 1995 are up to $2.13 \%$ (Spain) of total national acute-care hospital beds available. Estimated per-capita needs for outpatient visits in 1995 are highest in Itally, corresponding 108 doctor full-time equivalents. In line with per-capita epidemiological impact, per-capita hospital resource needs for AIDS are limited in the Netherlands and the UK.

For Greece and the Netheriands, differences in hospital resource utilization patterns are in line with differences between both health care systems (number of hospital beds, doctors and nurses per capita and some qualitative characteristics of medical care in both countries). In general, international comparison of AIDS hospital care is possible using standardized data analysis of national hospital resource utilization studies and standardized epidemiological modelling.

\section{Context}

This study has been performed for the European Research Team on AIDS Scenarios, that exists with in the framework of the European Union Concerted Action on "Multi-national AlDS Scenarios" (project-leader: Johannes C Jager $\mathrm{PhD}_{\text {; }}$ co-ordinator economic aspects: Maarten J Postma MSc). The study has been performed in the framework of this Concerted Action (BIOMED contract no PL941723) and the European Union Project on "AIDS Cost Analysis and Patient Classification" (project-leader: Prof John E Kyriopoulos). SH Heisterkamp $\mathrm{PhD}$ is acknowledged for statistical advice. 


\section{Cross-country Comparison}

\subsection{Introduction}

In 1993, a European Union (EU) Concerted Action of the Biomedical and Health Research programme started for the development of multi-national assessment of the epidemiological, economical and social impacts of A.IDS on society [111]. The paticipants in the EU-CA represent expertise in the fields of modelling, statistics and operations research, surveillance and epidemiology, health economics and health-services research, social sciences and scenario analysis; furthermore they represent most EU-countries. The standardized approach of analyzing available national information on thealth-care resource utilization, as has been developed in a parallel EU-project [66], is the starting point for the economic impact assessment in the EU-countries. In addition, standardized surveillance and modelling of the national HIV/AIDS epidemics is needed, since epidemiology is the focus of any assessment of the national burden on health care resources [210]. Much work has been done in this field in the past years, and the development of advanced standardized methods is progressing [20].

Country-specific results have been aggregated to a multi-national economic impact assessment for the EU as a whole [114]. For example, we showed that AIDS hospital inpatient care involves an estimated $0.40 \%$ of all available inpatient beds in the EU. Underlying this multi-national estimate of EU-totals for current hospital-care needs are country-specific estimates for the majority of the EU-countries. In this paper results from selected databases on AIDS hospital care in six European coumtries are presented. These databases were selected out of a total of almost 30 studies on hospital care in European countries. Elaborating on these data, this paper addresses the direct comparison of AIDS care in six EU-countries. The standardized approach chosen to work with these data enables valid comparisons to be made of hospital care for persons with AIDS (PWAs) between countries. The first part of this study presents these type of results on hospital inpatient days and ambulatory hospital care for six EU-countries (France, Greece, Italy, Netherlands, Spain and UK).

Furthermore, the standardized approach allows the identification of "real factors" of health-care systems determining AIDS care, such as the number of hospital beds. occupancy rates "numbers of doctors and nurses and organization of inpatient/outpatient care. Therefore, the second part of this study, addresses a selected comparison of AIDS care in two countries. As a comparison was previously made for Greece and the Netherlands in the context of the EU-project on "AIDS Cost Analysis and Patient Classification" (co-ordinate at the National School of Public Health, Athens Greece), 


\section{Chapter 9}

these two countries are chosen. Also, Greece and the Netherlands have similar AIDS epidemics on seweral aspects (PWAs per capita, predominantly homosexual patient population), whereas health-care systems differ on warious aspects. In consequence - in a quasi-experimental design - we study rather similar epidemics in different health-care systems.

\subsection{Data}

In the framework of a previous [108] and the current EU Concerted Actions (see above) a methodology was developed and applied as a standard approach for epidemiological estimations in all European countries. AIDS surveillance data of the European Centre for the Epidemiological Monitoring of AIDS (Paris) as of March 31 th 1994 according to the 1987 AIDS surveillance case definition were used as an input for this approach [84]. To calculate AIDS survival an exponential distribution with a mean survival of two years in the AIDS stage was used [14].

National studies were selected for extracting relevant information on hospital care. Studies are selected according to specific criteria. Since studies that extend over several years show a decreasing trend in per person-year hospital impatient days utilization $[220,289]$ a first criterium for selecting information for scenario analysis was recentness. Secondly, they should include data that can be supposed to be reasonably representative of the national situations. Therefore, preferably information should come from multi-hospital studies. Thirdly, the resource utilization registration of selected studies should be patientbased, enabling linkage of resource utilization to individual patients and patient groups according to, for example, illness, severity and health slatus. The studies satisfying most of these criteria are summarized in Table 9.1. Utilization figures refer to the period 1990-94. Baseline hospital services utilization was estimated for inpatient days and outpatient contacts (outpatient visits and day-care days). 
Table 9.1 Selected studies an hospital resource utilizarion: country, references, estimanion periad, number of hospitals involved and number of persoms with AIDS (PWAS) in the study (Source: (114))

Country and reference

France $[281,292,293,307]$

Greece $[282,283,308-310]$

Itally $[65,311]$

The Netherlands $[32,270]$

Spain $[312]$

UK $[286,313]$
Period

1992-13

1990-91

1994

$1991-92$

$1990-93$

1990-91
Hospitals

PWAs

1384

101

264

182

97

122

Baseline hospital care utilization was expressed per person-year and severity stage. Previously for the Netherlands, we have developed a further staging of the AIDS-stage intio a possibly long chronic (early) substage and a short (maximally a half year) late terminal substage 2701 . This staging is relevant to account of differences in severity of illness. Intensity of hospital inpatient days utilization in the late stage appeared to be almost four times that in the chronic stage. Furthermore, more than half of the lifetime hospitalization costs are generated during this final half year in the late stage. Similar findings are reported in the the American literature [271-273]. For example, one study shows that hospitalization costs in 1990-91 for PWAs rise sharply in the final six months prior to death up to $\$ 23000$, compared to below $\$ 7000$ in other sixmonthly periods [273]. For outpatient hospital costs, the US study shows a slight drop in the late stage of AIDS, which is in line with a relatively high involvement of inpatient care in terminal care.

In consequence of this, studies with completely different distributions over late and nonbate (chronic) stages of PWAs are likely to report completely different ppy hospital impatient resource utilization. Neglecting this phenomenon could lead to serious errors and biases in estimating hospital resource utilization and hence in scenario analytic projections. [322]. We have therefore chosen to adopt the further staging of AIDS in this paper as well. In the progression-of-disease model for the AIDS-stage we differ between a period lasting for a maximum of a half year before death (late stage; LS) and the foregoing period (chronic stage; CS). Estimated ppy hospital resource utilization is used as a proxy for resource needs, implicitly assuming that recorded resource utilization reflects the actual care needs. 


\section{Chapter 9}

\subsection{Methods}

An incidence-based approach was applied to derive lifetime person-years in the AIDS stage and to link epidemiologic and hospital-care data. Illustrating this approach, lifetime hospital inpatient-day needs can be derived from our estimates of per person-year (ppy) resource needs in the chronic stage (CS) and late stage (LS) - respectively ppyIPD ${ }^{C S}$ and ppyIPD ${ }^{L S}$. If $\lambda$ reflects the parameter of the exponential distribution for AIDS survival it can be proved that the expected value of the lifetime number of inpatient days is

$\exp (-\lambda / 2) / \lambda^{*} p p y \| P^{C s}+((1-\exp (-\lambda / 2)) / \lambda)^{*} p^{*} p y I P D^{L *}$

The formula expresses that the expected durations in both chronic and late AIDS stages are multiplied with the appropriate ppy inpatient-days needs. As mentioned, in this study results were evaluated for a total survival in both AIDS stages of $(1 / \lambda=2$ years.

In the next step, lifetime hospital resource needs of PWAs are linked to estimated AIDS incidence for 1995. The incidence-based approach used for estimating hospital care impact involves a straightforward multiplication of annual incidence and lifetime resource needs. In this paper hospital resource needs are evaluated on the basis of AIDS incidence; an alternative would be to use HIV as a starting point. The incidence-based approach doesm't show actual annual burdens of care, it is favoured in situations where all resource needs associated with the incidence of the base-year are to be expressed.

The two-stage-model (CS and LS) introduces statistical variability in resource needs. Let:

$$
\begin{array}{ll}
\mathrm{D}^{\mathrm{LS}}=\mathrm{T} \text { and } \mathrm{D}^{\mathrm{CS}}=0 & \text { if } \mathrm{T} \leq 0.5 \text { years } \\
\mathrm{D}^{\mathrm{LS}}=0.5 \text { and } \mathrm{D}^{C S} \neq 0 & \text { if } \mathrm{T}>0.5 \text { years. }
\end{array}
$$

$D^{L S}$ and $D^{c s}$ reflect durations of stay in respectively late and chronic stages. Associated variance for lifetime inpatient days is:

$\operatorname{Var}\left(D^{c S}\right)^{* *}\left(p p y \int P D^{C s}\right)^{2}+\operatorname{Var}\left(D^{L S}\right)^{*}\left(p p y\left[P D^{L S}\right)^{2}+2^{*} \operatorname{Cov}\left(D^{c s}, D^{L S}\right)^{* *} p p y I P D^{c s *} p p y I P D^{L S}\right.$.

Here, $\operatorname{Var}\left(D^{C S}\right)$ and $\operatorname{Var}\left(D^{L S}\right)$ reflect the variances of durations of stay in LS and $C S$ and 


\section{Cross-country Comparison}

$\operatorname{Cov}\left(D^{\infty}, D^{15}\right)$ reflects the covariance of both durations of stay ${ }^{3 i}$ :

$\operatorname{Var}\left(D^{\infty}\right)=(2 * \exp (-\lambda / 2)-\exp (-\lambda)) / \lambda^{2}$

$\operatorname{Var}\left(\mathrm{D}^{2}\right)=\left(1-\exp (-\lambda)-\lambda^{*} \exp (-\lambda / 2)\right) / \lambda^{2}$;

$\operatorname{Cov}\left(D^{\infty}, D^{L S}\right)=\left(\left(0.5^{*} \lambda-1\right) * \exp (-\lambda / 2)+\exp (-\lambda)\right) / \lambda^{2}$.

Confidence intervals for hospital inpatient-day meeds of a cohort of incident PWAs result from applying the Central Limit Theorem. An example is presented in chapter 8 for the Netherlands [322]. Such confidence limits are elaborated for a range of 1995incidences of PWAs (normality assumption on ranges reported in [84]). For example, the $95 \%$-confidence limit for French incident PWAs in 1995 is 6193-7684. Finally。95\%confidence limits are approximated for country-specific total hospital inpatient-day needs ${ }^{32}$.

To allow valid comparisons between countries and with EU-averages, hospital resource needs are presented per million population $[332]^{33}$.

\subsection{Results at the EU-level}

Figure 9.1 shows country-specific expected lifetime hospital resources for a PWA during the expected two years survival in the AIDS stage. Italy, the Netherlands and the UK have comparabie inpatient-days amounts of $70-80$ on a lifetime basis. In Italy however, inpatient days reflect the minority of total lifetime hospital contacts, whereas in the other two countries outpatient involvement is below $40 \%$ in the total number of hospital contacts. In Greece the share of outpatient care is even above $80 \%$. The lowest shares of outpatient care are found in France and Spain. All countries are similar in showing up a low outpatient involvement in the late stage of AIDS; Greece has a rather low hospital involvement in LS in general. The distribution of lifetime inpatient days over chronic and

3) The variance-formulas follow straightforward using the general relationship between the expectancy and variance of a variable $X(E[X]$ and $V$ ar $[X]$, respectively): $\operatorname{Var}[X]=\mathrm{E}\left[X^{2}\right]-\mathrm{E}[X]^{2}$.

similarly, 95\%-confidence limits for lifetime AIDS person-years and outpatiemt-contact needs are derived.

${ }^{30}$ Inpatient dlays are transformed to hospitai beds using an occupancy rate $85 \%$ \% $[1144$. 
late AIDS stages is approximately fifty-fifty for all countries, despite the relatively short duration of the latter stage (an expected 0.44 years in the late stage compared to an expected 1.56 in the chronic stage).

Vig. 9

Expected liferime hospital resources for a PWA in six Earopean countries: inpatient days in the chronic sage (black) and late stage (dark-grey); aupatient contacis in the chronic stage (light-grey) and late stage (white); the sum of inpatient days and oupatient contacts reffect total hospital contacts and represents the intensity of hospitalpatient interaction

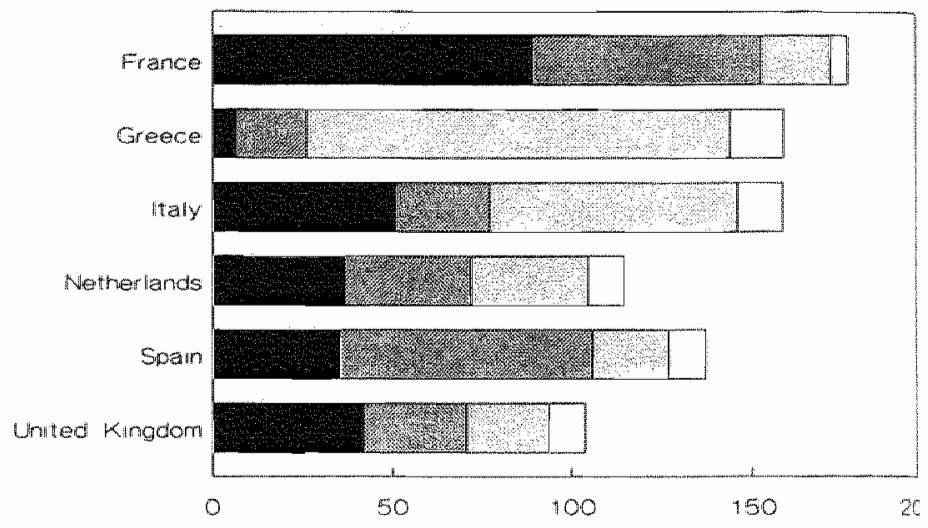

The assumptions indicate that an incident PWA has some kind of contact - an inpatient day or an outpatient contact - with the hospital in 14\% (UK) to $24 \%$ (France) of the days spent in the AIDS stage. These percentages are around the estimated EU-average of $20 \%$ for the incident PWAs in 1995 [114].

Hospital bed needs for 1995-incident PWAs range from almost 80 per million population in the upper 95\%-confidence limit in Spain to only a few in Greece (Fig 9.2; left axis). Rankings of countries are generally in line with epidemiological impact; for example, both countries showing the highest hospital bed needs per million population (Spain and France) also have the highest estimated lifetime person-years per million population related to 1995-incident. PWAs (95\%-confidence intervals are 366-462 and 213-258, respectively). Contradicting epidemiological impact are Italian and Greek estimates. Italian hospital bed needs are less than half of the French, whereas lifetime person-years per million population almost similar (95\%-confidence interval for lifetime person-years of 197-246): Greek hospital bed needs are disproportionate small compared to its epidemic (95\%-confidence interval 28.9-60.5). Furthermore, Italian and Greek outpatient 


\section{Cross-cowtiry Comparison}

contacts are higher than expected on the basis of epidemiological impact (Fig 9.2; right axis). Expressed in rankings, outpatient contacts in Italy are in first rank, whereas lifetime AIDS person-years rank after Spain and France; outpatient contacts in Greece rank third only surpassed by Italy and Spain -, whereas lifetime AIDS person-years rank last.

Fig 9.2 Hospital beds (left bars; left axis) and outpatient contacts per million popularion (righ bars: righ axis): expected values (grey), lower (black) and upper (white) 95 -confidence limis

0
0
0
0
0
0
0
0
0
0
0
0
0
0

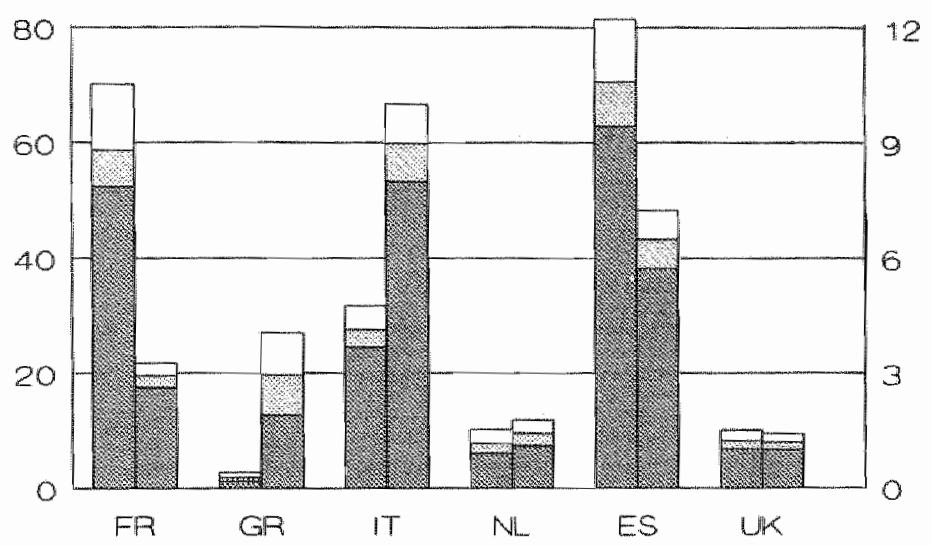

Summarizing, Italy and Greece seem to have relatively low bed needs and high needs for outpatient involvement. Hospital resource-need patterns in the other countries are in accordance with what would be expected from epidemiological impact. For example, we note a high similarity in Dutch and UK resource-need patterns, corresponding to a similarity in lifetime AIDS person-years per million population of 1995-incident PWAs (confidence intervals are respectively 51.6-82.8 and 60.1-84.7).

\subsection{Comparing AIDS Care in two Selected Countries}

This section illustrates AIDS hospital care in Greece and the Netherlands. These countries have quantitatively comparable AIDS epidemics (limited for EU-standards) and similar types of epidemics with the majority of AlDS-cases coming from the homosexual riskgroup, with approximately $25 \%$ of the cases attributed to other transmission groups than the homosexual group in both countries [84]. Therefore, we can elaborate upon the developments of two comparable AIDS epidemics in two very different health care 


\section{Chapter 9}

systems. The Greek system resembles the UK. National Health Service in covering and financing health care costs. Hospital care is provided through public and private (33\%) hospitals, with the latter type involving high co-payment, shorter stays and higher quality of care. The Dutch health care insurance is a mixed system of social and private health insurance funds. Finally, the Dutch have a much higher density of inpatient care beds per capita than the Greek have $[333,334]$. In fact, both studies provide a quasi experimental design for comparing hospital care utilization in two different health-care systems.

As shown (Fig 9.1), lifetime hospital inpatient days are significantly higher in the Netherlands, than in Greece, whereas outpatient contacts exhibit the opposite pattern. Referring to the quasi-experimental design underlying these figures and the standardized approach in calculating them, we could speculate on and analyze the differences between both countries. In general, differences in hospital management of PWAs between both countries may be related to factors associated with the health-care systems and with factors of epidemiological nature. To start with the latter, 60 of the 101 PWAs in the Greek hospital database are visitors of the hospital specialized in dermatology. Almost all of these visitors are homosexual men with a high occurance of complaints and treatment related to Kaposi's sarcoma (KS). The treatment of KS has a relatively high outpatient involvernent with drug administering, blood testing and transfusion. PWAs treated for Pneumocystis carinit pneumonia (PCP) in this hospital had 110 outpatient contacts ppy. versus 150 for PWAs treated for other - primarily KS - conditions. Furthermore, inpatient days show the opposite pattern: 99.9 days ppy for PWAs treated for PCP and 22.3 for non-PCP PWAs. So, AIDS manifestation form influences results.

The most striking difference between hospital-care systems in Greece and the Netherlands concerns the number of inpatient beds per capita; the Dutch level more than doubles that of Greece - approximately 11.5 versus 5.1 in 1990 [335]. Although the Greek multim hospital study refers to the Athens region (Attica) with a $15 \%$ higher bed density than average [336], this difference could be one of the explanations for the lower ppy inpatient-days utilization for AIDS in Greece. Furthermore, the Greek system has a large share of the private for-profit sector in the provision of hospital care, whereas in most other EU-countries - for example, the Netherlands - all hospital beds are not for profit. In Greece, approximately one third of the hospital beds belong to the for-profit sector, leaving only 2.7 public not-for-profit hospital beds per 1000 population. The thigh co-payment required in private hospitals, together with high quality and comfort in these hospitals have caused great inequallities and accessibility problems in hospital care [337]. In particular the latter, might also have contributed to low inpatient hospital utilization 


\section{Cross-country Comparison}

compared to other $\mathbb{E U}$-countries.

The relative scarcity of nurses in Greece (approximately 2 per 1000 population versus 6.0 in the Netherlands) and the low occupancy rate of hospital beds (Greece 55$65 \%$; the Netherlands $73 \%$ ) are also in line with low levels of inpatient hospital care utilization for AIDS in Greece compared to the whole EU-spectrum, and the Netherlands in particular [338-340]. However, Greece has one of the highest number of doctors in the EU (appriximately 3.5 per 1000 population versus 2.2 in the Netherlands), which is a possibie factor for high levels of hospital outpatient care [341]. Whereas in the Netherlands the General Practitioner is the "gatekeeper" to hospital care almost all Greek doctors are specialists and a "gatekeeper" is lacking [335]. A programme to develop primary health centres was executed in the 1980 s in rural areas, but the plan to build urban centres was postponed and the outpatient facilities of public hospitals are still performing the primary care in urban centres, such as Athens. As a consequence, doctors in urban outpatient facilities see many patients with sometimes only a very short visit for, for example, prescribing drugs only [342-345]. These features of the Greek and Dutch systems are in accordance with a higher outpatient share in total hospital care in Greece.

\subsection{Discussion and Conclusions}

Table 9.2 shows expected hospital bed needs represented as percentages of national total acute care hospital beds available. This percentage ranges from $0.05 \%$ (Greece) $102.13 \%$ (Spain). In terms of inpatient care AIDS is estimated to have posed a significant managerial challenge to Spanish hospitals. Also for France, a share of AIDS care in inpatient hospital care of more than one percent is estimated. Itally comes up with a share of only a half percent. On the other hand an estimated 108 full-time equivalents of specialists ${ }^{34}$ are needed to provide the outpatient hospital care for Italian AIDS patients. Lalian specialist time for outpatient hospital care represents half of estimated specialist time for outpatient care in the six selected countries together (222 full-time equivalents ${ }^{34}$ ).

The importance of severity stages for AIDS have been pointed out previously for survival, costs and prospective financing $[118,314,316]$. Our operationalization of the concept of severity in chronic and late stages (CS and LS) has been chosen to suit the

34 Based on an assumed duration of an outpatient hospital contack of 20 minutes and 200 working days per year for one full-time equivalent. 
Tablle 9.2 ADS hospital bed needs in 1995 as percentage of national total numbers of acute care hospital beds available [45]

$\begin{array}{ll}\text { Prance } & 1.26 \% \\ \text { Greece } & 0.05 \% \\ \text { Italy } & 0.51 \% \\ \text { The Netherlands } & 0.19 \% \\ \text { Spain } & 2.13 \% \\ \text { UK } & 0.40 \%\end{array}$

outcomes of epidemiological modelling and to be in line with resource-utilization studies that have been set up in six EU-countries. We have previously shown the importance of AIDS severity stages for analysing AIDS resource-utilization databases and for constructing relevant future scenarios [322], for example, hospital bed needs could be overprojected for Greece by upto $25 \%$ if the severity-mix concept were not applied. The estimates presented demonstrate a fifty fifty contribution of hospital impatient days for chronic and late stages, despite the relatively short duration of the latter (just over one quarter of the former). Furthermore, as it can be assumed that the intensity-of-care in terms of nursing, specialist consultations and drugs is higher for an LS-irpatient day than for a CS-inpatient day, the implication for AIDS hospital costs is that the majority of these will be spend on late-stage PWAs. Furthermore, we have observed that our rankings of country-specific hospital resource needs are generally in line with epidemiologic impact, however in Italy and Greece rankings change due to relatively high outpatient involvement in AIDS hospital care.

We conclude that international comparison of AIDS care is possible using standardized methods for health-care data gathering and epidemiological modelling. Illustrated by a comparison of Dutch and Greek figures, we showed that differences can be explained considering characteristics of the health care systems. It is yet not possible to draw strict policy conclusions from our comparison of Greek and Dutch AIDS care, for example in the sense that it miglat be useful for Dutch authorities to consider the option of more outpatient care, or for Greek authorities to consider easing the access to inpatient care. Further research is needed and health effects of AIDS hospital care should be considered as well. Explanation of any differences between survival times between Greek and Dutch patients would then certainly need a more detailed standardization for the diagnostic case mix than applied here. Therefore, future research would certainly require to continue and compare the national databases used, extend the number and level-of-detail of analyses and validate their representativeness for the national situation. 


\section{Chapter 10}

\section{General Discussion and Main Conclusions}

This chapter is partly based on book contributions:

1C. Jager, MJ Postma, K Tolley, J Kennelly: Assessment of the Bocio-econonic Impact of AWS; from Dathonal towards multinational scenarios. Im: D Fitzsinons; V Hardy, K Tolley (Eds) The Economic and Social Impact of AIDS in Furope. London: Cassell 1995, pp 40.53.

MI Postma, H Kornarow. V Paparizas, R Leid, K Tolley, J Kyriopoulos, JC Jager tor the European Research Tearn on ADS Scenarios: Hespital Care for Persons with AIDS in Greece and the Netherlands; assessment of current and furture impact. In: I Kynopoulos (Ed) ALDS Cost Analysis and Patient Classification (in press). 



\subsection{The Objectives Revisited}

This thesis addresses the economic impact of HIV/AIDS in the Netherlands and the European Union (EU) as a whole. It provides descriptions of methods to link epidemiological modelling to economic information for scenario analysis on AIDS impacts. The chapters refer to different methodological and empirical estimation issues. First, methods to estimate parameter values for models of AIDS economic impact are treated (chapters 3 and 4) as indicated in one of the objectives of this thesis. Second, methodological aspects of linking population-dynamical and statistical epidemiological modeis and economic information are dealt with in chapters 4,5 and 7 , with explicit consideration given to resource utilization and costs in different stages of the disease. Also, chapter 7 addresses quality criteria for economic impact studies attributing to the development of the Standardised Costing Framework for HIV/AIDS hospital care. For planning purposes, potential future trends in the epidemic have been translated into health-care resource needs and corresponding costs at the national (chapters 5 and 9) and EU-level (chapters 4,8 and 9). Chapter 6 deals with a requested application of the AIDS-impact model for policymaking, estimating the impact of AIDS on life insurance. The comparability of AIDS impacts on hospital resource utilization in different countries and with other diseases is treated in chapter 9 and the Annex of this thesis. Some issues surpassing the level of an individual chapter are stressed in the current concluding chapter. These issues relate for example to checking resource-need projections for years that have yet gone by, broadening the hospital costing viewpoint to other health-care sectors, policy implications of the scenario work (at the national and EU-levels) and methodological aspects of linking epidemiological models and economic information (incidence-based versus prevalencebased impact calculus). This final chapter concludes with evaluating all the objectives in the same order as presented in chapter 1.

\subsection{Disease-staging and Cost-standardization of HIV/AIDS}

Previously, doubts have been expressed about the quality of published estimates of the costs of HIV/AIDS hospital treatment and care produced for EU-countries $[66,218]$. The explicit use of a standardised framework for cost estimation would help improve the quality of methods in studies on resource utilization and costs and enhance the comparability of cost estimates produced. This maximises their usefulness for a range of reseanch 


\section{Chapter 10}

and policy purposes at the local, national and multi-national levels. Within the Standardised Hospital Costing Framework (SHCF) features of good quality studies are defined and these have been applied to EU-studies on hospital costs. Features of good quality refer to representativeness, the possibility of disaggregation, producing homogeneous cost groups: and adherence to elementary standards of cost-of-illness studies. The SHCF is not intended to be a prescriptive instrument. It is used retrospectively for reviewing existing cost studies and can be prospectively used for helping in the development and conduction of new cost studies. The framework represents a combination of good costing practice and technical standards for cost estimation. An important area with uncertainty about the best method to employ is the choice of the patient classification system for HIV/AIDS stages (for example, CDC-stages, CD4-cell counts, viral load, AIDS-defining diagnoses or stages derived from variation in health-care resource utilization) [346]. Whatever classification is used, if it is to be useful for prospective financing and projection of health care it should reflect severity of illness, as this has been found to be the major indicator of variation in health-care resource utilization [347].

Profiles on hospital inpatient days utilization during the AIDS-stage show that a major part of health-care resources are utilized in the terminal phase. This is an important finding with respect to the previous section in that hospital resource utilization and cost studies ought to be standardized according to the patient distribution over terminal and non-terminal phases. The empirical approach chosen differentiates two substages: the final half year of AIDS preceding death (late stage) and the foregoing period (chronic stage). As illustrated in this thesis, hospital inpatient days utilization and hospital costs in the late stage are several times those in the chronic stage. Next to the need for standardizing the patient population, chapter 7 convincingly shows the importance of disease-staging for providing valid future projections under a range of assumptions. In particular in the situation of HIV/AIDS with rapid medical developments and related improvements in survival, neglection of disease-staging is shown to overproject hospital bed needs and costs by almost $15 \%$ over a period of five years into the future. Of course, further improvements in projection might be attained by distinguishing more than two substages.

Obviously, this staging concept is also relewant for other diseases. As studies from the US showed, ppy health-care costs and hospital discharges in the last year of life amount to approximately seven times those in other stages of disease. Gathering comparable information and developing similar methodology on diseases such as respiratory disease, cardiovascular disease and cancer, is needed and could benefit policy decisions in these fields. For example, Koopmanschap et al. illustrated the importance of choosing an 
appropriate disease-staging for constructing future scenarios on Dutch cancer costs [348]. They introduce three stages: an incidence phase, an intermediate phase and a last year. Their analysis shows that - under specific assumptions - a prevalence-based model neglecting disease-stages might overproject cancer costs in 2005 by up to $20 \%$. Although the disease-stagings for cancer and HIV/AIDS are still rather crude in only accounting for the major dynamics in disease progression, the type of conclusions reached are rather similar: neglecting disease-staging might significantly misproject health-care resources and costs in future scenarios. Staging of disease for economic reasons can follow different strategies, depending on purpose, disease characteristic and data availability; they typically have to be developed, motivated and tested just as any other analytical concept in economic evaluation and costing.

\subsection{Linking Epideniology and Economics}

Results of epidemiological models and economic information can be linked prevalencebased or incidence-based to assess and project health-care resources and costs. Traditionally, health economic research uses two basic methods for expressing the economic impact of disease, labelled incidence-based and prevalence-based methods [40]. The first concerns accounting lifetime health-care resources to the year of incidence of disease (see chapters 7 and 9). The second method concerns an annualization of these lifetime healthcare resources (see for example, chapters 5 and 8). To cover the full economic impact of a healch-care intervention, it is necessary to analyse the lifetime consequences for resource needs incurred by a representative case. This incidence-based approach does however assume that the future health-care technologies will remain the same as in the analysis, and also extends all other assumptions up to the time until the last incident case has been dealt with. If the assumption of everything staying equal holds true for the period of analysis, and if the full economic impact is what is being referred to in a decision context (for example, in decisions on prevention investments/budgets), the incidence-based approach is the more appropriate one. If on the other hand, the budget impact of a health-care technology is the focus of analysis, and if this impact is expected to change with new treatment technologies, then the prevalence-based approach, applied over a well-defined period of analysis, will be more appropriate to support decisions on the economic side. With respect to the full economic impact both methods are myopic. On the short-term however, the incidence and prevalence-based approaches may differ 
ewen when applied to the same epidemiologic data set. As an example, the recent introduction of Highly Active Antiretroviral Therapy (HAART) in HIV treatment may serve. On the short-term HAART seems to cause major improvements in health and related cuts in hospitalizations. As a consequence, prevalence-based assessment for budgetting purposes one or two years ahead indicates reductions in hospital budgets for HIV/AIDS care [349]. However, resource-intensive and costly late stages of HIV/AIDS are merely shifted a few years ahead and on a lifetime basis costs will rise, also because HAART is quite expensive. An incidence-based approach would typically show the latter development, whereas a prevalence-based approach might focus on the short-term cost reductions only. In consequence, implications drawn for health policy might differ depending on the approach and presentation used. Obviously, the framework for linking epidemiology and economics should encompass the possibility of using both types of assessments and projections. The developed framework in this thesis satisfies this condition. Finally and completing the developed framework, confidence intervals and sensitivity analyses have been elaborated for various aspects (for example, per personyear monetary costs of AIDS and the duration of stay in the AIDS-stage).

\subsection{Dutch Scenario Results}

At the time we performed the Dutch AIDS scenario study (chapter 4) reliable national data on hospital resource utilization for the new disease HIV/AIDS were lacking [350]. During the 1990s the coding of HIV/AIDS hospital care has become integrated in the routine daily hospital administration [351]. Over $99 \%$ of Dutch hospitals contribute to the national hospital register of SIG Health Care Information (Utrecht). In 1993, hospital inpatient days for HIV/AIDS as primary diagnosis amounted to 20600 for AIDS and 2300 for the pre-AIDS stages (codes 042 for AIDS, 043 for AIDS Related Complex and 044 for other HIV). The estimate for hospital inpatient days in 1993 amounts to 39900 for AIDS and 5400 for the pre-AIDS stages (chapter 5). Using more recent information that possibly better reflects hospital practice in the 1990s, the figure for AIDS was updated to 30100 in chapter 9 . An important drawback for comparing the estimation and the registration involves the classification systems used, that do not entirely match. The estimates are based on the AIDS surveillance case definition, whereas the national registration applies the 9 th revision of the International Classification of Diseases. Because the AIDS surveillance case definition includes slightly more disease complicati- 
ons than code 042 of the Classification of Diseases does, there is probably a better match if an unknown part of the inpatent days in the national register with AIDS as additional diagnosis were included. The national figures for HIV/AIDS as any (primary or additiomal) diagnosis were 60000 , including 54200 days for ADS. The combined estimate of chapters 5 and 9 of 35600 inpatient days is now inbetween the nationally registered figures for HIV/AIDS as primary and as any diagnosis. This suggests that the estimates are in line with the national hospital registration. In consequence, the extrapolation of results of individual Dutch hospital studies seems to provide valid results for the nationa! lewel. Furthermore, this extrapolation methodology has a major advantage when applied to other countries and the EU as a whole (chapters 8 and 9). Many other European countries lack an accessible national hospital register and hospital impact must necessarily be based on individual hospital studies.

In order to provide an indication of the monetary costs that are involved with the figures on hospital care one can elaborate on Dutch estimates of the costs of a hospital inpatient day, a hospital outpatient hospital visit and a day-care hospital contact that are available for 1990 [35]. Since then these costs per contact have increased due to price increases of inputs in hospital care - for example, salaries and investments in new technologies - and to increases in the care-intensity of a hospital contact - for example, the number of procedures during an inpatient day or outpatient contact [352]. Corrected for price increases due to both factors the respective cost figures in 1995 ECUs are 328 (inpatient day) and 125 (outpatient contact; including day care) ${ }^{34}$. Multiplication with the respective number of days and contacts results in 13.9 million ECUs, corresponding to $0.18 \%$ of the 1995 national budget for hospital care. This figure roughly corresponds to what was projected in chapter 5 for AIDS-related inpatient and outpatient hospital care in 1995 in one of three scenarios presented.

Combining the statistical methodology elaborated in chapter 9 and the monetary cost estimates of table 5.2 enables the estimation of lifecime hospital costs. In chapter 7 this type of calculation was used to motivate the application of a staged instead of a nonstaged model, here we estimate the lifetime costs persé. In the reference sceriario, as defined in chapters 8 and 9 for the Netherlands, lifetime hospital costs amount to 43850 ECUs (95\%-confidence interval for an individual PWA: $2260-107700$ ECUs). This figure underestimates the total lifetime hospital costs per person for groups of HIV-

34 To transform the 1990 cost level to the 1995 level a nominal growth factor of 1.24 and a factor for intensity-of-care increases of 1.10 is used 1352]. For the exchange of Dutch guilders $(f)$ into ECUs an exchange rate of 1 ECU equals $f 2.12$ is used. 
infected persons who survive longer than 2 years in the AIDS stage. Lifetime pre-AIDS hospital costs can be derived straightforward from chapter 5 to amount 23100 ECUs. In an overview on the economic impact of AIDS in Europe, Jager et al. [107] provided an extension of the Dutch scenarios on hospital impacts to other sectors of health care. For patients in the pre-AIDS stages they estimated cosis per person-year (ppy) of 120 ECUs for the GP and 4120 ECUs for early AZT-treatment (500 mg/day), during respectively 7 and 1 years in average. For PWAs these ppy costs amount to 280 ECUs for the GP, 605 ECUs for home care (district nurse), 615 ECUs for home help and 375 ECUs for the nursing home. Elaborating on the expected lifetime hospital costs, total lifetime healthcare costs would be 75700 ECUs. So, on total lifetime health-care costs the share of non-hospital costs is estimated to be relatively small with only $12 \%$. In future projections of the total health-care costs it was however shown that the share of home care grows in all scenarios investigated. This is a consequence of epidemiological developments solely, and the Dutch government policy of substifuting home care for hospital care might be expected to sharpen this trend. In order to adequately monitor developments in the costs: of HIVIAIDS it is necesary to set up a patient-based monitoring system in home care that is analogous to the one already existing in the hospital sector.

\subsection{Extension of EU-results on Hospital Care}

For the EU-level this thesis focusses on the impact of the AIDS-stage on the hospital resource needs (chapter 8) and hospital costs (chapter 4). Tolley et al. [276] provide some details from a review of EU cost studies published between $1985-1995$. It was possible to make comparisons of inpatient and outpatient costs and to a limited extent of day-care costs, by AIDS and pre-AIDS stages for a number of EU-countries $[95,353,354]$. This review enables the update of the EU cost figures in chapter 4 to reflect the 1999 monetary cost projection. For this purpose, costs have been transformed from original price year and local currency to 1993 ECUs, using country-specific health-care expenditure price indices and the latest available health-care-specific purchasing power parities [355]. Resulting hospital costs ppy in the period 1988-1.992 are between 20-40 thousand ECUs for AIDS patients across a range of EU-countries. In combination with the various scenarios this range indicates total hospital costs in 1999 to vary between 1.1 and 3.4 billion ECUs, compared to the baseline level around 0.8 - 1.6 billion ECUs in 1993. If the upper limit were the actual figure, 1999 hospital costs would reflect over $1 \%$ of the 
current health-care expenditure of all EU-countries. One should realize though that these future projections don"t include any trends in ppy hospital cosits.

Whereas utilization has declined over time in the late eighties and early nineties in all studies and countries for which trend data are available, any changes in hospital costs ppy have been far less dramatic $[62,65,153,285,286-288]$. Possible explanations are that the intensity of care and unit costs of resources have increased and more expensive medications have been introduced. For example, the recent introduction of antiretroviral combination triple therapy involves relatively high costs of approximately 15000 ECUs per year [356]. However, as a consequence of the new therapy, cuts in HIW/AIDS hospitalizations have been reported in Los Angeles, New York and France [357-359]. Another study shows that benefits of averted hospital care might even surpass the incremental costs associated to the new therapy [360]. The calculations in chapter 8 on hospital bed needs for the EU after widespread introduction of triple combination therapy indeed show that significant reductions in prevalence-based calculated bed needs might result. As mentioned, it can be assumed that the costly (late) AIDS-stage is merely postponed and not prevented, and lifetime hospital bed needs and costs per HIV-infected person increase.

Tolley et al. [276] indicate that hospital costs are between 2 thousand (asymptomatic HIV in the UK in the period 1987-1989) and 10 thousand (symptomatic HIV in Spain in 1990) ECUs ppy for pre-AIDS stage patients, corresponding to $5 \%$ and $40 \%$ of the corresponding AIDS figures. In particular, levels of ppy inpatient days are significantly lower for the pre-AIDS stages, whereas the outpatient hospital utilization levels for AIDS and pre-AIDS stages are quite similar. For example, in one French study outpatient visits equal in both stages at approximately seven ppy [281]. Jager et al. [107] extended the preliminary scenario results of chapter 4 to encompass some of the indirect costs as well. In particular, they focus on the potential years of life lost (PYLL) due AIDS deaths. PYLL provide a proxy of indirect costs of HIV/AIDS in the EU, as a monetary value of the life years lost has not been estimated. Using an annual incidence-based procedure, they estimated the number of PYLL at the end of the century to range between 203800 and 520500 . As illustrated by a number of studies $[144,361,362 \rrbracket$ and for some selected EU-countries, PYLL for AIDS has surpassed those due to other infectious diseases and is in the order of magnitude of those due to suicide and road accidents. Recently, a possible doubling of PYLL up to the year 2000 in the Netherlands compared to the 1990-level has been indicated by Jager et al. [111]. It is shown that PYLL due to AIDS approaches those of diabetes, several types of cancer and chronic respiratory disease. 


\subsection{Impact of Scenario Analysis on Health-care Policies}

The scenario analysis for HIV/AIDS in the Netherlands influenced the development of healin-care policies at the national and the international level. At the national level, the summary and recommendations of the Scenario Study [101] were passed through to the delegates of the Dutch Lower House to serve in the discussions on AIDS-policies in 1992 [363]. A specific request referred to an advise on the global cost-effectiveness of the national budget of 944000 ECUs for campaigns and projects to prevent the further spread of HIV within the Dutch population [364]. Discounting the lifetime hospital costs per HIV-infected person at $5 \%$ per year for 14 years between infection and death, it may be argued, from an economic point of view, that such budget would start to be cost-effective if more than approximately 20 new infections would be prevented on an annual basis. This seems quite feasible. Moreover, if the indirect costs of HIV infection were taken into account, one could qualify the budget as cost-effective with even fewer new infections prevented required. Thus there was an economic argument in favour of the present prevention budget unless of course the budget could be spent on another disease prevention area that has a better cost-effectiveness ratio.

In chapter 6 the request for a study on the impact of AIDS on life insurance was discussed. Also, some economic analyses in HIV prevention and treatment drew on work performed in the Scenario Study. For example, cost-effectiveness of HIV combinationtherapy after percutaneous exposures of Dutch medical personell was calculated at $f 20300-88600$ net direct costs per life-year gained [365]. The study suggests a sharpening of indication to improve cost-effectiveness. Furthermore, in 1990 a study on the evaluation of HIV screening among pregnant women in Amsterdam was started. One of the goals of the study was to investigate the cost-benefit ratio [366]. Benefits were thought to occur through possibly preventing the birth of an HIV-infected child and associated health-care costs, if an HIV-infected pregnant woman decides to terminate pregnancy. Costing figures derived from the Scenario Study were used. At present, an evaluation study of HIV-screening is much more complex since several new factors have proven to affect both the vertical transmission probability and the costs, such as AZT/Zidowudine treatment during and after pregnancy, breast-feeding versus formula feeding and an elective ceasarian section. Furthermore, early detection of HIV-infection through screening and early uptake of antiretroviral treatment might also have beneficial effects on the progression of HIV in the mother. To cover these recent developments and insights a model has been developed and a first application to England has been elabora- 
ted [367-370].

From the start of the Dutch Scenario Study, it was the objective to build a scenario analytic approach that could easily be extended to foreign situations [100]. Therefore, the methodology of the approach and the illustrative results for the Netherlandls have often been highlighted at international conferences. Furthermore, the Dutch Scenario Team was involved in meetings of several working groups of the EU and the World Health Organization on the economic impact of AIDS $[109,110,303,304,371]$. National study groups from Greece, Spain and France were advised on scenario construction for their respective countries [274,372-374]. In addition, future projects on the costs of ADS in France and Belgium were drawn up with explicit reference to our scenario methodology $[374,375]$. During 1993 the finalized Dutch Scenario Study and related publications were crucial for being assigned with the grant for multi-national AIDS scenarios (EU-grant PL941723 of DG XII). A preliminary version of chapter 8 of this thesis was integrated in the final report of another EU-project in DG V [95]. As illustrated in Chapter 9 of this thesis, the standardized scenario analytic approach enables international comparisons. So in consequence, a monitoring system of AIDS impacts in Europe has been developed that addresses the wide range of epidemiology, economic aspects and societal responses. The importance of such a system was stressed by the Council of Europe in 1992, in order to enable a proper timing of rapid reaction procedures to new emerging dewelopments in the HIV/AIDS epidemic, treatments and care [376]. More recently, a similar argument was published Vaccine [377]. Finally, during the international AIDS Conference in Vancouver the need for standardized procedures on performing economic impact assessments to help health-care policy development was stressed [378].

The studies on AIDS scenario analysis in this thesis, provide an example of scenario analysis in infectious diseases. As infectious diseases exhibit their characteristic dynamics, extension of the "traditional" cost-of-illness approach is motivated in his thesis. This extended approach is labelled dynamic cost-of-illness assessment. Combining this approach with scenario analysis - where a set of different assumptions on core-parameters is investigated - provides the basis for cost-effectiveness analysis in infectious disease prevention and treatment [379]. Above, examples on cost-effectiveness analysis of HIVscreening in pregnant women and post-exposure HIV prophylaxis were mentioned. Examples of the extension of the approach to other infectious diseases refer to screening for Chlamydia trachomatis [380-382] and Infuenza vaccination [383-385]. Scenario analysis has already been mentioned as an integral part of cost-effectiveness [31], and this 


\section{Chapter 10}

seems to be true in particular for infectious diseases. Other specific features of costeffectiveness analysis in infectious diseases illiustrated in this thesis refer to the linkage with a model for the spread of the disease and the importance of sound costing figures on lifetime and per person-year basis. Ultimately, this thesis seeks to attribute to the development of guidelines for cost-effectiveness in infectious diseases $[386,387]$.

\subsection{Main Conctusions}

Guidelines should be applied for the estimation of HIV/AIDS-related personal health-care costs, allowing valid comparisons between studies performed at different times and settings by different researchers. (objective 1 ; chapters 3 and 7)

In general, there is a need for a standardized approach to cost-of-illness studies to increase the comparability of studies. (objective 2; chapters 4 and 7 )

The choice of an appropriate disease-staging averts structural biases in projections of hospital care and costs. (objective 3; chapters 5,7 and 8)

Estimates of the resources and costs of hospital care for HIV/AIDS can be used for planning at the national or multi-national level if a standardized/generic approach in epidemiological modelling, data-gathering and severity-staging is applied. (objective 4; chapters 3 and 4 )

In the Netherlands, ppy hospital costs in the late stage of CDC IV are almost threefold those in the chronic CDC-IV stage. Lifetime costs from the time of HIV-infection onwards are estimated to amount 76000 ECUs, hospital costs constitute almost $90 \%$ of this figure. (objective 5; chapters 5 and 9)

Studies in several EU-countries show that utilization of hospital inpatient days in the careintensive late stage of AIDS is twice to tenfold that in the chronic stage. In most investigated countries total hospital contacts in the chronic stage are approximately half of those in the late stage. (objective 5; chapter 8)

Dutch scenarios demonstrate that approximately one quarter to a half percent of total 
hospital costs will be required for HIV/AIDS by the end of the century, a sizeable but probably manageable proportion. Cost projections in several scenarios indicate a range for AIDS hospital costs of 0.5 and $1.0 \%$ of total EU-expenditures on hospital care by the end of the century. (objective 6; chapters 3,5 and 10 ).

Hospital bed needs for AIDS in the EU will amount to $0.5 \%$ to $0.65 \%$ of all hospital beds available in the EU. Sensitivity analysis shows that new combination triple therapy mught lower the estimate for hospital beds by $20-30 \%$. (objective 6 ; chapter 8 )

Statistical confidence limits in combination with several scenarios on hospital bed needs for AIDS by the end of the century, indicate a range of $0.2 \%$ to $0.3 \%$ of currently available hospital beds in the Netherlands. (objective 6; chapters 5 and 9)

Projected hospital bed needs in the Netherlands for HIV/AIDS by the end of the century are limited compared to projections for coronary heari disease, stroke and diabetes. (objective 7; chapter 5 and annex)

Quantitative information on hospital care for AIDS indicates that it is organised differently in the various EU-countries, varying from high inpatient (France) or outpatient (Greece) involvements to a mixed organisation form (Netherlands). (objective 7; chapter 8)

Differences in AIDS care between two selected countries can be explained from differences in the respective health-care systems. (objective 8; chapter 9)

Scenario analysis on economic impacts of HIV/AIDS has influenced the development of health-care policies at the national - advise on life-insurance impact, planning and economic evaluation - and international level - advisory role in set-up of foreign AIDS scenario studies. (objective 9; chapter 6,9 and 10 )

The dynamic cost-of-illness approach for HIV/AIDS can be applied to other infectious diseases and therefore merely serves as an illustration for analyses in, for example Influenza and Chlamydia trachomaris. (objective 10; chapter 10)

The scenario analytic approach can be integrated in HIV/AIDS cost-effectiveness analysis 


\section{Chapter 10}

(objective 11; chapter 10)

In this thesis a dynamic cost-of-illness approach has been developed for HIV/AIDS. The approach esteems the importance of linking cost-of-illness with epidemiological modelling into future scenarios. Further, the relevance of disease staging in costing and scenario analysis has been demonstrated and deserves broad attention in the standardization of costing methods. Future research should be directed to the development of dynamic costeffectiveness analysis of treatment and prevention for infectious diseases. This type of research is currently in progress in both national and international initiatives $\llbracket 388,389]$ 
References 

1 Council of Ministers for Health of the Member States: Resolution of Meeting on the Fight against AIDS, December 22nd 1989. Off I Eur Communities 1990; 33:36. Rowira J: Economic Aspects of AIDS. In: D Schwefel, R Leidl, I Rovira, MF Drummond (Eds) Economic Aspects of AIDS and HIV Intection. Springer Verlag: Berlin 1990. Hodgson TA. Meiners MR: Cost-of-IIness Methodology; a guide to current practices and procedures. Milbank Memorial Quarterly 1982; 3:429-61.

Barre-Sinoussi F, Cherman JC. Rey F et al.: Isolation of a T-lymhotropic Retrovirus from a Patient at Risk for Acquired Immune Deficiency Syndrome (AIDS). Science $1983 ; 220: 868-71$.

Ciallo $\mathbb{R C}$, Salahuddin SZ, Popovic M et al.: Frequent Detection and Isolation of Cytopathic Retroviruses (MTLV-IIn) from Patients with ADS and at Risk for AIDS. Science $1984 ; 224: 500-3$.

6

Curran JW, Morgan WM, Hardy AM et al: The Epidemiology of AIDS; current status and future prospects. Science 1985; 229:1352-7. Acquired Immunodeficiency Syndrome. MMWR 1987; 36 (suppl 1S):1-15.

Centers for Disease Control: Acquired Immunodeficiency Syndrome (AIDS) 1987 Revision of CDC/WHO case Definition for AIDS. Wkly Epidewiol Rec 1988; 63:1-7.

Volberding PA, Lagakos SW, Koch MA et al.: Zidowudine in Asymptomatic Human Immunodeficiency Virus Infection; a controlled trial in persons with fewer than 500CD4-positive cells per cubic millimeter. NEJM 1990; 322:941-9.

0 Centers for Disease Control: Recommendations for Prophylaxis against Pneunocystis carinii Pneumonia for Adults and Adollescents Infected with Human Immunodeficiency Virus. MMWR 1992; 4I(RR4):1-11.

Baiter: New Hope in HIV Disease. Sckence 1996; 274:1988-9.

12 Buchbinder $S$, Hessol $N$, O Malley $P$ ef al: HrV Disease Progression and the Impact of Prophylactic Therapies (PROP) in the San Francisco City Clinic Cohort (SFCCC); a 13-year follow-up. Int Conf on AIDS, Flotence 1991, abstract WC42.

13 Hoover DR: The Effects of Long Term Zidowudine Therapy and Pneumocystis carinü prophylaxis on HIV Disease; a review of the literature. Drugs 1995; 49:20-36.

14 Bindels PJ, Poos MJJC, Jong JThL, Mulder JW, Jager JC, Coutinho RA: Trends in Mortality among AIDS patients in Amsterdam 1982-1988. ADDS 1991; 5:853-8.

15 Paltiel AD: The Human and Economic Costs of ADS Therapies. Risk in Perspective 1995; 34:10M-1.

16 Centers for Disease Control: Classification of HTLV-IU/LAV Infections. Annals of Internal Medicine 1986; 105:234-7.

$\| 7$ Centers for Disease Control: Classification System for HIV Infection in Children under 13 years of Age. MMWR 1987; 36:225-36.

18. Houweling $\mathrm{H}$, Coutinho RA: Acquired Immunodeficiency Syndrome. In: Oxford Textbook of Public Health. Oxford: Oxford University Press 1997.

19 Lumey HL, Houweling $H_{1}$ Jager JC: Noodzaak en Mogelijkheden wan Prevalenthe Onderzoek nar HV-infectie in Nederland. NTWG 1989; 133:923-7.

20 Jager JC. Heisterkamp SH. Brookmeyer R: ADS Surveillance and Prediction of the HIV and AIDS Epidemic: methodologgical developments. AIDS 1993; 7:567-S71.

21 Centers for Disease Control: Kaposi"s Sarcoma and Pneumocystis Pneumonia among Homosexual Men - New York City and Callornia. MMWR 1981; 30:305-8.

22 Centers for Disease Control: Pneumocystis Pneumonia-Los Angeles. MMWR 1981; $30: 250-2$.

23 Jager JC, Poos MUC, Postma MJ, Houweling H, Postema CA, Coutinlio RA: Prognoge 
arangaande HV infectie ten AIDS-epidemie in Nederland op Basis ran Wiskundige Analyge. $N T V G$ 1990; 134:2486-91. Bijkerk H: AIDS 1982-1988. NTWG 1988; 10:523-5. Inspectorate for Public Health: ADS in the Netherlands; report as of December 1996. Rijswijk: 1997. UNAIDS \& WHO: The HIV/AIDS Situation in MId-1996. Switzerland. UNAIDS 1996. AIDSCAP/Harvard School of Public Health/UNADS. The Status and Trends of the Global HIV/AIDS Pandemic. Int Conf on AIDS, Vancouver 1996. Manin $J$, Tarantola D: AIDS in the World II; the global AIDS-policy coalition. Oxford: Oxford University Presss, 1997. European AIDS Survelllance Data. In J Rovira \& F Antoñanzas (Eds) Proceedings of the Int Conf on the Econometrics of AIDS. Barcelona: University of Barcelond 1993. Anomymous: HIV/AIDS Survellance in Europe: 1994-1996 (Quarterly report no 49). Saint Maurice (France): European Centre for the Epidemiological Monitoring of AIDS 1.996.

31 Russel LB, Gold MR, Siegel JE, Daniels N, Weinstein MC: The Role of Cost-effectivemess Analysis in Health and Medicine. JAMA 1996, 276:1172-7.

32 Dijkgraaf MGW: Utilization of Hospital Resources and the Costs related to HIV Infection (thesis at the University of Utrecht, Netherlands). Amsterdam: Thesis Publishers 1995.

33 Drummond MF, Stoddart GL, Torrance GW (Eds) Methods for the Evaluation of Health Care Programmes. Oxford: Oxford University Press 1987.

34 MeGuire A, Henderson J, Mooney G: The Economics of Health Care. London: Routledge 1992. Rutten FFH, van Ineveld BM, van Ommen R, van Hout BA, Huijsman R: Kostenberekeming bij Gezondheidszorgonderzoek; richtlijnen voor de praktijk. Utrecht: Jan wan Arkel 1993.

.
Im: JC Jager, EJ Ruitenberg (Eds) Statistical Anallysis and Mathematical Modelling of AIDS. Oxford: Oxford University Press 1988.

Bilheimer L: AODS Cost Modelling in the US: a pragmatic approach. Heath Policy $1989 ; 11: 147-168$.

Bloom DE, Glied S: The Evolution of AIDS Economic Research. Health Policy 1989; 11 : $187-196$.

Drummond MF, Davies LM (Eds): Treating AIDS: the economic issues. Health Policy $1988,10: 1-19$.

Hartunian NS, Smart CN, Thompson MS: The Incidence and Economic Costs of major Health Impairments. Toronto (Massachusetrs): Lexington Books 1981.

Hardy AM, Rauch K, Echemberg D et al: The Economic Impact of the First 10000 Cases of Acquired Immunodeficlency Syndrome in the United States. JAMA 1986; 255:209-11.

2. Scitovsk AA, Cline M, Lee PR: Medical-care Costs of patients with AIDS in San Fransiswco. JAMA 1986; 256;3103-6.

Seatge GR, Landers $S$, Barry A et al:: Medical-care Costs of AIDS in Massachusetts. IAMA 1986: 256:3107-9.

Pascal A: The Costs of "Treating AIDS under MEDICAID: 1986-1991. Santa Monica: Rand Corporation 1987 .

5. Andrulis DP, Beers VS, Bentley ID, Giage LS: The Provision and Financing of Medical 
care for AIDS Patients in US Public and Private Teachüng Mlospitals. JAMA 1987: 258: $11343-6$.

Green J. Singer $M$, Winterfield $N$ : The AIDS Epidemic: a projection of its impact on hospitals 1986-1991. Washington DC: Committee on National Strategy for AIDS 1987. Cifford KA, luculano RP: AIDS and Insurance; the rationale for AIDS-related testing. Harwara Law Review 1987, 100:1817. Hay IW, Osmond DH, Jacobson MA: Projecting the Medical Cests of ADS and ARC in the United States. Journal of Acquired Immune Deficiency Syndromes $1988 ; 5: 466-85$ Bloom DE, Carliner G: The Economic Impact of AIDS in the United States. Science $1988: 239: 604-10$.

Hellinger FJ: Forecasting the Personal Medical-care Costs of AIDS from 1988 through 1991. Public Health Reports 1988; 3:309-19. Hellinger FJ: Forecasting the Medical Care Costs of the HIV Epidemic: 1991-1994. foquiry 1991;28:213-25. Hellinger FJ: Forecasts of the Costs of Medical Care for Persons with HIV: 19921995. Inquiry 1992:29:356-65.

Hellinger FJ: The Lifetime Cost of Treating a Person with HIV. JAMA 1993: 270:474. 8.

4 Scitonsky AA, Rice DP: Estimates of the Direct and Indirect Costs of Acquired Immunodeficiency Syndrome in the United States, 1985, 1986, 1991. Public Health Reports 1987; 102:5-1.7.

Johnson AM, Adler MW, Crown JM: The Acquired Immune Deficiency Syndrome and Epidemic of Infection with Human Immunodeficiency Virus: costs of care and prevention in an inner London district. $B M J 1986 ; 293: 489-92$. Debeaupuis J, Tcheriatchoukine I: Report on the Cost of Hospital Treatment for ADS. Paris: Inspectorate General of Social Affairs 1987.

Bez G: La Prise en Charge des Malades Infectes par le VIH: utilisation des structures hospitaliers et coût. Cah Socio Démo Méd 1989; 2:107-35. Borleffs JCC, Jager JC: Registratie en Kastenschatting wan Kilinische en Poliklinische Werkzammeden yoor patiênten met HIV-infectie. NTVG 1989; 133:767-72. Koock-Walewski A: Was kostet ADS? Eine Kosten-Leistungs-Analyse stationärer Fälle. Stuttgart: Schwer Verlag 1989. Wiggers CCMC, Bijlsma PRE: Kosten van Ziekenhuishehandeling van ADDS patiènten in het AZUA/AMC in de periode 1982-1988. TSG 1989; 67:227-31.

1 Bijlsma PRE: The Costs of Hospital Care of AIDS patients at the Teaching Hospital of the University of Amsterdam. In: D Schwefel, R Leid!, J Rovira, M Drummond (Eds) Economic Aspects of AIDS and HIV Infection. Berlin: Springer-Verlag 1990. Postma MJ, Dijkgraaf MGW, Borleffs JCC, Reinking DP, Van den Boom FMLG, Jager JC: Ornwang en Kosten van Ziekenhitszorg voor HIV-geinfecteerden; vergelijking en integratie van Nederlandse studies voor scenariomanalyse. TS G $1992 ; 3: 189,96$. Wiggers CCMC, Bergsma EW: De Kosten van AIDS/HIV in Nederland lin 1988; een inventarisatle. Leiden (the Netherlands): NIPG-TNO 1990.

64 Wiggers CCMC. Bergsma EW: De Kosten wan
Ecomomisch Statistische Bertichten 1990; 592-5. Tramarin A. Milocchi $F$, Tolley $K$, Vaglia $A$, Marcolini F, Manfion $V$, De Lalla F: An Economic Evaluation of Home-care Assistance for AIDS Patients; a pilot study tha a town in Northern Italy. ADDS $1992 ; 6: 1377-83$. and AIDS; development of a standardlued framework for Europe. Health Policy 1993; 
24:55-70.

67 Hassig SE, Perriens J, Baende J et al.: An Analysis of the Economic Impact of HTV Infection among Patients at Mana Yemo Hospital, Kinshasa, Zaire. AIDS 1990; $4883-7$.

Over M. Bertozzi $\$$, Chin J $t$ al.: The Direct and Indirect Cost of HIV Infection in Developing Countries; the cases of Zaire and Tamzania. Int Conf on AIDS, Stockholmi 1988, abstract 9595 .

69 Jackson H. Mhambi K: AIDS Home care;a baseline surwey in Zimbabwe. Jownal of Social Development in Africa 1992; no 3.

70 Foster S: The Cost and Burden of AIDS on the Zambian Health Care System; pollicies to mitigate the impact on health services. Report prepared for the Government of Zambia, USAID/John Snow Inc, 1994.

71 Jackson $\mathrm{H}$, Kerkhoven $\mathrm{R}$ : Developing AlDS carre in Zimbabwe; a case for residential community centres? ADOS Care $1995 ; 5: 633-73$.

72 Mann J, Tarantola DJM, Netter TW: AIDS in the World; a global report. Cambridge (Massachusetts): Harvard University Press 1992. Hanvelt RA, Ruedy NS, Hogg RS al.: Indirect Costs of HIV/AIDS Mortality in Canada. AJDS 1994; 10:F7-F11.

Castillo-Chavez (Ed): Mathematical and Statistical Approaches to AIDS Epidemiology. Lecture Notes in Biomathematics (vol 83). Berlin: Springer-Verlag 1989. Heisterkamp SH, Jager JC, Downs AM, Van Druten JAM, Ruitenberg EJ: Statistical Estimation of ADS Incidence from Surveillance Data and the Link with Modelling of Trends. In: JC Jager, EJ Ruitenberg (Eds) Statistical Analysis and Mathematical Modelling of AIDS. Oxford: Oxford Uniwersity Press 1988. Morgan WM, Curran IW: AlDS: Current and Future Trends. Public Wealth Reports $1986 ; 101: 459-64$.

77 Downs AM, Ancelle RA, Jager JC, Brunet J-B: AIDS in Europe: current trends and short-term prediction, estimated from routine survelllance data, January 1981-June 1986. ADS 1987; 1:53-57.

Downs AM, Ancelle RA, Jager JC, Heisterkamp SH, Van Druten JAM, Ruitenberg EJ, Brunet J-B: The Statistical Estimation, from Routine Surveillance Data, of past, present and future Trends in AIDS Incidence in Europe. In: JC Jager, EJ Ruitenberg (Eds) Statistical Analysis and Mathematical Modelling of AIDS. Oxford: Oxford University Press 1988.

Her Majesty's Stationary Office (HMSO): Future Trends in AIDS. London: HMSO 1987.

80 Brookmeyer R, Gail MH: Minimum Size of the Acquired Immunodeficiency Syndrome (AIDS) Epidemic in the United States. Lancet 1986; ii: 1320-2.

81 Brookmeyer R, Damiano A: Statistical methods for Short-term Projections of AIDS Incidence. Statistics in Medicine 1989; 8:23-44. Heisterkamp SH: Quantitative Analysis of AIDS/HIV; development of methods to support policy-making for infectious-disease control (thesis at the University of Luiden, Netherlands). Utrecht: Elinkwijk 1995. Hay JW: Econometric Issues in Modelling the Costs of AIDS. Health Policy 1990; 11:125-45.

84 European Centre for the Epidemiological Modelling of AIDS: Back-calculated Estimates of HIV Cumulative Incidence and Prevalence to December 31 st 1993 and Predicted Annual Numbers of AIDS Cases to 1998 among Adults and Adolescents. ANDS Survellance in the European Community and COST Countries 1994, quartely report no 32. 
Anderson RM: The Role of Mathematical Models in the Study of HIV Transmission and the Epidemiology of AIDS. Jounal of Acquired Immune Deficiency Syndromes $1988 ; 1: 241-56$.

$\$ 6$ Bailey NTJ, Estreicher J: Implications of Stochastic Variations in HIV/AIDS modelling. In: JC Jager, EJ Ruitenberg (Eds) Statistical Analysis and Mathematical Modelling of AlDS. Oxford: Oxford University Press 1988.

87 Dietz $\mathrm{K}$ : The Dynamics of Spread of HIV-lintection in the Heterosexual Population. In: JC Jager, EJ Ruitemberg (Eds) Statistical Analysis and Mathematical Modelling of ALDS. Oxford: Oxford University Press 1988.

88 Van Druten JAM. Reintjes AGM, Jager JC et $a l$ : HIV Infection Dynamics and Interwention Experiments in Linked Risk Groups. Statistic in Medicine 1990; 9:721736.

89 Griffiths JD, Wheeler KP: Modelling the Spread of ArDS. MA $J$ Math Appl MeddBiol $1993 ; 3: 54-75$.

90 Dangerfield B, Roberts C: A Role for System Dymamics in Modelling the Spread of AIDS. Trans Int MC 1989; $4: 189-95$.

91 Leidl R: Model-based Scenarios to Describe Economic Impact of AllDS: the role of the case-mix. In: D Schwefel, R Leid, J Rovira, MF Drummond (Eds) Economic Aspects of AIDS and HIV Infection. Springer Verlag: Berlin 1990.

92 Heisterkamp SH, de Haan BJ, Jager JC, Van Druten JAM, Hendriks JCM: Short-and. Medium-term Projections of the AIDSHIV Epidemic by a Dynamic Model with an Application to the Rusk Group of Homo-/bisexunl Men in Amsterdam. Statistics in Medicine 1992; $11: 1425-41$.

93 Lingren B, Silverberg R: Economic Burden of AIDS. In: MF Drummond, LM Davies (Eds) AIDS: the Challenge for Economic Analysis. Birmingham: Health Services Management Centre 1990.

94 Drummond MF, Davies LM: Topies for Economic Amalysis. In: MF Drummond, LM Davies (Eds) AIDS: the challenge for economic analysis. Birmingham: Health Services Management Centre 1990.

95 Tolley K, Gylldmark M: A Standardized Costing Framework for HIV/AIDS Hospital Care in the European Union. Nottingham: University of Nottinglham 1995.

96 Tolley K, Gyldmark M: Towards a Standardized Framework for Costing HIV and AIOS Treatment and Care in Europe. In: D Fitzsimons, V Hardy, $\mathrm{K}$ Tolley (Eds) The Economic and Social Impact of AIDS in Europe. London: Cassell 1995.

97 Jager $\mathrm{JC}$, van den Boom FMLG: Scenario Analysis, Health policy and Decision Making. In: EH Kaplan, ML Brandeat (Eds) Modelling the AlDS Epidemic: planning, policy and prediction. New York: Raven Press 1994.

98 OECD: Facing the Future. Paris: OECD 1979.

99 IIASA: Energy in a Finite World. Laxenburg (Austria): IASA 1980.

100 Brouwer J. Schreuder RF: Scemarios and other Methods to Suppont Long-term Health Planning: theory and practice. Utrecht: Jan van Arkel 1987.

101 Steering Committee on Future Health Scenarios: AIDS up to the year 2000. Dordrecht (Netherlands): Kluwer Academic Publishers 1992.

102 Postma MJ, Reinking DP, Albers CES, Var den Boom FMLG, Jager JC: De Gewolgen wan AIDS in Nederland tot het jaar 2000. Medisch Contact 1992; 47:653-6.

103 Reinking DP, Postma MJ, Albers CES, Van den Boom FMLG Jager JC." HIV/AIDS in the Netherlands up to the year 2000; impact assessment and fulure explorations by scenario analysis. In: I Kyriopoulos, H Kornarou, M Gitona (Eds) AIDS Economics: costs analysis, management and prospective financing. Athens: Exandas 1996. 
104 Beckman M, Leidl $R$; Mielck $A$, Salzinger $W$, Weber U; Szenarien für Soziale Folgen von AIDS. Munchem: GSF Forschungszentrum für Umwelt und Gesundheit 199\%. Hoogenveen RT, Brouwer JJ: Scenarios in de Volksgezondheid: inteiding in the methodiek wan de STG. Utrecht: Jan van Arkel 1989.

106 Kahn $H$, Wienier A: The year 2000. New York 1967.

107 Jager JC. Postma MJ. Tolley K, Kennelly J: Assessment of the Socio-economic Impat of AIDS: from mationall towards multinationall scenarios. $I m$ : D Fitzsimons, $V$ Hardy, $K$ Tolley (Eds) The Economic and Social Impiact of ADS in Europe. London: Cassell 1995.

108 Jager $\mathrm{JC}$, Ruitenberg EI: AIIDS Impact Assessment; modeling and scenario analysis. Amsterdam: Elseviers Science Publishers 1992.

109 Schwefel D, Leid R, Rowira J, Drummond MF (Eds): Economic Aspects of AIDS and HIV Infection. Berlin: Springer-Verlag 1990.

110 Drummond MP. Davies L (Eds) AIDS; the Challenge for Economic Analysis. Birmingham: University of Birmingham 1990.

111 Jager JC, Achterberg PA, Postma MJ, Howweling H: Comparative Impact Assessment of AIDS; between doornstlay and complacency. AIDS 1996; 10:238-40.

H2 Jager JC, van den Boom FM, Heisterkamp SH, Postma MJ, Reinking DP: Report on Planning Meting 25th-26th August 1994 Bilthoven, the Netherlands. RIVM: Bithoven 1994.

113. Bailey NTT, Heisterkamp SH: Preliminary Review on the Mathematical Models and Data used for the Baseline Amalysis. Report for the EU Concerted Action on Multinational Scenario Analysis Concerning Epidemiological, Social and Economic Impacts of HIV/AIDS on Society. Billthoven: RIVM 1995.

1.14. Postma MI, Tolley K, Leidl RM et al. for the European Research Team on AIDS Scenarios: Hospital Care fon Persons with AIDS in the European Umion. Health Policy $1997 ; 41: 157-76$.

115 Scitowsky AA: The Economic Costs of AlDS in the United States. Int Conf on AIDS, Paris 1986, abstract $\$ 24 a$.

116 Heseltine PNR, Meyer P, Appleman MD et al.: Economics and Health-care Requirtements of patients with LAV/HTLV-III (ARV) Related Diseases at a Large Municipal. Hospital. Int Conf on AIDS, Paris 1986, abstract 454.

117 Arno PS: The Non-profit Sector's Response to the AllOS Epidemic; community-based services in San Francisco. Int Conf on ALD, Paris 1986, abstract 463.

118 Johnson AM, Adler MW, Crown JM: Health Care Planning for the HTLV-IMLAV Epidemic in the British National Health Service. Int Conf on AIDS, Paris 1986, abstract 474.

119 Shere R, Joo E: The Cost of Hospitalization and Clinic Care for Patients with AIDS: and the AIDS-related Complex. Int Conf on AIDS, Paris 1986, abstract 710.

120 Andrulis DP. Pittrnann-Lindeman M: ADS and ARC treatments; costs and stafing characteristics at major teaching hospitals and urbam planning hospitals throughout the United States. Int Conf on AIDS, Paris 1986, abstract 711.

$12 \|$ Seage G, Landers $S$, Barry MA at al. Dired Costs of Medical Care for Patients with AIDS. Int Conf on AIDS, Paris 1986, abstract 712 .

122 Belmont MF, Manten JE, Spinak HB: Utilization of Resources by AIDS Patients in the Acute Care Hospital. Int Conf on AIDS, Paris 1986, abstract 715.

123 Hay JW, Osinond DH. Jacobson MA: Projecting the Future Medical Costs of AIDS in the United States. Int Conf on AIDS, Stockholm 1987, abstract 9578.

124 Griffiths A: Evaluating the Economic Impact of AIDS. Int Conf on AIDS, Stockhollm 1987, abstract 9579 . 
125 Winkerwerder $W$, Roper WL. Federal Covernment Spending on AIDS in the United States. Int Conf on AIDS, Stockholm 1987, abstract 9580.

126 Leidl R: Seenarios Linking Epidemiology and Economics; possible impacts of drug treatment of HIV-infected in the FRG. Int Cont on AIDS, Montreal 1989, abstract WHO16.

127 Freedberg KA, Cohen CJ, Cotton DJ, Tosteson ANA: Prophylaxis for Pneumotystis cariniti Pneumonia (PCP): a cost-effectiveness analysis. Int Conf on AIDS, Montreal 1989, abstract TBP 68.

128 Rowley J, Ng TW, Anderson RM: Some Economic Implications of Introducing Control Measures to Reduce the Spread of HIV Infection in sub-Saharan Africa. Int Conf on ADDS, Montreal 1989, abstract THO 16.

129 Jager IC. Poos MJJC, Postma MJ, Houwelling H, Postema CA, Coutinho RA: Short Term Scenarios on the Socioeconomic Impact of AIDS on Society. Int Conf on AIDS, San Francisco 1990, abstract FD121.

130 Jager IC, Poos MJJC, Postma MI, de Haan BJ, Heisterkamp SH, Reinking DP, Van den Boom FMLG: Use of Epidemiological Models for Socio-economic AIOS Impact Scenarios illustrated by analysis of data on the Netherlands. Int Conf on AlDS, Florence 16-21 June 1991, abstract TUDS8.

131 Postma MJ, Dijkgraaf MGW, Borleffs JCC et al.: Analysis of Economie Information for Impact Scenarios; illustration by application to the hospital. Int Conf: on AIDS, Florence 1991, abstract MD4262.

132 Reinking DP. Van den Boom FMLG, Albers CES, Postma MU, Jager JC. Scenarios on the Impact of the HIV/AIDS Epidemic on the Care System in the Netherlands Int Conf on AIDS, Florence 1991, abstract MD4259.

133 Jager JC, Van den Boom FMLG, Postma MJ et al.: ADS Scenario Analysis; general methods and applications to the Netherlands. Int Conf on AIDS, Amsterdam 1992. abstract PoD5842.

134 Postma MJ, Jager JC. Reinking DP, et al.: Economic Impact Assessment of AIDS; results for the Netheriands. Int Conf on ADDS, Amsterdam 1992, abstract PoD5772.

135 Reinking DP, Albers CES, Postma MJ et al. AIDS Prevention in the Netherlands; 1992-2000. Int Conf on AIDS, Amsterdiam 1992, abstract WeC1095.

136 Jager JC, Heisterkamp SH, Houweling $H$, Postma MJ, Reinking DP for the European Team on AIDS Scenarios: EU Concerted Action for Multinational Scenario Analysis on the Impacts of HTV/AIDS on Society (1994-1997). Int Conf on AIDS, Vancouver 1996, abstract ThD 4967.

137 Postma MJ, Leidl RM, Tolley $K$, Jager JC for the European Research Team on AIDS Sicenarios: Economic Impact Assessment of AlDS in the EU; Updated Scenarios on Hospital Care for the Year 2000. Int Conf on AIDS, Vancouver 1996, abstract TuD253.

138 Antoñanzas F Dijkgraf MCW, Santin M, Luijben A IIP, Borleffs JCC, Postma MI, Jager JC: A Comparative Study of Data Sets for HIV-related Hospital Resource Utilization in Spain and the Netherlands, 1990-1993. Int Conf on AlDS, Vancouver 1996, abstract ThD4968.

139 Tolley K, Gyldmark M, Postma MJ, Jager JC: A Standardised Costing Framework for HIV/AIDS Hospital Care in the European Union. Int Conf on AIDS, Vancouver 1996 , abstract TuD252.

140 Mann J AIDS Epidemiology, Impact, Prevention and Control; the World Health Organization perspective. ADS Public Health Pol $/ 1988,3: 10-3$.

141 Jager JC, Ruitenberg El (Eds): Statistical Analysis and Mathematical Modelling of AIDS. Oxford: Oxford Uniwersity Press 1988. 
142 Jager $J C$. Ruiterberg EJ: The Statistical and Mathematical Modelling of AMS. AWDS $1987 ; 1: 129-30$.

143 Heisterkamp SH, Jager JC, Downs AM et al.: Correcting Reported AIDS Incidence: a statistical approach. Statistics in Medicine 1989; 8:963-76.

144 Leidll R, Pogtma MJ, Poos MJC et al.: Construction of Socio-economic Impact Scenarios thased on routine AIDS survellance-data. Im: JC Jager, EJ Ruitenberg (Eds) AIDS Impact Assessment; modelling and scenario analysis. Ansterdam: Elsevier 1992.

145 Instifute of Medicine/National Academy of Sciences: Confronting AIDS; update 1988. Washington DC: National Academy Press 1988.

146 Schreuder R: Scenarios as a Tool to Support Health Planning and Management. In: D Schwefel, R LeidI, I Rowira, MF Drummond (Eds) Economic Aspects of AIDS and HIN Irtection. Berlin: Springer Verlag 1990.

147 Wiggers CCMC, Bergsma EW: The Costs of HIV in the Netherlands in 1988; a preliminary estimate. In: JC Jager, EJ Ruitenberg (Eds) AIDS Impact Assessment; modelling and scenario analysis. Amsterdam: Elsevier 1992.

148 KPMG Klynweld Bosboom. Hegener: Kosten en Meerkosten van Ziekenhuiszorg voor HIV Geinfecteerden. KPMG: Utrecht (Netherlands) 1989.

149 Gosselink $A$, Vandermeulen IJR: Dummy Rapportage ower de Uitkonsten van het Meerkosten-onderzoek AIDS-hulpverlening. Nederlands Ziekenhüs Instibunt: Utrecht (Netherlands) 1989.

150 Danner SA, Meenhorst PL, Paus W, Reiss P: Diagnostiek en Behandeling van Patienten met een HIV-infectie. Utrecht (Netherlands): Bohn, Scheltema \& Holkema 1989.

15] Dijkgraaf MGW, Jong JThL, Poos MJIC, Borleffs JCC, Jager JC: A Relational Database for Monitoring Hospital Activities, Costs of Care and Quality of Life rellated to treatment of HIV infection and AIDS. In: JC Jager, EI Ruitenberg (Eds) AIDS Impact Assessment; modelling and scenario analysis. Amsterdam: Elsevier 1992.

152 Jager JC, Postma MJ, van den Boom FMLG et al.: Epidemiological Models and Socioeconomic Information; methodological aspects of AIDS/HIV scenario analysis. I $n$ : D Schwefel, R Leidl, J Rovira, MF Drummond (Eds) Economic Aspects of AIDS and HIV Infection. Berlin: Springer-Verlag: Berlin 1990.

153 Borleffs JCC, Jager JC, Poos MJJC et al.: Hospital Costs for Patients with HIV Infection in a University Hospital in the Netherlands. Health Policy 1990, 16:43-54.

154 World Health Organization: Training Workshop on Scenario Building and Long-term Planning for AIDS. Madrid: September 19-21 1990.

155 Dijkgraaf MGW, Borleffs JCC, Poos MJJC, Jager JC, Schrijvers A P: Monitoring Hospital Resource Use and Cost: a three-and-a-half year follow-up. Int Conf on AIDS, Florence 1991, abstract MD112.

156 Scitovsky $A A_{\text {. }}$ Over M: AIDS; costs of care in the developed and developing world. ALS 1988, 2(suppl 1):S71-S81.

157 Hiat LA. Quesenbery CP Jr. Selby IV et al.: The Cost of Acquired Immunodeficiency Syndrome in Northerm California; the experience of a large prepaid health plan. Arch Intern Med 1990; 8;833-8.

158 Ministry of Welfare, Public Health and Culture: Financial Statement on Health Care. The Hague: Sdu Publishers 1991.

159 Dijkgrate MCW, van Weelderen J, Vrehen HM, Jager JC, Borleffs JCC: Monitoring the Growing Workload for the Treatment of Persons with ACDS (PWAs) in a University Hospital 1987-1990. ALDS $1992 ; 6: 433-5$.

160 Jager JC . Postma MJ, Leidl R, Majnoni d"Intignano B, Baert AE: AlDS Impaet Scenart- 
0s: questions for the years to come. AIDS 1990; 11:1166-7.

161 Anonymous: AIDS Survellance in Europe Quarterly Report No 32. Paris: WHO Collaborating Centre on AIDS, 1991.

162 Anonymous: AlDS Surveillance in Europe Quarterly Report No 23. Paris: WHO Collaborating Centre on AIDS, 989.

163 Bachetri $\mathrm{P}$ : Estimating the Incubation Period of AIDS by Comparing Population Infection and Diagnosis Patterns. J Am Stat Assoc 1990; 85:1002-8.

164 Bachetri P. Moss AR: Incubation Period of AllOS in San Francisco. Nature 1989 ; $338: 251-3$.

165 Rutherford GW, Lifson AR, Hessol NA et al: Course of HIV-l Infection in a Cohort of Homosexuall and Bisexual Men; an 11 year follow up study. BMJ 1990; 301:1 183-8.

166 Ward IW, Bush TJ, Perkins HA et at: :The Natural History of Transfusion Associated Infection with Human Immunodeficiency Virus; factors influencing the rate of progression to disease. NEJM 1989; 321:947-52.

167 Downs AM, Ancelle-Park RA, Costagliola D, Rigaut JP, Brunet J-B: Transfusionassociated ADDS Cases in Eunope; estimation of the incubation periond distribution and prediction of future cases. Journal of Accuired Immune Deficiency Syndrone 1991; 4:805-13.

168 Gorter RW, Vranizan K, Moss AR at al.: Progression of HIV Disease in Intravenous Drugy Users. Int Conf on AIDS, San Francisco 1990, abstract ThC644.

169 Medley GF, Anderson RM, Cox DR, Billard L: Estimating the Incubation Period for AlDS Patients. Nature 1988; 333: 504-5.

170 Goedert J, Kessler CM, Aledort LM et al.: A Prospective Study of HIV type 1 Infection and the Development of AIDS in Subjects with Haemophilia. NEJM 1989; $321 ; 1141-8$

171 Lee CA, Phillips AN, Elford J et al: Eleven-year follow-mp of an HrY-infected Haemophiliac Cohort. Int Conf on ADDS. Florence 1991, abstract MD3187.

172 McNeil A, Gore SM, Bird AG, Brettle RP: Progression to AIDS or ARC in the Edinburgh City Hospital Cohort. Int Conf on AIDS, Florence 1991 , abstract MC3142.

173 Schinaia $N$. Chiarotti F: Risk Factors for the Progression to AIDS in the ltalian Cohort of MIV-positive Haemophiliacs. Int Conf on AIDS, Florence 1991, albstract MC3131.

174 Rezza G, Lazzarin A, Angarano G et al: AIDS-free Time after Seroconversion in Injecting Drug Users and other Risk Groups. Int Conf on AIDS, San Francsisco 1990, abstract ThC647.

175 Darby SC, Doll $\mathrm{R}$, Thakrar B ef al. Time from Infection with HIV to Onset of AIDS in Patients with Haemophilus in the UK. Statistics in Medicine 1990; 9.681-9.

176 Blaxhult $A$, Granath $F$, Lidman $K$, Giesecke J: The Influence of Age on the Latency Period to AIDS in People Infected by HIV through Hood Transfusion. ARDS 1990; 4: $125-9$

177 Marriotto AB, Mariotti S. Pezzotti P et al: Estimation of the Acquired Immumodeficiency Syndrome Inculation Period in Intrawenous Drug Users; a comparison wilh male homosexuals. Am $J$ Epidemiol 1992; 135:428-37.

178 Taylor JMG, Kuo J-M, Detels $\mathbb{R}$ : Is the Incubation Period of AIDS Lengthening? Jownal of Acquired Immune Deficiency Syndrome 1991; 4:69-75.

179 Ragni MV, Kingsley LA, Zhon Si: The Effect of Antiviral Therapy on the Natural Mistory of Human Immunodeficiency Virus Imfection in Cohort of Haemophtiacs. Journal of Acquired Immune Deficiency Syndrome 1992; 5:120-6.

180 Peters BS. Beck EJ. Coleman DG et al.: Changing Disease Patterm in Patients with 
AIDS in a Referral Centre in the United Kingdom; the changing face of AIDS. BMS $1991 ; 302: 203-7$.

181 Lemp GF, Payne SF, Neal D at al.: Survival Trends for People with AIDS. JAMA $1990 ; 263: 402-6$.

182 Lafferty WE, Glidden D. Hopkins SG: Surwival Trends of People with AIDS in Wrashington State. Am J Public Health 1991; $81: 217-9$.

183. Moore RD, Hidalgo $J$, Sugland $B W$, Chaisson RE: Zidowudine and the Natural History of the Acquired Immunodeficlency Syndrome. NEJM 1991; 324:1412-6.

184 MeCullagh P., Nelder JA: Generalized Linear Models. London: Chapman and Hall 1983.

185 Heisterkanp SH, Downs AM, Poos MJJC: MIDAS; a PC-program for adjusting reported ADS data and short-term projections. In: JC Jager, EJ Ruitenberg (Eds) AlDS Impact. Assessment; modelling and scenario analysis. Amsterdam: Elsevier 1992.

186 Anonymous: AIDS Surveillance in Europe Quarterly Report No 29. Paris: WHO Collaborating Centre on ADDS, 1991.

187 Leld $\mathrm{R}$ : Konzeption, Eigenschaften und Arwendung eines Deterministischen Modells der HIV- und AIDS-Epidemie. In: W van Eimeren, K Ueberla, K Ulm (Eds) Gesundheit und Umwelt. Bertin: Springer-Verlag 1992.

188 Griffiths JD, Williams JE: Identification of Some Important Factors in Modelling the Spread of AIDS. I $n$ : IC Jager, EJ Ruitenberg (Eds) AIDS Impact Assessment; modelling and scenario analysis. A.msterdam: Elsevier 1992.

189 Cameron $C$. Tarantola $\mathrm{D}$ : The Costs of AIDS Care in the World, 1990. Int Conf on AIDS, Amsterdam 1992, abstract WeC1038.

190 Lambert J. Carrin G: Direct and Indirect Costs of AIDS in Belgium; a preliminary analysis. In: D Schwefel, R Leidl, J Rovira, MF Drummond (Eds) Economic Aspects of AIDS and HIV Infection. Berllin: Springer-Verlag 1990.

191 Hanpft $R$, Reinecke F, Beske F: Comparing Inpatient and Outpatient Costs for HIV, LAS and AIDS: Methodology, Results and Consequences from a Study in Germany. In: D Schwefel, R Leidl, I Rovira, MF Drummond (Eds) Economic Aspects of AIDS and HIV Infection. Berlin: Springer-Verlag 1990.

192 Hatzakis $\mathrm{A}$. Trichopoulos D: Methodological and Practical Issues in Estimating the Direct Cost of AIDS/HIV; Greece. In: MF Drummond, L Davies (Eds) AIDS: the Challenge for Economic Anallysis. Birmingham: Health Services Management Centre / University of Birmingham 1990.

193 Ginestal Gomez J: The Regional Costs of AIDS in Spain. In: D Schwefel, R Leidl, I Rovira, MF Drummond (Eds) Economic Aspects of AlDS and HW Infection. Berlin: Springer-Verlag 1990.

194 Rees M: Methodologicall and Practical Issues in Estimating the Direct Cost of ADS/ HIV; England and Wales. In: MF Drummond. L Davies (Eds) AIDS: The challange for Economic Analysis. Birmingham: Health Services Management Centre / University of Birmingham 1990.

195 Ward M: Punchasing Power Parities and Reall Expenditures in the OECD. Paris: Organization for Economic Co-operation and Developement 1985.

196 Organization for Economic Co-operation and Development (OECD): Health Data. (Datahase); wersion 1.01 . Paris: OECD 1991.

197 Gerdthan U-G, Sogaard J, Andersson F, Jönsson B: An Econometric Analysis of Healthcare Expenditure; a cross-section study of the OECD countries. Journal of Healih Economics $1992,1: 63-84$.

198. Anonymous: ADS Surwelllance in Europe Quarterly Report No 30. Paris: WHO Collaborating Centre on AIDS 1991. 
199 Downs AM, Ancelle-Park RA, Brunet J B: Indirect Estimation of the Prevalence of HIV Infection and Advanced HIV Disease in the European Community. Int Conf on ADS, Amsterdam 1992, abstract We1094.

200 Leid R: Oekonomisch Bedeutsame Folgen von ADS in der Bundesrepublik; werlorene Lebensjahre und Bedarf an Krankenhausbetten. Arbeir und Sozialpolitik 1990, 7:23843.

20: Organization for Econornic Co-operation and Development (OECD): Health Care Systems in Transition. Paris: OECD 1990.

202 Schneider M, Köse A, Scholtes L, Sommer JH: Gesundheitssysteme im Internationalen Vergleich (3rd Edition). Bonn: Ministry of Health 1991.

203 Hamilton JD. Hartigan PM simberkoff MS et al.: A Controlled Trial of Earty versus Late Treatment with Zidovudine in Symptomatic Human Immunodeficiency Virus Infection. NENM 1992; 7:437-43.

204 Paltiel AD, Kaplan EH: Modelling Zidovudine Therapy; a cost-effectiveness analysis. $J$ ALDS $1991: 8: 795-804$.

205 Anderson RM, Gupta S, May RM: Potential of Community-wide Chemotherapy or Immunotherapy to Control the Spread of HIV 1 . Nature $1991 ; 356-9$.

206 Anderson RM: Editorial Review Mathematical and Statistical Studies of the Epidemiology of HIV. ADDS 1989; 3:333-46.

207 United Nations / World Heallh Organisation (UN/WHO): Proceedings of UN/WHO Workshop on Modelling the Demographic Impact of the AIDS Epidiemic in Paiteri II Countries; progress to date and policies for the future. UN/WHO: ST/ESA/SER.A/119 1991.

208 Drummond MF, Brandt $A$, Luce BR, Rovira J: Standardizing Ecomomic Evaluations in Health Care; Practice, Problems and Potential. Int I Technol Assess in Healh Care $1993: 1: 26-36$.

209 Tolley $\mathbb{K}$, Maynard A, Robinson D: HIV/AIDS and Social Care (Discussion Paper No. 811). York: Centre for Health Economics / University of York 1991.

210 Brookmeyer R, Liao J: Statistical Modelling of the AIDS Epidemic for Forecasting Health-care Needs. Biomerrics 1990; 46:1151-63.

211 Rizakou $E$, Rosenhead J. Reddington K: AIDSPLAN: A Decision Support Model for Planning the Provision of HIV/AIDS-related Services. Interfaces 1991; 21:117-29.

212 Rovira I, Leidl R: Projecting Personal Health-care Costs of HIV/AIDS Patients in Catalonia. International Conference on Econometrics of $\mathrm{AIDS}_{x}$ Barcellona 1993.

213 Antonanzas F, Anton F, Juarez C. Tomas C. Simulation Models for the Costs of AlDS in Spain. Intermational Conference on Econometrics of AIDS, Barceliona 1993.

214 Giraldes MR, Cortes MF: Simulation Model of the Cost of Treatment of AlDS Patients in Portugal by the Year 2000. International Conference on Econometrics of AIDS, Barcellona 1993.

215 De Lissovoy G, Foreword. Health Policy $1989 ; 11: 10144$.

216 Blanpain J, Davis K, Gunji A: Special Issue on The Economic Impact of AlDS; reverirch methodology. Health Policy 1989; 11/2.

217 Jager $X_{C}$, Pastma MJ: De AIDS-epidemie; prognoses en economische gevolgen. In: $H$ Vuijsje, R Coutinho (Eds) Dilemma s rondom AIDS. Amsterdam: Swets \& Zeitlinger 1989.

218 Postma MJ, LeidI $R$, Downs AM, Rovira J, Tolley $K$, Gyldmark M, Jager JC: Economic Impact of the A IDS Epidemic in the European Community: Lowards multi-national scenarios on hospital care and costs. ADDS 1993; 7.541-53.

219 Chief Medical Inspector (Geneeskundige Hoofd Inspectie; GHD): Aids in Nederland: 
tweede kwartaal 1993. Rijswijk (The Netherلands), GHI 1993.

220 Dijkgraaf MGW, Luijben AHP, Jager JC, Schrijvers AJP, Borleffs ICC: Trends in Hosphtal Resource Utillisation by HIV-infeeted Persons, January 1987-June 1990. Health Policy 1994, 27:175-91.

221 Bennett CL, Deneffe D: Does Experience Improve Hospital Performance in Treating Patients with AIDS? Health Policy 1993; 24:35-43.

222 Ministry of Welfare, Health and Culturall Affairs (Ministerie van Welzijn, Volkgezondheid en Cultur, WVC): Financieel Overzicht Zorg 1993. Den Haag (Netherlands): WVC 1993.

223 Leidl R: A Survey of the Economic Evaluation of Early Drug Intervention in MIV Infection. In: EH Kaplan, ML Brandeau (Eds) Modeling the AIDS Epidemic: planning, policy and prediction.. New York: Raven Press 1994.

224 Aboukler JP, Swart AM: Preliminary Analysis of the Concorde Trial. Lancet 1993: $341: 889490$.

225 Day NE (Chairman of the Working Group): The Imcidence and Prevalence of AIDS and other Severe HIV Disease in Englland and Wales for 1992-1997: projections using datat to the end of June 1992. Communicable Disease Report 1993; 3(S1) :S1-17.

226 McCormick A: Estimating the Size of the HIV Epidemic by using Mortality Data. Phil Trans R Soc London 1989; B325:163-73.

227 Ministry of Economic Affairs: Research group on Discounting (Studiegroep Discontering: De Rol van de Disconteringvoet in het Beleid. Den Hagg (Netherlands): Ministry of Economic Affairs 1985.

228 Parrot RH: Childhood Human Immunodeficiency Virus Infection: the spectrum of costs. Journal of ACquired Immune Deficiency Syndromes 1991; 4:122-9.

229 European Collaborative Studly: Children born to Women with HIV-ll Infection: natural history and risk of transmission. Lancet 1991; 337:253-60.

230 Van Grienswen GJP, de Vroome EEM, Goudsmit J, Coutinho RA: Changes in Sexual Behaviour and the Fall in Incidence of HIV Infection among Homosexual Men. BMJ $1989 ; 298: 2 \Perp 8-21$.

231 Van den Hoek JAR, Van Griensven GJP, Coutinho RA: Aanwijzingen voor Toename van Onvellig Seksueel Gedrag bij Homosexuele Mannen in Amsterdam. NTVG 1990; 134: 1229-30.

232 De Wit JBF, Van den Hok JAR, Santfort ThGM, van Griensven GJP: Increase in Unprotected Anogenital Intercourse among Homosexual Men. Am $J$ of Public Health $1992 ; 83: 1451-3$.

233 Wiessing LG, Houweling H, Santfort ThGM, Schop W, Bosga MB, Van den Aklker R: HIV-infectie in een Nederlandse Groep Homosexuele Mannen. Bilthoven (The Netherlands): RIVM 1993.

234 Houweling $\mathrm{H}$, Jager JC, Coutinho RA, Bijkerk $H$, Ruitenberg EJ: Epidemiologie van AIDS en HIV in Nederland; huidige situatie en prognose voor de periode 1987-1990. NTVG 1987; 131:818-24.

235 Van de Water HPA, Bijleveld CCJH, Berkane $\mathrm{M}$, Wiggers CCMC: Is the Worst of the Epidemic over? Backcalculation of HIV seroprevalence in The Netherlands. Health Policy 1992; $21: 211-21$.

236 Solomon PJ, Wilson SR: Accomodating Change due to Treatment in the Method of Back-projection for Estimating HIV Infection Incidence. Biometrics 1990; 46:1165-70.

237 Cox D (Chairman of the Working Group): Short-term Prediction of HIV Infection and AIDS in England and Wales. London: Her Majesty"s Stationary Office 1988.

238 Hellinger FJ: Forecasting the Number of ADS Cases: an analysis of two techniques. 
Inquiny 1990; 27:212-24.

239 Heisterkamp SH, Downs AM, Van Houwelingen JC: Empirical Bayesian Estimators for the Reconstruction of HIV Incidence and Prevalence and Forecasting of AIDS. submitted.

240 Bloom DE, Glied S: Projecting the number of new AlDS Cases in the United States. International Journal of Forecasting 1992; 8:339-65.

241 Commissie Structuur en Financiering Gezondheidszorg: Bereidheid tot Verandering. Den Haag (Netherlands) 1987.

242 New York State Department of Health: ArDS in New York State Through 1990. Albany: State Department 1991.

243 Hiehle $G$, Max field WT, Kizer KW: Medical Studies in AlDS Demographics and Expenditures for Persons with AIDS, 1980-1989. Sacramento: California Department of Health Services 1990.

244. Dijkgraaf MGW, Luyben AHP, Kauffmann R, Claessen F, Van Leusden R, Jager JC, Borlteffs JCC: Resource Use by HIV-infected Patients in 1991: a comparison of four Dutch hospitals. Int Conf on AIDS, Florence 1991, abstract MD 4262.

245 Ruward D, Kramers PGN (Eds): Public Health Status and Forecasts; the health status of the Dutch population over the period 1950-2010. The Hague: Sdu Uitgeverij 1994.

246 Koopmansclap MA, Van Roijen L, Bonneux L: Costs of Diseases in The Netherlands. In: D Ruwaard, PGN Kramers (Eds) Public Health Status and Forecasts. The Hague: Sdu Uitgeverij 1994.

247 Box GEP, Jenkins GM: Time Series Analysis; forecasting and control. San Francisco: Holden Day 1970.

248 Postma MJ, Ruwaard D, Jager JC, Dekker's ALM: Projecting Utilization of Hospital Inpatient days in the Netherlands; a time-series analysis. IMA I Math Appl MeddBiol $1995 ; 4 / 5: 185-202$.

249 Scitowsky AA. Cline MW, Abrams DI: Effects of the Use of AZT on the Medical Care Costs of Persons with AIOS in the First 12 Months. Journal of Acquired Inwmut Deficiency Syndromes 1990; 3:904-12.

250 Johnson AM: Economic Aspects of Care and Prevention of HIV infection and AlDS. In: JC Jager, EJ Ruitenberg (Eds) Statistical Analysis and Mathematical Modelling of AIDS. Oxford: Oxford University Press 1988.

251 Drummond MF, Davies LM: Treating AIDS: the economic issues. Health Policy 1988; 10:1-19.

252 Program Co-ondination Committee AIDS Research (Programma coordinatie commissie AIDS onderzoek; PccAo): Jaarverslag 1992/93. The Hague: PccAo 1992.

253 Jansen J, Lourijsen ECMP, Poppelaars CAM et al.: Een Verkennüng van Voorspellend Medisch Onderzock in Keuringssituaties (RIVM-report 442013001). Bilthowen: RIVM 1993.

254. Mooji WA: De Aidstest bij Verzekeringen is Redelijk en Noodzakelijk. Welwezen 1992. 9:16-19.

255 Sandberg P. HIV and Life Insurance: costs and ethics of non-discrimination. In: D Fitasimons, V Hardy, K Tolley (Eds) The Economic and Social Impact of ArDS in Europe. London: Cassell 1995.

256 Clifford KA, RP Iuculano: AIDS and Insurance: the rationalle for AIDS-related testing. Harvard Law Review 1987: 100:1817.

257 Scherzer M: Insurance. In: E Dalion (Ed) AIDS and the Law; a guide for the public. $1988,185-200$.

258 Nederlandse Vereniging wan Levensverzekeraars (NVL): Haalbaarheidsstudile ower de 
Opzet woor ven Vorzlening woor Seroposilieven. Den Halag (Netherlands): NVL 1990.

259 Santfor "ThCM: Bisexuality in the Netherlands" some data from Dutch studies. Im"

Tielman RAP. Hendriks A. Carballo M (Eds) Bisexuality and HIVADDS. Buffalo: Prometheus 1991.

260 Fads WA, Van der SteI HG. HIV/ADS geztien vanuit het Perspectlef wan de Vitwoering van de WAOVAW-wetgeving. Amsterdam: Gemeenschappelijke Medische Dienst 1991

261. Brookmeyer $\mathbb{R}$ : Software for Penalized Backcalculation. New York 1993.

262 Downs AM. Heisterkamp SH, Ancelle-Park RA. Brunet J-B: Reconstruction and Prediction of HIV/AIDS in Europe. Int Conf on AIDS, Yokohama 1994, abstract PC025\%.

263 Nys H: Predictive Genetic Information and Life Insurance; Legal Aspects - towards European Policy. Mastricht: University of Limburg 1993.

264 Leigh S: UK Special Report - Special Risk; striking a balance on A.IDS Question. Money Marketing 1993, 4:10-4.

265 Kelly JM: HIV and Insurance. In: DC Jayasuriya (Ed) HIV Law, Ethics and Human Rights. New Delhi: Har A nand Publications 1995.

266 Roth P: AIDS and Imsuramce. Im: D Fitzsimons, V Hardy, K Tolley (Eds) The Economic and Social Impact of AIDS in Europe. London: Cassell 1995.

267 Drummond M: Cost-of-IIness Studies: a major headache? PharmacoEconomics 1992; $2: 1 \cdot 4$.

268 Anent A, Evers $S$ : Cost of Illness Studies in Health care: a comparison of two cases. Health Policy 1993; 26:29-42.

269 Boas G: Scenario-analyse Economische Aspecten Coronaire Hartziekten (Scenario Analysis Economic Aspects Coronary Heart Disease; in Dutch). Thesis at the Universiy of Limburg, Maastricht (the Nerherlands) 1994.

270 Postma MJ. Jager JC, Dijkgraaf MGW, Borleffs JCC, Tolley K, Leidl R: AIDS Scenarïos for the Netherlands; the economic impact on hospitals. Heath Policy 1995; 31:127. 150.

271 Hellinger FI, Fleishman JA, Hsia DC: AIDS treatment costs during the last months of life: evidence from the ACSUS. Health Services Research 1994; 29:569-581.

272 Fleishman IA, Mor V. Laliberte LL: Longitudinal patterns of medical service use and costs among people with AIDS. Health Services Research 1995; 3:403-424.

273 Bennett CL, Lubeck DP, MsShane DJ et al: Costs of Terminal Care for People with AIDS. AIDS Parient Care 1995; 2:7-9.

274. Postma MJ, Kornarou H, Paparizos V. Leidl RM, Tolley K, Kyriopoulos J, Jager JC for the European Team on AIDS Scenarios: Hospital Care for Patients with AIDS in Greece and the Netherlands; assessment of current and future impact. In: I KyriopouIos (Ed) AIDS Cost Analysis and Patient Classification. In press.

275 Ministry of Public Health, Welfare and Sports: Financial Statement on Health Care (Finandeel Overzicht Zorg; in Dutch). Den Haag (Netherlands) 1995.

276 Tolley K, Postma MJ, Jager JC, Good M: A Standardized Costing Framework for MIV/AIDS Hospital Care in the European Union. In: IKyriopoulos (Ed) AIDS Cost Analysis and Patient Classification. In press.

277 Kelly JV, Ball JK, Turner BJ: Duration and Costs of AlDS Hospitalizations in New York; variations by patient severity of illness and hospital type. Med Care 1989; 12:1085-98.

278 Turner B.J, Markson LE, McKee Let al.: The AIDS-defining Diagnosis and Subsequent Complications: a surviwallbased severity index. Joumal of Acquired Immune Deficiency 
Syndrowier $1991 ; 4: 1059-1071$.

279 Oleson B, Gotzsche I, Bygberg L, Möller W: Hospital Casts for AIDS Patients. Im: D Schwefel, R Leidl, J Rovira, MF Drummond (Eds) Economic Aspects of AlDS and HIV Infection. Berlin: Springer-Verlag 1990.

280 Labadie JC, Leng B, Mamane G et al: Le Coût de l'Hospitalisation des Malades atteints de SIDA a Bordeaux. Cahiers de Sociologie er de Demographe Medicales $1989_{\text {* }}$ 2: $193 \% 205$.

281 Flori YA, Banchet E: Prospective SIDA 2010; projet de base d"analyse (volet economique). Paris: Centre de Recherches en Economie de la Sante (INSERM Units 357) 1995.

282 Kyriopoulos I, Kornarou H, Gitona M, Paparizos V: Estimates of HIV/AIDS Healtheare Expenditure in Greece: an analytic approach for prospective finaming. In: D Fitzsimons, V Hardy, K Tolley (Eds) The Eonomic and Scial Impact of AIDS in Europe. London: Cassell 1995.

283 Papaevangelou $G$, Kornarou $H$, Roumeliotou $A$, Y fantopoulos J: Estimates of HIV/ADDS Healtheare Expenditure in Greece: an analytic approach for prospective financing. In: D Fitzsimons, V Hardy, K Tolley (Eds) The Economic and Social Impact of AIDS in Europe. Cassell 1995.

284 Calleri $G$, Macor A, Belloro S, Caramello P, Dirindin N: Costo Ospedaliero del Malato di ALS. Epidemiologio e Prevenzione 1989; 39" 47-51.

285 Visco-Comandini V: II Trattamento Ospedaliero di Pazienti Affetti da ALDS; un' analisi economica. Economia Pubblica 1992; 6:285-295.

286 Beck EI, Kennelly J, McKevitt C. Whitaker L, Wadsworth J, Miller DL, Easmon C, Pinching $\mathrm{AJ}$. Harris JRW: Changing Use of Hospital Serwices and Costs at a London AIDS Referral Centre, 1983-1989. AIDS: 1994; 8:367-377.

287 Morton A, MeCallum A, Parkin D., Bhopal R, O'Brien S: The Costs of caring for Patients with HIV Infection and ADDS. Newcastle: University of Newcastle upon Tyne 1994.

288 Kennelly JM, Tolley K, Ghani ACH, Sabin CA, Maymard AK, Lee CA: Hospital Costs of Treating Haemophiliac Patients Infected with HIV. ADDS 1995; 9:787-93.

289 Johnson AM, Shergold C. Hawkins A, Miller R, Adler MW: Patterns of Hospitall Care for Patients with HIV Infection and AIDS. J Epidemiol Community Health 1993" 46:232-7.

290 Riley G, Lubitz $\mathbb{J}$, Prihoda R, Rabey E: The Use and Costs of Medicare Services by Cause of Death. Inquiry 1987;24:233-244

291 Lubitz JD, Rilley GF: Trends in Medicare payments in the last year of Iffe. MEJM $1993 ; 328: 1092-1096$.

292 Flori YA, Kerkleau M, Le Vaillant M: Analyse de l'Mếtérogénéité des Praquiques Médicales dans la Prise en Charge des Malades Infectês par le VIH; une méthode centrểe sur le DMI2. Paris: Centre de Recherches en Economie de la Sante (INSERM Unite 357) 1994.

293 Kerkleau M, Le Vaillant M, Flori YA: Measuring the Variability of Prescription Use in Patients with HIV Infection or AIDS. Pharmacoeconamics 1997: 3:246-61.

294. Jacobs I, Sema M, Fox N: The Cost of Hospitalization for the Late Complications of Diabetes in the United Staites. Dicabetic Medicine 1991; 8:523-9.

295 Rovira I, Leidl R: Projecting Individual Health-care Costs of HIV IIDS Patients in Catalonia. In: D Fitzsimons, V Hardy, K Tolley (Eds), The Economic and Social Impact of AIDS in Europe. London: Cassell 1995.

296 Kyriopoulos J, Georgoussi $\mathrm{E}$, Gennimata D, Niakas D, Skoutelis G: AIDS Cost in Greece: 1989-1993 - macroeconomic approach and estimations. Health Review 1992; 


\section{References}

4.35 .8$.

297 Ministere des Affares Sociales de la Santê de la Ville: Prospective SIDA 2010; le SIDA en Fance etat des connailssances en 1994. Paris: Agence Nationale de Recherchies sur le SIDA 1994.

298 Milochi F: Scenari Futuri dell'AIDS nel Veneta. In: F De Lalla (Ed) AIDS Prospettive Sociosanitarie ed Organizzazlione dei Servizi. Rome: Anti Grafiche Jasillo 1992.

299 Downs AM, Heisterkamp SH, Brunet J-B, Hamers FF: Reconstruction and Prediction of the HIV/AIDS Epidemic among Aduits in the European Union and in the Low Prewalence Countries of Central and Eastern Europe. ADDS 1997; 11:649-62.

300 Longini M. Byers RH, Hessol NA, Tan WY: Estimating the Stage-specific Number of HIV Infections using a Markow Model and Backcalculation. Statistics in Medicine $1992 ; 11: 831-43$.

301 Longini M, Scott Clark W, Karon JM: Effect of Routine Use of Therapy in Slowing down the CInical Course of Human Immunodeficiency Virus (HIV) Infection in a Population-based Cohort. Am J of Epidemiol 1993; 137:1229-40.

302 Choo $V$ : Combination Superior to Zlidovudine in Delta Trial. Lancet 1995; 34.895.

303 Kyriopoulos I, Kornarou H, Gitona M (Eds): AIDS Economics; cost analysis, management and prospective financing. Athens: National School of Public Health 1996.

304. Fitzsimons D, Hardy V. Tolley K (Eds): The Economic and Social Impact of AIDS in Curope. London: Cassiell Publishers 1995.

305 Kitahata MM, Koepsell TD, Deyo RA ef al.: Physicians' Experience with the Acquired Immunodeficiency Syndrome as a Factor in Patients' Survival. NEJM 1996; 334:7016.

306 Widman M, Light DW, Platt JJ: Barriers to Out-of-hospital Care for AIDS Patients. ADS Care 1994; 1:59-67.

307 Direction des Hopitaux, Mission SIDA: Hospital and AIDS; key figures. Paris: Ministetre de la Santé et de l'Action Humanitaire 1993.

308 Paparizos V: Study on the Economic Cost of Hospital Care for Patients in Greece (Doctoral thesis at the University of Athens). Athens 1992.

309 Kornarou H: Direct and Indirect Costs of AIDS in Greece (Doctoral thesis at the University of Athens). Athens 1992.

310 Niakas D, Kyriopoulos I: Methodological Problems in Cost Estimations of ADS un Greece and a Framework for Cost Measurement. In: J Kyriopoulos, H Kornarou, M Gitona (Eds) AIDS Economics; cost analysis, management and prospective financing. Athens: Exandas 1996.

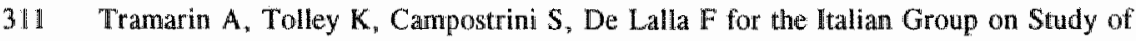
Altemative Care for AIDS patients: The Application of the Balance of Care Model to a National AIOS Health Plan. AIDS 1997; 11:809-16.

312 Rovina $\Pi$, Lopez G, Roman A, Santin M, Badia X: Els Costos de l'Assisténcia Sanitaria als Malats Infectats per VIH i Ia SIDA; una aproximacio empirica. Salut Catalonya $1992 ; 6: 139-44$.

313 Beck EJ: "The Cost of Hospital Care for HIV Infected Patients; the impact of changing survival patterns and wise of services in London in the 1980s. I $m$ : D Fitzsimons, Hardy, K Tolley (Eds), The Economic and Social Impact of AIDS in Europe. London: Cassell 1995.

314 Tolley $K$, Ghani A, Kennelly $J$, Lee C, Tramarin AM, De Lalla F: Comparing the Costs of HIV/AIDS Treatment and Care: examining the relationship between diagnostic stages and costs. In: I Rovira (Ed) Proceedings of the International Conference on the Econometrics of AIDS. Barcelona: University of Barcelona 1993. 
315 De Graeve D. Nonmeman W: Prospective Financing of Health Care for ADDS Patients and HIV-seroposittiwes in Belgium. In: J Kyriopowlos, H Kornarou, M Gitona (Eds) AIDS Economics; Cost analysis, management and prospective financing. Athens: Exandas 1996.

316 Kyropoulos JE: Presentation and Appraisal of the Severity Classification of AIDS Patients for the Implementation of a Prospective Financing System. In: J Kyriopoulos, H Konarou, M Gitona (Eds) AIDS Economics; cost analysis, management and prospectiwe financing. Athens: Exandas 1996.

317 Dijkgraf MGW, Luiben AHP, Jager JC, Schrijvers AJP, Borteffs ICC. ln-patient Care for Symptomatic, HIV-infected Persons; a longitudinal stindy of hospitalizations, inpatient drug use, and related cests. ADDS Care 1995; 7:321-36.

318 Pascal A: Conceptual Issues in Assessing the Economic Effects of the HIV Fpidemic. Healih Policy 1989; 11:105-113.

319 Kizer KW, Rodriquez J, McHolland GF: An Updated Quatutitative Analysis of ADS in Californila. Sacramento: Department of Health Services 1987.

320 Dijkgrafif MGW, Luijben AHP, Postma MJ, Borleffs JCC, Schrijvers AJP, Jager JC: Lifetime Hospitalization Pronlles for Symptomatic, HIV-infected Persons. Hedth Palicy 1996; 35:13,32.

321 Quesenberry ChP, Fireman B, Hiatt RA, Selby JV: A Survival Analysis of Hospitalizations among Patients with Acquired Immunodeficiency Syndrome. Am $f$ of Public Healh 1989; 79:1643-47.

322 Postma MJ, Jager JC, Ruwaard D, Van Loy NCM, Leidl RM: Disense-staging for Modelling Current and Future Health-care Impact of Disease; illustations for Diabetes mellitus and AIDS. Health Policy 1998; 43:45-54.

323 Scitovsky AA: "The High Costs of Dying": what do the data show? The Milbank Quarterly 1984; 62:591 608 .

324 Scitovsiky AA: Medical Care in the Last 12 Months of Life; the relation between age; functional status and medical care expenditures. The Milbank Quorterly 1988; 66:64060.

325 Ginzberg E: The High Costs of Dying. Inquiry 1980; 17:293-95.

326 Temkin-Greener H, Meiners MR, Penty EA, Szydlowski IS: The Use and Cost of Health Services prior to Death; a comparison of Medicare-only and Medicare-Medicaid elderly populations. The Milbank Quarterly 1992; 4:679-701.

327 Sutton GF: Hospitalization in the Last Year of Life, United States - 1961. Viral and Health Statistict 1965; 22:1-10.

328 Lubitz J, Prihoda R: The Use and Costs of Medicare Services in the Last 2 Years of Life. Health Care Financing Rewiew 1984; 5:117-131.

329 Riley GF, Lubitz J: Longltudinal Patterns in Medicare Costs for Cancer Decendents. In: RM Scheffler, NC Andrews (Eds) Cancer Care and Cost; DRGs and beyond. Anu Arbor: Health Administration Press Perspectives 1989.

330 OECD: Health Care Systems in Transition. Paris: OECD 1990.

331 Anonymous: Update; Trends in AIDS lincidence, Deaths and Prevalence - United States 1996. MMWR 1997, 46:165-73.

332 EUROSTAT: EUROSTAT Jaarboek '95. Luxemburg: Bureau voor Officiele Publikaties der Europeese Gemeenschappen 1995.

333 Schnedter M, Dennerlein RK-H, Köse A, Scholtes L: Health Care in the EC Member States. Health Policy 1992; 20 (special issue).

334 Tragakes E, Polyzos N: Health-care Systems in Transition; Greece. Copenhagen: WHO 1996. 
335 OECD: The Refform of Healh-care Systems: a review of seventeen OECD-countries. Paritas: OECD 1994.

336 Politis C. Yfantopoullos J: Blood Transfusion and the Challenge of ADS in Greece; medical and economic aspects. Athens: Beta Medical Publishers 1993.

337 Spreuwenberg C, Schrijvers AJP: Health Care in Europe. Ir: WW Holland, R Detels, GKnox (Eds) Oxford Textbook of Public Health; Wol 1 Influences of Public Health. New York: Oxford University Press 1991.

338 OECD: OECD Health Systems: facts and trends 1960-1991. Paris: OECD 1993.

339 Statistics Netherlands: Costs and Financing of Health care; 1972-1992. The Hague: Sdu Publishers 1994.

340 Lueschen $G$, Cockerham $W$, Van der Zee $J$ et al.: Health Systems in the European Union; diversity, convergence and integration. Mürchen: $R$ Oldenbourg Verlag 1995.

341 McCarthy, Rees S: Health Systems and Public Mealth Medicine in the European Commumity. London: Royal College of Physicians 1992.

342 V paparizos: Personall communication. Athens 1995.

343 Mossialos E, Karokis A: Greece; Health care Reforms. Lancet 1992; 340:41-2.

344 Sissouras A: Backgrounds and Developments in Health Care an Greece. In: AF Casparie (Ed) Competitive Health Care in Europe; furure prospects. Dartmouth 1990.

345 Kyriopoulos JE. Niakas D: Economic and Health Policy Issues in Blomedical Technology, the case of Greece. In: M Malek, J Rasquinha, P Vacani (Eds) Strategic lssues in Health-care Management. Chichester: Wiley 1993.

346 Starace $\mathbb{F}$, Dijkgraal MGW, Houweling H, Postma MJ, Tramarin AM: HIV-associated Dementia: clinical, epidemiological and resource-utilization issues. ADDS Care 1998; 8(suppl 2).

347 Tramarin $A$, Campostrini S, Tolley $\mathrm{K}$, De Lalla F: The Imfluence of Socioeconomic Status on Health Service Utilization by Patients with HIV in North Italy. Social Sicience and Medicine, in press.

348 Koopmanschap MA, Van Roijen L, Bonneux L. Barendregt JJ: Current and Future Costs of Cancer. Eur I Cancer 1994, 30A(1):60-5.

349 Postma MJ, Beck EJ, LeidI R, Tolley K. Jager JC: Estimated Future Economic Impact of HIV/AIDS in the Europesn Union. Int Conf on AIDS, Geneva 1998, abstract 43488.

350 SIG Health Care Information / B Bergstra: Personal communication. Utrecht 1990.

351 SIG Health Care Information/De Groot RRM: Personal correspondence on AIDSrelated hospital inpatient days. Utrecht 1995.

352 Postma MJ, Kommer GJ, Niessen L: Projections of Dutch Heallh-care Costs using Economic Analysis. In preparation (presented Abstract availlable).

353 Triomphe A: The Cost of AIDS in France. In: J Kyriopoulos, H Kornarou, M Gitona (Eds) AlDS Economics; cost analysis, management and prospective financing, Athens: Eximndas 1996.

354 De Graeve D, Lescratwat B, Nonneman W: Patient Classification and Cost Anallysis of AIDS and HIV: the case of Belginm. Health Policy 1997; 39:93-106.

355 OECD; Health Database; wer 3.6. Paris: OECD 1995.

356 Farthing $C$ : Protease Inhibitors and Direct Virall Load Measurement: impact on cost of care and funding sources. Int Conf on AIDS, Vancouver 1996, abstract ThD4973.

357 Ruane PI, Ida J, Zakowsi et al: Impact of New Antiretroviral Therapies on Inpatient and Outpatient Utilization of Health-care Resources in Patients with HIV 4 th Conf on Retroviruses and Opportunistic Infections, Washington DC 1997 , abstract 262.

358 Torres $\mathrm{R}$, Barr $\mathrm{R}$ : Impact of Potent New Antiretrowiral Therapies on In-patient and Oul-patient Hospital Utilization by HIV-infected Persons. 4th Conf on Retroviruses and 
Opportunistic Infections, Washington DC 1997 , abstract 264.

359 Mouton $F$, Cartier P. Dellamonica P: Dramatic Cut in AIDS-defining Events and Hospitalization for Patients under Protease Imhibitors and Tritherapies in Nife AlDS Reference Centers and 7391 Patients. 4th Conf on Retroviruses and Opportunistic Infections, Washington DC 1997 , abstract LB12.

360 Sinpson $K$, Revicki $D$, Nabuisi $A$, Sarocco $P$. Adding Ritonavir to Current Amtiviral Therapy for Advanced HIV Patients in the US: comparison of costs of care predicted by modelling and actual costs from trial setting. Int Conf on AIDS. Vancouver 1996, abstract ThD4 112 .

361 Guiguet M, Valleron AJ: Demographic Impact of Mortality from ADS in France; projection for 1991. In: D Schwefel, R Leidl, I Rovira, MF Drummond (Eds.) Economic Aspects of AIDS and HIV Infection. Berlin: Sptinger-Verlag 1990.

362 Heilig GK, Wils AE: AIDS Costs more "Years of Potential Life" before Age 65 than Diabetes, TBC or Viral Hepatitis; patterns of mortality in Switzerland, Austria and Germany. Popnet, 15:2-10.

363 Ministry of Welfare, Public Health and Culture: Voortgangsnotitie Aidsbeleild. Den Haag (Netheriands) 1992.

364 F Cline: Memorandum aan Werkgroep Publiekscampagne AIDS/SOA. Den Haag (Netherlands): Ministry for Welfare, Public Health and Culture 1994.

365 Van Bergen I Postma MJ: Kasten en Daten van HIV Profylaxe na Prikaccidenten. $T S O 1998 ; 5: 272-6$

366 PJE Bindels namens de Werkgroep: Resultaten van de Screening op HIV-antistoffen biy Zwangere Vrouwen, Bezoeksters van Infertiliteitspolikinieken en Abortusklinieken in de Regio Amsterdam in 1990. NTVG 1991, 135:2123-2128.

367 Postma MJ, Sherr L. Jager JC: Cost-effectiveness of Screening Pregnamt Women for HIV in the UK. Third Int Conf on AIDS Impact, Melbourne 1997.

368 Postma MJ, Jager JC, Beck EJ, Mandalia S, Sherr L: HIV-sereening of Pregnant Women; decision analysis using UK cost-data. Abstract presented at EURO XVI, Brussels July 1998.

369 Postma MJ, Beck EJ, Mandalia S, Walters MDS, Sherr L, Houweling H, Jager JC: Uniwersal Screening of Pregnant Women is it cost-effective in England? Int Conft on AIDS, Genewa 1998, abstract 43134.

370 Postma MJ, Beck EJ, Mandalia S, Walters MDS, Sherr L, Houweling H, Jager JC: Universal Screening of Pregnant Women; îs it cost-effective in England? Submitted.

371 Rowira J (Ed): Econometrics of AIDS. Barcelona: University of Barcelona 1993.

372 Jager $J C$, Postma MJ van Genugten MLL, Kommer GI, Antoñanzas $\mathbb{F}$ : Multinational Scenario Analysis on AIDS Impacts: methodological accomplishments. Paper presented at the $6 \mathrm{t}^{\text {th }}$ Int Conf on System Science in Health Care, Barcelona 1996.

373 Postma MJ, Jager JC, Dijkgraaf MGW, Borleffs JCC. AIDS-Gcenarios for the Netherlands; the impact on the health-care system. In: I Rovira (Ed) The Econometrics of ALDS. Barcelona: University of Barcelona 1993.

374 R Demeulmeester, $G$ Antoine, V Basque, Bez G, Nadal JM, Souterrand $Y$, Varei $F$ : Projet d'Etude Prospective SIDA 2010; rapport de Jétwde de faisabilité. Paris: Direction Générale de la santê 1993.

375 Bongo-Wanga $\mathrm{E}$, Couvreur $\mathrm{P}$, Dersin $\mathrm{A}$, Pagano $\mathrm{G}$, Wantiez $\mathrm{P}$. Epudémie de SIDA; que coutera-t-elle a la Belgique, a l"Allemagne et a la France d'ici la fin du stècle? Universite de Mons-Hainaut 1995.

376 Council of Europe: Impact of the AIDS Epidemic on Heralth care Serwlces and Planning in Lurope. Strasbourg 1992. 
377 Lehner T, Buterfeld P. Boucher C et at: European Contribution to the Seience Prewention and Management of HIV lnfection. Vaccine 1997; 5:465-8.

378 Forsythe S, Sigel G, Nyamete A. The Evolution and the Role of Socioeconomic Impact Assessments in the Policy Process. Xlth lat Conf on AIDS, Vancouver 1996, abstract ThD4972.

379 Postma MU, van Bergen $J_{*}$ Jager JC: Pharmacomeconomic Evaluation of Antiretrovirallsi in Treatiment and Prevention HIV/AIDS. Proceedings of the 12 th Imt Conf on ADS (Geneva 1998) Bologna: Monduzzi Editore SpA 1998.

380 Postma MJ, Welle R, Kretzschmar M, Van Doornum GJJ, Coutinho RA, Mulder-Folkerts D. Wan den Hoek JAR: Kosten-effectivitell wan Opportunistische Sereening op Chlamydia Trachomatis. TSG 1998; 128.

381 Postma MI, Welke R, Van den Hoek MAR, Van Doornum GIJ, Mulder-Folkerts D, Coutinho RA, Jager JC: Kosten-effectiwiteits Analyse van Screening op Chlawydia trachomatis büf Vrouwen; opportunistische screening in Amsterdamse huisartspraktijken. Submitted.

382 Postma MJ, Welte R, Van den Hoek JAR, Van Doornum GJJ, Mulder-Folkerts D, Coutinho RA, Jager JC: Cost-effectiveness of Screenimg Asymptomatic Women for Chlawydia trachomatis; methodological advances and application in Dutch Generat Practices. Submitted.

383 Postma MJ, Reinders A. Jager JC. Sprenger MJW: Cost-effectiveness Analysis of Infuemza Vaccination in the Netherlands. In: Anumal Scientific Report 1996. Bithoven (Netherllands): National Institute of Public Health and the Enviroment 1997.

384 Postma MJ, Jager IC, Reinders A, Van Furth R, Sprenger MJW: Policy Options and Scenarios for Influenza Vaccination in the Netherlands. ESWI-bulletin 1997; 7:5-6.

385 Postma MJ, Bos J, van Gennep M, Rumke H, Sprenger MJW, Jager JC: Gelijktijdige Vaccinatie wan Ouderen tegen Infuenza en Pneumokokken. Im preparation.

386 Postma MJ, Jager JC, Reinders AR, Sprenger MJW: Standards for Cost-effectiveness Analysis; experiences in a Dutch study on influenza vaccination. Health and System Science $1997,3 / 4: 25-35$.

387 Haddix AC, Teutsch SM, Shaffer PA, Duñet DO: Prevention Effectiveness; a guide to decision analysis and economic evaluation. New York: Oxford University Press 1996.

388 Postma MJ, Tolley K, Jager JC: Modelling the Health-care Costs of Drug-use-related Disease. $/ n$ : C Godfrey, S Parrot, M Sutton el $a$. (Eds) Study of Options ti Develop Dynamic Models of Drug Use and Related Problems using Epidemiological Data. York: University of York 1997.

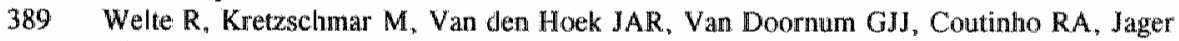
JC, Postma MJ: Cost-effectiveness of an Opportunistic Screening Programme for Chlamydia trachomatis using a Population-dymamical Model (working titlle). In preparation. 
Annex

\section{Projecting Utilization of Hospital In-patient Days in The Netherlands; a time-series analysis}





\title{
Projecting utilization of hospital in-patient days in The Netherlands: A time-series analysis
}

\author{
MaArten J. Postma, Dirk Ruwaard, and Hans (J.) C. Jager \\ Centre of Public Health Forecasting, National Institute of Public Health and \\ Environmental Protection \\ (Rijksinstituut voor Volksgezondheid en Milieuhygiëne; RIVM), PO Box 1, \\ 3720 BA Bilthoven, The Netherlands \\ ARNOLD L. M. DEKKERS \\ Centre for Mathematical Methods, National Institute of Public Health and \\ Environmental Protection \\ (Rijksinstituut voor Volksgezondheid en Milieuhygiëne; RIVM), PO Box I, \\ 3720 BA Bilthoven, The Netherlands
}

[Received 16 December 1994 and in revised form 7 August 1995]

The object was to model and project utilization of hospital in-patient days for selected diseases in The Netherlands. We used sex- and age-specific standardized monthly utilization of hospital in-patient days during 1980-90 for lung cancer, diabetes, coronary heart disease, stroke, and pneumonia. These data were supplied by the Health Care Information Centre (Stichting Informatiecentrum voor de Gezondheidszorg). We applied Box-Jenkins time-series analysis seasonal autoregressive integrated moving-average (SARIMA) models. Estimated models are tested by considering the Portmanteau test and the Akaike information criterion. SARIMA models give an adequate representation of hospital-in-patient-days utilization for the major sex and age classes of most selected diseases. Poor modelling results are obtained for diabetes in all sex and age groups and in elderly women with coronary heart disease or with stroke. Seasonality is an important factor in most of the models that we have estimated, particularly for utilization of pneumonia and stroke patients. The major trends in standardized in-patient days are downward, and projected 1995 levels of standardized utilization are below the 1990 levels for all the selected diseases. Population-based projections for 1995 are lower than the 1990 projections only for lung cancer and diabetes. The adequacy of the SARIMA models appears to be sensitive with respect to the parameter in the Portmanteau test. We discuss two possible explanatory developments for in-patient-days utilization: (i) developments in the provision of hospital care, and (ii) epidemiological developments. The selected diseases showed a decreasing mean duration of stay in 1980-90. Only for coronary heart disease did a rise in discharges in the same period outweigh this trend. We assessed contrasts between published epidemiological developments and the trends in in-patient-days utilization. Possible explanations concern shifts from in-patient to out-patient care and changes in treatment. Finally, complementary to our SARIMA models, the investigation of future in-patient days utilization by means of scenario analytic appoaches remains important.

Keywords: time series; SARTMA model; thospital care; projection; health-care planning. 


\section{Introduction}

A range of factors influence the utilization of health care. In The Netherlands, the main pressures on utilization are an ageing population, an increase in the demand for out-patient care, and advancements in medical technology. However, a decreasing average length of hospital stay and effective preventive interventions appear to be having a controlling effect on utilization. The influences of such factors are likely to differ for each disease, and analysis of their relative importance will require a disease-specific approach. The impact on health-care utilization will also depend on trends in the prevalence of disease.

The Financial Overview on Care Provision [1] is an annual governmental report of the financial and resource policy for health-care provision in The Netherlands. This policy is based on an extrapolation of past developments in health-care utilization and expected future developments. However, there is no explicit consideration of the impact of trends in the occurrence of diseases on utilization and policy setting. In this paper we examine the impact of developments in the occurrence of diseases on health-care utilization in The Netherlands.

Analysis of disease-specific health-care utillization has been undertaken in research coordinated by the Steering Committee on Future Health Scenarios (Stuurgroep Toekomstscenario's Gezondheidszorg: STG) [2-5]. Ideally, this type of research requires information on demographical and epidemiological developments (number of patients) and trends in the utilization of health-care for each patient. However, such data is not extensively available and it has only been used to a limited extent in the STG projects [5]. Our study uses a time-series analytical method applied to standardized resource-utilization data, reflecting a combination of epidemiological developments and patient-based trends in service utilization.

Disease-specific utilization data for the whole Dutch population is available for a number of health-service indicators. For example, in-patient hospital care, nursinghome care, and in-patient-psychiatric-care data is available from the SIG Health Care Information Centre in Utrecht (Stichting Informatiecentrum voor de Gezondheidszorg: $\$(\mathrm{G})$. In our study we focus on the utilization of hospital in-patient care, using in-patient days as the utilization indicator, since this is a substantial element of the total cost of health care (hospital costs were one-third of the total cost of health care in The Netherlands in 1993 [1]). Specific diseases which reflect the range of factors influencing resource utilization have been selected for analysis. These are lung cancer, diabetes, coronary heart disease, stroke, and pneumonia. Twelve per cent of hospital in-patient days were associated with these diseases in 1990. In addition, we have already incorporated these diseases in an integral model of public health. Our analysis is sex and age specific to allow for ageing effects on the utilization of hospital in-patient-days [6]. This approach goes beyond the use of traditional resource-utilization scenario techniques, which use cross-sectional data on resource utilization for different diseases [7], or use data on trends but do not distinguish by disease [8]. We know of only one previous application of time-series analysis to resource-utilization data; this was for specific chronic conditions associated with alcohol abuse [9].

The results can contribute to the rational planning of hospital beds over time for 
different diseases and across hospital specialities. In the next stage of research we plan to develop and further apply the methodology for examining disease-specific patterns in order to inform the Ministry of Health, Welfare and Sports on planning future resources for health care [10].

\section{Data and methods}

\subsection{Data and basic data management}

We use data available from the SIG on the monthly utilization of hospital in-patient days for the period 1980-90. Data on utilization of hospital facilities is sent to the SIG by all academic, general, and specialist hospitals in The Netherlands. The use of monthly data allows the application of accurate methods of modelling and projection.

The SIG attributes all the days of an in-patient stay to the month of admission. For an economic analysis this is insufficient because it does not reflect the actual monthly utilization of scarce health-care resources. Therefore, using a computer program developed in cooperation with the SIG, we have adjusted the data to record the actual number of in-patients days for the month in which they occur. If an in-patient stay exceeds one calendar month, the total number of days are divided over the respective months.

Disaggregated analysis is undertaken using the six age categories: $0-14,15-24$, $25-44,45-64,65-74$, and $75+$ (some of the analysis was conducted at a more detailed level). International classification of diseases (ICD) codes for the primary diagnosis are used to define the disease corresponding to the in-patient days [11]. The ICD code at discharge is used since this is more reliable than the code at admission. The respective ICD codes for lung cancer, diabetes, coronary heart disease, stroke, and pneumonia are $162,250,410-414,430-438$, and $480-486$. The quality of the process of ICD coding in the individual hospital is safeguarded adequately. Explicit attention is given to the accuracy of the computerized recording of data by the hospital's medical registrar, and cross-checks exist to verify the reliability of the data. However, we do not know of any research that has evaluated the quality of the ICD coding process.

Sex-and age-specific utilization data is standardized with reference to the mean Dutch population of 1990 , using the midpoint population halfway each month during 1980-90. The mean population of 1990 is defined as the sum of the population sizes on 1 January and 31 December divided by two. A linear change in the population over one year is assumed in the calculation of midpoint population figures for the period 1980-90. Population data is supplied by the Central Bureau of Statistics in Rijswijk (Centraal Bureau voor de Statistiek: CBS).

By 1990 all hospitals in The Netherlands supplied their data to the SIG. Previously this was not the case. For example, $2.5 \%$ of the hospitals did not supply data in 1986, and some specialist hospitals (eye clinics and cancer centres) only started supplying data to the SIG very recently. To ensure consistent and nonbiased time series we raise in-patient days for years with only partial participation by means of simulated disease-, sex-, and age-specific discharges. The simulations are consistent with the size and structure of the missing hospitals and they take into account the demographic 
characteristics of the population served by these hospitals. Finally, we assume that the registered average length of stay applies to simulated discharges for calculating simulated in-patient days. Because of missing data, discharges can only be simulated for the year 1984 onwards-for 1980-83 we assume the same disease-, sex-, and age-specific associations between observed and simulated in-patient days as were calculated for 1984. This basic data management produces 12 time-series of standardized hospital-in-patient-days utilization (i.e. 2 sex and 6 age categories) for each disease, with 132 monthly observations per series (covering $\mathbb{1 1}$ years).

\subsection{Analytical framework}

We use the Box-Jenkins statistical technique [12] to analyse the time series, specifying seasonal autoregressive integrated moving-average (SARIMA) models. (For two time series the number of nonzero observations is insufficient for analysis and we use the owerall mean as a model.) For this purpose a time series $\left\{X_{t}\right\}(t=1, \ldots, 132)$ is conceived to represent a series of observations within a system that is influenced by several factors. The approach is suited to model dependencies between successive observations (trend and seasonal pattern) by making a distinction between structural relationships and chance occurrences. It describes the behaviour of the system without the need for exploratory data on factors such as developments in epidemiology and in the provision of hospital care. These developments are implicitly incorporated in the resulting model. The form of the SARIMA model is specified by seven parameters $p, d, q, P, D, Q, s$ with the notation SARIMA $(p, d, q) \times(P, D, Q)_{s}[12]$. The parameter $s$ indicates the seasonal lag $s$ (here $s$ equals 12 months), with the parameters $P, D$, and $Q$ defining the seasonal model structure. The other parameters refer to the overall model. In mathematical terms the general form is

$$
\phi(B) \Phi\left(B^{12}\right)(1-B)^{d}\left(1-B^{12}\right)^{\mathcal{D}} X_{t}=\theta(B) \Theta\left(B^{12}\right) \varepsilon_{q} \quad(t=1, \ldots, 132),
$$

with

$$
\begin{aligned}
B^{k}\left(X_{t}\right) & =B^{k-1} B\left(X_{t-1}\right)=\cdots=X_{t-k}, \\
\phi(B) & =\left(1-\phi_{1} B-\phi_{2} B^{2}-\cdots-\phi_{p} B^{p}\right), \\
\Phi(B) & =\left(1-\Phi_{1} B^{12}-\Phi_{2} B^{24}-\cdots-\phi_{p} B^{12 P}\right), \\
\theta(B) & =\left(1-\theta_{1} B-\theta_{2} B^{2}-\cdots-\theta_{q} B^{4}\right), \\
\Theta(B) & =\left(1-\Theta_{1} B^{12}-\Theta_{2} B^{24}-\cdots-\Theta_{Q} B^{12 Q}\right),
\end{aligned}
$$

assuming all chance epsilons to be identically and independently normally distributed with a zero mean and a constant variance. Therefore $p$ and $P$ indicate the orders of the autoregressive parts of the model, and $q$ and $Q$ are those of the moving-average parts. In practice a nonzero $d$ can be interpreted as indicating a trend in the mean level of the series, whereas a nonzero $D$ might indicate the presence of a significant seasonal effect. To remain within acceptable confidence limits of the projections, we extrapolate standardized utilization of hospital in-patient days only for the period $1991-95\left\{X_{t}\right\}(t=133, \ldots, 192)$. 
A time sertes is monstationary if the standard deviation of the observation depends systematically on the mean of the observations (heteroscedasticity). We transform a heteroscedastic time series $\left\{X_{t}\right\}$ into a homoscedastic one $\left\{Y_{t}\right\}$ by

$$
Y_{t}=\ln \left(X_{i}\right) \quad(t=1, \ldots, 132),
$$

and we replace $Y_{f}$ for $X_{t}$ in expression (2.1).

To test for nonstationarity we cut the series into $1 !$ equal (yearly) parts of 12 observations. For each part we calculate the mean and the standard deviation. The logarithmic transformation is applied if regression of the standard deviation on the mean exhibits a significant linear rellation (two-sided $t$-test; $p<0.05$ ). In case the projected untransformed utilization of in-patient days becomes negative in the short term, we also apply the logarithmic transformation.

Finally, the projected logarithmic utilization of in-patient days in transformed back into real projections $\left(X_{t}^{\prime}\right)$ using

$$
X_{i}=\exp \left(Y_{i}\right) \quad(t=133, \ldots, 192),
$$

with $X_{t}$ and $X_{t}(t=133, \ldots, 192)$ providing median-unbiased estimators of the median future-in-patient-days utilization [13-15]. An estimator is median unbiased if the median of its distribution equals the parameter to be estimated. There are both theoretical and practical reasons for choosing the median as the measure of the central tendency [16].

The orders $p, d, q, P, D, Q$ in the SARIMA model are identified by studying the autocorrelation function and the partial autocorrelation function [12]. $\mathrm{Next}_{\text {, a maxi- }}$ mum-likelihood procedure is used to estimate the parameter values in the model. Specification of the SARIMA model is conducted using an interactive computer program designed in S-PLUS [17, 18].

To test the model we use graphical inspection of the residual autocorrelations, the Portmanteau test and the Akaike information criterion. The graphical pattern of the residual autocorrelations should not include too many values outside the range $\left[-2 / N^{-1 / 2},+2 / N^{-1 / 2}\right]$. As these autocorrelations differ significantly from zero $(p<0.05)$ the wrong choice of model is indicated [12]. If none, one, or two residual autocorrelations differ significantly from zero with no obvious interpretation in reality there would be insufficient evidence to reject the model $[19,20]$. The Portmanteau test statistic involves the first $M$ residual autocorrelations as a hole [21]. The test statistic is approximately chi-squared distributed with $(M-p-q-$ $P-Q$ ) degrees of freedom. The approximation is acceptabie if the number of observations exceeds 100 [22]. We report the p-values of the Portmanteau test statistic with $M$ equalling 36.

We compare different models for the same time series using the Akaike information criterion [23]. This criterion involves the likelihood of the model penalized for the number of independent parameters. Therefore, an increase in likelihood can be accompanied with a decrease of the Akaike information criterion if the number of parameters is increased.

Furthermore we apply the population forecasts of the CBS to transform standardized future utilization into population-based utilization. This enables the population-based projections to include the effects of the ageing in the Dutch population. 


\section{Results}

The orders of each estimated SARIMA model and the corresponding $p$-value for the Portmanteau test are presented in Table 1. The adequacy of the estimated models varies. In general, the models for lung cancer and diabetes do not perform well, although estimated models for men aged $65-74$ have acceptably low p-vallues. Men aged 65-74 form the most important age group for lung cancer. We estimate adequate models for men with coronary heart disease, especially in the two major age groups, 45-64 and 65-74. However, weak models are produced for coronary heart disease and for stroke for the most important age group for women, those aged $75+$. For pneumonia the overwheiming importance of seasonal patterns enables satisfactory representation by SARIMA modelling.

\section{TABLE 1}

Estimated SARIMA model for hospital-in-patient-days wtilization, the corresponding p-value for the Portmanteau test (see text), and standardized observations of annual-in-patient-days utilization (1990; in thousands) and projections (1995; in thousands)

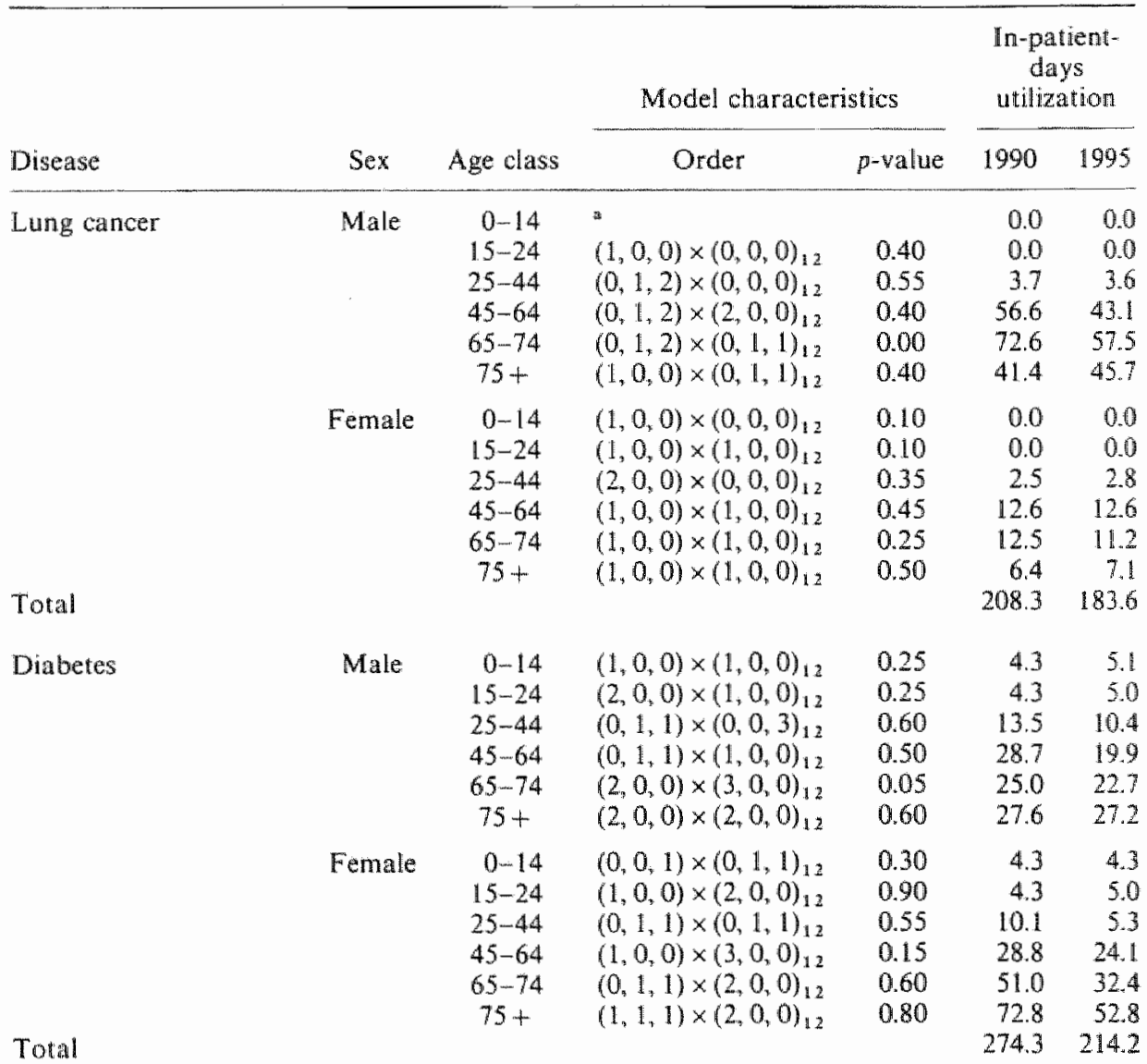


TABLE 1 (continued)

\begin{tabular}{|c|c|c|c|c|c|c|}
\hline \multirow[b]{2}{*}{ Disease } & \multirow[b]{2}{*}{ Sex } & \multirow[b]{2}{*}{ Age class } & \multicolumn{2}{|c|}{ Model characteristics } & \multicolumn{2}{|c|}{$\begin{array}{c}\text { In-patident- } \\
\text { days } \\
\text { utilization }\end{array}$} \\
\hline & & & Order & p-Walue & 1990 & 1995 \\
\hline Coronary heart disease & Male & $\begin{array}{c}0-14 \\
15-24 \\
25-44 \\
45-64 \\
65-74 \\
75+\end{array}$ & $\begin{array}{l}(1,0,0) \times(1,0,0)_{12} \\
(0,1,1) \times(0,1,1)_{12} \\
(0,1,1) \times(0,1,1)_{12} \\
(0,1,1) \times(0,1,1)_{12} \\
(2,0,0) \times(1,0,0)_{12}\end{array}$ & $\begin{array}{l}0.20 \\
0.20 \\
0.05 \\
0.05 \\
0.20\end{array}$ & $\begin{array}{r}0.0 \\
0.0 \\
32.2 \\
253.5 \\
161.6 \\
80.2\end{array}$ & $\begin{array}{r}0.0 \\
0.1 \\
26.3 \\
231.3 \\
160.4 \\
80.0\end{array}$ \\
\hline Total & Femalle & $\begin{array}{r}0-14 \\
15-24 \\
25-44 \\
45--64 \\
65-74 \\
75+\end{array}$ & $\begin{array}{l}(1,0,0) \times(2,0,0)_{12} \\
(1,0,0) \times(0,0,0)_{12} \\
(2,0,0) \times(0,0,0)_{12} \\
(1,1,1) \times(0,1,2)_{12} \\
(2,0,0) \times(2,0,0)_{12} \\
(1,0,0) \times(2,0,0)_{12}\end{array}$ & $\begin{array}{l}0.15 \\
0.75 \\
0.20 \\
0.65 \\
0.25 \\
0.45\end{array}$ & $\begin{array}{r}0.0 \\
0.0 \\
5.7 \\
53.6 \\
100.7 \\
100.7 \\
788.5\end{array}$ & $\begin{array}{r}0.0 \\
0.0 \\
6.3 \\
49.4 \\
100.6 \\
102.4 \\
756.7\end{array}$ \\
\hline Stroke & Male & $\begin{array}{l}0-14 \\
15-24 \\
25-44 \\
45-64 \\
65-74 \\
75+\end{array}$ & $\begin{array}{l}(1,0,0) \times(0,0,0)_{12} \\
(1,0,0) \times(1,0,0)_{12} \\
(0,0,2) \times(3,0,0)_{12} \\
(0,1,1) \times(2,1,0)_{12} \\
(1,0,0) \times(0,1,1)_{12} \\
(1,0,0) \times(0,1,1)_{12}\end{array}$ & $\begin{array}{l}0.05 \\
0.20 \\
0.25 \\
0.10 \\
0.20 \\
0.30\end{array}$ & $\begin{array}{r}0.7 \\
1.0 \\
9.4 \\
69.4 \\
92.4 \\
110.6\end{array}$ & $\begin{array}{r}0.7 \\
1.3 \\
8.0 \\
60.2 \\
95.3 \\
114.2\end{array}$ \\
\hline Total & Female & $\begin{array}{c}0-14 \\
15-24 \\
25-44 \\
45-64 \\
65-74 \\
75+\end{array}$ & $\begin{array}{l}(1,0,0) \times(0,0,0)_{12} \\
(3,0,0) \times(0,0,0)_{12} \\
(1,0,0) \times(1,0,0)_{12} \\
(0,1,1) \times(0,0,3)_{12} \\
(1,0,1) \times(3,0,0)_{12} \\
(1,0,1) \times(0,1,1)_{12}\end{array}$ & $\begin{array}{l}0.45 \\
0.35 \\
0.05 \\
0.55 \\
0.35 \\
0.45\end{array}$ & $\begin{array}{r}0.5 \\
1.3 \\
11.4 \\
35.0 \\
87.5 \\
221.9 \\
641.2\end{array}$ & $\begin{array}{r}0.5 \\
1.4 \\
11.7 \\
34.4 \\
83.3 \\
221.4 \\
632.4\end{array}$ \\
\hline Pueumonia & Male & $\begin{array}{l}0-14 \\
15-24 \\
25-44 \\
45-64 \\
65-74 \\
75+\end{array}$ & $\begin{array}{l}(2,0,0) \times(3,0,0): 2 \\
(1,0,1) \times(3,0,0)_{12} \\
(1,0,0) \times(1,0,0)_{12} \\
(2,0,0) \times(2,0,0)_{12} \\
(4,0,0) \times(2,0,0)_{12} \\
(1,0,0) \times(2,0,0)_{12}\end{array}$ & $\begin{array}{l}0.10 \\
0.50 \\
0.25 \\
0.05 \\
0.10 \\
0.10\end{array}$ & $\begin{array}{r}20.1 \\
1.9 \\
7.1 \\
17.0 \\
23.2 \\
40.6\end{array}$ & $\begin{array}{r}17.2 \\
1.1 \\
7.8 \\
16.9 \\
22.5 \\
39.2\end{array}$ \\
\hline Trotal & Female & $\begin{array}{c}0-14 \\
15-24 \\
25-44 \\
45-64 \\
55-74 \\
75+\end{array}$ & $\begin{array}{l}(3,0,0) \times(2,0,0)_{12} \\
(1,0,0) \times(3,0,0)_{12} \\
(3,0,0) \times(3,0,0)_{12} \\
(2,0,0) \times(2,0,0)_{12} \\
(2,0,0) \times(2,0,0)_{12} \\
(1,0,0) \times(1,0,0)_{12}\end{array}$ & $\begin{array}{l}0.30 \\
0.05 \\
0.05 \\
0.05 \\
0.10 \\
0.05\end{array}$ & $\begin{array}{r}14.0 \\
1.3 \\
5.8 \\
7.1 \\
12.7 \\
32.5 \\
183.3\end{array}$ & $\begin{array}{r}12.8 \\
1.6 \\
6.1 \\
7.4 \\
12.9 \\
27.4 \\
172.9\end{array}$ \\
\hline
\end{tabular}

"Insufficient data to estimate the SARIMA mode", 

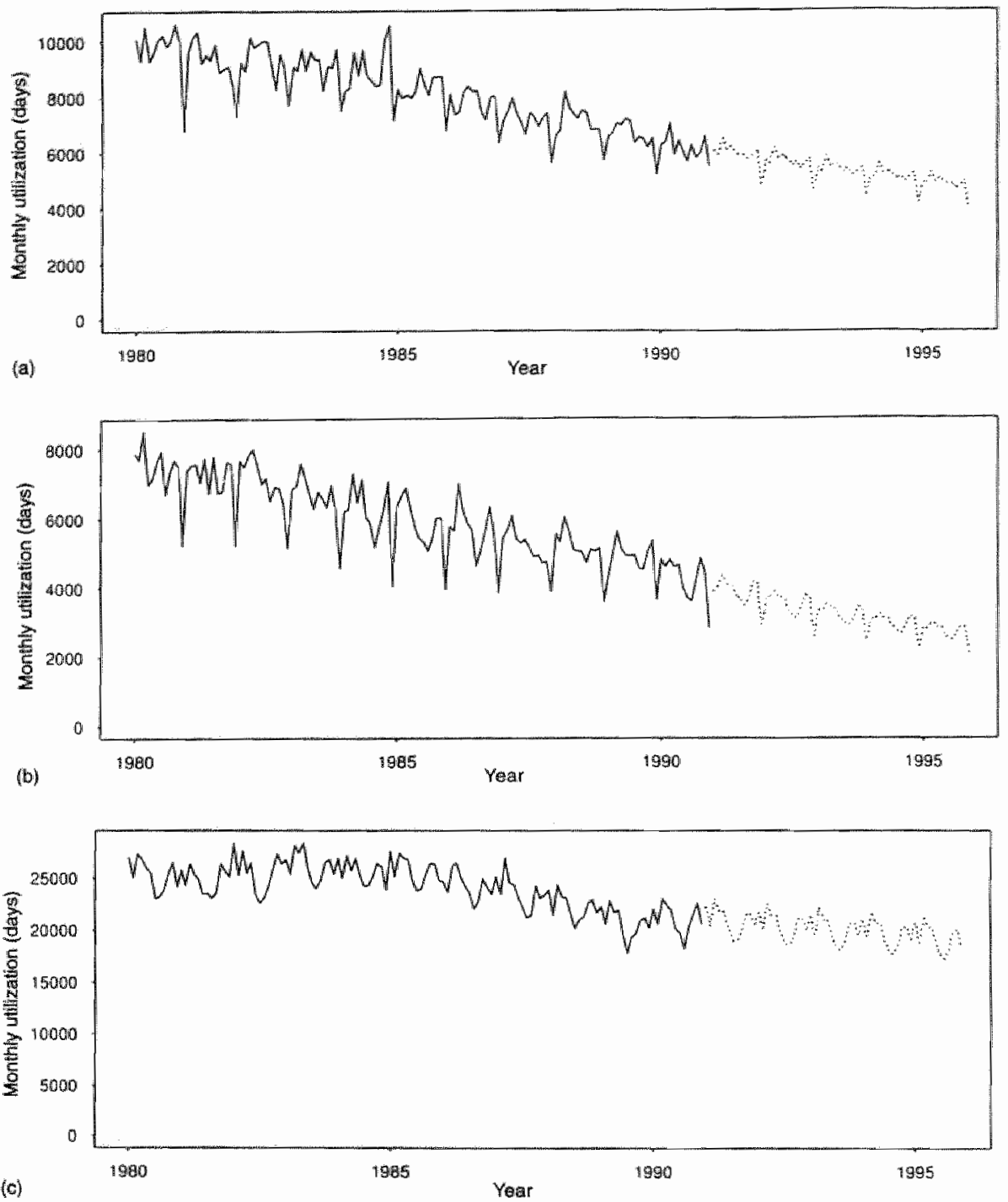

"120. 1. Standardized monthly utilization of hospital ir -patient days: (-) abservations (1980-1990), and (-.) projections (1991-1995). (a) Men aged 65-74 for lung cancer, (b) women aged 65-74 for diabetes; (c) men aged 45-64 for coronary heart disease.

Table $\mathbb{1}$ also presents standardized annual hospital-in-patient-days utilization for 1990, and projections for 1995. A comparison of the results in the two years for lung cancer demonstrates decreasing utilization for men and a stable pattern for women. For men in the age groups $45-64$ and $65-74$ we estimate downward trends in utilization (Fig. 1(a)). For diabetes downward trends prevall; this is most pronounced 

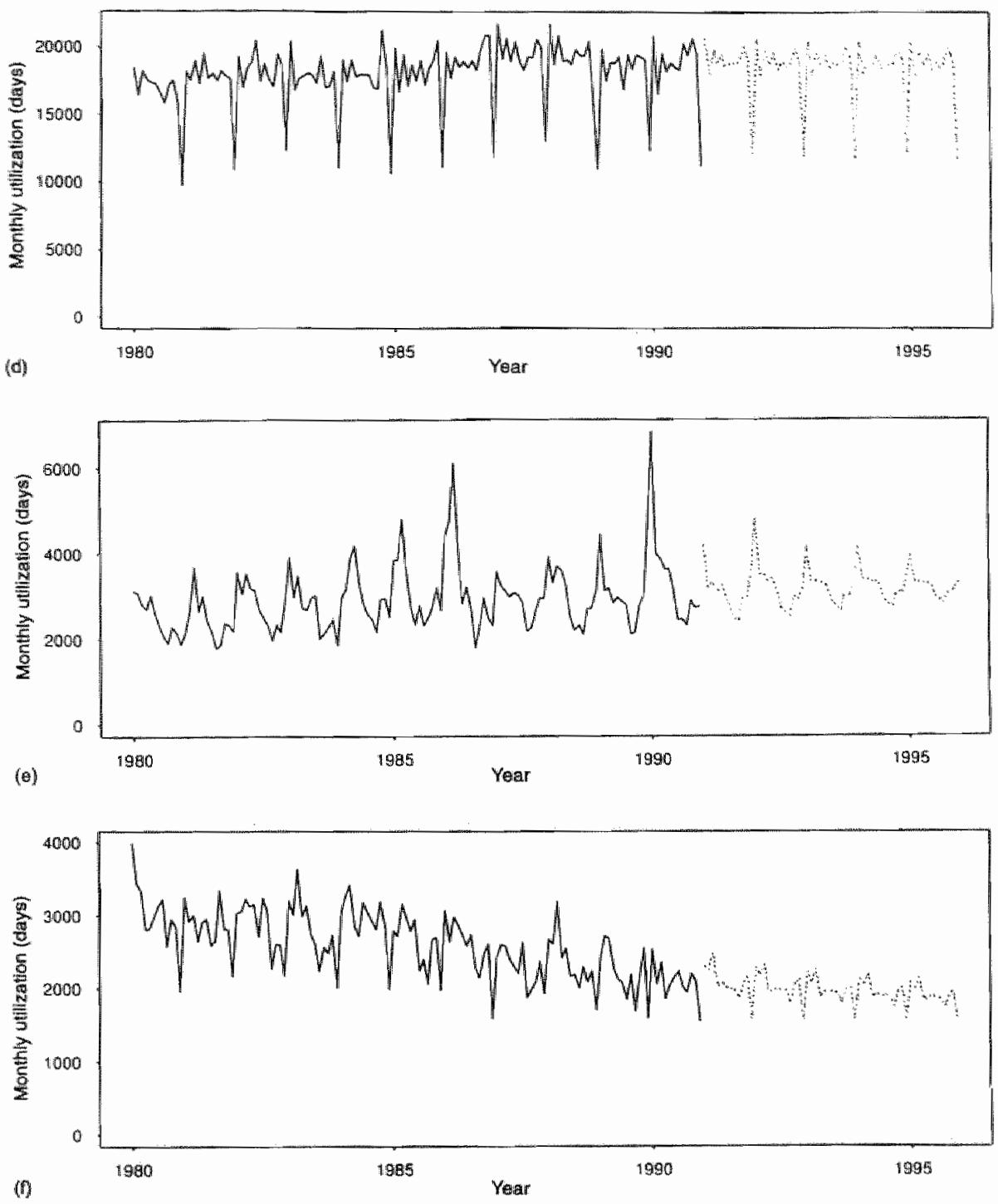

FiG. 1. (continued) (d) women aged $75+$ for stroke, (e) men aged $75+$ for pneumonia, (1) men aged $65-74$ for diabetes,

(continued)

for women in the age groups $65-74$ and $75+$ (Fig. 1(b)). For young men and women with diabetes (mainly insulin-dependent diabetes mellitus, IDDM), we project a rather stable utilization with a slightly higher utilization estimated for 1995 than in 1990. Further, we estimate downward trends in utilization for coronary heart disease for all age groups (especially the 45-64 age group; Fig. 1(c)), whereas utilization patterns for stroke victims are fairly stable (Fig. l(d)). In general, the projections of 

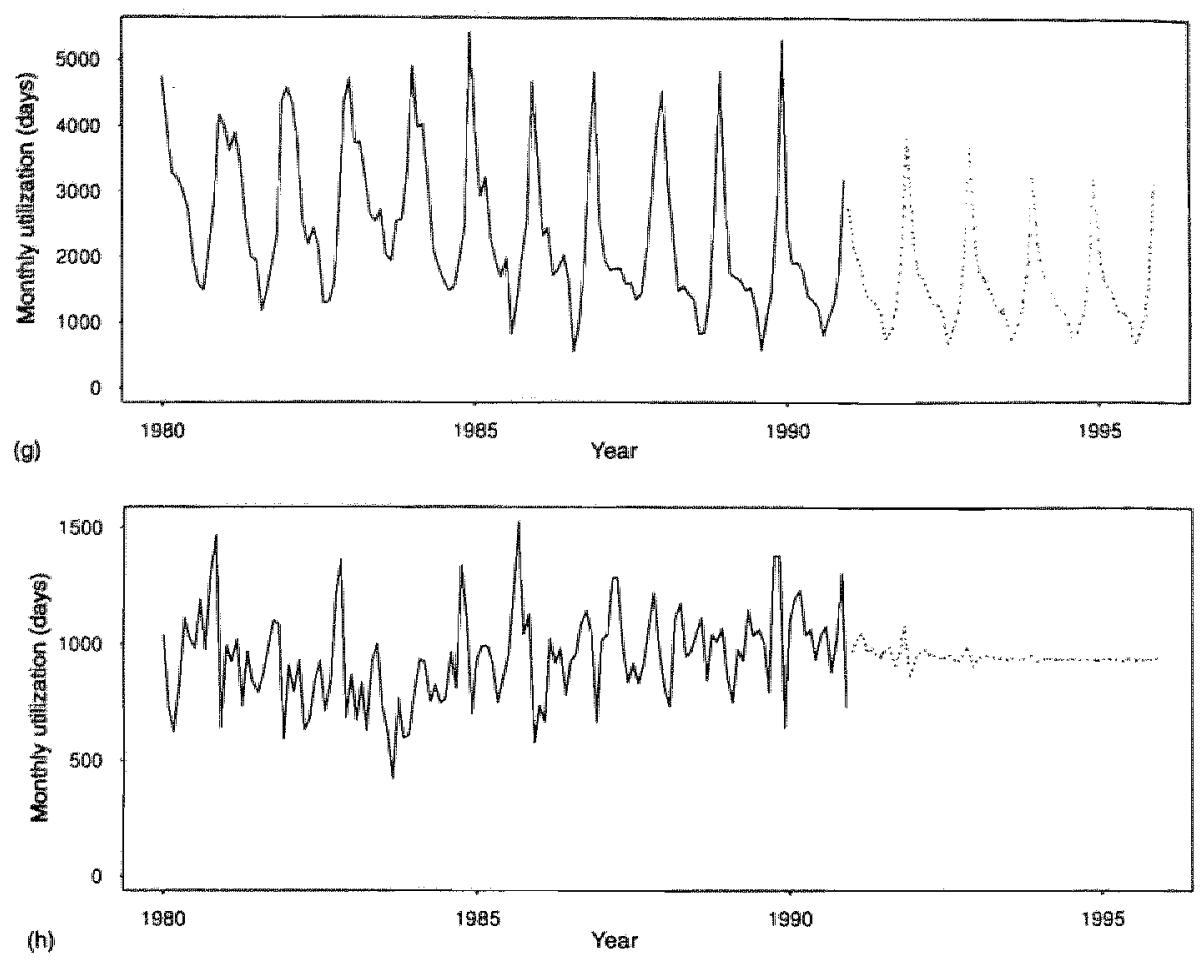

Fio. 1. (continted) (g) boys aged 0-14 for pneumonia, and (h) women aged 65-74 for lung cancer.

utilization for pneumonia are slightly lower in 1995 than the 1990 levels. However, some time series demonstrate a positive or negative tendency (Fig. 1(e)). For all the diseases selected, the overall projections of standardized in-patient days for 1995 are lower than the levels observed in 1990.

The seasonal effect evident in SARIMA models with a nonzero $D$ is illustrated in Figs 1(a) and (c). In addition, in models with a $P$ of at least two, seasonality only slowly declines in the projections (Figs $\mathbb{l}(\mathrm{f})$ and $(\mathrm{g})$ ). If the order of $P$ is lower than two the seasonal pattern disappears very quickly (Fig. $1(\mathrm{~h})$ ).

Seasonality appears to be a very important factor influencing hospital-in-patientdays utilization. The effect is absent only for women with lung cancer. The pattern for men with lung cancer and for all patients with diabetes is characterized by a dip in utilization in December, followed immediately by a rise towards a peak in March (see Figs 2(a) and (b)). These findings agree with the notion of holiday periods causing relatively low utilization because of low staff capacity and patients postponing in-patient care. For female IDDM patients aged $0-14$ there is no evidence of a December dip in utilization (Fig. 2(c)). Instead, for both this group and for coronary-heart-disease patients (Fig. 2(d)) the pattern is of a late-winter peak followed by a late-summer dip. For diabetes, this trend appears to reflect seasonal 

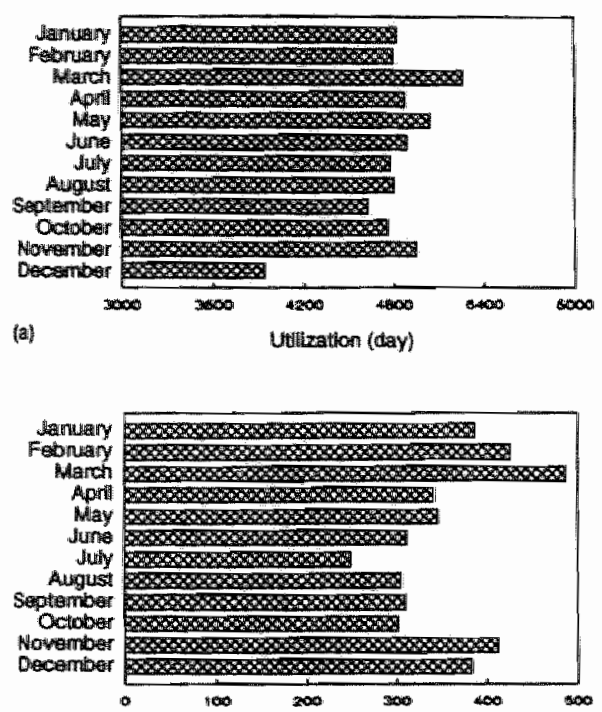

$(k)$

Utillzation (uay)

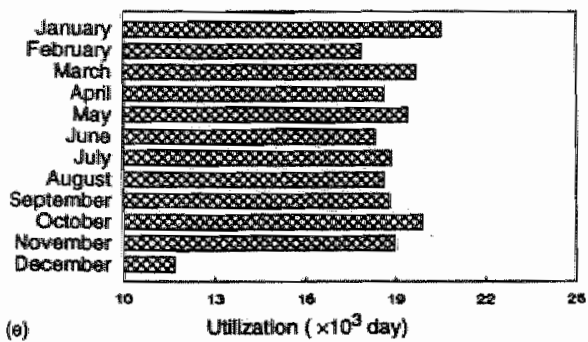

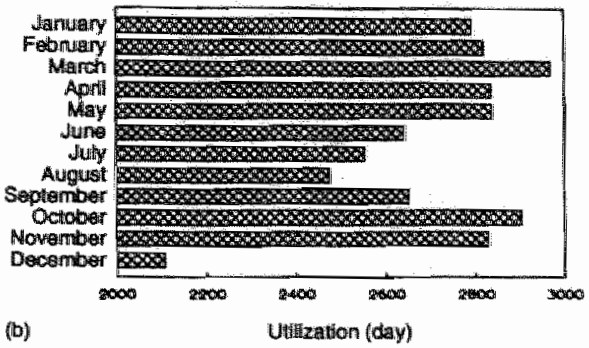

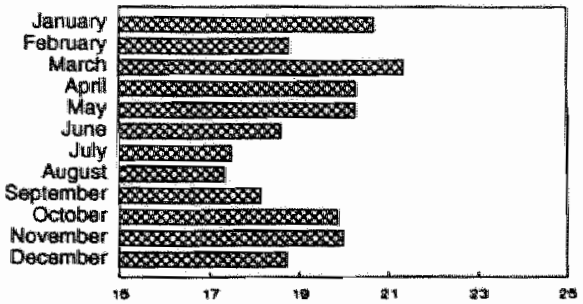

(di)

Uttilization ( $\times 10^{3}$ day)

FIG. 2. Projected standardized, monthly utilization of hospital in-patient days in 1995: (a) men aged 65-74 for lung cancer, (b) women aged 65 - 74 for diabetes, (c) girls aged 0 - 14 for diabetes, (d) men aged $45-64$ lor coronary heart disease, (e) women aged $75+$ for stroke, and (f) boys aged $0-14$ for pneumonia.

patterns in incidence $[24,25]$, whilst the pattern for coronary heart disease may be associated with seasonal mortality rates [26].

The seasonal pattern is most pronounced for stroke and pneumonia. In-patient utilization by stroke patients is up to one-third lower in December than in other months (Fig. 2(e)). For pneumonia, utilization is up to four times higher in late autumn and winter compared to midsummer (Fig. 2(f)), which reflects the usual seasomal epidemic of respiratory infections [27].

Figure 3 presents $95 \%$ confidence intervals for a number of projections. For Fig. 3 (a) to (f) the intervals vary from near $0 \%$ to almost $100 \%$ around the projected levels.

Taking demographic effects into account, we estimate population based projections for the overall utilization of hospital in-patient days in 1995 of 201000 for lung cancer, 230000 for diabetes, 832000 for coronary heart disease, 685000 for stroke, 

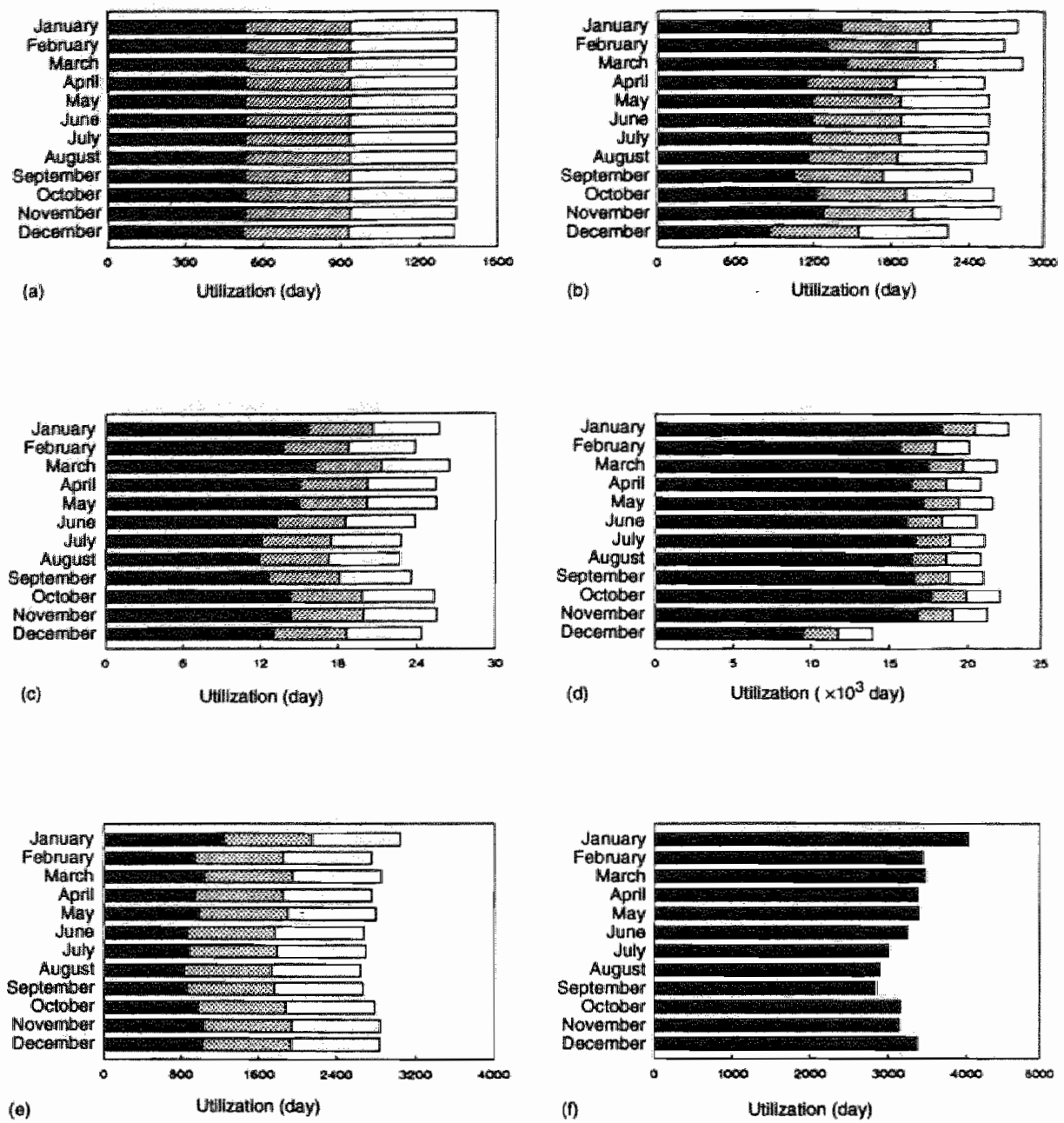

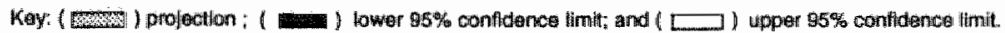

Fio. 3. Projected standardized monthly uilization of hospital in-patient days in 1995 and the corresponding lower and upper 95\% confidence limits. (a) women aged 65-74 for lung cancer, (b) men aged $65-74$ lor diabetes, (c) men aged 45-64 for coronary heart disease, (d) women aged 75 - for stroke, (e) men aged $65-74$ for pneumonia and (f) men aged $75+$ lor pneumonia.

and 186000 for pneumonia. Over the five-year period investigated we estimate that the changing demographic structure results in an additional in-patient-days utilization of $9 \%$ for lung cancer, $7 \%$ for diabetes, $10 \%$ for coronary heart disease, $8 \%$ for stroke, and $7 \%$ for pneumonia. Similar figures of the demographic impact on Dutch-health-care utilization and costs have been reported by others [28, 29]. Finally, the 1995 population-based in-patient utilization is projected to be below the 1990 level only for lung cancer and diabetes. 


\section{Discussion and conclusions}

Our time-series analysis has demonstrated that for most sex and age groups disease-specific series for the utilization of hospital in-patient days can be adequately represented by SARIMA models. However, there are doubts about the adequacy of the models for some specific groups and diseases: men with lung cancer, all diabetes patients, and women with coronary heart disease or with stroke.

We have also found that the Portmanteau test is very sensitive to the size of $M$. For certain groups, such as men with lung cancer in the age groups $45-64$ and $75+$, a different choice of $M$ would even have resulted in p-values below 0.10 (respectively, $M=21$ and $M=15$ ). As a further example, the poor Portmanteau test scores for women aged $75+$ with coronary heart disease or stroke can be much improved by choosing $M$ in the range $15-21$, lowering the p-values down to 0.20 and 0.15 . Only for diabetes is an insensitivity to the value of $M$ apparent; representation of the diabetes series by SARIMA models remains inadequate.

Further analysis can be conducted by creating two utilization time series for discharges and for mean duration of stay (Fig. 4). The number of discharges acts as a proxy for the trend in the occurrence of disease, whilst the mean duration of stay provides an indicator of trends in care provision and efficiency; see, for example, [30]. The fact that the information on discharges is not patient basedone patient may account for several discharges in the data file-can disturb these interpretations [31]. We estimate that $55 \%$ of the total number of discharges for coronary heart disease in 1993 were for patients with one discharge in that year and $23 \%$ were readmissions [32]. However, if there is no significant change in clinical practice, for example by splitting up a long in-patient stay into two shorter ones, the possible bias we introduce in our analysis is likely to be only very small.

We find that projected decreases in hospital in-patient days for lung cancer and diabetes patients is associated with decreases in the mean duration of stay in 1980-90 (Fig. 4), as has also been demonstrated by Ruwaard et al. [10]. For pneumonia the reduction in the mean duration of stay outweighs the increase in discharges over the period. The same pattern exists for coronary heart disease and for stroke in the period 1980-85, whilst for stroke in the period 1985-90 the opposite trend of an increasing mean duration of stay and decreasing discharges is apparent.

There is limited information available on epidemiological developments for certain diseases. An epidemiological model for diabetes has been developed for The Netherlands, and some sampled data is available for incidence and prevalence [33]. The estimated increase in prevalence for the period $1980-90$ is $28 \%$ and a further increase of 13\% for 1991-95 is expected (demographical developments account for hall of the increase in both periods). This development appears to conflict with our SARIMA-model projection, although the discrepancy might be partially explained by the decrease in the mean duration of stay. But the epidemiological development is not in line with the trend in the number of discharges. One important factor infuencing this pattern could be a shift from in-patient to out-patient treatment [34], since it is presumed to be cheaper [35] and more convenient for diabetic patients to start administering insulin in the latter setting. 

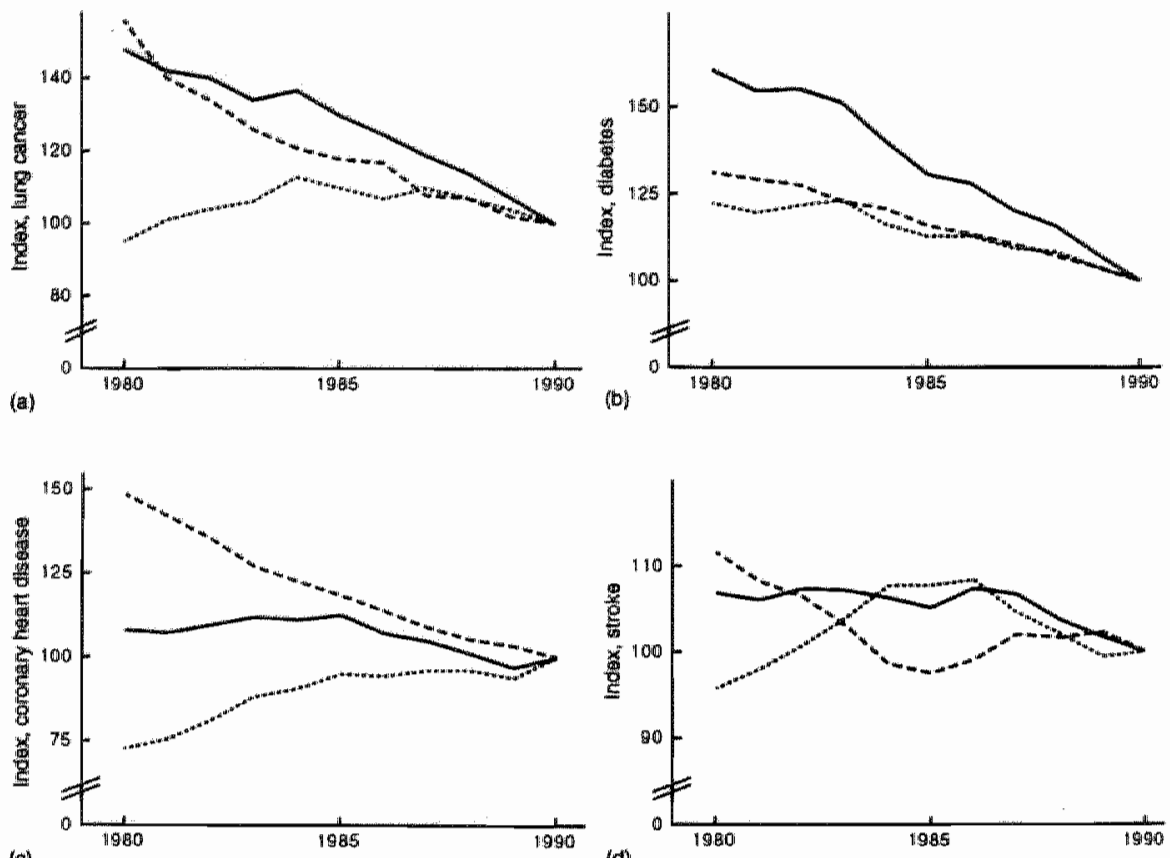

(c)
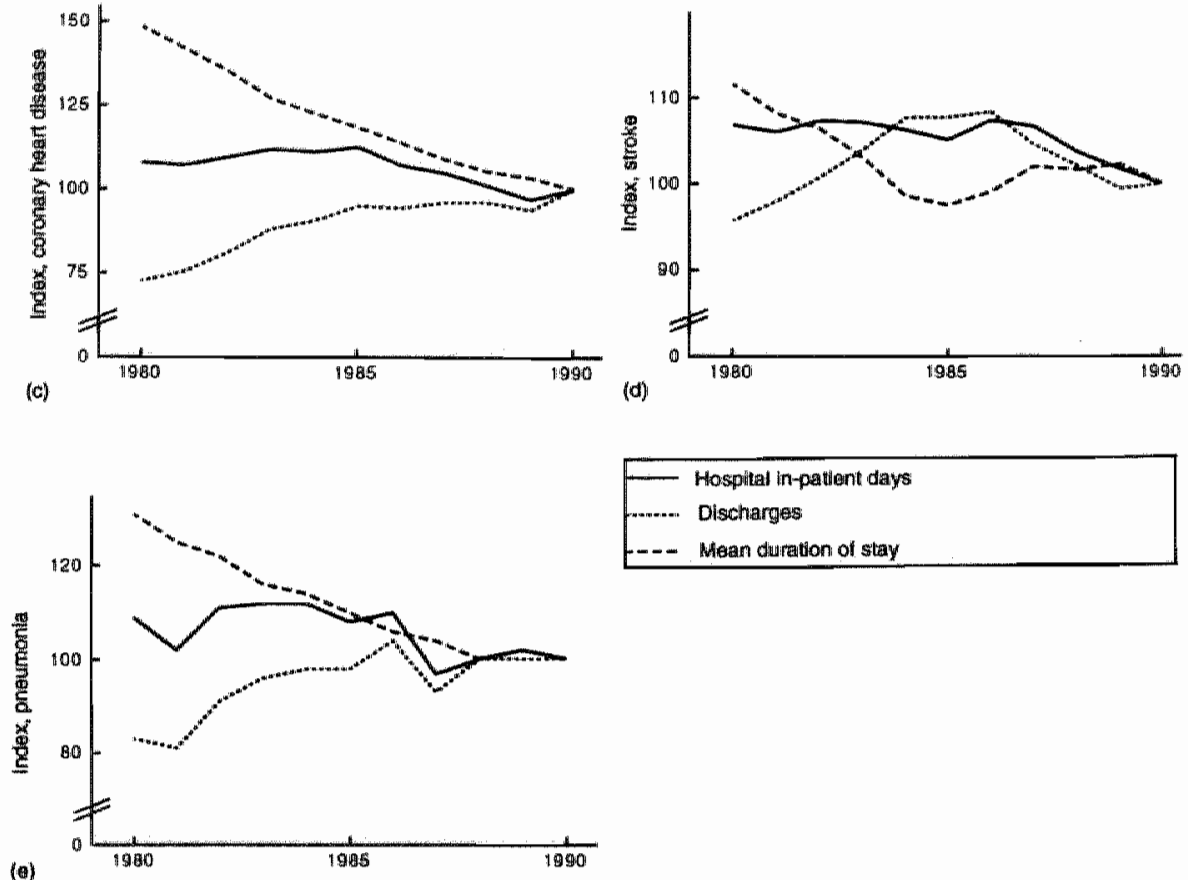

Fio. 4. Indexed developments in anmual standardized number of discharges, mean duration of stay per discharge and utilization of hospital in-patient days (1980-1990; the base year for indexing is 1990): (a) lung cancer, (b) diabetes, (c) coronary heart disease, (d) stroke, and (e) pneumonia. Source, SIG, data processed by RIVM. (After, Ruward et at. [10])

Results from models for both main diseases of the circulatory system have recently been published [36,37]. For the period 1980-90 the standardized incidence and prevalence of coronary heart disease is estimated to have decreased, whereas we saw a contrasting increase for in-patient stays. This pattern has also been found in the USA [38]. For stroke, the decrease in the number of stays in 1985-90 is in line with an estimated decrease in incidence in the same period. These patterns clearly need further investigation. 
Obviously, the projections of in-patient days would differ substantially if these were based on epidemiological developments rather than SARIMA modelling. (A projection based on epidemiological developments would be defined, reflecting the demand for in-patient days, assuming a constant sex- and age-specific per-patient utilization. In practice, this means that age- and sex-specific utilization of in-patient days, as registered in 1990, is multiplied by some factor of change for incidence or prevalence. For acute hospital care, incidence based is favoured (e.g. ICD 410 and stroke), whereas for chronic care prevalence based is favoured; for example, diabetes in a hospital or stroke in a nursing home.) Possibly, extrapolations of SARIMA models more closely reffect reality, since these take into account all the factors influencing the utilization of in-patient-days (for instance, shifts from in-patient to out-patient care, improved treatment, reductions in physical (bed) and budgetary capacity, increased productivity; see [39-41]).

We plan to extend our time-series analytical approach to other diseases which have a major impact on health-care-resource utilization, such as obstructive chronic lung diseases, arthrosis, dementia, and other types of cancer [42]. We also intend to extend the method to other health-care sectors, enabling comparison between settings, for example, acute wersus long-term care for stroke [43].

In addition, an important issue concerns the nature of reductions in duration of stay and the downward effect this has on in-patient days. For acute myocardial infarction (ICD 410 ) Scitovsky showed that most of the decrease in duration of stay in the 1970s in the USA was due to a reduced utilization of care in regular wards, with a much lower reduction in intensive-care days [44]. Similarly, for diabetes the low intensive-care days will be shifted to out-patient facilities.

Of course our SARIMA approach has its limitations. Assumptions that recent trends. will continue may be unrealistic and may llead to misleading results. For example, a continuing fall in the mean duration of stay for some diseases might be questioned. Availability of data for more recent and coming years will reveal this. More data would also enable us to extend the projection beyond the year 2000 . Finally, there may be unforeseen events, such as the appearance of a new medical technology or changes in waiting-list management. Such events are not incorporated in our approach and would require construction of several future scenarios instead of one time-series extrapolation. Therefore it is important to design a complementary set-up for studying the scenario analytic approach to diseases $[45,46]$. However, we may conclude that, despite the limitations, our projections are logical and reasonable illustrations of the probable short-term trend in in-patient-day utilization in Dutch hospitals.

\section{Acknowledgements}

The authors would like to thank the organisers of the Quantitative Modelling in the Management of Health Care Conference in Salford (UK) 19-21 September 1994 for an excellent opportunity to present and discuss research in this field. In particular, we thank Dr R. Baker (University of Salford), Dr. R. Stevens (Bolton Health Authority, Manchester, UK), and Mrs P. Bye (Institute of Mathematics and its Applications, Southend-on-Sea, UK) for their involvement in our contribution to the 
conference. This paper also benefited from cooperation in the European Community Concerted Action 'Multinational Scenario Analysis Concerning Epidemiological, Social and Economic Impacts of HIV/AIDS on Society' (contract number PL 931723) within the framework of the Research and Technological Development Programme of the European Economic Community in the field of biomedical and health research. In particular, we would like to thank Professor R. Leidl (University of Limburg, Maastricht, The Netherlands) for improving the methodology and presentation, and Dr K. Tolley (University of Nottingham, UK) for improving the style and language.

\section{REFERENCES}

1. Ministik y OF Welfare, Health and Cultural Affairs, 1995. Financieel Overzicht Zorg (Financial Overview on Care Provision, in Dutch). The Hague: Sdu Publishers.

2. Bons, G. M., 1994. Scenario-analyse Economische Aspecten Coronaire Hartziekten (Scenarioanalysis coronary heart disease; in Dutch). Thesis. University of Limburg.

3. Idenburg, Ph. A., Ketring, E., \& Bur, R. V., 1991 . Care for Mental Health in the Future. Dordrecht: Kluwer.

4. Casparie, A. F., Verkiejs, H., \& Ruwardo, D. et al. 1991-93. Chronic Diseases in the Year 2000, Vols 1-3. Dordrecht: Kluwer

5. VAN den BoOm, F. M. L. G., Jager, J. C., Reenking, D. P., Postma, M. J., \& Albers, C. E. S. 1992, AIDS up to the Year 2000; epidemiological, sociocultural and economic scenario analysis for The Netherlands. Dordrecht: Kluwer.

6. Steering Committee on Future Health Scenarios, 1992. The influence of Demographic Change on the Burden of Disease and Care Provisions; estimates 102005 (De Invloed van de Bevolkingsontwikkeling op Ziektelast en Zorgvoorzieningen; ramingen tot 2005; in Dutch). Utrecht: Jan van Arked.

7. LEtDL, R, 1992. Health economic issues relevant to countries with ageing populations. World Health Statistics Quarterly 45, 95-108.

8. LIN, T., 1989. Modeling and forecasting hospital patient movements; univariate and multiple time series approaches. Int. $J$. Forecasting 5, 195-208.

9. HisNaNicK, J. J.. 1994. Forecasting the demand for inpatient services for specific chronic conditions. Med. Syst. 18,9-21.

10. Ruwaard, D. Kramers, P. G. N., Van den Berg Jeths, A., \& Achterberg, P. W. (eds), 1994. Public Health Status and Forecasts; the health status of the Dutch population over the period 1950-2010. The Hague: Sdu.

11. WORLD HEALTH ORGaNizATION, 1978. International Classification of Diseases, 9 th revision, Clinical Modification. Geneva: WHO.

12. BOX, G. E. P.. \& JENkINS, G. M., 1970. Time Series Analysis; forecasting and control San Francisco: Holden. Day.

13. GRANGer, C. W. I., \& NEWBold, P., 1977. Forecasting Economic Time Series. New York: Academic Press.

14. DUAN, N., 1983. Smearing estimate: a nonparametric retransformation method. J. Aw. Stat. Assoc. 383, 606-10.

15. SLOB, W., 1994. Uncertainty analysis in multiplicative models. Risk Analysis 14, 571-6.

16. SLOB, W., 1986. Strategies in applying statistics in ecological research. PhD thesis at the Free University (Vrije Universiteit: VU) of Amsterdam. Amsterdam: VU Publishers.

17. Statistical. SCIEnCES INC., 1992. S-PLUS User's Mamual: version 3.1. Seattle, WA: Statistical Sciences Inc.

18. Statistical SCILNCES INC., 1991. S-PLUS Reference Manual; version 3.1. Seattle, WA: Statistical Sciences Inc.

19. CHATFIELD, C., 1989. The Analysis of Time Series. London: Chapman \& Hall.

20. ANDERSEN, A., \& WEISs, A.; 1984. Forecasting: the BormJenkins approach. In: The 
Forecastiong Accuracy of Major Time Series Methods (S. Makridakis et al. eds.). Chichester: Wiley.

21. BOX, G. E. P., \& PERCE, D. A., 1970. Distribution of residual auto-cortelation in autoregressive-integrated moving average time-series models. J. Am. Statist. Assac. 65, 1509-26.

22. Lung, G. M., \& Box, G. E. P., 1978. On a measure of lack of fit in time sertes models. Biometrika $66,265-70$.

23. AKAIKE, $H_{n}$, 1978. Time-series analysis and control through parametric models. In: Appled Time Series Analysis (D. F. Findley, ed.). New York: Academic Press.

24. Castell, C., Goday, A., Tresserras, R., Salto, E. de Lara, N. Canhal, J., Taberner, I. L., \& SALLERAS, L., 1992. Seasonability patterns in non-communicable diseases; the example of diabetes. In: Procedings of the Fifh International Conference on Systen Science in Health Care (M. K. Chytil, G. Duru, W. Eimeren, \& Ch. D. Flagle, eds.). Prague: Omnipress Publishing.

25. Jones, R. H., Ford, P. M., \& HAMMAN, R. F. 1988. Seasonality comparisons among groups using incidence data. Biometrics 44,1131-44.

26. ALDERSON, M. R., 1985, Season and mortality. Healih Trends 17, 87-96.

27. RuWAARD, D., \& KRAMERS, P. G. N., 1993. Volksgezondheid Toekomst Verkenning, Deel II.8, Ziekren wan het ademhalingsstelsel (Public Health Status and Forecasts, Part II.8: Diseases of the respiratory system; in Dutchy. The Hague: Sdu Publishers.

28. ZANT, W., 1992. Zorg op Lange Termijn (Care in the Long Term; in Dutch). The Hague: Central Planning Bureau.

29. KOOPMANSCHAP, M. A., ROIJEN, L. VAN, BONNEUx, L., BONSEl, G, J, RutTEN, E. F. H., \& MAAS, P. J. WAN DER, 1994. The technology assessment methods project team: Cost of diseases in international perspective. $E J P H 4,258-64$.

30. Grat, A. M., \& Bosanquet; N., 1992. Forecasting the impact of demographic change; The case of the British National Health Service. Health Policy 20, 269-75.

3. Halliday, M. L., COREY, P. N. J., CoAtes, R. A., \& RaNkin, J. G., 1987. A method for estimating "persons" versns "cases" from hospital morbidity data in the absence of unique personal identifiers. American Journal of Epidemiology 125, 885-91.

32. Postma, M. I., and Boas, G. M., 1995. Unpublished material.

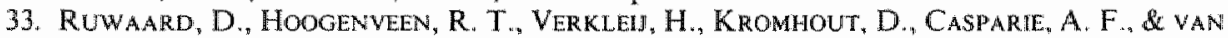
DER VEEN, E. A., 1993. Forecasting the number of diabetic patients in The Netherlands. Am. $J$. Public Health 83, 989-95.

34. Van Ballegoole, E., Offerman, J.J.G., Casparie, A. F., E Israél-Bultman, H., 1990. Poliklinische Instelling op Insuline bij Patiēnten met Diabetes Mellitus (Starting patients with diabetes mellitus on insulin in outpatient clinics, in Dutch). Nederlands Tijdschrift loor Geneeskunde 134, 68-70.

35. VAN DER RIET, A. A. P. M, 1992. Kostenueffectiviteitsanalyse Diabetes Centrum Rotterdam (Cost-effectivity Analysis Diabetes Centre Rotterdam; in Dutch). Rotterdam: Institute of Medical Technology Assessment (Erasmus Universily).

36. BONNEUX. L., BARENDREGT, J. J., MEETER, K., BONGEL, G., \& YAN DER MAA, P. J., 1993. Estimating climical morbidity due to ischemic heart disease and congestive heart fallure. Am J. Public Health 84, 20-8.

37. NIESSEN, L. W., BARENDREGT, I.. J., BONNEUX, L., \& KoudSTAal L, P. J., 1993. Stroke in an ageing population. Stroke 24,931-9.

38. RothenberG, R. B., KoplaN, J. P., 1990. Chronic diseases in the 1990s. Anm. Rev. Public Healch 11, 267-96.

39. Ministry OF WELFARE, HeALTH AND CUltura., AFFARs, 1992. Analyse Volume oniwikheling Zorgsector (Analysis of Volume-trend in Care Sector; in Dutch). The Hague: Sdu Publishers.

40. CAsparie, A. F., \& HoogendoorN, D., 1991. Effects of budgeting on health care services: in Dutch hospirals. Am. J. Public Heaith 81, 1442-7.

41. SloAN, F. A., \& VALVONA, J., 1985. Why has hospital length of stay declined?; an evaluation of alternative theories. Soc. Sci. Med. 22, 63-73. 
42. KoOpMANSCHAP, M. A., VAN ROUEN, L., \& BonNEUx, L., 1994 Costs of diseases in The Netherlands In Public Health Status and Forecasts (D. Ruvaard, P. G. N. Kramers, A. yan de Berg Jeths, and $P$. W. Achterberg, eds.), The Hague: Sdu Publishers.

43. HARRSON, G. W. \& MrLLAD, P. H., 1991. Balancing acute and long-term care: the mathematics of throughput in departments of geriatric medicine. Meth. Inform, Med. 30, $221-839$.

44. Scrovsky, A. A., 1985. Changes in the costs of treatment of selected ilnesses, 1971-1981. Medical Care, 23, $1345-57$.

45. POSTMA, M. J. JAGER, J. C. DUKGRAAF, M. G. W., BORLEFF, J. C. C., TOLlex, K., \& LEIDL, R., 1995. AlDS-scenarios for The Netherlands; the impact on hospitals. Health Policy 30, 127-50.

46. VAN Gienugten, M. L. L. HoOgenveEN, R. T., YAN DeR Giessen, A. \& Postma, M. J., 1995. A scenario-analytic tool to simulate the effect of prevention and intervention strategies. Paper presented at the XIVth European Conference on Operational Research, Jerusalem 1995, 3-6 July (proceedings in preparation). 